Thiago Ferreira Valins

\title{
RELÉ DIGITAL DE DISTÂNCIA BASEADO \\ NA TEORIA DE ONDAS VIAJANTES \\ E TRANSFORMADA WAVELET
}

Dissertação apresentada à Escola de Engenharia de São Carlos da Universidade de São Paulo, como parte dos requisitos para obtenção do Título de Mestre em Engenharia Elétrica.

Orientador: Prof. Tit. Denis Vinicius Coury

São Carlos

2005 
Aos meus pais, David e Ivone e ao meu irmão Ricardo 


\section{AGRADECIMENTOS}

Em primeiro lugar a DEUS, sem o qual nada seria possível realizar.

Ao Prof. Titular Denis Vinicius Coury, pela paciente e segura orientação nas fases deste trabalho.

Ao Prof. Doutor Mário Oleskovicz, pelo seu importante auxílio no desenvolvimento deste trabalho.

Ao amigo Murilo da Silva pelo auxílio na solução de problemas encontrados no desenvolvimento do algoritmo, pela paciência de ler e discutir o trabalho tanto na preparação para o exame de qualificação quanto ao exame de defesa.

A Alessandra pelo apoio, carinho, amizade e por ser esta pessoa tão especial nesta etapa da minha vida.

Aos amigos do LSEE - "O LAB" e aos alunos de iniciação científica, pelo estímulo e amizade.

Aos demais colegas do Departamento de Engenharia Elétrica, pelo companheirismo e ensinamentos.

Aos docentes, funcionários e técnicos do Departamento de Engenharia Elétrica da Escola de Engenharia de São Carlos, pela colaboração e atenção de todos os momentos.

A todos aqueles que, direta ou indiretamente, contribuíram para a realização deste trabalho.

À CAPES - Fundação Coordenação de Aperfeiçoamento de Pessoa de Nível Superior -, que financiou a pesquisa. 
"Lâmpada para

os meus pés é a tua palavra, e luz para o meu caminho" .

Salmos 119:105 


\section{RESUMO}

VAlins, T. F. (2005). Relé Digital de Distância Baseado na Teoria de Ondas Viajantes e Transformada Wavelet. Dissertação (Mestrado) - Escola de Engenharia de São Carlos, Universidade de São Paulo, São Carlos, 2005.

Neste trabalho, será abordada a proteção digital fundamentada na teoria de ondas viajantes e da ferramenta Transformada Wavelet. Um algoritmo completo para proteção digital foi implementado, consistindo basicamente nos módulos de detecção, classificação e localização da falta, com a conseqüente determinação das zonas de proteção do relé. Para este esquema completo de releamento, empregou-se como ferramenta de análise a Transformada Wavelet. Sinais transitórios de alta freqüência gerados por uma situação de falta podem ser analisados pela Transformada Wavelet, detectando-se com precisão o instante de chegada das ondas em um ou nos dois terminais da linha. Conhecendo o instante de chegada dessas ondas e sua velocidade de propagação, a zona de proteção na qual a falta está alocada pode ser estimada de maneira fácil e rápida. A capacidade de acusar com precisão os instantes de chegada das ondas torna a Transformada Wavelet adequada ao problema de determinação das zonas de proteção. Nessa implementação, o usuário pode escolher entre as técnicas de aquisição de dados provenientes de um ou de dois terminais. O algoritmo foi implementado através do software $\operatorname{Matlab}{ }^{\circledR}$ e posteriormente testado, quando se utilizaram dados de faltas obtidos através de simulações no software ATP (Alternative Transients Program). Nas simulações aplicadas a este software, considerou-se um sistema de transmissão de $440 \mathrm{kV}$. As simulações produziram uma base de dados, variando-se os seguintes parâmetros: tipos de faltas, localizações ao longo da linha, ângulos de incidência, resistências de faltas, entre outros. Pelos resultados alcançados, pode-se afirmar que a aplicação é bastante adequada para uso em relés digitais de distância.

Palavras-chave: relé digital de distância, ondas viajantes, transformada wavelet, sistemas elétricos de potência. 


\section{ABSTRACT}

VAlinS, T. F. (2005). Positional Protection Using Traveling Waves and Wavelet Transform Theory. M.Sc. Dissertation - Escola de Engenharia de São Carlos, Universidade de São Paulo, São Carlos, 2005.

The present work deals with digital protection based on the traveling wave theory and Wavelet transform. An complete algorithm for digital protection was implemented. It is composed of modules of fault detection, classification, location, with protection zone determination. For this complete relaying scheme the Wavelet transform was employed as analysis tool. Transient signals of high frequency generated by the fault occurrence was analyzed by the Wavelet transform, and also the instant of the waves arrival was accurately detected in one or two terminals of the line. By knowing the instant of the arrival of the waves and their propagation velocity, the protection zone, in which the fault is located, can be estimated easily and quickly. The Wavelet transform property of accurate detection the instant of waves arrival make it appropriate to the problem of protection zone determination. In this implementation, the user can choose between the location techniques using data from one or two terminals. The algorithm was implemented by Matlab® software and then tested utilizing data of faults obtained by means of simulations of ATP software (Alternative Transients Program). In these simulations, a transmission line of $440 \mathrm{kV}$ was considered. These simulations produced a database composed of various fault types considering different fault locations, fault inception angles and fault resistances. According to the analysis of the test results, it is possible to verify that the application is very adequate for use in digital distance relays.

Keywords: digital distance relay, traveling waves, wavelet transform, power system. 


\section{LISTA DE FIGURAS}

FIGURA 1 - Arquitetura de um relé digital

FIGURA 2 - Diagrama Lattice representando as sucessivas reflexões de um sinal qualquer. 27

FIGURA 3 - Escalamento de uma função seno. 33

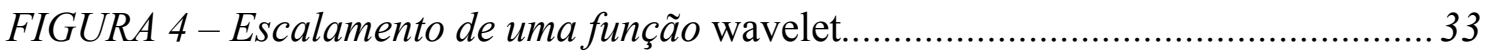

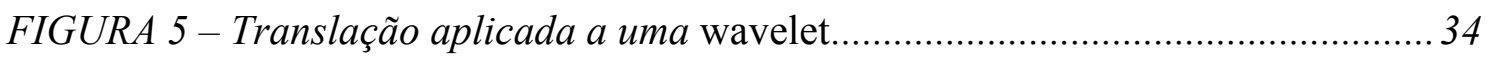

FIGURA 6-Cálculo do fator $C$ de relação entre a wavelet-mãe e o sinal ..................... 34

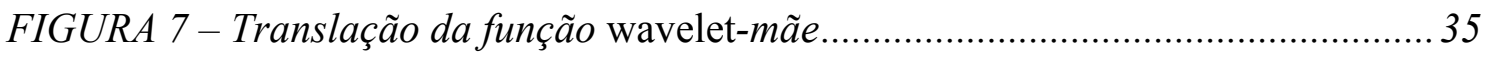

FIGURA 8 - Escalonamento da função wavelet-mãe ................................................. 35

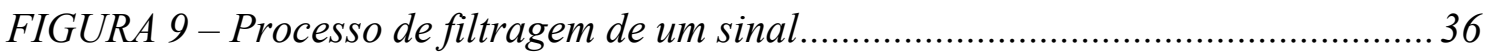

FIGURA 10 - Processo de diminuição do número de amostras do sinal (downsampling)

FIGURA 11 - Exemplo de filtragem com downsampling de um sinal senoidal ruidoso

FIGURA 12 - Processo de decomposição de um sinal em AMR.................................... 38

FIGURA 13 - Processo de reconstrução de um sinal filtrado ........................................ 39

FIGURA 14 - Processo de aumento do número de amostras para reconstrução de um sinal 40

FIGURA 15 - Processos de decomposição e reconstrução de um sinal. 40

FIGURA 16 - Reconstrução de um sinal a partir de seus coeficientes de aproximação

FIGURA 17 - Reconstrução do primeiro nível de detalhe do sinal .

FIGURA 18 - Diferentes formas para se reconstruir o sinal a partir de seus coeficientes

FIGURA 19 - Áreas de aplicação da TW em SEP .......................................................... 42

FIGURA 20 - Representação do sistema elétrico analisado .......................................... 45

FIGURA 21 - Silhueta de torre da linha de $440 \mathrm{kV}$.......................................................46

FIGURA 22 - Representação de um trecho de uma linha de transmissão por parâmetros distribuídos.............................................................. 47

FIGURA 23 - Transposição de uma linha de transmissão........................................... 48 
FIGURA 24 - Rotina Line Constants para o sistema simples vertical tipo VVV 49

FIGURA 25 - Arquivo de entrada de dados do ATP para uma falta-fase-terra (AT) ... 51

FIGURA 26 - Formas de onda de tensão para uma falta-fase-terra aplicada a 100 km da barra $E$.

FIGURA 27 - Formas de onda de corrente para uma falta-fase-terra aplicada a $100 \mathrm{~km}$ da barra $E$. 52

FIGURA 28 - Situações de faltas sobre o sistema 54

FIGURA 29 - Sistema Elétrico e diagrama Lattice ........................................................56

FIGURA 30 - Fluxograma do algoritmo do relé de distância ........................................58

FIGURA 31 - Esquema de janelamento do sinal de entrada para detecção da falta .... 63

FIGURA 32 - Exemplo de deteç̧ão de uma falta ....................................................... 64

FIGURA 33 - Exemplo 1: detecção de T2 para uma falta-fase-terra, sem necessidade do limiar 3.

FIGURA 34 - Exemplo 2: detecção de T2 para uma falta-fase-terra, com necessidade do limiar 3. 70

FIGURA 35 - Fluxograma referente às etapas para a determinação do tempo T2....... 71

FIGURA 36 - (a) Falta-fase-terra na segunda metade da linha, (b) falta-fase-terra na primeira metade da linha

FIGURA 37 - Sinais de detalhe 1 dos modos aéreo 1 e terra para uma falta-faseterra na segunda metade da linha.

FIGURA 38 - Exemplo de detecção dos picos iniciais...... 77

FIGURA 39 - Formas de onda da tensão para uma falta-fase-terra aplicada a 180 km da barra E.

FIGURA 40 - Janela de decomposição em AMR para detecção de um distúrbio .......... 82

FIGURA 41 - Classificação dos diversos tipos de faltas ............................................... 84

FIGURA 42 - Coeficientes wavelets para uma falta-fase-fase(AB) a $170 \mathrm{~km} \mathrm{da}$ barra E, com ângulo de incidência de $90^{\circ}$ 85

FIGURA 43 - Coeficientes wavelets para uma falta-fase A-terra a $60 \mathrm{~km}$ da barra

E, com ângulo de incidência de $0^{\circ}$ e resistência de falta de $0,1 \Omega$ 89

FIGURA 44 - Coeficientes wavelets para uma falta-fase A-terra a $190 \mathrm{~km} \mathrm{da}$ barra E, com ângulo de incidência de $0^{\circ}$ e resistência de falta de $0,1 \Omega$. 90

FIGURA 45 - Influência do tipo da falta na precisão do algoritmo. 91

FIGURA 46 - Influência do ângulo de incidência da falta para faltas-fase-fase. 92 
FIGURA 47 - Influência da resistência de falta para faltas-fase-fase-terra (ABT).......93

FIGURA 48 - Exemplo de detecção dos picos iniciais................................................... 94

FIGURA 49 - Influência do tipo da falta na precisão do algoritmo ................................ 98

FIGURA 50 - Influência do ângulo de incidência da falta para faltas-fase-fase .......... 99

FIGURA 51 - Influência da resistência de falta para faltas-fase-fase-terra (ABT)..... 100

FIGURA 52 - Influência da perda de sincronismo (1 amostra), considerando situações de faltas-fase-terra (AT), com ângulo de incidência de $0^{\circ}$ e

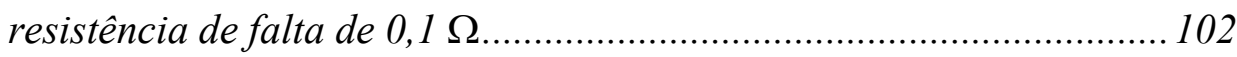

FIGURA 53 - Influência da distância para faltas-fase-fase $(B C)$.............................. 114

FIGURA 54 - Influência da distância para faltas-fase-fase $(A C)$............................... 115

FIGURA 55 - Influência da distância para faltas-fase-fase-terra (BCT), com ângulo de incidência de $0^{\circ}$.

FIGURA 56 - Influência da distância para faltas-fase-fase-terra (BCT), com ângulo de incidência de $90^{\circ}$......

FIGURA 57 - Influência da distância para faltas-fase-fase-terra (ACT), com resistência de falta de $50 \Omega$.

FIGURA 58 - Influência da distância para faltas-fase-terra (BT), com resistência de falta de $0,1 \Omega$

FIGURA 59 - Influência da distância para faltas-fase-terra (CT), com resistência de falta de $100 \Omega$

FIGURA 60 - Influência da distância para faltas-fase-fase (BC) 118

FIGURA 61 - Influência da distância para faltas-fase-fase (AC). 119

FIGURA 62 - Influência da distância para faltas-fase-terra (BT), com resistência de falta de $0,1 \Omega$.

FIGURA 63 - Influência da distância para faltas-fase-terra (CT), com resistência de falta de $50 \Omega$

FIGURA 64 - Influência da distância para faltas-fase-fase-terra (BCT), com resistência de falta de $100 \Omega$

FIGURA 65 - Influência da distância para faltas-fase-fase-terra (ACT), com resistência de falta de $0,1 \Omega$ 


\section{LISTA DE TABELAS}

TABELA 1 - Distribuição de faltas em um sistema de $500 \mathrm{kV}$, em um período de dez anos, com a ocorrência de noventa e nove faltas ............................. 1

TABELA 2 - Parâmetros da linha de transmissão de $440 \mathrm{kV} \mathrm{.........................................} 49$

TABELA 3 - Parâmetros dos equivalentes de geração das barras $D$ e $G$..................... 50

TABELA 4 - Dados das barras de geração $D$ e $G$............................................................. 50

TABELA 5 - Sub-rotina para classificação do tipo da falta ............................................ 67

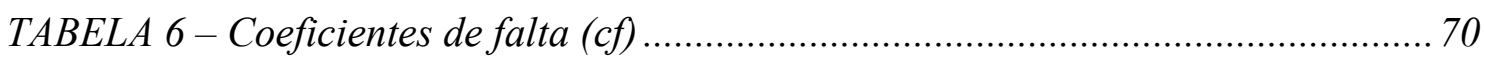

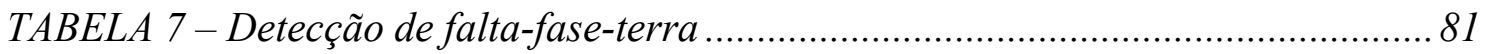

TABELA 8 - Faltas-fase-fase $(A B)$, com ângulo de incidência de falta de $0^{0}$................. 88

TABELA 9 - Faltas-fase-fase (AB), com ângulo de incidência de falta de $90^{\circ}$.............. 88

TABELA 10 - Faltas trifásicas $(A B C)$, com ângulo de incidência de falta de $0^{0}$............88

TABELA 11 - Faltas trifásicas $(A B C)$, com ângulo de incidência de falta de $90^{\circ}$.........88

TABELA 12 - Detecção de falta-fase-terra …........................................................ 95

TABELA 13 - Faltas-fase-fase (AB), com ângulo de incidência de falta de $0^{0}$..............97

TABELA 14 - Faltas-fase-fase (AB), com ângulo de incidência de falta de $90^{0}$............ 97

TABELA 15 - Faltas trifásicas $(A B C)$, com ângulo de incidência de falta de $0^{0}$............97

TABELA 16 - Faltas trifásicas $(A B C)$, com ângulo de incidência de falta de $90^{\circ}$..........97

TABELA 17 - Resultados alcançados pela técnica de um terminal aplicada a um circuito simples.

TABELA 18 - Resultados alcançados pela técnica de dois terminais aplicada a um circuito simples.....

TABELA 19 - Perda de sincronismo (1 amostra) para faltas AT, com ângulo de incidência de falta de $0^{0}$.

TABELA 20 - Perda de sincronismo (1 amostra) para faltas AT, com ângulo de incidência de falta de $90^{\circ}$

TABELA 21 - Perda de sincronismo (2 amostras) para faltas AT, com ângulo de incidência de falta de $0^{0}$

TABELA 22 - Perda de sincronismo (2 amostras) para faltas AT, com ângulo de incidência de falta de $90^{\circ}$ 
TABELA 23 - Perda de sincronismo (lamostra) para faltas AB, com ângulo de

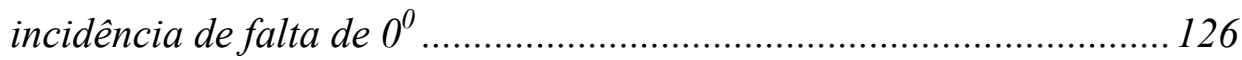

TABELA 24 - Perda de sincronismo (lamostra) para faltas AB, com ângulo de incidência de falta de $90^{\circ}$

TABELA 25 - Perda de sincronismo (2 amostras) para faltas AB, com ângulo de incidência de falta de $0^{0}$

TABELA 26 - Perda de sincronismo (2 amostras) para faltas AB, com ângulo de incidência de falta de $90^{\circ}$ 


\section{LISTA DE SIGLAS E ABREVIATURAS}

\begin{tabular}{|c|c|}
\hline $\mathrm{AB}$ & Falta-fase(A)-fase(B) \\
\hline $\mathrm{ABT}$ & Falta-fase(A)-fase(B)-terra \\
\hline $\mathrm{ABC}$ & Falta-fase(A)-fase(B)-fase(C) \\
\hline $\mathrm{AC}$ & Falta-fase(A)-fase(C) \\
\hline $\mathrm{ACT}$ & Falta-fase(A)-fase(C)-terra \\
\hline $\mathrm{A} / \mathrm{D}$ & Analógico/Digital \\
\hline AMR & Análise Multirresolução \\
\hline AT & Falta-fase(A)-terra \\
\hline ATP & Alternative Transients Program \\
\hline $\mathrm{BC}$ & Falta-fase(B)-fase(C) \\
\hline BT & Falta-fase(B)-terra \\
\hline $\mathrm{BCT}$ & Falta-fase(B)-fase(C)-terra \\
\hline $\mathrm{CC}$ & Corrente Contínua \\
\hline CESP & Companhia Energética de São Paulo \\
\hline $\mathrm{CT}$ & Falta-fase $(\mathrm{C})$-terra \\
\hline CWs & Coeficientes Wavelets \\
\hline EMTP & Eletromagnetic Transient Program \\
\hline GPS & Global Positioning Satellite \\
\hline LT & Linha de Transmissão \\
\hline MATLAB & Matrix Laboratory \\
\hline OPGW & Fiber Optic Overhead Ground Wire \\
\hline SEP & Sistemas Elétricos de Potência \\
\hline STFT & Short-Time Fourier Transform \\
\hline $\mathrm{TC}$ & Transformador de Corrente \\
\hline $\mathrm{TF}$ & Transformada de Fourier \\
\hline TFJ & Transformada de Fourier Janelada \\
\hline TPC & Transformador de Potencial Capacitivo \\
\hline TW & Transforma Wavelet \\
\hline TWC & Transformada Wavelet Contínua \\
\hline TWD & Transformada Wavelet Discreta \\
\hline TWDI & Transformada Wavelet Discreta Inversa \\
\hline
\end{tabular}




\section{LISTA DE SÍMBOLOS}

\begin{tabular}{|c|c|}
\hline$V$ & tensão \\
\hline$i$ & corrente \\
\hline$R$ & resistência da linha por unidade de comprimento \\
\hline$L$ & indutância da linha por unidade de comprimento \\
\hline$t$ & variável tempo \\
\hline$x$ & variável correspondente a tempo ou espaço \\
\hline$a$ & fator de escala para a Transformada Wavelet Contínua \\
\hline$b$ & fator de translação para a Transformada Wavelet Contínua \\
\hline$\varphi$ & Função-escala \\
\hline$\psi$ & Função Wavelet \\
\hline$m$ & parâmetro de escala para Transformada Wavelet Discreta \\
\hline$k$ & fator de translação relacionado à Análise Multirresolução \\
\hline$A$ & versão aproximada de um sinal \\
\hline$D$ & versão de detalhes de um sinal \\
\hline$c A$ & versão aproximada de um sinal com operador downsampling \\
\hline$c D$ & versão de detalhes de um sinal com operador downsampling \\
\hline$h_{0}$ & filtro passa-baixa \\
\hline$h_{1}$ & filtro passa-alta \\
\hline$C$ & capacitância shunt da linha por unidade de comprimento \\
\hline$\Delta x$ & elemento da linha de transmissão \\
\hline$l$ & comprimento da linha \\
\hline$Z_{C}$ & impedância característica da linha \\
\hline$d$ & distância ao ponto de falta \\
\hline $\mathrm{T}$ & matriz inversa da transformação modal de Clarke \\
\hline $0, \alpha, \beta$ & índices modais \\
\hline$a, b, c$ & fases da linha \\
\hline$v_{m 0}, v_{m 1}$ & velocidades de propagação do modo-terra (modo 0$)$ e aéreo 1 (modo 1$)$ \\
\hline$L_{0}$ & indutância de seqüência zero da linha por unidade de comprimento \\
\hline$C_{0}$ & capacitância de seqüência zero da linha por unidade de comprimento \\
\hline$L_{1}$ & indutância de seqüência positiva da linha por unidade de comprimento \\
\hline$C_{1}$ & capacitância de seqüência positiva da linha por unidade de comprimento \\
\hline
\end{tabular}




\section{SUMÁRIO}

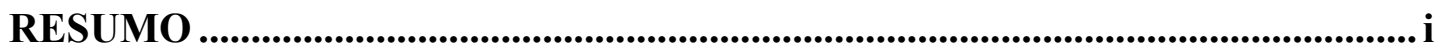

ABSTRACT ................................................................................................................ ii

LISTA DE FIGURAS ...............................................................................................ii

LISTA DE TABELAS ............................................................................................. vi

LISTA DE SIGLAS E ABREVIATURAS.............................................................viii

LISTA DE SÍMBOLOS........................................................................................... ix

1 INTRODUÇÃ

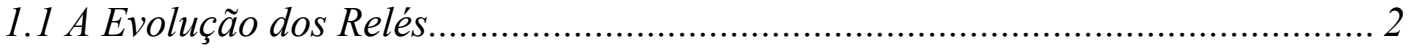

1.2 Algoritmos para Proteção em Linhas de Transmissão........................................ 7

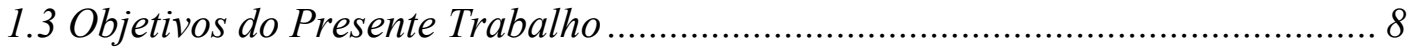

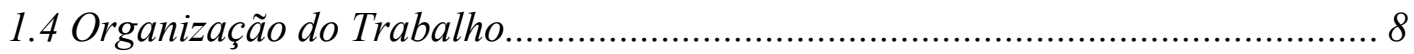

2 REVISÃO BIBLIOGRÁFICA...................................................................... 10

2.1 Técnicas de Estimação das Componentes de Freqüência Fundamental........... 10

2.1.1 Técnicas Baseadas na Transformada de Fourier e Função Walsh ............. 10

2.1.2 Técnicas Baseadas em Filtros de Kalman ............................................... 13

2.1.3 Técnicas Baseadas no Ajuste por Mínimos Quadrados .............................. 14

2.2 Técnicas Baseadas nos Cálculos de Parâmetros do Modelo RL-Série da Linha

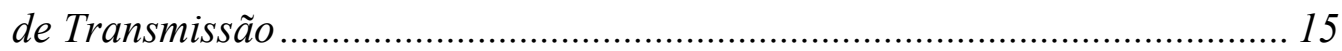

2.3 Técnicas Baseadas nos Componentes de Alta Freqüência e Transformada

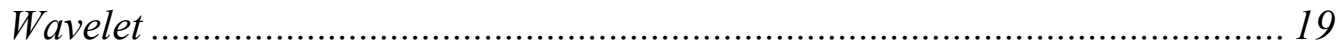

2.3.1 Algoritmos que Utilizam Dados Somente do Terminal Local da Linha...... 19

2.3.2 Algoritmos que Utilizam Dados de Múltiplos Terminais da Linha...... 23

\section{FUNDAMENTOS SOBRE ONDAS VIAJANTES E TRANSFORMADA}

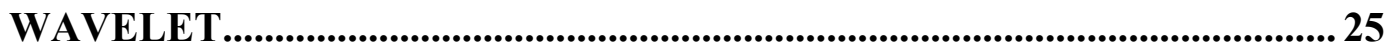

3.1 Ondas Viajantes em Sistemas de Transmissão ............................................... 25

3.1.1 Reflexões e Refrações de Ondas Viajantes................................................... 26

3.1.2 Reflexões Sucessivas e Diagrama Lattice ................................................ 26 
3.1.3 Atenuação e Distorção das Ondas Viajantes ............................................... 27

3.2 Motivação para o Uso da Transformada Wavelet ........................................... 28

3.3 A Utilização da Transformada Wavelet .............................................................. 29

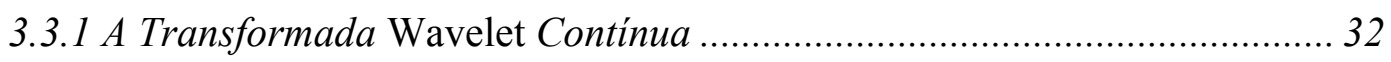

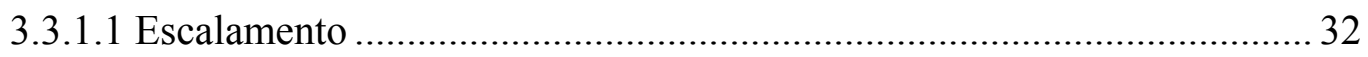

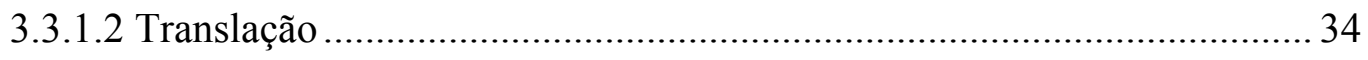

3.3.2 Cálculo da Transformada Wavelet Contínua ............................................ 34

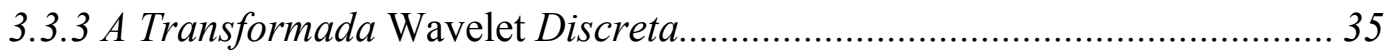

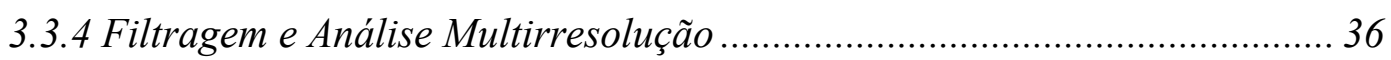

3.3.4.1 Decomposição em Múltiplos Níveis ou Análise Multirresolução .......... 38

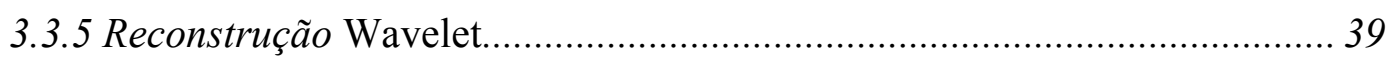

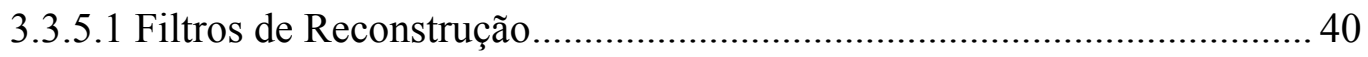

3.3.5.2 Aproximações e Detalhes na Reconstrução ............................................ 40

3.3.6 Aplicações da Transformada Wavelet em Sistemas Elétricos de Potência. 42

4 O SISTEMA ELÉTRICO ANALISADO ........................................................... 44

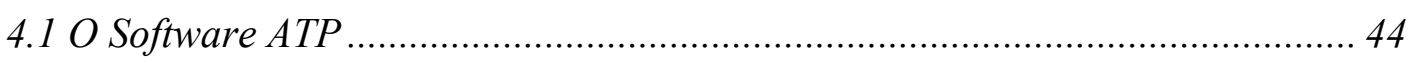

4.2 Configuração do Sistema de Potência Estudado............................................... 45

4.3 Modelagem da Linha de Transmissão ........................................................ 45

4.3.1 Parâmetros do Sistema Elétrico................................................................... 47

4.3.2 Rotina Line Constants e Arquivo de Entrada para o Software ATP............ 48

4.4 Variações nas Simulações das Condições de Faltas Aplicadas ao Circuito de

Transmissão Simples Horizontal .................................................................. 53

5 FUNDAMENTOS E LÓGICA DA ABORDAGEM PROPOSTA ....................55

5.1 Princípio Básico do Método da Determinação das Zonas de Proteção ........... 55

5.2 O Algoritmo do Relé de Distância .......................................................................... 56

5.3 Lógica Computacional Implementada para o Relé de Distância...................... 57

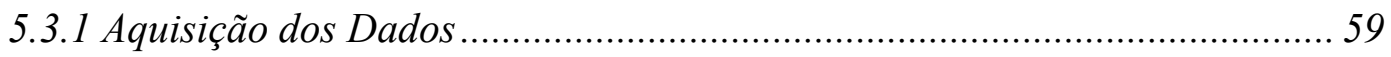

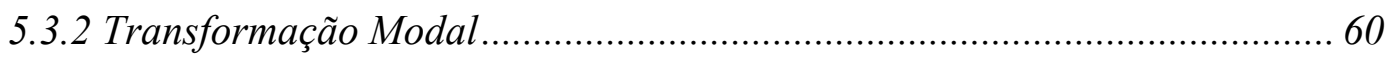

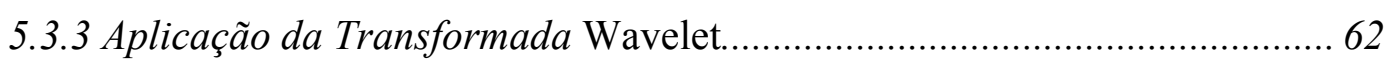

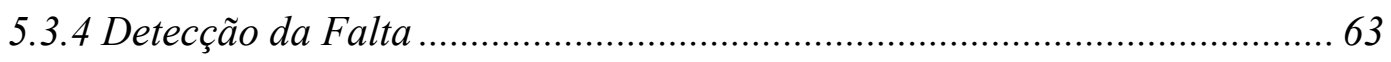

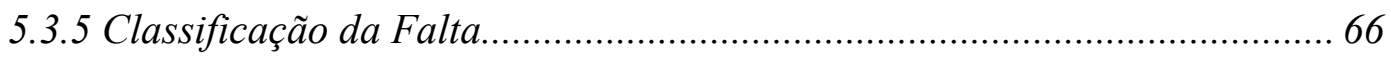


5.3.6 Procedimento para a Localização da Falta e Estimação da Zona de Proteção Alocada. 68

5.3.7 Determinação dos Tempos de Reflexão no Terminal Local......................... 68

5.3.7.1 Pré-Localização para Faltas-Fase-Terra................................................ 72

5.3.7.2 Determinação das Zonas de Proteção para Faltas-Fase-Terra ................ 74

5.3.7.3 Determinação das Zonas de Proteção para Faltas-Fase-Fase-Terra, FaseFase e Trifásica 76

5.3.8 Determinação das Zonas de Proteção com Dados Provenientes de Dois Terminais da Linha

\section{TESTES E RESULTADOS OBTIDOS RELATIVOS AO ALGORITMO} ESTUDADO.

6.1 Resultados Alcançados Utilizando-se Dados Provenientes de um Terminal da Linha. 80

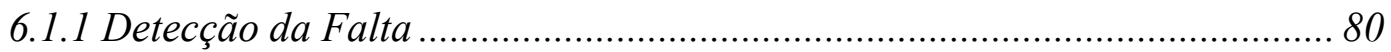

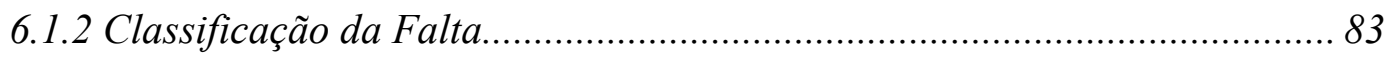

6.1.3 Determinação das Zonas de Proteção ......................................................... 85

6.1.4 Influência dos diferentes tipos de falta.................................................... 91

6.1.5 Influência do ângulo de incidência da falta ............................................ 92

6.1.6 Influência da Resistência de Falta ............................................................. 93

6.2 Resultados Alcançados Utilizando-se Dados Provenientes de Dois Terminais 94

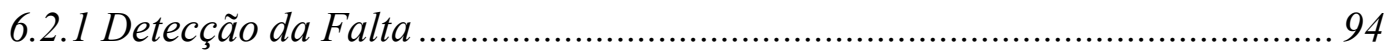

6.2.2 Determinação das Zonas de Proteção ........................................................ 96

6.2.3 Influência dos Diferentes Tipos de Falta ..................................................... 98

6.2.4 Influência do Angulo de Incidência da Falta .............................................. 99

6.2.5 Influência da Resistência de Falta ........................................................... 100

6.2.6 Influência da Perda de Sincronismo dos Dados ......................................... 101

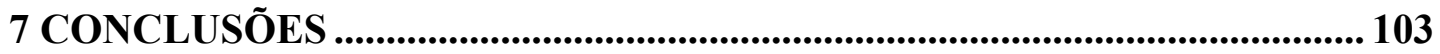

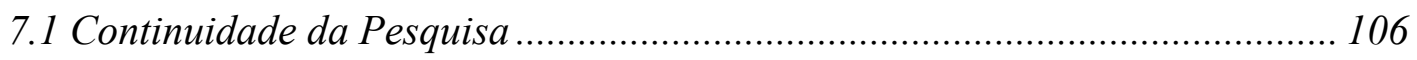

REFERÊNCIAS BIBLIOGRÁFICAS ......................................................... 107 


\section{INTRODUÇ̃̃̃O}

Os Sistemas Elétricos de Potência (SEP) são projetados para fornecer energia dentro de padrões de qualidade, confiabilidade e continuidade. No entanto, o SEP está exposto a condições adversas e imprevisíveis, podendo ocorrer interrupções em pontos aleatórios do sistema. Nesse contexto, o sistema de proteção deve promover a rápida retirada de operação de um elemento defeituoso do SEP, que possa causar danos, ou interferência na correta operação do resto do sistema [1].

Dentre os componentes de um SEP, a linha de transmissão (LT) é o elemento mais suscetível a falhas, especialmente se considerarmos suas dimensões físicas, visto que esta característica física, as LTs encontram-se sobre terrenos de diversos climas e topologias , que caracterizam, muitas vezes, locais de difícil acesso, apresentando maior dificuldade para manutenção, reparo e monitoramento. A Tabela 1, de acordo com a referência [2], ilustra o registro da distribuição de faltas, em um sistema de $500 \mathrm{kV}$, num período de dez anos, levando em consideração as características específicas do sistema. Observa-se nesta tabela a predominância de faltas em linhas de transmissão, com cerca de $80 \%$ em relação ao conjunto total. As estatísticas ainda indicam que de $70 \%$ a $80 \%$ das faltas nas linhas de transmissão são do tipo fase-terra sendo bastante influenciadas pela natureza do aterramento utilizado. Um menor número de faltas, cerca de $5 \%$, refere-se a faltas trifásicas [3].

TABELA 1 - Distribuição de faltas em um sistema de $500 \mathrm{kV}$, em um período de dez anos, com a ocorrência de noventa e nove faltas

EQUIPAMENTOS FALTOSOS

Linha de transmissão

Circuitos disjuntores

Autotransformadores

Barramentos

Geradores

Erro humano
NÚMERO DE FALTAS

82

4

6

1

5 
Para a proteção de linhas de transmissão frente às possíveis situações de faltas, podemos delegar, em primeira instância, as funções de proteção aos relés, sejam eles convencionais ou digitais. Dentre os diversos tipos de relés convencionais, os mais empregados para a proteção das linhas de transmissão são os relés de distância eletromecânicos e de estado sólido. Como a impedância por quilômetro de uma linha de transmissão, conforme Horowitz e Phadke [4], é favoravelmente constante, eles respondem à distância da falta sobre a linha de transmissão. O relé de distância recebeu esta denominação, porque sua atuação baseia-se na observação da impedância entre a localização da falta e a localização do relé, obtida em função dos valores de tensão e corrente registrados. Assim, esse relé reconhece faltas ocorrendo dentro de uma seção ou zona protegida da linha, considerando que a distância do relé à falta é menor do que o seu valor de ajuste predefinido [5]. Contudo, essa seção ou zona de proteção do relé de distância não pode ser precisamente determinada, e uma certa incerteza sobre o seu exato alcance na proteção deve ser respeitada, para aumentar a confiabilidade do sistema, evitando-se o desligamento de zonas além da área de cobertura do relé. A incerteza sobre o alcance da zona de proteção é tipicamente da ordem de 5\% da zona marcada.

A zona de proteção primária abrange de 85 a 90\% do comprimento da linha a ser protegida. Usualmente essa zona é definida pelos disjuntores, e o sistema de proteção deve atuar instantaneamente na área delimitada. Deve-se estar claro que a zona de proteção primária não protege o total da linha de transmissão. Conseqüentemente, o relé é projetado com outras zonas de proteção (zonas de proteção secundária e terciária), as quais deliberadamente vão além do terminal remoto da linha de transmissão. Além disso, essas zonas de proteção devem ser temporizadas, de maneira que os relés operem de maneira coordenada. Tratando-se da zona de proteção secundária, usualmente ela apresenta um alcance que varia de 120 a 150\% do comprimento da linha de transmissão a ser protegida. A zona de proteção terciária é ajustada para uma variação de 120 a $180 \%$ do comprimento da linha de transmissão a ser protegida, conforme Horowitz e Phadke [4].

\subsection{A Evolução dos Relés}

Atualmente, devido a grande expansão e complexidade dos SEPs, torna-se cada vez mais importante o desenvolvimento de relés de proteção mais rápidos e eficientes. 
Os primeiros relés projetados eram dispositivos eletromecânicos, mais conhecidos como relés convencionais. Eles foram os primeiros a serem projetados e são, ainda, maioria nas usinas e subestações. Esses relés atuam através de forças que são produzidas pela interação eletromagnética entre correntes e fluxos. De forma geral, os relés eletromecânicos respondem a uma ou mais entradas: tensão, corrente, produto entre a tensão, corrente e o ângulo entre estes fasores ou então pela força física produzida por molas. A baixa confiabilidade desses relés representa seu grande problema. Sendo assim, estes tipos de relés dependem da interação de forças que podem se alterar com o tempo. As molas, eixos, discos e outros componentes mecânicos do relé vão sofrendo um processo natural de desgaste, que muitas vezes reduz a confiabilidade do relé, pois podem provocar a falha de operação.

Os relés de estado sólido foram desenvolvidos posteriormente e possuem desempenho e características mais sofisticadas em relação aos eletromecânicos. O desenvolvimento de dispositivos semicondutores, e outros componentes eletrônicos, possibilitou a criação dos mesmos. Todas as funções e características disponíveis nos relés eletromecânicos podem ser implementadas nos equipamentos de estado sólido constituídos de componentes discretos ou circuitos integrados. Os relés de estado sólido utilizam componentes de baixa potência com pouca tolerância a altas temperaturas, umidade, sobrecorrentes e sobretensões. Estas características os tornam mais suscetíveis a falhas ao ambiente hostil de subestações e usinas. Entretanto, esses relés possuem menor tamanho físico e maior desempenho e flexibilidade em relação aos eletromecânicos, além de não serem prejudicados por vibrações e poeira.

Com o avanço da tecnologia digital, deu-se início ao desenvolvimento dos relés computadorizados ou digitais. Esses relés são gerenciados por um microprocessador específico, controlado por um software. Os sinais de entrada para esses relés são os sinais de tensão e corrente, obtidos através de transdutores. Portanto, é necessário obter uma representação digital para esses sinais e, usando-se um algoritmo apropriado, a abertura dos disjuntores é conseguida.

Esses relés são extremamente rápidos em comparação com os relés eletromecânicos e eletrônicos, porém são muito suscetíveis a interferências eletromagnéticas, necessitando de filtros do tipo passa-baixa analógicos e digitais. Estes filtros são empregados para atenuação ou eliminação das componentes de alta freqüência presentes no sinal. Finalmente, os relés são normalmente modulares e necessitam de fonte de alimentação. 
Dentre as vantagens oferecidas pela utilização dos relés digitais em relação às tecnologias convencionais (eletromecânicos, estado sólido), conforme Phadke e Thorp [6], temos:

- custo: o custo do relé é a sua principal consideração na sua aceitação. O custo dos primeiros relés computadorizados era de 10 a 20 vezes maior do que o custo dos relés convencionais. Com a evolução dos processadores, esse custo diminuiu e ao mesmo tempo houve um aumento na capacidade de processamento. Estimase hoje que o custo do relé computadorizado, incluindo custos de software, seja equivalente ao custo de um relé convencional;

- autochecagem e confiabilidade: um relé digital pode ser programado para monitorar seu hardware e software continuamente, detectando assim qualquer mau funcionamento que possa ocorrer. Além disso, o relé pode ser retirado de operação se a falha for detectada, diminuindo assim, as chances de falha de operação. Essa característica do relé digital é o argumento mais forte em favor da digitalização das subestações;

- integração digital: os computadores e a tecnologia digital têm se tornado a base da maioria dos sistemas empregados nas subestações. Medições, comunicação, telemetria e controle são funções executadas por computadores digitais. Nas subestações modernas, os relés digitais devem estar integrados naturalmente nesses sistemas;

- flexibilidade funcional: o relé digital pode ser programado para realizar diversas funções em uma subestação, tais como: medição, monitoramento e controle, entre outras. Esse relé pode ainda possuir característica adaptativa, modificando sua atuação em várias funções, para torná-las mais adequadas às condições dos SEP;

- velocidade de operação: o tempo entre a incidência da falta e o comando de abertura do disjuntor dado pelo relé é determinado pela configuração do sistema e, no caso da proteção digital, são tipicamente alguns ciclos de freqüência do sistema. Assim, deseja-se que o relé tenha uma velocidade de atuação necessária para assegurar um rápido isolamento da menor porção possível do sistema que está sob falta do resto dele, dentro da sua zona de proteção. 
- seletividade: é a habilidade do relé de isolar a menor parte possível do sistema que está sob falta do resto deste, operando os disjuntores adequados a ele associados o mais rápido possível, dentro da sua zona de proteção, para assegurar a máxima continuidade dos serviços com a retirada de operação do sistema apenas das linhas que estejam sob falta.

Os relés digitais consistem de subsistemas com funções bem definidas. $\mathrm{O}$ diagrama de blocos da Figura 1 mostra os principais subsistemas de um relé computadorizado.

- Os transformadores reduzem as tensões e correntes de entrada a níveis adequados aos microprocessadores. Os transformadores também permitem a isolação galvânica entre as placas eletrônicas da proteção e os sinais provenientes dos TCs e TPs.

- Os sinais transitórios possuem grande quantidade de componentes harmônicas de alta ordem. Um filtro analógico passa-baixa é usado como filtro anti-aliasing impedindo que as altas freqüências sejam amostradas com o objetivo de se evitarem erros no processamento digital dos sinais.

- Um circuito Sample and Hold realiza a amostragem das entradas analógicas em um mesmo instante e disponibiliza os sinais ao multiplexador. Esse circuito evita a deformação provocada pela amostragem seqüencial e conseqüente operação incorreta da proteção.

- O MUX (Multiplex) permite que seja usado apenas um conversor A/D (Analógico/Digital) para várias entradas analógicas. As entradas analógicas são conectadas uma a uma pelo multiplicador ao conversor A/D.

- No conversor A/D, os sinais analógicos são convertidos para a forma digital em intervalos definidos de amostragem.

- O módulo de entrada lógica informa o processador sobre o estado de chaves, disjuntores, seccionadoras e sobre a atuação de outras proteções.

- O processador controla o funcionamento do relé, faz a filtragem digital dos sinais para extração da componente fundamental, se pertinente, executa os cálculos e decide atuações. Observa-se então que o processador permite o desenvolvimento de aplicação de softwares que podem ser embutidos no mesmo como ferramentas de análises para o problema evidenciado neste trabalho. 
- O módulo de saída lógica é responsável pelas atuações de disjuntores e alarmes decididos pelo processamento.

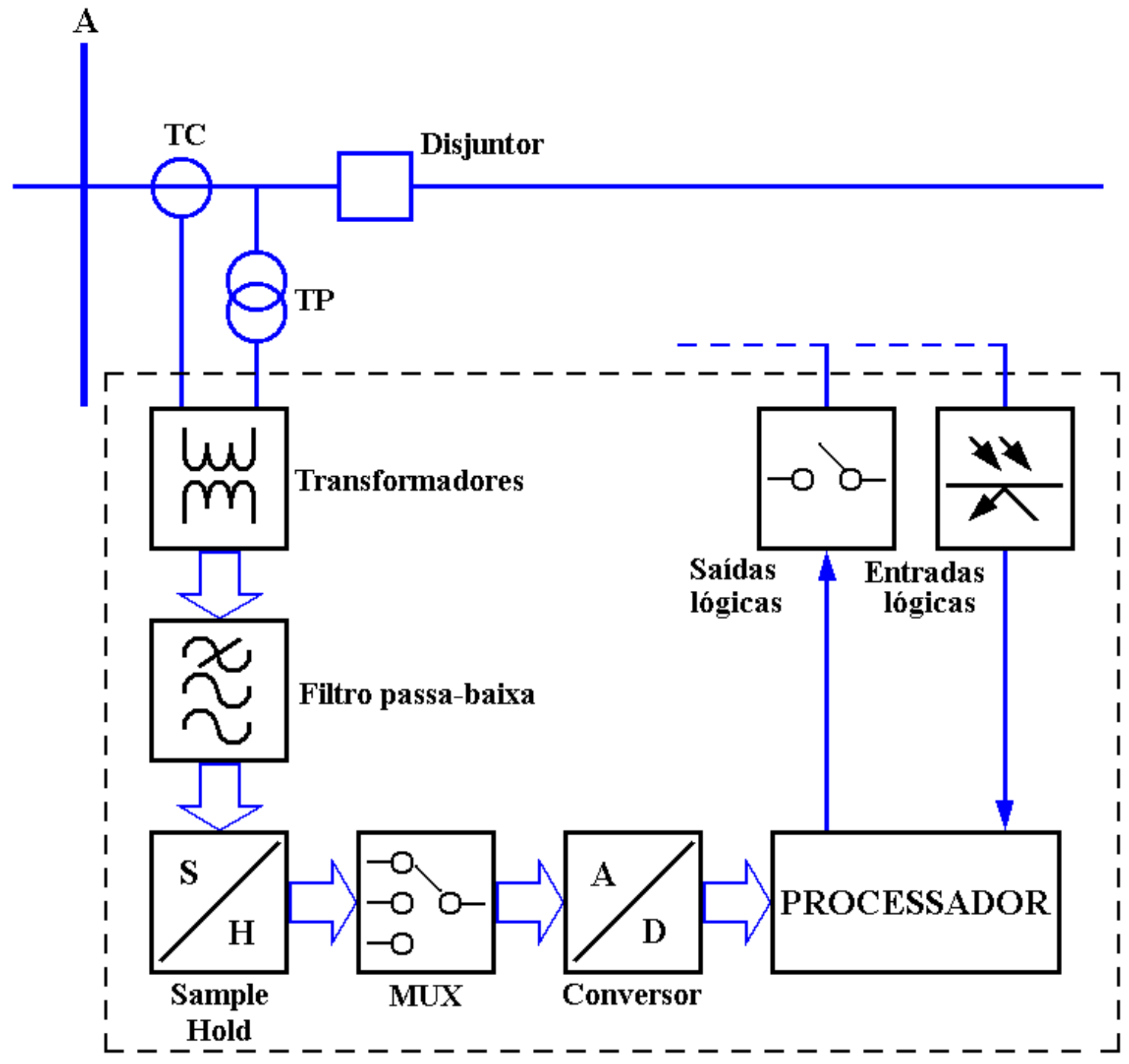

FIGURA 1 - Arquitetura de um relé digital 


\subsection{Algoritmos para Proteção em Linhas de Transmissão}

Quando tratamos da proteção digital de distância para LTs, esta pode ser abordada segundo a filosofia adotada. Tal filosofia pode ser classificada em três grandes categorias ou metodologias:

1) de estimação das componentes fundamentais (Fourier, Walsh, Kalman, Mínimos Quadrados);

2) as baseadas na equação diferencial da linha;

3) as baseadas em componentes de altas freqüências e Transformada Wavelet.

O primeiro método é fundamentado na teoria de transformadas ortogonais. Admite-se que a forma de onda medida consiste de uma componente fundamental, acrescida de uma infinita soma de certos harmônicos. Um par ortogonal de funçõesbase, senoidais ou quadradas, é correlacionado com os dados amostrais para extrair as componentes da função-base da forma de onda de entrada digitalizada. Nessas técnicas, a única parcela que interessa é a componente fundamental do sinal, portanto, o objetivo da aplicação do algoritmo é o de resgatar essa parcela dos sinais de entrada, funcionando, assim, como um filtro digital.

O segundo método assume a representação de um modelo de linha de transmissão fundamentado na resistência e na indutância da linha, onde os sinais de tensão e corrente do sistema são relacionados através de uma equação diferencial.

A base para a solução desse método é utilizar amostras digitalizadas dos sinais de tensão e corrente para expandir a equação diferencial, em termos de $R$ e $L$, por meio da aplicação de métodos diferencias apropriados. $R$ e $L$ são então determinados por meio da solução das equações diferenciais.

O terceiro método baseia-se na determinação do intervalo de tempo de viagem da onda do ponto da falta ao terminal de monitoramento e na velocidade de propagação dessa onda na linha para a determinação da localização da falta, e conseqüentemente, a que zona de proteção ela pertence. Esse método visa a superar as dificuldades encontradas pela aplicação do método baseado em componentes de freqüência fundamental. Uma limitação desse método é a necessidade do emprego de uma elevada taxa amostral do sinal. Entretanto, com o enorme avanço proporcionado, em grande parte, pela tecnologia digital, essa limitação já pode ser superada. Pode-se ilustrar o 
crescente interesse de engenheiros e pesquisadores pelo estudo de novas técnicas para relés de distância, como nas referências [7], [8] e [9].

\subsection{Objetivos do Presente Trabalho}

O presente trabalho aborda a proteção digital de distância fundamentada na teoria de ondas viajantes, aliada ao emprego de uma promissora ferramenta matemática denominada Transformada Wavelet. O desenvolvimento deste trabalho baseia-se na implementação de um algoritmo para proteção digital, o qual, pelo emprego da Transformada Wavelet, é capaz de analisar os sinais transitórios de alta freqüência gerados por uma situação de falta e indicar, com precisão, no domínio do tempo e da freqüência, o instante de chegada das ondas em um ou mais terminais da linha. Uma vez determinado o instante de chegada dessas ondas e conhecendo-se a velocidade de propagação das mesmas, a zona de proteção na qual a falta está alocada pode ser estimada de maneira fácil e rápida. Essa propriedade de detectar com precisão a torna adequada para ser aplicada ao problema em questão.

No algoritmo implementado, o usuário pode escolher entre as técnicas de aquisição de dados provenientes de um ou de dois terminais. Esse algoritmo é implementado com o uso do software Matlab ${ }^{\circledR}$ e posteriormente testado, usando-se dados de faltas obtidos através de simulações, dispondo-se do software ATP (Alternative Transients Program).

Nas simulações realizadas no software ATP, empregando-se um sistema de transmissão de $440 \mathrm{kV}$, os seguintes parâmetros foram variados: tipos de faltas, localizações delas ao longo da linha, ângulos de incidência de falta, resistências de faltas, entre outros. Pelos resultados alcançados, pode-se observar uma precisão altamente satisfatória na localização das zonas de proteção. Além disso, pode-se afirmar que a aplicação é bastante adequada para uso em relés digitais de distância.

\subsection{Organização do Trabalho}

Antes de apresentar a técnica proposta no Capítulo 2, apresenta-se uma revisão dos principais trabalhos referentes às diferentes metodologias aplicadas à proteção digital de distância para LTs. Essas metodologias são divididas em três categorias: (i) técnicas de estimação das componentes de freqüência fundamental, (ii) técnicas 
baseadas nos cálculos de parâmetros do modelo $R L$-série da linha de transmissão e (iii) técnicas baseadas em componentes de altas freqüências e Transformada Wavelet.

No Capítulo 3, são abordados os fundamentos básicos da teoria sobre ondas viajantes, Transformada Wavelet e suas aplicações no SEP. A modelagem do SEP a ser analisado, bem como as considerações referentes às variações nas simulações das faltas aplicadas sobre o sistema proposto são apresentadas no Capítulo 4.

O Capítulo 5 aborda a formulação do problema de determinação das zonas de proteção em linhas de transmissão, baseada em ondas viajantes, dispondo-se da TW, seguida da descrição do algoritmo proposto. Dando seqüência, no Capítulo 6, são apresentados e discutidos os resultados obtidos pelo algoritmo implementado.

Por fim, o Capítulo 7 destaca as principais contribuições deste trabalho e as conclusões sobre o mesmo. Ainda neste capítulo, há a apresentação de sugestões para a continuidade do trabalho. 


\section{REVISÃO BIBLIOGRÁFICA}

Neste capítulo, será apresentado um levantamento bibliográfico de alguns trabalhos sobre relé de distância para linhas de transmissão. Na literatura especializada, têm-se diferentes categorias em que podem ser classificados estes trabalhos: técnicas de estimação das componentes de freqüência fundamental, técnicas baseadas nos cálculos de parâmetros do modelo $R L$-série da linha de transmissão e técnicas baseadas em componentes de altas freqüências e Transformada Wavelet. Esses trabalhos serão apresentados em ordem cronológica. As técnicas baseadas em componentes de altas freqüências e Transformada Wavelet foram subdivididas em dois grupos, segundo a obtenção dos dados de um ou de mais terminais da linha.

\subsection{Técnicas de Estimação das Componentes de Freqüência Fundamental}

\subsubsection{Técnicas Baseadas na Transformada de Fourier e Função Walsh}

Essas técnicas se fundamentam na teoria de transformadas ortogonais. Admitese que a forma de onda medida consiste de uma componente fundamental, acrescida de uma infinita soma de certos harmônicos. Um par ortogonal de funções-base, senoidais ou quadradas, é correlacionado com os dados amostrais para extrair as componentes da função-base da forma de onda de entrada digitalizada [10]. Nessas técnicas, a única parcela que interessa é a componente fundamental do sinal, portanto, o objetivo da aplicação do algoritmo é o de resgatar essa parcela dos sinais de entrada, atuando, assim, como um filtro digital. 
Phadke et al. [11] apresentaram um algoritmo baseado na Transformada de Fourier para relé de distância em linhas de transmissão. O tempo de resposta do algoritmo é um pouco maior que meio ciclo após a ocorrência da falta. Os autores observaram que a componente CC e altas harmônicas, presentes em alguns sinais, introduzem erros substanciais na estimação da distância. Em função disso, sugeriu-se um esquema de compensação de erros.

Phadke et al. [12] derivaram a equação de um relé de distância de alta velocidade fundamentada na teoria de componentes simétricas. Nessa época o relé de distância trifásico empregava seis unidades ou módulos para cobrir os dez tipos de faltas. A vantagem desse novo algoritmo foi que uma única equação foi adequada para definir todos os tipos de faltas que possam ocorrer em um sistema de potência. A abordagem proposta é baseada em uma relação entre os sinais de tensão e corrente sob condições faltosas. As componentes simétricas das tensões e correntes de fase foram determinadas através da Transformada de Fourier utilizando uma taxa de amostragem de $720 \mathrm{~Hz}$. Observa-se então que esse método de releamento é implementado no domínio da freqüência, conseqüentemente, o tempo de processamento do algoritmo não pode ser muito rápido.

Eichhorn et al. [13] apresentaram um novo método para melhorar o comportamento do transitório de algoritmos para proteção a distância. Os fasores de tensões e correntes foram determinados em tempo real, utilizando-se a Transformada de Fourier ou filtros de Kalman. Além da dupla filtragem dos sinais, propôs-se o uso de uma janela amostral variável. Foi proposto também que o algoritmo fosse implementado de maneira recursiva. A freqüência de amostragem empregada nos testes foi de 1000 Hz. Os métodos propostos permitem uma estimação mais rápida dos parâmetros desejados para proteção de linhas de transmissão sob condições transitórias.

Altuve et al. [14] realizaram um estudo comparativo de diferentes algoritmos de filtragem para relé de distância em linhas de transmissão. Propôs-se um método de avaliação que forneceu informações sobre o comportamento transitório do filtro numa ampla faixa de freqüência de ruído. A discussão foi focada em algoritmos fundamentados na Transformada de Fourier e Walsh. Além disso, foi proposto um filtro seno-cosseno. Observou-se que esse filtro exibiu melhor resposta quando o sinal de 
corrente apresentou componente $\mathrm{CC}$, e o sinal de tensão estava contaminado com oscilações de alta freqüência.

$\mathrm{Yu}$ e $\mathrm{Gu}$ [15] propuseram um novo algoritmo o qual combina um filtro passabaixa apropriado e um algoritmo da Transformada de Fourier de um ciclo completo ou de meio ciclo para remover a componente $\mathrm{CC}$ no sinal de tensão e corrente. Inicialmente, um filtro passa-baixa foi utilizado para remover harmônicas de alta ordem. Entretanto, esse filtro produziu simultaneamente uma nova constante de tempo da componente CC. Essa nova constante de tempo foi derivada de acordo com a equação característica do filtro passa-baixa. A componente de freqüência fundamental foi estimado depois da aplicação dos sinais de tensão e corrente no filtro passa-baixa. Além disso, a Transformada de Fourier modificada foi empregada para calcular e remover a componente CC do sinal de pós-falta. O algoritmo da Transformada de Fourier de um ciclo completo requer um ciclo mais três ou quatro amostras e o algoritmo da Transformada de Fourier de meio ciclo requer meio ciclo mais quatro amostras. Para demonstrar a eficiência do algoritmo proposto, o software EMTP (Eletromagnetic Transient Program) foi utilizado para simular as situações de falta em uma linha de transmissão e para obter os sinais de tensão e corrente durante o período de falta. $\mathrm{O}$ algoritmo proposto conseguiu remover eficientemente a componente $\mathrm{CC}$ e conseguiu operar dentro do limite de tempo do relé de distância.

Micheletti e Pieri [16] desenvolveram uma técnica de filtragem digital fundamentada na função Walsh para extração das componentes fundamentais dos sinais de tensão e corrente sob condições faltosas presentes nas linhas de transmissão. A função Walsh, que está intimamente relacionada com a Transformada de Fourier de ciclo completo, extrai os fasores das componentes fundamentais de tensão e corrente e calcula com exatidão a impedância da linha. As funções ortogonais que são correlacionadas com a forma de onda faltosa são ondas quadradas que assumiram valores de $\pm 2 \mathrm{~V}$. Observou-se que esse método de medição é rápido e preciso além de ser adequado para medições das formas de ondas na freqüência fundamental. As fontes de erros devidas aos transformadores de tensão e corrente não foram incluídas nas análises. Também não foi considerado, nos cálculos, o efeito das impedâncias dos transformadores de potência. O método pode ser aplicado para qualquer tipo de falta em 
uma linha de transmissão trifásica através de alterações apropriadas nas interconexões das fases analisadas.

\subsubsection{Técnicas Baseadas em Filtros de Kalman}

Em 1960, Rudolf Emil Kalman publicou a solução recursiva para o problema de filtragem linear discreto, criando assim o filtro de Kalman. Segundo Silva et al. [17], esse estimador realiza o processamento das medidas em tempo real e ainda, em suas equações, o ruído dinâmico tem participação na estimação dos estados. O filtro de Kalman pode ser definido como um conjunto de equações matemáticas utilizadas para estimar estados de um processo, minimizando o erro médio quadrático da estimativa de estados. Esse filtro combina todas as medidas coletadas juntamente com o conhecimento anterior da dinâmica do sistema e dos equipamentos de medidas, mais as estatísticas do ruído dinâmico e finalmente os erros nas medidas.

Girgis [18] desenvolveu um algoritmo utilizando filtro de Kalman para filtragem das componentes fundamentais de tensão e corrente ruidosas para cálculo da impedância aparente vista pelo relé. $\mathrm{Na}$ formulação do filtro de Kalman, foram considerados os conhecimentos estatísticos para as condições iniciais do sistema e o processo de modelamento e medição do sinal ruidoso.

Coury [2] analisou o uso das técnicas de filtragem baseado no filtro de Kalman, para uma estimação ótima das componentes de freqüência fundamental da tensão e corrente. De posse dessas estimativas, montou-se um esquema completo de releamento por computador, consistindo basicamente em detecção, classificação, cálculo da impedância aparente e localização de uma falta em sistemas elétricos. Dentro da subrotina de classificação de faltas, baseada no filtro de Kalman adaptativo, foram considerados dois modelos para tensão: um com a fase faltosa e o outro com fase não faltosa. A verdadeira condição de fase, faltosa ou não, é então decidida pelas probabilidades calculadas "a posteriori”. A técnica utilizou-se de valores calculados nos modelos de estimação recursiva de tensão de fase e, após a classificação, só o modelo relacionado com a hipótese correta prossegue na estimativa. Pela análise dos resultados apresentados pode-se verificar que a técnica é altamente satisfatória. 
Soliman e El-Hawary [19] propuseram uma nova aplicação do algoritmo, utilizando o filtro de Kalman para estimação direta das componentes simétricas em sistemas trifásicos desbalanceados. Os efeitos da freqüência de amostragem, tamanho da janela de dados e alteração na freqüência foram estudados, utilizando-se conjunto de dados simulados e reais. Os autores observaram que o número de amostras e freqüência de amostragem pode influenciar nos parâmetros estimados. Pelos resultados apresentados nos experimentos, a abordagem proposta foi capaz de identificar harmônicos e estimar as componentes simétricas.

\subsubsection{Técnicas Baseadas no Ajuste por Mínimos Quadrados}

A técnica de mínimos quadrados pode ser aplicada na proteção digital, obtendose estimativas razoavelmente boas.

Sachdev e Baribeau [5] desenvolveram um algoritmo baseado na técnica de ajuste por mínimos quadrados. O algoritmo assume que a entrada é composta da componente $\mathrm{CC}$, componente de freqüência fundamental e harmônicas de ordem específica. Além disso, os autores realizaram a expansão dos termos exponenciais e senoidais, utilizando a série de Taylor. A taxa de decaimento da componente CC não foi considerada anteriormente porque ela pode afetar tanto a resistência de arco da falta quanto a resistência efetiva do sistema. Efeitos da freqüência de amostragem, janela de dados, tempo de referência e mudança do modelo da componente CC foram examinados. Os parâmetros selecionados foram então empregados pelo algoritmo no cálculo da impedância. Deve-se salientar que o método de ajuste por mínimos quadrados é computacionalmente bastante complexo. Mesmo assim, a abordagem proposta pode ser aplicada com eficiência na determinação da impedância aparente vista pelo relé. Os autores empregaram uma freqüência de amostragem de $720 \mathrm{~Hz}$ nos testes realizados.

Sachdev e Nagpal [20] apresentaram um algoritmo recursivo para aplicações de medição e proteção digital de sistemas de potência. O algoritmo foi desenvolvido utilizando a técnica de ajuste por mínimos quadrados. Inicialmente foram fornecidos os fundamentos matemáticos necessários para um algoritmo de ajuste por mínimos quadrados não recursivo. Em seguida foi descrito um procedimento que modifica esse 
algoritmo de uma forma não recursiva para uma recursiva. $\mathrm{O}$ algoritmo assume que a entrada é composta somente de componente de freqüência fundamental. O modelo foi então estendido para incluir componentes CC e harmônicas de ordem específica. Nenhuma informação estatística com relação ao sinal foi necessária. Finalmente, exemplos de estudos foram apresentados para demonstrar o desempenho do algoritmo desenvolvido.

\subsection{Técnicas Baseadas nos Cálculos de Parâmetros do Modelo $\boldsymbol{R L}$-Série da Linha de Transmissão}

Essas técnicas assumem a representação de um modelo da linha de transmissão baseado na resistência e na indutância da linha. A tensão e corrente que são fornecidas para diferentes tipos de faltas são expressas pela equação geral:

$$
V=R i+L \frac{d i}{d t}
$$

em que:

$V$ e $I$ representam os valores amostrados dos sinais de tensão e corrente provenientes dos terminais do relé, $R$ e $L$ são os valores de resistência e indutância da linha por quilômetro, respectivamente.

Esse grupo de algoritmos, apoiado no modelo resistivo-indutivo da linha, usualmente despreza a capacitância shunt. Obtendo amostras digitalizadas dos sinais de tensão e corrente resolve-se a equação diferencial da linha com respeito à resistência e indutância de seqüência positiva. Essa representação admite a componente CC como parte válida da solução. Assim, a equação diferencial será usada para determinar os parâmetros do sistema sob condições de falta. Na literatura, são propostos vários métodos para a solução das equações diferenciais da linha, e alguns destes são apresentados a seguir.

McInnes e Morrison [21] sugeriram a integração da eq.(2.1) sob dois intervalos de tempo, para que um número de equações seja solucionado. As integrais foram resolvidas numericamente utilizando-se a regra trapezoidal, em que foram obtidos os valores da resistência e da indutância da linha. 
Sanderson e Wright [22] incluíram o capacitor de compensação-série no modelo básico da eq.(2.1). Nesse caso, a nova equação foi integrada sobre três intervalos de tempo. Essas três equações podem ser solucionadas para se obterem os parâmetros do sistema. Os autores incluíram nessa técnica os seguintes efeitos: do acoplamento mútuo, de linhas não transpostas e da resistência de falta.

Esse método foi melhorado por Ranjbar e Cory [23], que investigaram a mesma técnica proposta por McInnes e Morrison [21], porém com limites de integração da equação diferencial selecionados para determinar a resistência e a indutância da linha de tal modo que se eliminassem qualquer harmônico particular e seus múltiplos. Uma linha de transmissão de $230 \mathrm{kV}$ foi empregada nas simulações. A taxa amostral empregada foi de 32 amostras/ciclo em um sistema de $50 \mathrm{~Hz}$. Observa-se que, para um cálculo eficiente e preciso, a taxa amostral deve ser múltipla da ordem da harmônica a ser removida, ou seja, essa técnica está restrita à seleção da taxa amostral.

Breingan et al. [24], juntamente com a General Electric Company, desenvolveram um relé digital de distância experimental onde o programa do minicomputador utilizava um algoritmo baseado na equação diferencial em que não eram exigidos os conceitos de componentes fundamentais da forma de onda. Uma linha de transmissão de $500 \mathrm{kV}$ foi empregada nas simulações. Deve ser considerado que a linha de transmissão é uma aproximação de um circuito $R L$ com efeito da capacitância shunt. Esse efeito introduz transitórios de alta freqüência no sistema. Esses transitórios podem ser filtrados por um filtro passa-baixa. Com a aproximação da equação diferencial, esse filtro é suficiente para a aproximação da impedância. Os autores realizaram aproximadamente 8000 testes para testar a eficiência do sistema de proteção.

No mesmo ano, Smolinsk [25] apresentou dois algoritmos para o cálculo da impedância em uma linha de transmissão, considerando a representação em circuito PI, resultando em equações diferenciais de segunda ordem. Essa representação permite o cálculo da impedância da linha através de quatro amostras dos sinais de tensão e corrente que contêm componentes transitórios de alta freqüência. Esse modelo não requer qualquer filtragem adicional tanto para remover a componente transitória $\mathrm{CC}$ como as componentes de alta freqüência presentes nos sinais de entrada do relé. As soluções das equações diferenciais foram obtidas por meio da diferenciação numérica 
sob dois períodos de tempos sucessivos fixos. Os esforços computacionais desses dois algoritmos foram analisados. Dessas análises observa-se que o segundo algoritmo exigia um esforço computacional maior que o primeiro, entretanto, o segundo não requer filtragem dos sinais nos cálculos da impedância.

Jeyasurya e Smolinsk [26] fizeram um estudo detalhado de vários algoritmos para proteção de linhas de transmissão, com o propósito de comparar os diversos tipos de algoritmos para a determinação da impedância aparente da falta na linha de transmissão. Os seguintes algoritmos foram testados: método de Fourier de meio e de um ciclo e solução de equações diferenciais com limites de integração selecionados. Baseados nos estudos de combinações de filtros recursivos de terceira ordem, os autores concluíram que o algoritmo da equação diferencial é o melhor para a implementação em tempo real empregando-se microprocessadores.

Ohura et al. [27] ilustraram a dificuldade da eliminação de componentes de transitórios através de filtros analógicos ou digitais. Com isso a medição exata do algoritmo baseada no estado estacionário senoidal apresentou erros. Entretanto, através da abordagem por equação diferencial, e utilizando amostras periódicas, esta não apresentou tais erros. Os autores desenvolveram um algoritmo baseado na modelagem da linha de transmissão por uma equação diferencial que apresentou uma aproximação com alta exatidão de medição na presença de transitórios. O erro de medição encontrado foi menor que $\pm 3 \%$. Desenvolveu-se também um novo algoritmo direcional que detecta a correta direção da falta. Ambos os algoritmos são usados comercialmente.

Rosolowski et al. [28] apresentaram uma nova técnica para o cálculo da impedância aparente da linha de transmissão que combina técnicas de componentes simétricas e equações diferenciais complexas. O método emprega a teoria de componentes simétricas para determinar o circuito equivalente de falta. Os fasores de tensão e corrente são transformados em componentes simétricas utilizando-se técnicas de filtragem de Fourier para uma janela de dados de meio ciclo. As componentes de seqüência positiva da impedância aparente são estimadas por meio da solução de complexas equações diferenciais originadas para o circuito equivalente. Conseqüentemente, o método proposto combina estimação no domínio da freqüência de 
componentes simétricas (filtragem precisa) e medição no domínio do tempo da seqüência positiva da impedância (alta velocidade de resposta).

Akke e Thorp [29] apresentaram algumas melhorias no método para a solução das equações diferenciais da linha previamente desenvolvidas por eles. As melhorias apresentadas foram: classificação da falta, novo método de filtragem digital para a localização estimada da falta e algoritmos para três novos tipos de faltas (fase-terra, fase-fase, fase-fase-terra e trifásica). A localização estimada da falta é a razão entre um numerador e um denominador. O numerador é composto de amostras de tensão e corrente, enquanto o denominador é constituído de amostras de corrente. Essa razão torna-se singular se o denominador se aproximar de zero. Esse efeito é reduzido por meio da filtragem do denominador antes do cálculo da localização da falta. $\mathrm{O}$ numerador é também filtrado por um filtro idêntico, então, a razão não é mudada. Primeiramente, o numerador e o denominador são filtrados separadamente antes da divisão. Em seguida, depois da divisão, a localização da falta é filtrada por um filtro de 7 ordem. A vantagem do filtro é que ele rejeita totalmente valores extremos. Resultados de simulações indicam um tempo de operação nominal de 5 a 7 milissegundos para faltas trifásicas. Somente os resultados para faltas trifásicas foram apresentados. Segundo os autores, o tempo de operação para os demais tipos de faltas é levemente superior.

Cho et al. [30] desenvolveram uma rede neural artificial para melhorar a velocidade do algoritmo do relé de distância baseada em equações diferenciais. Como a equação diferencial utilizada para proteção de linhas de transmissão é somente válida para baixas freqüências, o algoritmo do relé de distância requer um filtro passa-baixa para remover as componentes de alta freqüência. Entretanto, o filtro passa-baixa causa atraso de tempo nas componentes para o releamento. Para isso foi empregada uma rede neural artificial para predizer a distância da falta, melhorando a velocidade do algoritmo sem afetar sua precisão. A abordagem proposta foi testada num sistema de transmissão em $345 \mathrm{kV}$ com três taxas de amostragem: 24, 48 e 96 amostras/ciclo. Além disso, a precisão da técnica proposta pode acelerar mais ao empregar uma alta taxa amostral.

Macêdo e Coury [31] apresentaram um algoritmo completo para a proteção de linhas de transmissão, incluindo detecção, classificação e localização de faltas. A 
localização de faltas é baseada na modelagem do sistema por meio de equações diferenciais. Nessa abordagem, admite-se a presença da componente CC presente na falta como parte da solução do problema. Com relação ao uso direto das equações diferenciais na localização da falta, foi aplicada uma filtragem adicional às respostas do algoritmo, proporcionando-se um diagnóstico mais rápido das estimativas por meio de um filtro de mediana, de $5^{\mathbf{a}}$ ordem. Para todos os tipos de faltas testados, a detecção, classificação e a estimativa da localização da falta, com o uso do referido filtro, mostraram-se satisfatórias para a finalidade de proteção, convergindo em menos de um ciclo e meio pós-falta, após filtragem das estimativas, imprimindo uma velocidade de resposta para os relés digitais.

\subsection{Técnicas Baseadas nos Componentes de Alta Freqüência e Transformada Wavelet}

As técnicas baseadas nas componentes de alta freqüência geradas por uma situação de falta são fundamentadas na teoria de ondas viajantes, segundo Bewley [32]. Esta teoria baseia-se na determinação do intervalo de tempo de viagem da onda do ponto da falta ao terminal de monitoramento, e na velocidade de propagação dessa onda na linha para a determinação da localização da falta e, conseqüentemente, a que zona de proteção esta pertence. Abaixo é apresentada uma breve síntese sobre os métodos, dos quais, a aquisição de dados pode ser proveniente de um ou de múltiplos terminais da linha.

\subsubsection{Algoritmos que Utilizam Dados Somente do Terminal Local da Linha}

Vitins [33], baseado no uso das equações de onda da linha, apresentou um algoritmo de relé de distância para linhas de transmissão. A formulação para a localização da falta foi fundamentada na obtenção do tempo de atraso das ondas viajantes adquiridas no terminal local. Através de uma técnica de correlação, o intervalo de tempo de atraso foi extraído das formas de ondas fundamentais de tensão e corrente na presença de transitórios superpostos. Simulações numéricas e resultados obtidos sob condições laboratoriais indicaram que o método proposto apresentou resultados satisfatórios. 
Crossley e Mclaren [34], fundamentados na teoria de propagação das ondas viajantes geradas pela falta, apresentaram um relé de distância de alta velocidade. Através da informação relativa ao intervalo de tempo entre a primeira onda que atinge o relé e a correspondente onda refletida do ponto de falta que chega a este, estimou-se a localização da falta. O método foi aplicado para faltas em um sistema trifásico fazendose uso da teoria modal. A detecção da onda refletida foi função da correlação cruzada do sinal refletido contra o sinal inicial armazenado da onda. Quando o atraso da seção do sinal inicial corresponde a duas vezes a distância da falta, ocorre a máxima saída da função de correlação cruzada. Os parâmetros que influenciaram na exatidão da localização da falta são: o local, o tipo e o ângulo de incidência da mesma.

Shehab-Eldin e Mclaren [35] sugeriram novas técnicas para o relé de distância baseado em ondas viajantes apresentadas anteriormente por Crossley e Mclaren [34]. Para solucionar os problemas das reflexões do ponto de falta e distingui-las de outras reflexões provenientes do terminal remoto, como também para aumentar a amplitude da correlação cruzada, os autores utilizaram uma correlação composta, que consiste na correlação de funções simples de uma pequena e de uma longa janela de dados. Um fator de correção foi utilizado para compensar a queda na amplitude dos sinais do relé, devido aos efeitos do ângulo de incidência da falta e, conseqüentemente, manter a amplitude da saída da correlação dependente da distância da falta. Conforme apresentado pelos autores, a resistência da falta não afeta a precisão das técnicas.

Em 1988, Christopoulos et al. [36] apresentaram um estudo desenvolvido em um sistema de proteção baseado em ondas viajantes, sendo essa análise aplicada para a maioria das linhas de transmissão. Um tratamento analítico, baseado em uma linha ideal monofásica, foi incluído para indicar como a onda viajante inicial propagada de uma falta e uma onda posterior resultante de uma reflexão puderam ser identificadas. $O$ intervalo de tempo entre as chegadas dessas duas ondas nos transdutores, os quais poderiam energizar o sistema de proteção, foi proporcional à distância de falta. Sua posição pode ser então determinada com uma exatidão aceitável. Observou-se que o método foi capaz de detectar e extinguir uma variedade de faltas internas, e sua habilidade de discriminação foi tal que o relé não enviou sinal de tripping para situações de faltas externas às zonas protegidas. 
No ano seguinte, Christopoulos et al. [37] descreveram a incorporação de técnicas de correlação em um sistema de proteção baseado em ondas viajantes. Mostrou-se que características importantes dos sinais de chegada no ponto do relé puderam ser extraídas, mesmo através de complexas formas de ondas, utilizando-se de técnicas de correlação. A influência do comprimento da janela de dados na exatidão da detecção foi também investigada. Os resultados foram utilizados em um algoritmo de proteção apresentado no trabalho de Christopoulos et al. [36], para obter informações relevantes para o relé. Um método para faltas próximas ao relé foi também apresentado, junto com uma variedade de testes ilustrando a eficiência do algoritmo.

Uma abordagem da Análise Multirresolução (AMR) para detecção e classificação de faltas em linhas de transmissão foi proposta por Liang et al. [38]. Os sinais de detalhe do primeiro estágio da AMR, extraídos dos sinais originais, foram utilizados como critério para esse problema. Neste artigo foi utilizada uma taxa amostral de $600 \mathrm{~Hz}$. Os autores afirmaram que, pelo cálculo da variação dos valores distintos dos detalhes dos sinais AMR, as situações de faltas nos sistemas de potência puderam ser detectadas. A classificação da falta foi realizada pela comparação das variações distintas da AMR das três fases. A rotina de classificação de falta independe da distância, ângulo de incidência e impedância de falta. Os resultados apontados mostraram que esse algoritmo é seguro, robusto e promissor para a detecção de faltas caracterizadas por uma alta impedância.

Um relé de distância baseado em ondas viajantes e TW foi proposto por Xinzhou et al. [39]. O princípio do relé estava baseado essencialmente na teoria de ondas viajantes, utilizando-se da TW e do módulo máximo da mesma. Por meio da análise da distribuição dos módulos máximos da TW, diferentes componentes nas formas de ondas viajantes puderam ser distinguidas, identificando-se, então, as ondas incidentes e refletidas, e filtrando-se finalmente, as componentes indesejáveis. Nesse procedimento, as diferenças entre o tempo de chegada das ondas incididas e refletidas indicaram a localização da falta.

Liang et al. [40] descreveram uma metodologia baseada na função de correlação convencional usando ondas viajantes. Nesse artigo, esse método foi analisado do ponto de vista da TW, e propôs-se que um algoritmo baseado na função de correlação wavelet 
o substituísse. Nesse algoritmo, a TW spline multiescala foi utilizada para detectar os picos dos sinais das ondas viajantes, e a função de correlação wavelet foi então empregada para completar a operação de correlação no domínio da TW ao invés do domínio do tempo. A intensidade dos picos, a exatidão e a habilidade de rejeição de ruídos do algoritmo foram aperfeiçoadas, quando comparadas com o método da função de correlação tradicional.

O método apresentado por Shang et al. [41] descreveu novos critérios para proteção de alta velocidade para linhas de transmissão utilizando a TW. Baseando-se na representação das ondas viajantes através do valor máximo absoluto da TW, foram apresentados critérios de identificação para transitórios semelhantes, tais como: chaveamento sobre linha descarregada e sobre linha sob falta. Simulações foram realizadas para testar os critérios e as influências da localização da falta e dos ruídos. Observou-se que esses critérios levaram a uma identificação definitiva dos transitórios sob condições adversas.

Youssef [42] apresentou uma técnica de classificação de falta baseada na TW. A principal característica desta nova técnica foi a utilização de componentes de alta freqüência $(62,5-125 \mathrm{~Hz}$, taxa amostral de $1.0 \mathrm{kHz})$, presentes nas três correntes de linha, utilizando-se uma pequena janela de dados. Um extensivo estudo foi conduzido, e o método proposto foi descrito em detalhes. Finalmente, alguns estudos de caso foram examinados utilizando os softwares EMTP e MATLAB (Matrix Laboratory), a fim de destacar a performance do método. Mostrou-se que a técnica proposta foi confiável e apropriada para algoritmos de medição em tempo real e para técnicas de classificação de faltas.

Solanki e Song [8] apresentaram um método para detectar e classificar faltas em linhas de transmissão de extra-alta tensão, de forma rápida e exata, para aplicação em relés de proteção de alta velocidade. Para a implementação do algoritmo baseado na representação multirresolução de sinais, foi considerada como wavelet-mãe a Symm2, que foi escolhida após a realização de 38 simulações com cinco famílias de wavelets, através da comparação do número de pontos flutuantes na análise de um sinal de corrente de uma falta-fase-terra. O método proposto pelos autores baseou-se na decomposição, em três escalas, dos sinais de corrente das três fases. Considerou-se a 
energia espectral das versões detalhadas e aproximadas da terceira escala para a detecção e a classificação das faltas. Quando os limiares previamente estabelecidos às versões detalhadas e aproximadas são ultrapassados, uma falta é detectada e então é realizada uma comparação entre a energia espectral apresentada por cada um desses sinais, nas escalas consideradas, para identificar o tipo de falta. Ressalta-se que os autores não informaram a freqüência de amostragem utilizada para amostrar os sinais de corrente, nem os limiares a serem utilizados para a implementação do algoritmo.

Zhang et al. [9] apresentaram um novo sistema de proteção de alta velocidade para linha de transmissão denominado proteção de distância baseada em transitório. Esse método foi desenvolvido utilizando-se análise complexa wavelet e aplicando-se o conceito de proteção baseada em transitórios, na qual os sinais dos transitórios de alta freqüência, gerados pelas situações de faltas, foram empregados para acusar a localização do distúrbio, de acordo com seus tempos relativos de viagem e polaridades. Informações combinadas foram obtidas dos coeficientes wavelet complexos para extrair e localizar uma faixa de componentes de alta freqüência específicas que se propagam ao longo da linha de transmissão. Uma linha de transmissão de $400 \mathrm{kV}$ de extra-alta tensão foi simulada pelo PSCAD/EMTDC para avaliar o sistema. A taxa de amostragem utilizada foi de $1 \mathrm{MHz}$. Os resultados denotaram que esse método foi capaz de prover respostas corretas sobre várias configurações do sistema e condições de falta. Entretanto, os autores ressaltaram dois pontos que estão sob futuras investigações: o desenvolvimento de um método de classificação de faltas baseado nas características das informações combinadas; e a exigência de uma técnica adequada para distinguir a sobreposição das seqüências dos transitórios causados pela multirreflexão ou por algumas distâncias de faltas particulares.

\subsubsection{Algoritmos que Utilizam Dados de Múltiplos Terminais da Linha}

No ano de 1981, Vitins [43] descreveu uma abordagem fundamental para detectar a situação de falta em um sistema de potência, dentro dos primeiros milissegundos, baseada no ângulo de incidência da mesma. O ângulo de incidência foi representado por uma trajetória a qual caracterizou as variações das tensões e das correntes devido à ocorrência da falta. Uma abordagem geométrica foi discutida para extrair dados da localização da falta por sua trajetória. Fatores que influenciaram a 
forma da trajetória são descritos e verificados através de simulações numéricas e por experimentos em um analisador de transitórios em sistemas. Esse método solucionou vários problemas que ocorreram em relés convencionais e foi adequado para uso em sistemas de proteção de alta velocidade que dispunha de um rápido canal de comunicação entre os terminais do sistema protegido.

Partindo do mesmo princípio apresentado por Crossley e Mclaren [34], Rajendra e Mclaren [44] estenderam a técnica do relé de distância para circuitos com derivação ou de três terminais, fazendo uso dos sinais de ondas de tensão e corrente de pós-falta. O método utilizou a função de correlação cruzada entre uma seção da primeira onda viajante direta, detectada e armazenada, e a segunda onda viajante reversa que reflete do ponto de falta e retorna ao ponto do relé. Por meio dessa informação, conseguiu-se estimar o intervalo de viagem dos transitórios, determinando-se, assim, a distância da falta.

Mansour e Swift [45] empregaram a técnica de ondas viajantes com comunicação entre os terminais. Porém o método apresenta uma grande limitação prática, já que no processo de digitalização, para não ocorrer o fenômeno de sobreposição de espectros, é preciso limitar as altas freqüências em, no máximo, metade da taxa amostral. Isso limita a sua aplicação por eliminar componentes de altas freqüências importantes para a análise do método.

Thomas et al. [46] descreveram uma extensão do algoritmo do relé de distância apresentado no trabalho de Christopoulos et al. [36], para circuitos com derivação ou de três terminais. Esse método demonstrou bom desempenho para faltas trifásicas. Todas as faltas internas puderam ser identificadas. $\mathrm{O}$ algoritmo requer somente dados de préfalta em regime permanente, para a comunicação entre os relés localizados nos terminais da linha. Com isso, cada um dos três relés opera independentemente. Todos os três relés devem operar para faltas internas de tal maneira que eles somente necessitem estar conectados aos seus disjuntores. Esse sistema de proteção apresenta a vantagem de não requerer canais de comunicação de alta qualidade para sua operação. 


\section{FUNDAMENTOS SOBRE ONDAS VIAJANTES E TRANSFORMADA WAVELET}

Neste capítulo, serão apresentadas as teorias sobre ondas viajantes em linhas de transmissão, juntamente com a ferramenta matemática utilizada denominada Transformada Wavelet.

\subsection{Ondas Viajantes em Sistemas de Transmissão}

Qualquer distúrbio em uma linha de transmissão, seja uma descarga atmosférica ou uma interrupção das condições de regime permanente, dá origem a ondas viajantes que se propagam na direção das extremidades da linha, onde são refletidas e refratadas.

A teoria das ondas viajantes permite que sejam definidos os coeficientes de reflexão e refração da onda em descontinuidades, a velocidade de propagação da onda e a impedância de surto da linha de transmissão. Vale ressaltar que, durante a propagação ao longo da linha, as ondas viajantes são atenuadas principalmente por perdas resistivas e por corrente de fuga e ainda podem sofrer distorção na sua forma de onda [47].

Para que o comportamento transitório de uma onda eletromagnética sobre uma linha de transmissão possa ser representado de forma adequada, é necessário que os parâmetros da linha estejam distribuídos uniformemente sobre seu comprimento, pois somente essa representação permite que a teoria das ondas viajantes seja utilizada para analisar a propagação desses fenômenos eletromagnéticos na mesma [48].

Modelos que assumem que os parâmetros da linha de transmissão são constantes, à freqüência constante, não são considerados adequados para simular a resposta da linha de transmissão sobre uma grande escala de freqüências que estão presentes nos sinais durante condições transitórias, conforme Marti [49]. Apesar disso, na prática, os modelos de linhas com parâmetros distribuídos, à freqüência constante, apresentam resultados plenamente satisfatórios e são utilizados na maioria dos estudos 
de transitórios eletromagnéticos em sistemas elétricos, de acordo com o Alternative Transients Program - Rule Book [50].

\subsubsection{Reflexões e Refrações de Ondas Viajantes}

Quando uma onda viajante encontra uma descontinuidade em uma linha de transmissão na qual existe uma mudança abrupta das constantes do circuito, como por exemplo, um terminal em aberto ou em curto-circuito, ou uma junção com outra linha, uma parte dessa onda é refletida de volta ao terminal, e a outra parte é transmitida para outras sessões do circuito. A onda que chega no ponto de descontinuidade é chamada de onda incidente e as duas ondas oriundas desse ponto são chamadas de ondas refletidas e refratadas (que são as transmitidas). Tais ondas são formadas no ponto de descontinuidade, de acordo com as leis de Kirchhoff. Elas satisfazem as equações diferenciais das linhas de transmissão e são condizentes com os princípios de conservação de energia [32].

\subsubsection{Reflexões Sucessivas e Diagrama Lattice}

Uma forma alternativa para o estudo de ondas viajantes em qualquer ponto da linha de transmissão foi proposta por L. V. Bewley em 1933 e é conhecida como diagrama de Lattice. Essa representação está baseada em um diagrama espaço-tempo e indica a posição e a direção de cada onda viajante, seja ela incidente, refletida ou refratada em qualquer instante de tempo. Esse diagrama facilita o cálculo da forma das ondas refletidas e refratadas e também mostra uma visão completa do histórico de cada onda. Conhecendo-se as funções de atenuação e distorção, tais efeitos podem ser incluídos no diagrama [47].

O objetivo do diagrama Lattice é propiciar um meio gráfico simples que denote as relações espaço-tempo dos sinais em análise sobre redes de transmissão, com várias descontinuidades.

Uma aplicação do diagrama Lattice é no cálculo de surtos de descargas atmosféricas em linhas de transmissão, com muitos pontos de aterramento. Nessa situação, torna-se difícil o conhecimento de todas as ondas refletidas e refratadas ao longo da linha, especialmente após um intervalo de tempo relativamente longo. Observa-se que, à medida que cada onda atinge uma descontinuidade, uma nova onda 
refletida e refratada é gerada naquele ponto. A Figura 2 ilustra um diagrama Lattice onde se têm três junções de linhas com diferentes comprimentos. A onda incidente, ao encontrar um ponto de junção (1, 2 ou 3), gera duas ondas a partir desse ponto, as ondas refletidas e refratadas. A posição de uma onda, em qualquer instante de tempo, é dada pela escala de tempo localizada à esquerda do diagrama Lattice.

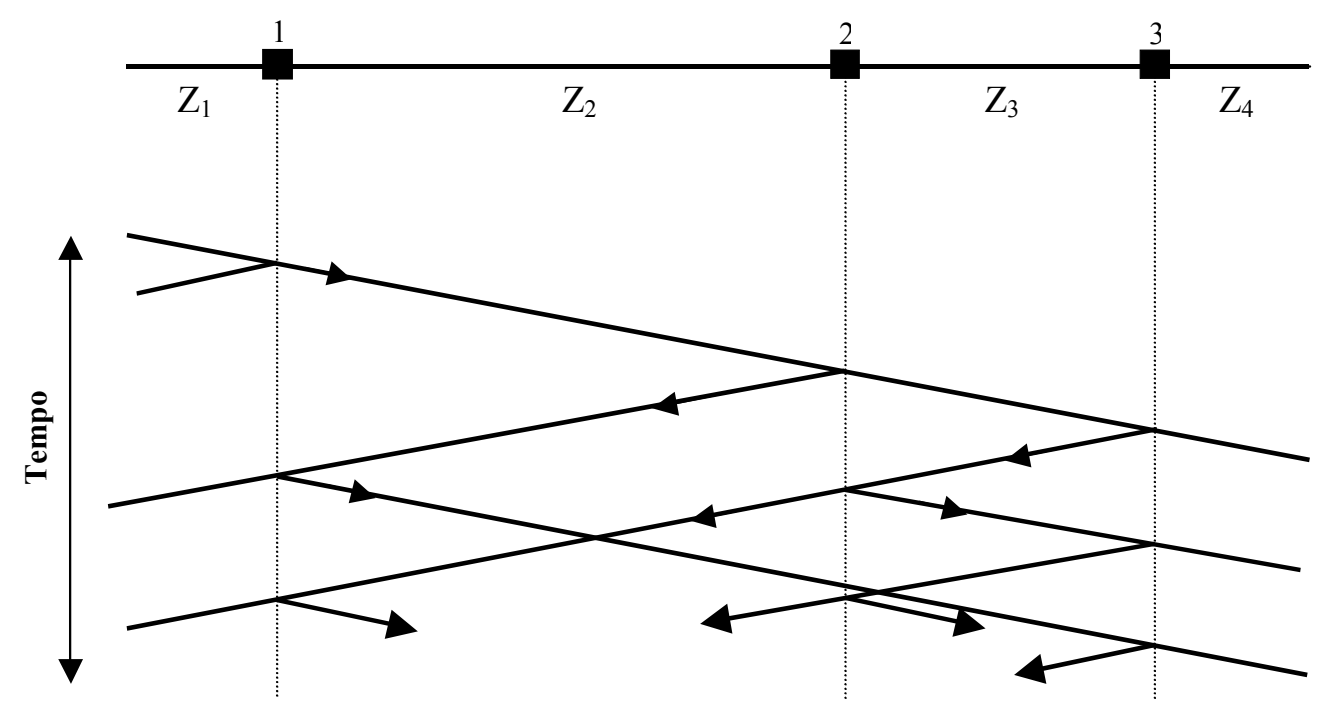

FIGURA 2 - Diagrama Lattice representando as sucessivas reflexões de um sinal qualquer

\subsubsection{Atenuação e Distorção das Ondas Viajantes}

As ondas viajantes em uma linha de transmissão sofrem três diferentes mudanças:

a) o valor de crista da onda decresce em amplitude, ou é atenuado;

b) as ondas mudam de forma, tornam-se mais alongadas, suas irregularidades são alisadas, e sua inclinação é reduzida;

c) as ondas de tensão e corrente tornam-se similares.

As mudanças descritas nos itens b e c ocorrem juntas e são chamadas de distorções. Atenuação e distorção das ondas viajantes são causadas por perdas de energia, e estas são devidas à resistência da linha, ao efeito skin, à dispersão sobre isoladores, às perdas dielétricas e ao efeito corona [32].

De fato, temos que as características da resistência e condutância de uma linha de transmissão contribuem para a atenuação da propagação das ondas viajantes ao longo da linha. Contudo, no modelo da linha de transmissão utilizado neste estudo, as perdas 
não foram consideradas com a finalidade de simplificar a solução do problema. Portanto os efeitos de atenuação foram desprezados.

Quando as perdas resistivas são iguais às perdas por corrente de fuga, a relação entre a tensão e a corrente na linha de transmissão é mantida constante, não havendo, portanto, distorção das formas dessas ondas viajantes. Porém, quando essas perdas não são iguais, as formas de onda sofrem distorção e são atenuadas por uma taxa inferior à impedância de surto da linha de transmissão [48].

Outro fenômeno que contribui para a atenuação e distorção das ondas viajantes é o efeito corona, decorrente da ionização do ar quando da disrupção da tensão dielétrica.

\subsection{Motivação para o Uso da Transformada Wavelet}

Transitórios em sistemas de potência os quais freqüentemente têm um efeito adverso em relação à operação normal do sistema são bastante comuns. Transitórios de correntes de descargas atmosféricas, correntes inrush de transformadores, correntes de partida de motores, transitórios devido a chaveamento de capacitores em linhas de transmissão são apenas alguns dos transitórios eletromagnéticos típicos em sistemas de potência que ocorrem na prática. A análise e o entendimento dos transitórios associados com tal condição anormal tem sempre ajudado a explicar e retificar a causa da condição. A identificação de transitórios em tempo real, o processo de medição dos sinais de tensão/corrente envolvendo rapidez e precisão, aplicações de controle online em transmissão e distribuição são de interesse particular de engenheiros de potência. Alguns dos métodos empregados para análise dos fenômenos transitórios são: (i) transformação dos dados no domínio da freqüência, empregando-se a análise de Fourier, Laplace ou a Transformada $Z$ ou o (ii) uso de programas de simulação computacional de sistemas de energia, como o programa de transitórios eletromagnético (EMTP), ou pelas soluções matemáticas de equações diferenciais seja analítica ou numericamente.

Um exemplo de limitação de ferramenta para a análise de sinais transitórios é a análise de Fourier. A série de Fourier requer periodicidade de todas as funções envolvidas no tempo. Isso efetivamente significa que as funções-base (isto é, sinais de seno e cosseno) utilizadas na análise de Fourier estão precisamente situadas na freqüência, mas existem para todo o tempo. A informação em freqüência de um sinal calculado pela transformada clássica de Fourier é a média de todo o tempo de duração do sinal. Assim, se existe um sinal transitório local durante algum intervalo de tempo 
pequeno, o transitório contribuirá para a TF (embora de modo um pouco ineficiente), mas a sua localização no eixo do tempo será perdida. A análise tradicional de Fourier não considera freqüências que variam com o tempo, isto é, sinais não estacionários.

Com o objetivo de corrigir a deficiência mencionada da TF, Dennis Gabor, de acordo com a referência [51], a adaptou para analisar apenas uma pequena extensão do tempo do sinal, originando a chamada Short-Time Fourier Transform (STFT), também conhecida como Transformada de Fourier Janelada (TFJ). Entretanto, a desvantagem é que a TFJ tem a limitação da largura da janela a qual precisa ser fixada. Nesse caso, não teremos uma resolução tanto no tempo quanto na freqüência, a qual é característica importante para a análise dos sinais transitórios abrangendo componentes de alta e baixa freqüência. Com uma janela larga, por exemplo, obteremos uma boa resolução em freqüência, mas teremos uma pobre resolução no tempo, enquanto que com uma janela estreita será obtida uma boa resolução no tempo, mas uma pobre resolução em freqüência. Deve ser mencionado que a técnica da TFJ pode ser aplicada com uma seqüência de janelas de diferentes larguras para se conseguir mais detalhes na localização do transitório. Entretanto, essa última opção é complexa e de grande esforço computacional.

A Transformada Wavelet supera as limitações do método de Fourier através do emprego de funções que são locais no tempo e em freqüência. A TW é bem adaptada para sinais de banda larga que não são periódicos e podem conter ambas as componentes senoidais e de impulsos, como é típico de rápidos transitórios em sistemas de potência. Em particular, a habilidade das wavelets em localizar curtos intervalos de tempo para componentes de alta freqüência e longos intervalos de tempo para componentes de baixa freqüência, melhora a análise de sinais com impulsos e oscilações, particularmente na presença de harmônicos fundamentais e de baixa ordem. De certo forma, as wavelets têm uma janela que se adapta automaticamente, para dar uma resolução apropriada [52].

\subsection{A Utilização da Transformada Wavelet}

Sob o ponto de vista histórico, a análise wavelet é uma técnica recente, apesar dos seus fundamentos matemáticos apontarem para o trabalho de Joseph Fourier no século XIX. Fourier fundamentou sua teoria em análise no domínio da freqüência, e provou que é muito importante e de enorme influência para os demais trabalhos. 
Pesquisadores começaram gradualmente a mudar o foco de seus trabalhos, partindo da análise no domínio da freqüência em direção da análise no domínio do tempo e da freqüência simultaneamente.

Na tese de Alfred Haar, em 1909, como descrito na referência [53], tem-se o primeiro registro sobre do uso de wavelets. As wavelets de Haar possuem a característica de terem suportes compactos, porém não são continuamente diferenciáveis, o que limitou o seu uso. Devido a essa limitação, as wavelets de Haar permaneceram no anonimato até que, em 1930, alguns autores pesquisaram como representá-las, utilizando funções de base com escala variável. O físico Paul Levy, em 1930, utilizou a função de base com escala variável, conhecida como função-base de Haar, para investigar o movimento Browniano, o qual é um tipo de sinal randômico. Nesse trabalho, Paul Levy verificou que as funções-base de Haar são superiores às funções-base de Fourier para analisar os pequenos e complicados detalhes do movimento Browniano. Littlewood, Paley e Stein, na década de 30, calcularam a energia de uma determinada função $f(x)$. O cálculo forneceu resultados diferentes, quando a energia foi considerada concentrada e distribuída. Esse resultado indicou que a energia não pode ser conservada. Esse trabalho proveu Davis Marr de um algoritmo eficiente para processamento de imagens, utilizando wavelets no início da década de 80 . Grossmann e Morlet, em 1980, definiram a wavelet no contexto da física quântica. Wavelets ganharam um novo impulso a partir de 1985, quando Stephane Mallat apresentou um trabalho na área de processamento digital de sinais. Esse autor descobriu algumas relações as quais foram a base do desenvolvimento do trabalho de Y. Meyer, que construiu a primeira wavelet não-trivial. As wavelets de Meyer são continuamente diferenciáveis e não possuem suporte compacto, ao contrário da wavelet de Haar. Alguns anos mais tarde, Ingrid Daubechies utilizou o trabalho de Stephane Mallat na construção de um conjunto de wavelets de função de base ortonormais suaves, com suportes compactos. Os trabalhos de Ingrid Daubechies são os alicerces das aplicações atuais de wavelets.

A Transformada Wavelet (TW) consiste em uma técnica de "janelamento" variável. A TW permite o uso de uma janela de tempo maior para analisar informações de baixa freqüência, de forma mais precisa, e de uma pequena janela para informações de alta freqüência [51]. 
De acordo com Daubechies [54], define-se a família das funções wavelets $\psi_{a, b}$, como segue:

$$
\psi_{a, b}(x)=|a|^{-\frac{1}{2}} \psi\left(\frac{x-b}{a}\right) \quad a, b \in \mathfrak{R}, \quad a \neq 0,
$$

em que:

$x$ representa a variável de tempo ou espaço, gerada a partir das operações de expansão (fator de escala $a$ ) e translação (fator $b$ ) da mesma função $\psi$, que é a wavelet-mãe.

A Transformada Wavelet (TW) pode ser encontrada em duas versões diferentes, a contínua e a discreta:

a) Transformada Wavelet Contínua (TWC): faz o mapeamento de um sinal original unidimensional no domínio do tempo, para uma nova função, em um espaço bidimensional, através dos fatores de escala $a$ e translação $b$ pela TW.

b) Transformada Wavelet Discreta (TWD): faz a decomposição de um sinal discretizado em diferentes níveis de resolução e realiza o mapeamento de uma seqüência de números em outra seqüência de números [52]. 


\subsubsection{A Transformada Wavelet Contínua}

A análise wavelet emprega um protótipo de função chamado wavelet-mãe que tem média zero e parte central oscilante, ou seja, decai para zero em ambos os lados de sua trajetória. Matematicamente, a Transformada Wavelet Contínua (TWC) de um dado sinal $x(t)$ em relação à wavelet-mãe $\psi(t)$ é definida por:

$$
T W C(a, b)=\frac{1}{\sqrt{a}} \int_{-\infty}^{\infty} x(t) \psi\left(\frac{t-b}{a}\right) d t
$$

em que:

$a$ é a dilatação ou fator de escala, $b$ é o fator de translação, e essas variáveis são contínuas.

A eq.(3.2) mostra que o sinal unidimensional original no domínio do tempo $x(t)$ é mapeado para uma nova função, em um espaço bidimensional, por meio dos fatores de escala $a$ e translação $b$ pela TW. Um coeficiente da TW, em uma determinada escala e translação - TWC $(a, b)$, representa quão bem o sinal original $x(t)$ e a wavelet-mãe escalada e transladada se combinam. Dessa forma, o conjunto de todos os coeficientes $T W C(a, b)$ associados a um sinal particular são a representação wavelet do sinal original $x(t)$ em relação à wavelet-mãe $\psi(t)$.

Pode-se visualizar a wavelet-mãe como uma função janela. O fator de escala $a \mathrm{e}$ o tamanho da função janela são interdependentes, desse fato decorre que menores escalas implicam em menores janelas. Conseqüentemente, pode-se analisar componentes de bandas estreitas de freqüência de um sinal com um pequeno fator de escala, e componentes de bandas largas de freqüência com fatores de escala maiores, o que permite capturar todas as características de um sinal particular [52].

\subsubsection{Escalamento}

A análise wavelet produz um escalamento no tempo de um sinal. A seguir será abordada uma discussão a respeito de escalamento e translação de wavelets.

Escalar uma wavelet significa simplesmente expandí-la ou comprimí-la. O fator de escala, usualmente denotado pela letra $a$, é utilizado para representar esses efeitos. 
Por exemplo, em se tratando de senóides, o efeito do fator de escala é facilmente observado, como é ilustrado na Figura 3 [51]:
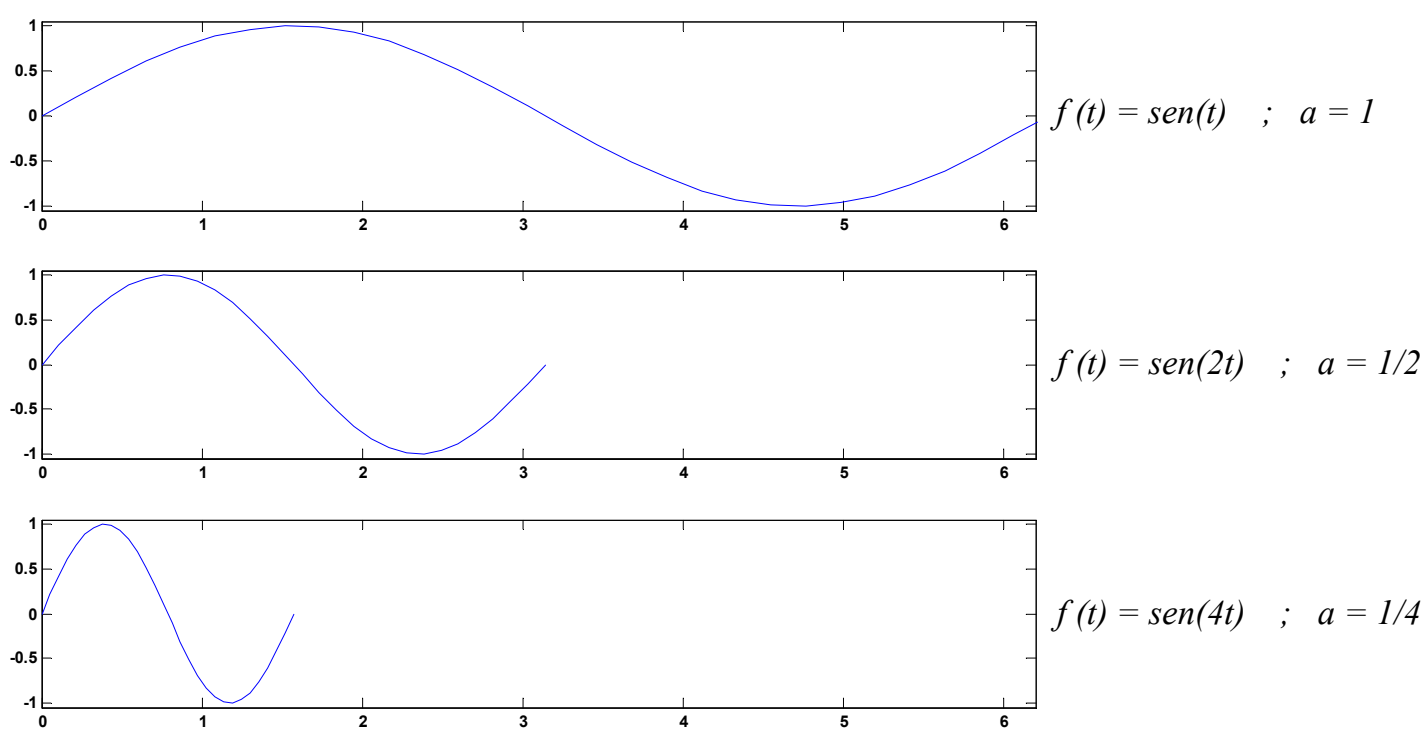

FIGURA 3 - Escalamento de uma função seno

$\mathrm{O}$ fator de escala trabalha exatamente da mesma maneira com wavelets. Quanto menor o fator de escala, mais comprimida será a wavelet, como é ilustrado na Figura 4:
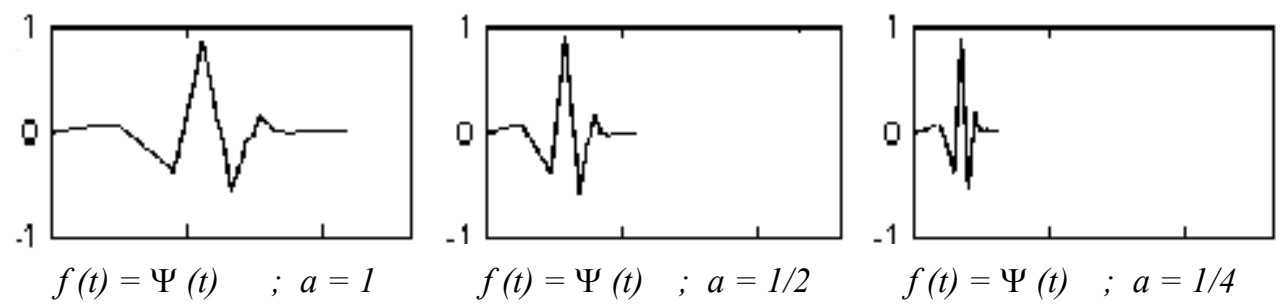

FIGURA 4 - Escalamento de uma função wavelet

A Figura 3 mostra que, para a senóide $\operatorname{sen}(w t)$, o fator de escala $a$ está relacionado de maneira inversa à freqüência do sinal em radianos $w$. De maneira semelhante na Figura 4, com a análise wavelet, a escala está relacionada com a freqüência do sinal. O que corresponde a:

baixa escala $a \rightarrow$ wavelet comprimida $\rightarrow$ detalhes que mudam rapidamente $\rightarrow$ alta freqüência $w$. 
alta escala $a \rightarrow$ wavelet expandida $\rightarrow$ detalhes que mudam vagarosamente $\rightarrow$ baixa freqüência $w$.

\subsubsection{Translação}

Transladar uma wavelet significa simplesmente atrasá-la ou adiantá-la em relação ao eixo das abscissas. Matematicamente, atrasar uma função $f(x)$ de um fator $k$, consiste na expressão $f(x-k)$, conforme mostrado na Figura 5 [51]:
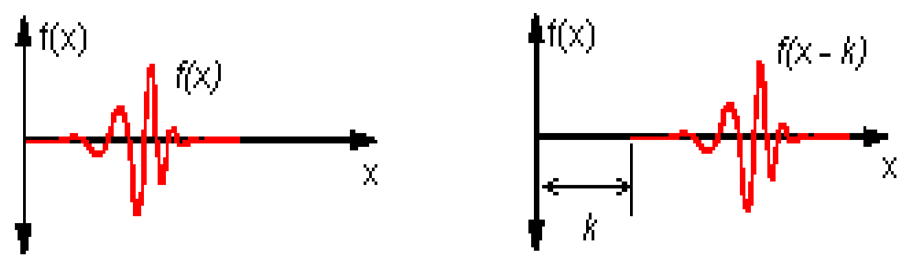

FIGURA 5 - Translação aplicada a uma wavelet

\subsubsection{Cálculo da Transformada Wavelet Contínua}

A TWC é a integral em todo o intervalo de definição do sinal, multiplicada pelas versões escalonadas e transladadas da wavelet-mãe. Esse processo produz coeficientes wavelet que são função da escala e posição. A seguir são ilustrados cinco passos para criar a TWC [51]:

1. alinhar uma wavelet-mãe e compará-la com uma seção inicial do sinal original;

2. calcular o coeficiente $C$, o qual representa quão intimamente está relacionada a wavelet-mãe com a seção do sinal, em que $C=T W C(a, b)$. Entre os coeficientes calculados, os maiores valores de $C$ significam uma maior similaridade do sinal com a wavelet. Mais precisamente, se a energia do sinal e a energia da wavelet são iguais a um, o coeficiente $C$ pode ser interpretado como um coeficiente de correlação. Note que o resultado dependerá da forma da wavelet-mãe escolhida, como na Figura 6:

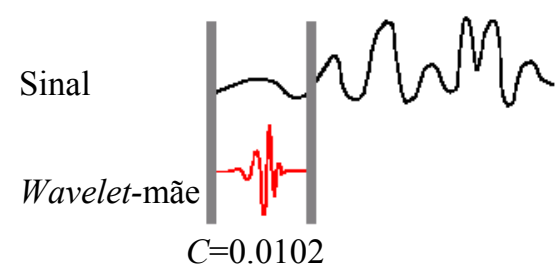

FIGURA 6-Cálculo do fator $C$ de relação entre a wavelet-mãe e o sinal 
3. transladar a wavelet-mãe para a direita, como mostrado na Figura 7, e repetir os passos 1 e 2 até que se tenha coberto todo o sinal.

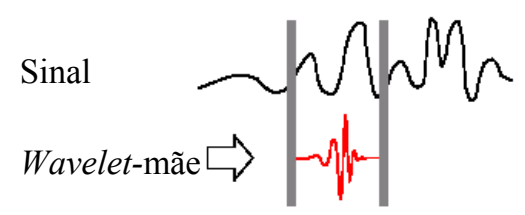

FIGURA 7 - Translação da função wavelet-mãe

4. escalar (expandir) a wavelet-mãe, como ilustrado na Figura 8, e repetir os passos de 1 a 3.

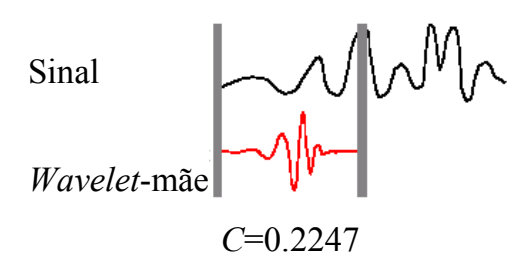

FIGURA 8-Escalonamento da função wavelet-mãe

5. repetir os passos de 1 a 4 para todas as escalas.

Quando o processo terminar, têm-se os coeficientes da TWC produzidos em diferentes escalas, por diferentes seções do sinal [51].

\subsubsection{A Transformada Wavelet Discreta}

A Transformada de Fourier (TF) pode ser encontrada em duas versões diferentes, a contínua e a discreta (TDF). De maneira análoga, a Transformada Wavelet Contínua tem uma versão digitalmente implementável, chamada de Transformada Wavelet Discreta (TWD) que é definida como se segue:

$$
T W D(m, k)=\frac{1}{\sqrt{a_{0}^{m}}} \sum_{n} x(n) \psi\left(\frac{k-n b_{0} a_{0}^{m}}{a_{0}^{m}}\right)
$$

em que:

$\psi($.$) é a wavelet-mãe e os parâmetros de escala e de translação a$ e $b$ são funções de um parâmetro inteiro $m$, isto é, $a=a_{o}^{m}$ e $b=n b_{o} a_{o}^{m}$, que permite uma expansão da família originada pela wavelet-mãe, gerando as wavelets filhas. $\mathrm{Na}$ eq.(3.3), $k$ é uma variável inteira que se refere a um número particular de amostras de um determinado sinal de 
entrada. O parâmetro de escala permite o aumento da escala geométrica, isto é, 1, 1/a $\mathrm{a}_{\mathrm{o}}$, $1 / \mathrm{a}_{\mathrm{o}}^{2}, \ldots$

A saída da TWD pode ser representada em um espaço bidimensional de maneira semelhante à da Transformada Discreta de Fourier Janelada, mas com divisões muito diferentes no tempo e na freqüência. A análise da TWD produz bandas de freqüência de tempo retangulares, as quais são estreitas nas componentes de alta freqüência e largas nas componentes de baixa freqüência [52].

\subsubsection{Filtragem e Análise Multirresolução}

Filtrar consiste em permitir passar algumas componentes de freqüência de um sinal e rejeitar outras. Um exemplo disso é a análise da voz humana. Se retirarmos as componentes de alta freqüência, a voz terá um som diferente, mas é possível entender o que está sendo dito. Entretanto, se retirarmos as componentes de baixa freqüência, será emitido um palavreado sem sentido.

$\mathrm{Na}$ análise wavelet, fala-se usualmente em aproximações e detalhes. As aproximações são as altas escalas, ou seja, as componentes de baixa freqüência do sinal. Os detalhes são as baixas escalas, isto é, as componentes de alta freqüência [51].

O processo de filtragem, em seu nível mais básico, está ilustrado na Figura 9:

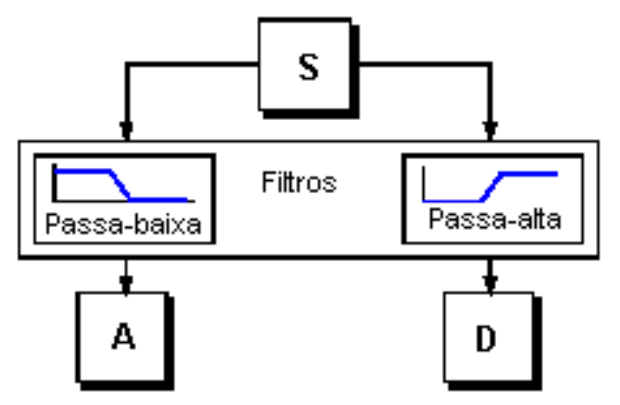

FIGURA 9 - Processo de filtragem de um sinal

O sinal original $S$ passa através de dois filtros complementares que fornecem dois sinais como saída.

Se aplicarmos esse esquema em um sinal digital real, obteremos duas vezes mais a quantidade de dados em relação aos dados iniciais. Por exemplo, considere um sinal original $S$ contendo 1000 amostras de dados. Sendo assim, as versões aproximadas $(A) \mathrm{e}$ 
detalhadas $(D)$ do sinal original terão 1000 amostras cada uma, totalizando 2000 amostras.

Para corrigir esse problema, foi introduzido um operador que reduz o número de amostras que é chamado de operador downsampling. Esse operador considera dados intercalados, ou seja, leva em consideração o primeiro dado e rejeita o segundo, e assim por diante. Com isso, é introduzido um fenômeno aliasing, ou superposição de espectro, nas componentes do sinal, o que deverá ser levado em conta em tratamentos posteriores.
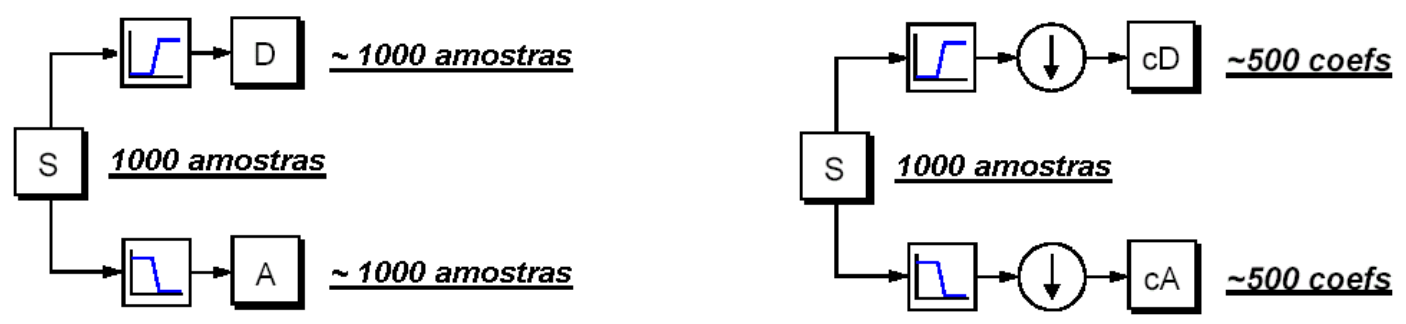

FIGURA 10 - Processo de diminuição do número de amostras do sinal (downsampling)

O processo na direita da Figura 10 ilustra a atuação do operador downsampling, o qual produz os coeficientes da TWD.

Para obter um maior entendimento do processo, ilustra-se no exemplo que segue, o desenvolvimento da TWD de um sinal. O sinal será uma senóide pura adicionada com ruído de alta freqüência.

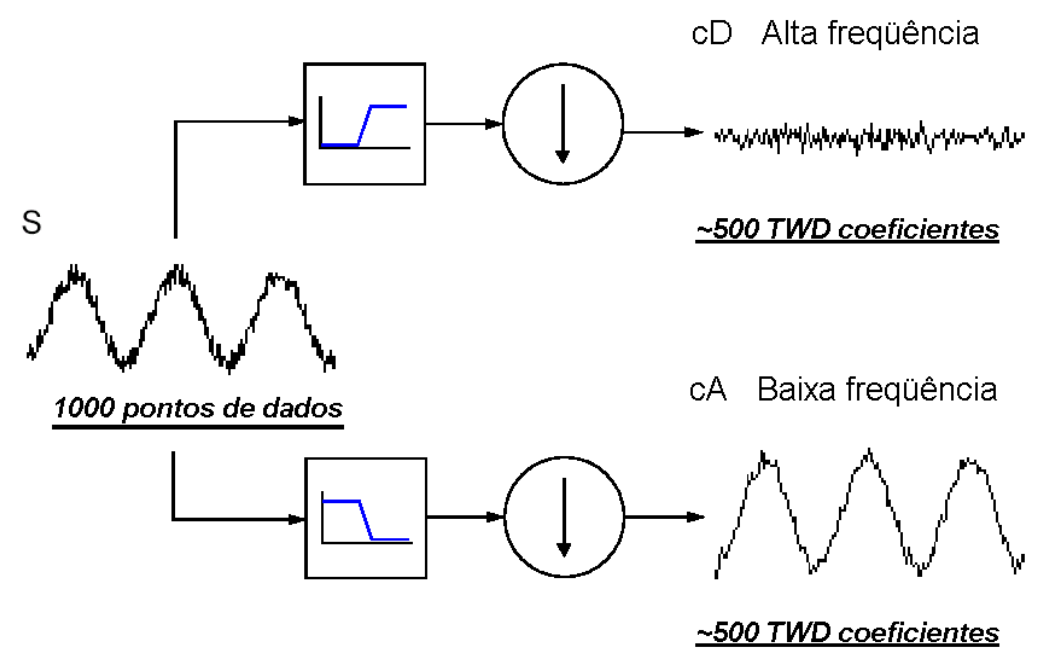

FIGURA 11 - Exemplo de filtragem com downsampling de um sinal senoidal ruidoso 
Observa-se na Figura 11 que os coeficientes de detalhe $c D$ são menores e consistem principalmente do ruído de alta freqüência, enquanto que os coeficientes $c A$ contêm menos ruído que o sinal original.

\subsubsection{Decomposição em Múltiplos Níveis ou Análise Multirresolução}

A análise multirresolução (AMR) refere-se ao procedimento para obter aproximações de filtros passa-baixa e detalhes de filtros passa-alta do sinal original. Uma aproximação é a representação em baixa resolução de um sinal original, enquanto um detalhe é a diferença entre duas sucessivas representações em baixa resolução do sinal original. Uma aproximação contém as baixas freqüências do sinal original, enquanto um detalhe representa o conteúdo de alta freqüência do sinal original. Aproximações e detalhes são obtidos por meio de um processo sucessivo de convolução. O sinal original é dividido em diferentes escalas de resolução, ao invés de ser dividido em freqüências diferentes, como é no caso da análise de Fourier.

O algoritmo de decomposição de um sinal em análise multirresolução, ilustrado na Figura 12, apresenta três níveis de decomposição. Os detalhes e aproximações do sinal original $S$ são obtidos por meio de bancos de filtros, os quais consistem de filtros passa-baixa $\left(h_{0}\right)$ e passa-alta $\left(h_{1}\right)$. Um filtro passa-baixa remove as componentes de altas freqüências, enquanto o filtro passa-alta seleciona o conteúdo de alta freqüência do sinal analisado [55].

Resumindo, o objetivo básico da AMR é dividir o espectro de um dado sinal em sub-bandas de freqüência e então tratar individualmente cada uma das sub-bandas, através de bancos de filtros passa-alta e passa-baixa.

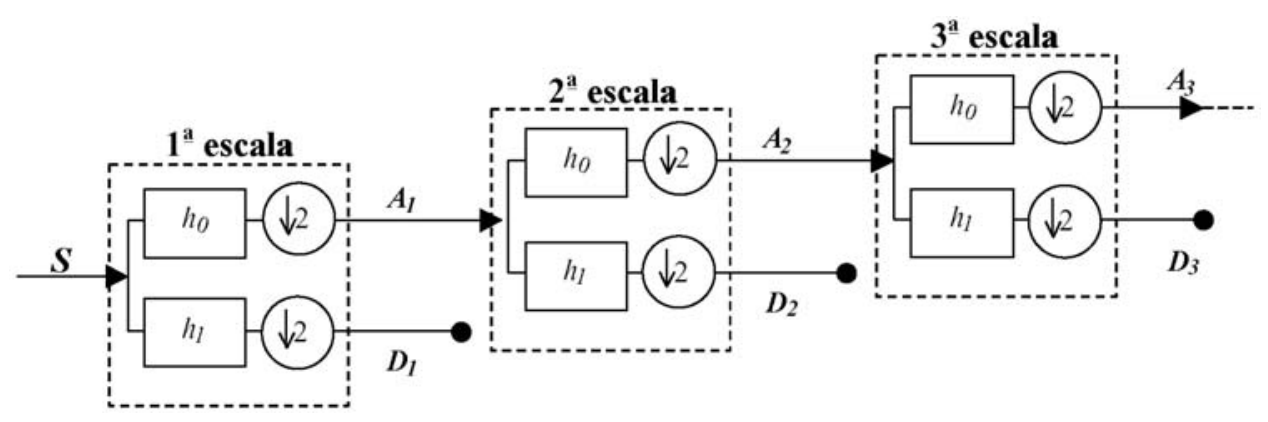

FIGURA 12 - Processo de decomposição de um sinal em AMR 
Para se conseguir uma representação não redundante e uma reconstrução única do sinal original, são necessários bancos de filtros ortogonais. A TW e a análise multirresolução estão estreitamente relacionadas.

O número máximo de níveis de decomposição wavelet é determinado pelo comprimento do sinal original, pela wavelet-mãe selecionada e pelo nível de detalhe exigido. Os filtros passa-baixa e passa-alta são determinados respectivamente pela função escala e função wavelet.

As famílias wavelets freqüentemente mais usadas para processamento de sinais são as wavelets Daubechies (db), Morlets, Coiflets (coif) e Symlets (sym). Essas wavelets exibem diferentes atributos e critérios de performance quando empregadas em aplicações específicas, tais como: detecção de transitórios, compressão de sinais e filtragem de ruído. Ainda que não exista um critério definido para a seleção das wavelets, a melhor escolha é uma wavelet que melhor caracterize o fenômeno ou o problema a ser estudado [55].

\subsubsection{Reconstrução Wavelet}

Já foi visto como a TWD pode ser usada para analisar, ou decompor, sinais ou imagens por meio do processo chamado análise multirresolução. Uma outra etapa é saber como aqueles componentes podem ser reagrupados para montar o sinal original, sem a perda de informações. Esse processo é chamado reconstrução ou síntese. A manipulação matemática que efetua a síntese é chamada de Transformada Wavelet Discreta Inversa (TWDI).

Para reconstruir um sinal, utilizam-se os coeficientes wavelets, como ilustrado na Figura 13:

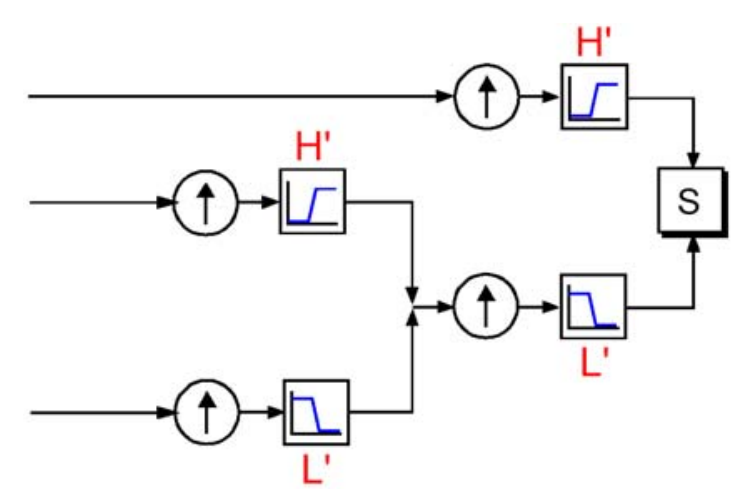

FIGURA 13 - Processo de reconstrução de um sinal filtrado 
Como a análise wavelet envolve filtragem e diminuição do número de amostras, a reconstrução wavelet consiste em filtragens e aumento do número de amostras. Aumentar o número de amostras é o processo de elevar o número de componentes do sinal pela inserção de zeros entre as amostras, o que está ilustrado na Figura 14 [51].
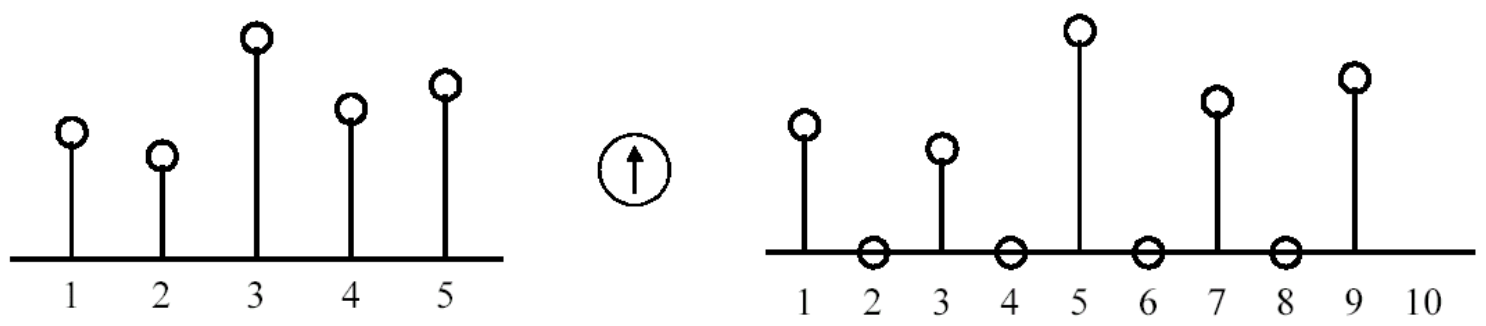

FIGURA 14 - Processo de aumento do número de amostras para reconstrução de um sinal

\subsubsection{Filtros de Reconstrução}

O que diz respeito à filtragem para o processo de reconstrução do sinal também merece algumas considerações devido ao fato da escolha do filtro ser crucial para uma perfeita reconstrução do sinal original.

O processo de diminuição do número de amostras do sinal introduz nele distorções aliasing. Uma escolha correta do filtro de reconstrução pode cancelar o efeito aliasing. Essa grande descoberta, mostrada na Figura 15, foi realizada por Ingrid Daubechies [51].

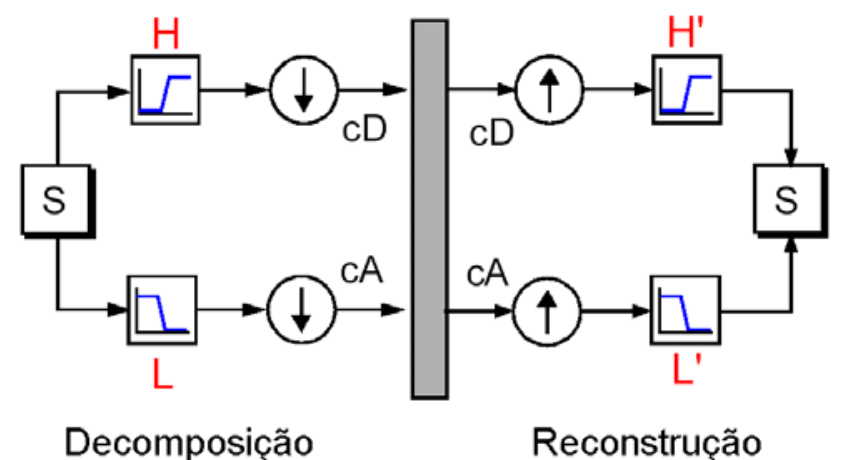

FIGURA 15 - Processos de decomposição e reconstrução de um sinal

\subsubsection{Aproximações e Detalhes na Reconstrução}

Observou-se anteriormente que também é possível reconstruir as aproximações e detalhes em si, a partir dos vetores de coeficientes. Como exemplo, será mostrado o processo de reconstrução do primeiro nível de aproximação $A 1$ a partir do vetor dos coeficientes $c A 1$. 
$\mathrm{O}$ vetor dos coeficientes $c A 1$ passa pelo mesmo processo utilizado para reconstruir o sinal original. Entretanto, ao invés de combiná-lo com o nível um de detalhes $c D 1$, será introduzido um vetor de zeros no lugar dos coeficientes de detalhe, como indicado na Figura 16.

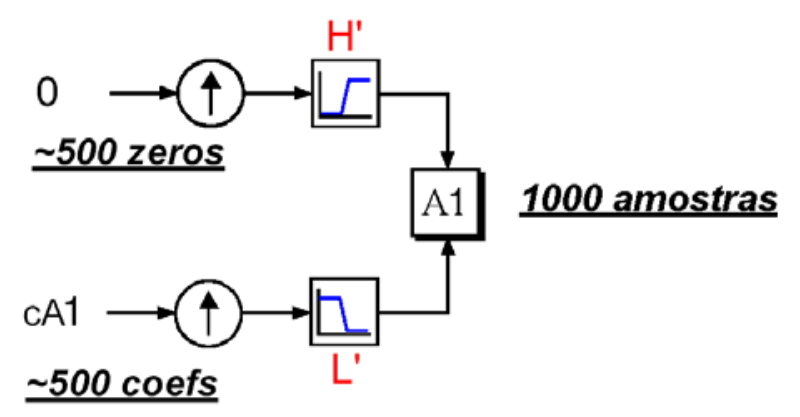

FIGURA 16 - Reconstrução de um sinal a partir de seus coeficientes de aproximação

O processo produz a reconstrução do sinal de aproximação $A 1$, que possui o mesmo tamanho que o sinal original $S$, sendo uma aproximação real.

Similarmente, pode-se reconstruir o primeiro nível de detalhe $D 1$, utilizando o processo análogo, como ilustrado na Figura 17.

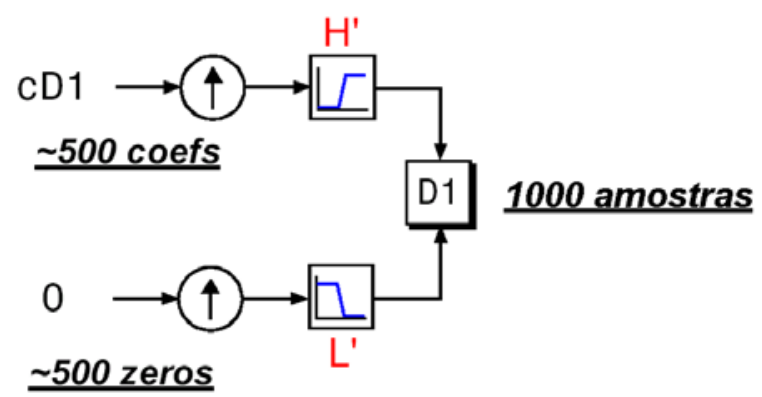

FIGURA 17 - Reconstrução do primeiro nível de detalhe do sinal

Os detalhes e aproximações reconstruídos são verdadeiramente constituintes dos sinais originais. De fato, encontramos isto quando combinamos $A_{1}+D_{l}=S$.

Note que, nos vetores de coeficientes $c A 1$ e $c D 1$, por serem produzidos pela diminuição do número de amostras, suas dimensões são somente a metade da dimensão do sinal original. Assim, não podem ser combinados diretamente para reproduzir o sinal original. É necessário reconstruir as aproximações e detalhes antes de combiná-los.

Estendendo essa técnica para componentes de uma análise multinível, encontram-se relações similares para todo o sinal reconstruído, como ilustrado na Figura 
18. Deve ser observado que existem vários caminhos para reconstruir o sinal original [51].

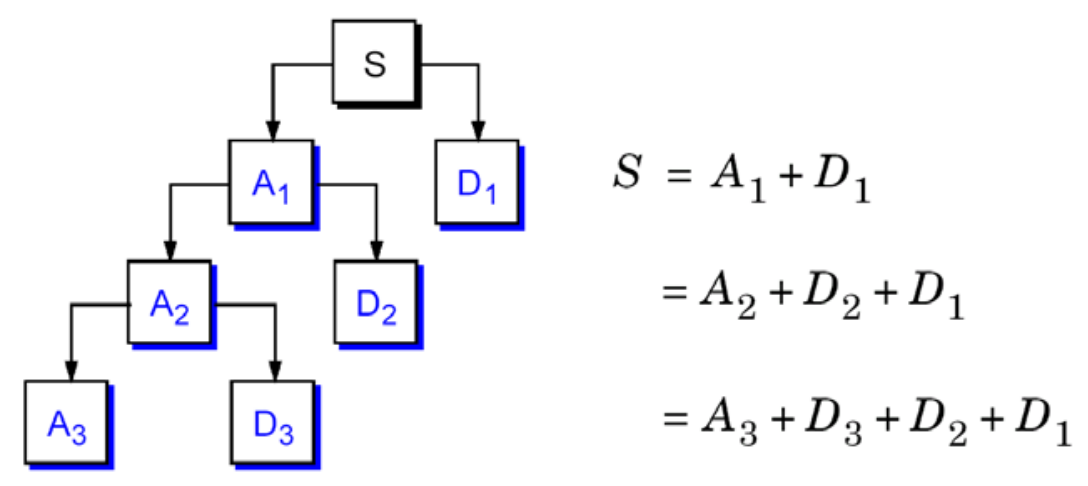

FIGURA 18 - Diferentes formas para se reconstruir o sinal a partir de seus coeficientes

\subsubsection{Aplicações da Transformada Wavelet em Sistemas Elétricos de Potência}

$\mathrm{Na}$ década de 90, houve um aumento no número de publicações sobre a aplicação da Transformada Wavelet nos SEP. A Figura 19 ilustra as áreas de aplicação da TW em SEP [55].

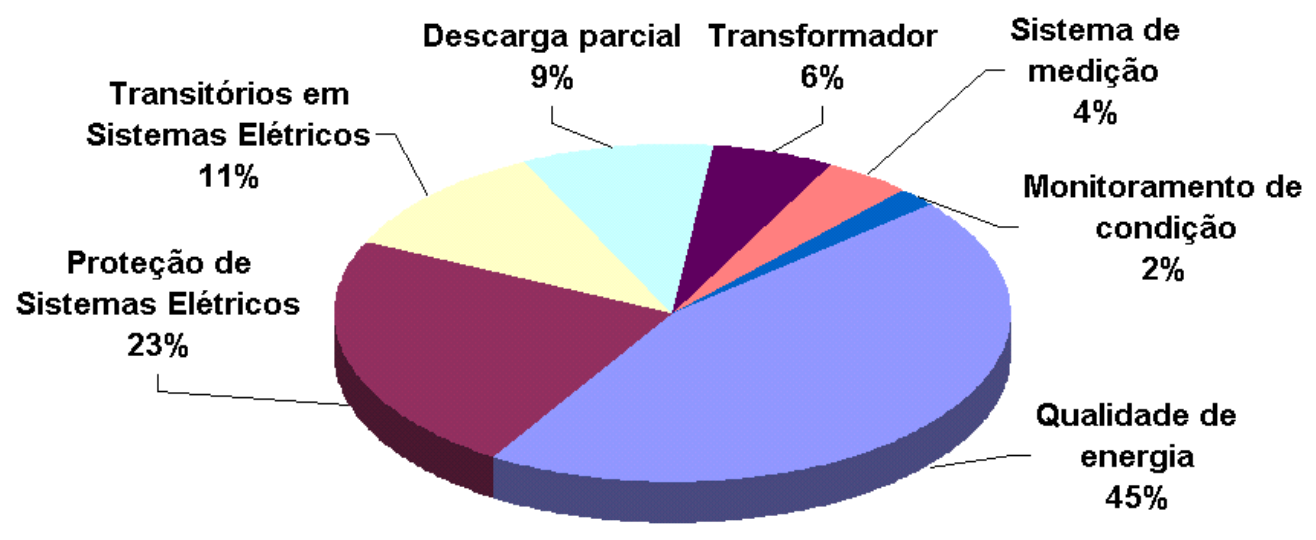

FIGURA 19 - Áreas de aplicação da TW em SEP

Observa-se na Figura 19 que, dentre as diversas áreas de aplicações da TW em SEP, a área relacionada à proteção apresenta uma contribuição de $23 \%$ em números de publicações científicas. Para a área relacionada a transitórios, a contribuição é de $11 \%$. Portanto, podemos observar o grande interesse dos engenheiros e pesquisadores na aplicação da ferramenta TW em ambas as áreas, referenciando [7], [8] e [9]. 
Quando aplicada, a TW pode ser implementada pelo uso de uma linguagem de programação, como por exemplo $\mathrm{C}, \mathrm{C}++$, ou pela utilização de pacotes computacionais, como é o caso do "Toolbox" incluído no software Matlab ${ }^{\odot}$ [55]. 


\section{O SISTEMA ELÉTRICO ANALISADO}

O objetivo deste capítulo é apresentar o sistema elétrico sobre o qual o algoritmo será testado e validado. Utilizou-se um sistema de transmissão o qual foi submetido a condições faltosas para a realização de uma série de simulações computacionais. Neste estudo foram consideradas as características dos condutores e suas respectivas disposições geométricas nas torres de transmissão.

A seguir, será comentado como se gerou uma série de simulações do sistema sob condições de faltas, dispondo-se do software ATP.

\subsection{O Software ATP}

Um simulador digital muito utilizado em sistemas de potência é o EMTP Electromagnetic Transient Program, desenvolvido na década de 60. O programa inicialmente trabalhava com simulações de circuitos monofásicos por meio de modelos de indutância, capacitância e resistência em linhas sem perdas, incluindo uma chave e uma fonte de excitação. Hoje o software apresenta-se no mercado sob várias versões, como o ATP - Alternative Transients Program. Essa versão de acesso restrito é uma continuação do programa EMTP e toda sua documentação consiste basicamente de um manual chamado Alternative Transient Program - Rule Book [50], onde estão todas as informações sobre os modelos disponíveis. Como já comentado, o ATP é um programa de distribuição gratuita com acesso restrito, tendo um número elevado de usuários no mundo inteiro, com inúmeras aplicações e publicações científicas da sua utilização em congressos, revistas etc.

O software ATP é utilizado tanto em áreas acadêmicas quanto em empresas de consultoria, indústrias de equipamentos e concessionárias em todo o mundo, permitindo uma representação detalhada do sistema elétrico a ser simulado e possibilitando que 
seus resultados sejam utilizados com grande aceitação para estudos de transitórios, aplicações em controle, proteção etc.

\subsection{Configuração do Sistema de Potência Estudado}

O sistema elétrico em análise está representado na Figura 20, e é encontrado em Oleskovicz [56], com a especificação das fontes, barramentos $(D, E, F$ e $G)$ e comprimento das linhas de transmissão.

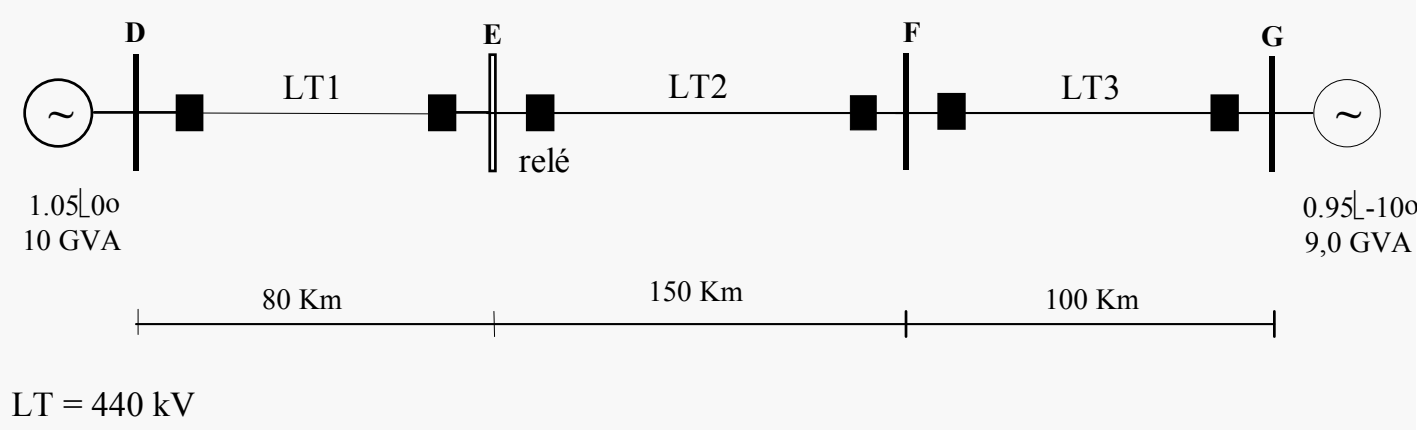

FIGURA 20 - Representação do sistema elétrico analisado

\subsection{Modelagem da Linha de Transmissão}

O desempenho de uma linha de transmissão depende quase exclusivamente de sua característica física, que não somente dita o seu comportamento em regime normal de operação, definindo os seus parâmetros elétricos, como também quando submetidas a sobretensões.

A linha de transmissão utilizada para o cálculo dos parâmetros é uma linha típica da CESP (Companhia Energética de São Paulo) de 440 kV (Figura 21), empregada entre as cidades de Araraquara - Bauru e Jupiá - Ilha Solteira. A seguir, tem-se as especificações referentes aos condutores, denotando-se as suas principais características, bem como a resistividade do solo considerada.

Condutor de fase: cabo Grosbeak

a) raio externo do condutor: $12,57 \mathrm{~mm}$;

b) raio interno do condutor: $4,635 \mathrm{~mm}$; 
c) resistência em corrente contínua: $0.08998 \Omega / \mathrm{km}$.

Cabos pára-raios: EHS 3/8"

a) raio externo do condutor: $4,572 \mathrm{~mm}$;

b) resistência em corrente contínua: $4,188 \Omega / \mathrm{km}$.

\section{Resistividade do solo}

$\mathrm{R}_{\text {solo }}: 250 \Omega . \mathrm{km}$

\section{Flecha a meio vão}

fase: $13,43 \mathrm{~m}$

pára-raios: $6,4 \mathrm{~m}$

Uma vez que os parâmetros elétricos da linha foram determinados, a linha pode ser representada para se iniciar a simulação no que diz respeito às situações de falta analisadas pelo software ATP.

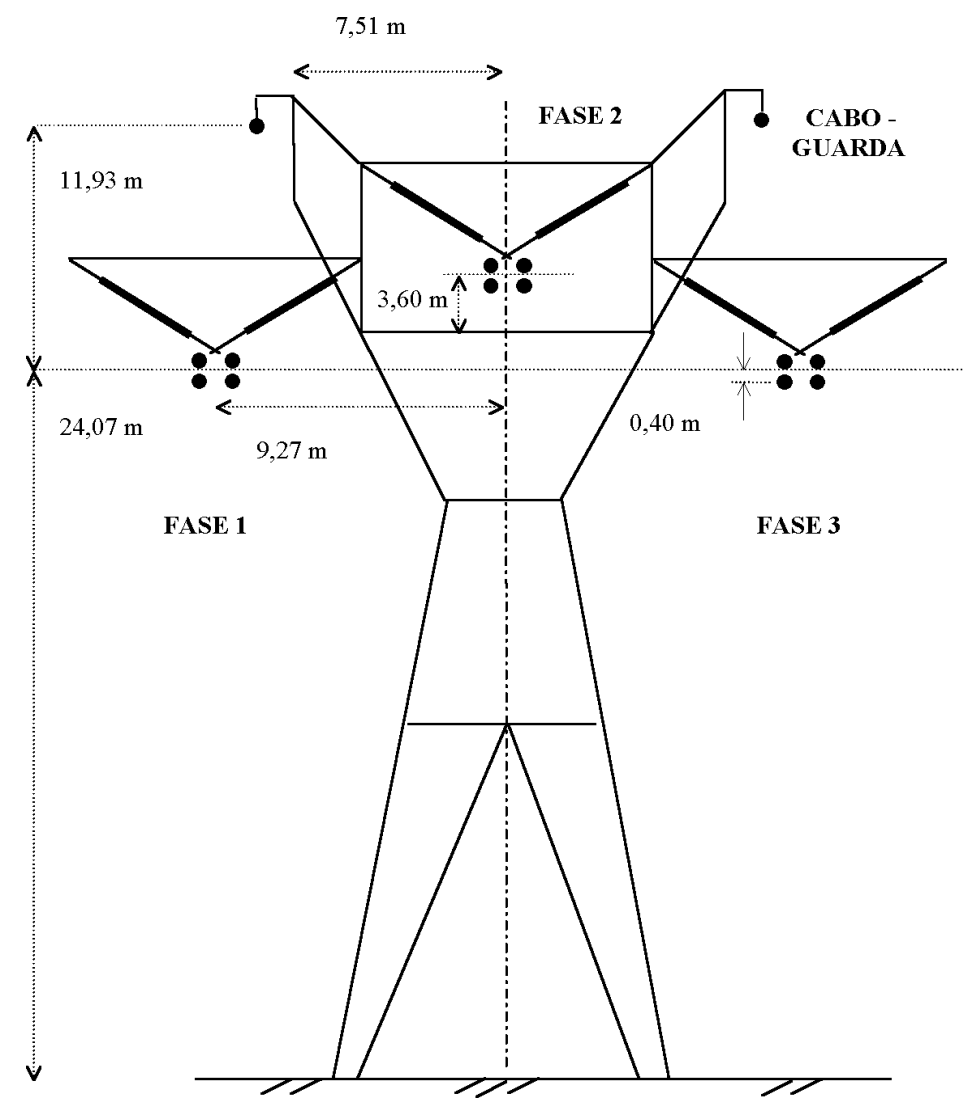

FIGURA 21 - Silhueta de torre da linha de $440 \mathrm{kV}$ 


\subsubsection{Parâmetros do Sistema Elétrico}

Para a simulação de linhas de transmissão longas, a melhor representação que se pode obter para o sistema é considerar o fato de que os parâmetros de uma linha não estão concentrados em um ponto, e sim, uniformemente distribuídos ao longo de todo o seu comprimento de linha. Na Figura 22, tem-se um esquema monofásico representando um pequeno trecho $(\Delta x)$ de uma linha de transmissão, sendo os parâmetros $(R, L$ e $C)$, distribuídos e constantes, determinados pela rotina Line Constants do software ATP. Nesta figura, $L$ é a indutância da linha por unidade de comprimento, $R$ é a resistência por unidade de comprimento em corrente alternada e $C$ é a capacitância shunt da linha por unidade de comprimento.

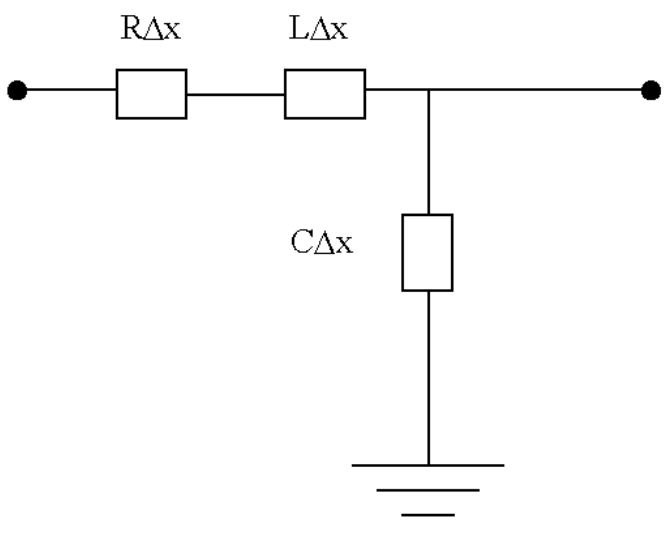

FIGURA 22 - Representação de um trecho de uma linha de transmissão por parâmetros distribuídos

Para a obtenção dos parâmetros da linha de transmissão, foram consideradas as características dos condutores e suas respectivas disposições geométricas nas torres de transmissão, como mostrado na Figura 21. Dentre as considerações, optou-se por linhas de transmissão transpostas, já que a transposição compensa os desequilíbrios dos campos magnéticos entre fases, cabos de cobertura, ferragens e solo sob a linha de transmissão. O resultado esperado da transposição, segundo Stevenson [3], será a mesma indutância média para cada condutor. Uma observação prática nos diz que raramente as linhas são transpostas em intervalos regulares, sendo a transposição executada onde for fisicamente conveniente, como por exemplo, em subestações. A transposição de uma linha de transmissão qualquer é ilustrada na Figura 23. 


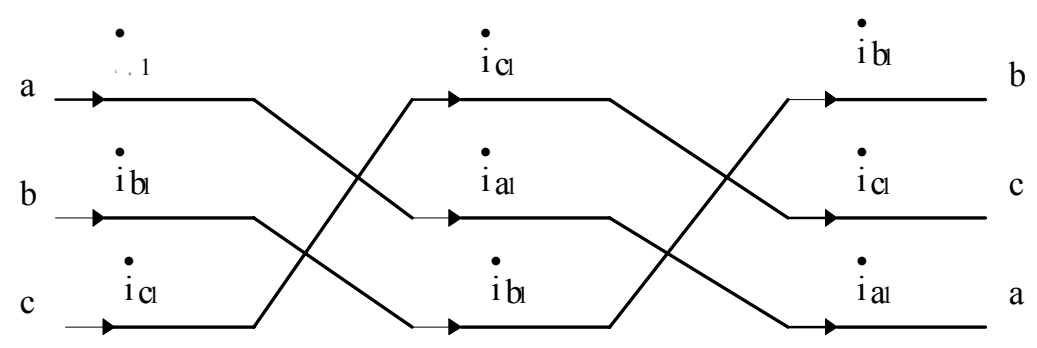

FIGURA 23 - Transposição de uma linha de transmissão

Uma observação importante a ser feita diz respeito à modelagem dos barramentos $E$ e $F$ sobre o sistema. Para a inclusão do barramento $E$ no sistema, o mesmo foi considerado como uma pequena linha de transmissão em circuito PI, sendo os seus parâmetros $R, L$ e $C$ obtidos também através da rotina Line-Constant. Já o barramento $F$ foi modelado apenas como um ponto de interconexão entre a segunda e a terceira linhas de transmissão. Empregou-se a modelagem em circuito PI, pois através desta representação conseguiu-se caracterizar a reflexão das ondas viajantes no terminal do barramento $E$.

\subsubsection{Rotina Line Constants e Arquivo de Entrada para o Software ATP}

A rotina Line Constants é uma rotina auxiliar que permite o cálculo dos parâmetros da linha de transmissão que são a resistência, a reatância e a susceptância de seqüência positiva e zero, para uma determinada freqüência. Como parâmetros de entrada para essa rotina têm-se: os espaçamentos e alturas relativas entre condutores, número de condutores por fase, resistividade do solo, freqüência em que os parâmetros foram calculados, condições da linha (com ou sem transposição), efeito skin ou peculiar etc. O arquivo de entrada da rotina Line Constants para o sistema anteriormente apresentado (linha de transmissão tipo simples vertical - VVV) é apresentado na Figura 24. 


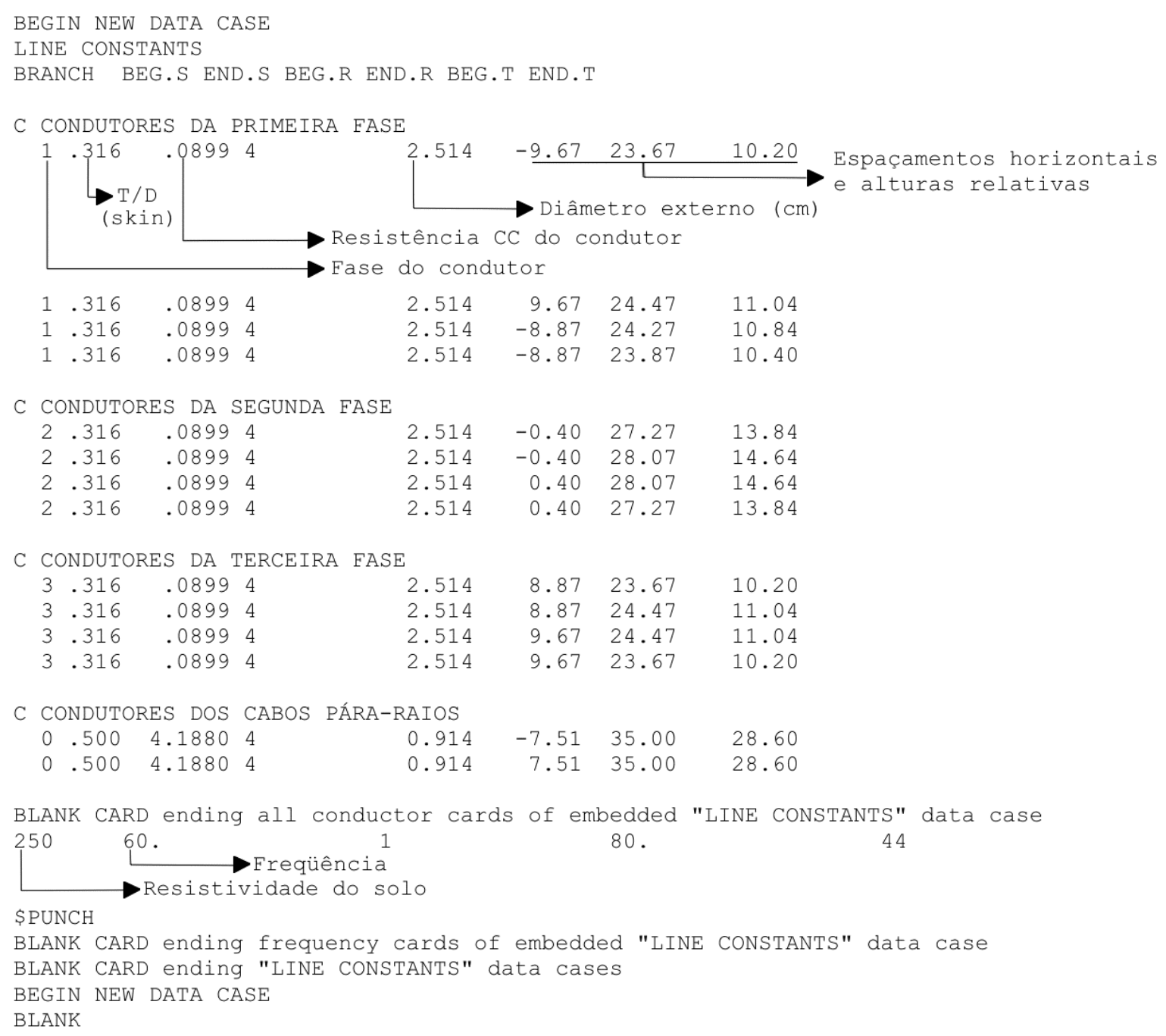

FIGURA 24 - Rotina Line Constants para o sistema simples vertical tipo VVV

Da execução da rotina Line Constants interessa-nos, dentre as inúmeras informações, os valores de seqüência negativa e positiva das grandezas referentes a resistências, reatâncias e susceptâncias, considerando a linha de transmissão com transposição e as características dos barramentos $E$ e $F$ os quais são mostrados na Tabela 2.

TABELA 2 - Parâmetros da linha de transmissão de $440 \mathrm{kV}$

\begin{tabular}{ccc|ccc}
\hline \multicolumn{3}{c|}{ Seqüência positiva } & \multicolumn{3}{c}{ Seqüência negativa } \\
$\mathbf{R}$ (ohms/km) & $\mathbf{L}(\mathbf{m H} / \mathbf{k m})$ & $\mathbf{C}(\mathbf{u F} / \mathbf{k m})$ & $\mathbf{R}($ ohms $/ \mathbf{k m})$ & $\mathbf{L}(\mathbf{m H} / \mathbf{k m})$ & $\mathbf{C}(\mathbf{u F} / \mathbf{k m})$ \\
\hline $3,853 \mathrm{E}-02$ & $7,410 \mathrm{E}-01$ & $1,570 \mathrm{E}-02$ & $1,861 \mathrm{E}+00$ & $2,230 \mathrm{E}+00$ & $9,034 \mathrm{E}-03$ \\
\hline
\end{tabular}

Nas Tabelas 3 e 4, são apresentados os parâmetros e dados de barra para os equivalentes nos terminais da linha de $440 \mathrm{kV}$ da CESP. 
TABELA 3 - Parâmetros dos equivalentes de geração das barras $D$ e $G$

\begin{tabular}{|c|c|c|c|}
\hline \multicolumn{4}{|c|}{ Gerador 1 - Barra D } \\
\hline \multicolumn{2}{|c|}{ Seqüência positiva } & \multicolumn{2}{|c|}{ Seqüência negativa } \\
\hline $\mathrm{R}$ (ohms/km) & $\mathrm{L}(\mathrm{mH} / \mathrm{km})$ & $\mathrm{R}$ (ohms/km) & $\mathrm{L}(\mathrm{mH} / \mathrm{km})$ \\
\hline 1,6982 & $5,14 \mathrm{E}+01$ & 0,3850 & $1,16 \mathrm{E}+01$ \\
\hline \multicolumn{4}{|c|}{ Gerador 2 - Barra G } \\
\hline \multicolumn{2}{|c|}{ Seqüência positiva } & \multicolumn{2}{|c|}{ Seqüência negativa } \\
\hline$R$ (ohms/km) & $\mathrm{L}(\mathrm{mH} / \mathrm{km})$ & R (ohms/km) & $\mathrm{L}(\mathrm{mH} / \mathrm{km})$ \\
\hline 1,7876 & $5,41 E+01$ & 0,4052 & $1,23 E+01$ \\
\hline
\end{tabular}

TABELA 4 - Dados das barras de geração De G

\begin{tabular}{l|c|c}
\hline & Gerador 1 - Barra D & Gerador 2 - Barra G \\
\hline Pot. (GVA) & 10 & 9 \\
\hline Tensão (pu) & 1,05 & 0,95 \\
\hline Ângulo (graus) & 0 & -10 \\
\hline
\end{tabular}

Com os resultados obtidos através da rotina Line Constants, elaborou-se um arquivo de entrada a ser executado pelo software ATP, o qual descreve a situação em que se encontra o sistema elétrico. Na Figura 25, tem-se o arquivo de entrada para uma falta-fase-terra referente ao sistema elétrico analisado, contendo cartões de informações gerais (passo de integração, tempo máximo de simulação, freqüência de saída dos resultados etc.), cartão para ramos lineares (indutâncias, capacitâncias, resistências, linhas de transmissão etc.), cartão para chaves, cartões para fontes e cartões para pedido das tensões e correntes nas barras.

O Transformador de Potencial Capacitivo (TPC) fez parte das simulações computacionais, pois os mesmos provêem um preciso desempenho no período transitório que segue a uma situação de falta. Com relação ao Transformador de Corrente (TC), não se considerou uma precisa modelagem dos mesmos. Para a atenuação das amplitudes dos sinais analisados, somente a relação de transformação do TC foi considerada, sem entrar em pormenores com relação ao seu efeito de saturação. 


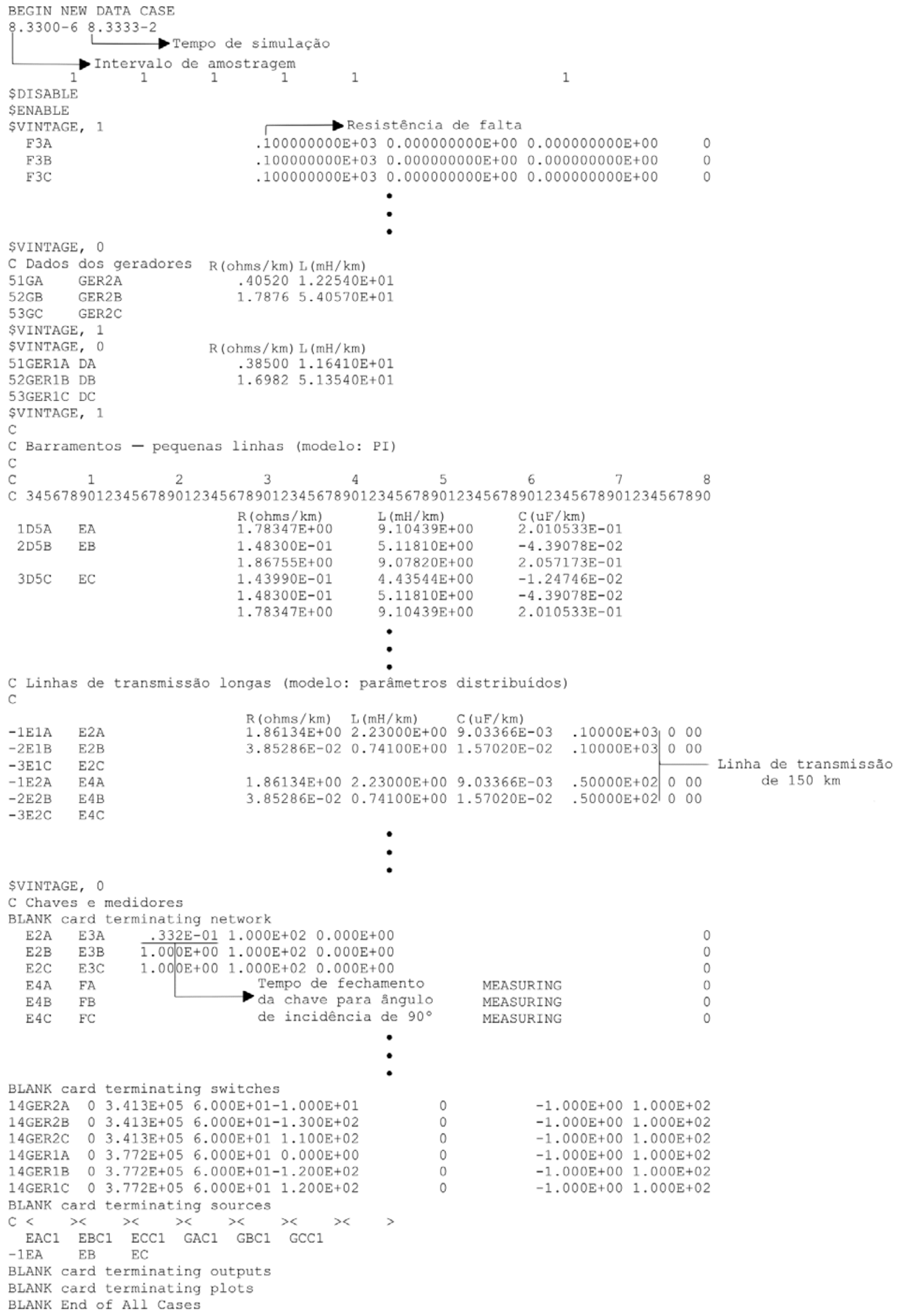


Executando o arquivo da Figura 25, o qual se refere a uma falta-fase-terra (AT) com ângulo de incidência de $90^{\circ}$, resistência de falta de $100 \Omega$, aplicada a $100 \mathrm{~km}$ da barra $E$, obtemos o registro das seguintes formas de ondas de tensão e corrente apresentadas nas Figura 26 e 27, respectivamente.

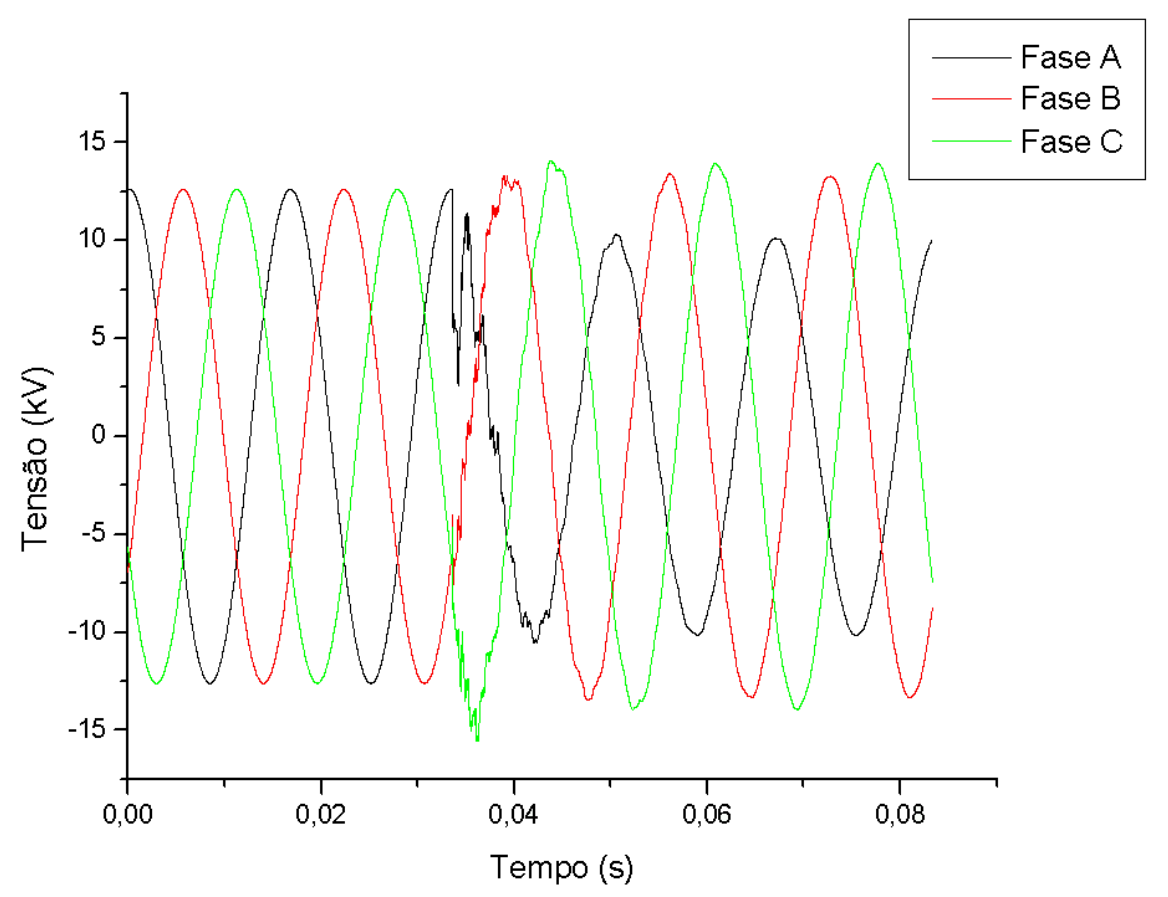

FIGURA 26 - Formas de onda de tensão para uma falta-fase-terra aplicada a $100 \mathrm{~km}$ da barra $\mathrm{E}$

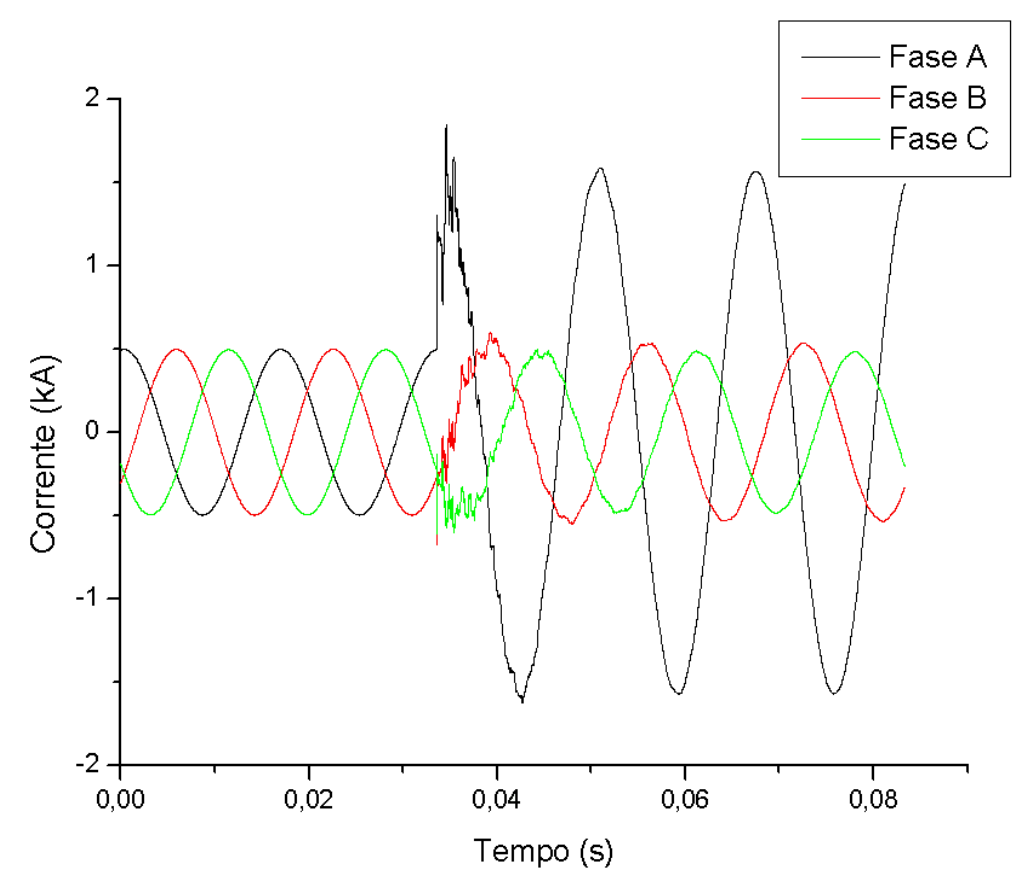

FIGURA 27 - Formas de onda de corrente para uma falta-fase-terra aplicada a $100 \mathrm{~km}$ da barra E 
A Figura 26 ilustra um afundamento de tensão na fase $A$, enquanto observa-se uma elevação na amplitude dos sinais de tensão nas fases $B$ e $C$ para a falta A-terra simulada. Já para a Figura 27 percebe-se uma elevação de corrente na fase $A$, enquanto as demais fases permaneceram com uma pequena alteração em relação ao período de pré-falta.

\subsection{Variações nas Simulações das Condições de Faltas Aplicadas ao Circuito de Transmissão Simples Horizontal}

Como já mencionado, os dados dos sinais faltosos foram obtidos dispondo-se do software ATP, levando-se em consideração vários tipos de falta em diferentes localizações ao longo da linha, entre os barramentos $E$ e $G$, caracterizados por diferentes ângulos de incidência e resistências de falta. As variações consideradas são descritas a seguir:

a) tipos de faltas aplicadas:

Fase-terra (A-terra, B-terra e C-terra);

Fase-Fase-terra (AB-terra, AC-terra e BC-terra);

Fase-Fase (AB, AC e BC);

Trifásica $(\mathrm{ABC})$.

b) distâncias em que as faltas foram aplicadas entre os barramentos $E$ e $G$ :

$10,25,40,55,70,85,100,115,120,125,130,145,155,170,175,180,185,200$,

215, 230, 235 e $240 \mathrm{~km}$ (referência barramento $E$ ).

c) ângulos de incidências de faltas:

0 e $90^{\circ}$.

d) resistências de faltas consideradas:

$0,1,50,100 \Omega$.

e) resistência de falta entre fases:

$0,1 \Omega$. 
As situações de faltas foram implementadas no software ATP conforme as combinações apresentadas na Figura $28 .{ }^{1}$

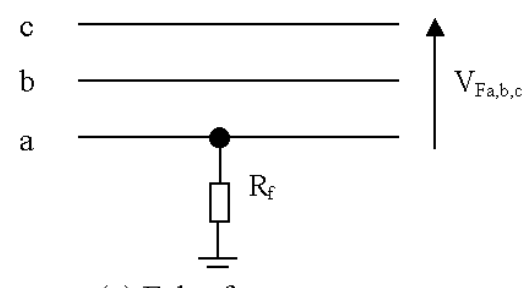

(a) Falta-fase a-terra

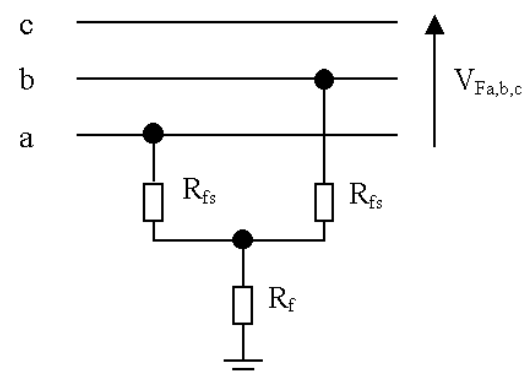

(c) Falta-fase ab-terra

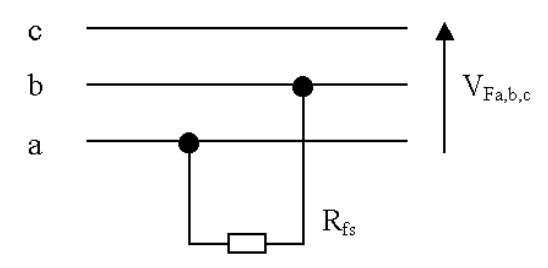

(b) Falta-fase ab

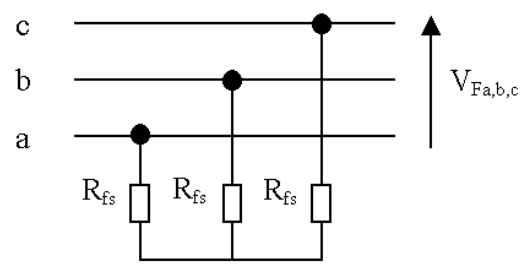

(d) Falta-fase abc

Valores usuais de $R_{f}: 0$ a $400 \Omega$

$\mathrm{R}_{\mathrm{fs}}:$ até $1 \Omega$

FIGURA 28 - Situações de faltas sobre o sistema

Como resposta da simulação de cada situação de falta no software ATP, obtêmse os valores de tensão e corrente trifásicos amostrados em relação aos barramentos $E \mathrm{e}$ G. O arquivo de dados descrevendo cada situação de falta é apresentado pelo software a um intervalo de amostragem de 8,33 $\mu$ s, o que corresponde a uma freqüência amostral de $120 \mathrm{kHz}$, freqüência esta estabelecida pelo usuário de acordo com suas necessidades.

1 Combinações obtidas da tese de doutorado A practical approach to accurate fault location on extra high voltage teed feeders, Denis Vinicius Coury, Tese C858p - Biblioteca Central da Escola de Engenharia de São Carlos - Figura B.5. 


\section{FUNDAMENTOS E LÓGICA DA ABORDAGEM}

PROPOSTA

Neste capítulo serão apresentadas as etapas de detecção e classificação das faltas, além da definição das zonas de proteção sobre linhas de transmissão fundamentada na teoria de ondas viajantes e da Transformada Wavelet. Além disso, serão descritas as respectivas técnicas que constituem o algoritmo desenvolvido.

\subsection{Princípio Básico do Método da Determinação das Zonas de Proteção}

Considera-se inicialmente uma onda propagando-se uniformemente ao longo de uma linha de transmissão monofásica sem perdas, de comprimento $l$, interligada entre as barras $A$ e $B$, com uma impedância característica $Z_{C}$, ilustrada na Figura 29, com o respectivo diagrama Lattice, para posteriormente analisarmos um sistema trifásico.

Caso um distúrbio ocorra na linha apresentada (Figura 29), como, por exemplo, uma descarga atmosférica ou um curto-circuito, incidente a uma distância $d$ do barramento $A$, inicia-se neste ponto uma súbita injeção de tensão e ou corrente de acordo com a teoria de ondas viajantes de Bewley [32]. Essa injeção equivale a uma onda sobreposta ao sinal fundamental do sistema que se propagará ao longo da linha no sentido das extremidades da mesma. Quando uma onda atinge uma descontinuidade em uma LT, a proporcionalidade entre as ondas de tensão e de corrente, dada por $Z_{C}$, deve ser mantida, como proposto em Greenwood [48]. Para manter essa proporcionalidade, duas novas ondas viajantes surgem: a onda refletida, que viaja de volta à barra $A$; e a onda refratada, que se propaga através da descontinuidade. Essas ondas retornam ao ponto de falta, de modo que, ao se encontrarem, duas novas ondas são criadas. Portanto haverá múltiplas reflexões ocorrendo entre as barras da LT até ser atingido o estado permanente de falta. Determinando-se o intervalo de tempo dos sinais entre o ponto de 
falta e o terminal de referência, pode-se determinar a localização da falta e, conseqüentemente, a zona de proteção a que esta pertence pode ser estimada. Ao contrário do método de correlação, no qual as ondas viajantes são estimadas e aplicadas para correlação cruzada, na abordagem wavelet, o sinal decomposto (tensão ou corrente) é diretamente analisado e as reflexões determinadas através de limiares apropriados.

Cabe apenas ressaltar que a abordagem proposta neste trabalho se baseia em componentes de alta freqüência decorrentes da situação de falta. Ainda como característica da implementação, dispõe-se de componentes modais de tensão, ao contrário dos valores totais (de fase) os quais são decompostos em um nível de decomposição por meio da análise multirresolução wavelet.

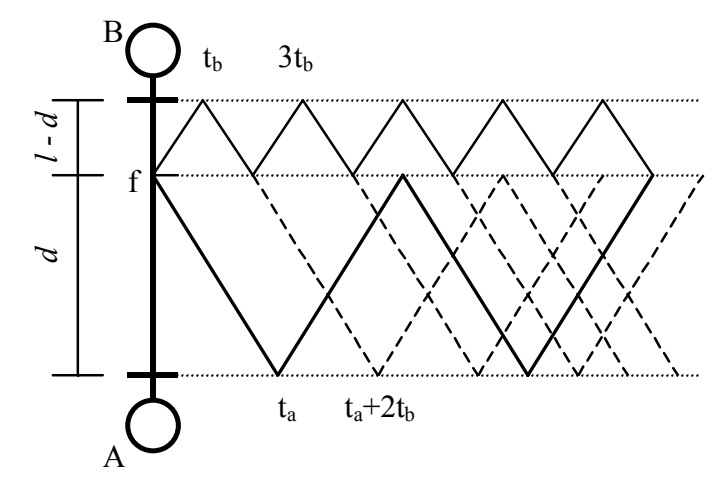

FIGURA 29 - Sistema Elétrico e diagrama Lattice

\subsection{O Algoritmo do Relé de Distância}

No Capítulo 1, analisou-se o relé de distância que recebeu essa denominação, porque sua atuação baseia-se na observação da impedância entre a localização da falta e a localização do relé. Ou seja, esse relé reconhece faltas ocorrendo dentro de uma seção ou zona protegida da linha.

Neste trabalho, tomando-se como referência o sistema elétrico apresentado na Figura 20, as zonas de proteção foram consideradas com as seguintes proporções:

a) zona de proteção primária: até $120 \mathrm{~km}$, a partir do barramento $E$, o que corresponde a $80 \%$ da LT2 de $150 \mathrm{~km}$;

b) primeira zona de incerteza: $120 \pm 3,6 \mathrm{~km}$, a partir do barramento $E$, o que corresponde a um índice de incerteza de $\pm 3 \%$ sobre os $120 \mathrm{~km}$ considerados para a zona de proteção primária; 
c) zona de proteção secundária: até $180 \mathrm{~km}$, a partir do barramento $E$, o que corresponde a $120 \%$ da LT2 de $150 \mathrm{~km}$;

d) segunda zona de incerteza: $180 \pm 5,4 \mathrm{~km}$, a partir do barramento $E( \pm 3 \%$ de 180 $\mathrm{km})$;

e) zona de proteção terciária: até $240 \mathrm{~km}$, a partir do barramento $E$, o que corresponde a $160 \%$ da LT2 de $150 \mathrm{~km}$.

Com base nessas especificações, observam-se áreas de incertezas onde determinações errôneas podem vir a ser caracterizadas. Essa área, para a zona de proteção primária, varia de 116,4 km a 123,6 km e, para a zona de proteção secundária, $174,6 \mathrm{~km}$ a $185,4 \mathrm{~km}$.

Para se determinar as zonas de proteção anteriormente especificadas, deve-se inicialmente determinar os tempos de viagem das ondas de tensão, utilizando-se da Transformada Wavelet. A determinação dos tempos provém da análise multirresolução wavelet (AMR), analisando-se o primeiro nível de decomposição. Dados os instantes de reflexões das ondas, pode-se determinar a localização da falta e, conseqüentemente, as zonas de proteção do relé (primária, secundária e terciária).

\subsection{Lógica Computacional Implementada para o Relé de Distância}

A implementação do algoritmo computacional seguindo a abordagem proposta foi realizada de maneira que o usuário possa selecionar a técnica de aquisição de dados (de um ou dois terminais) a ser aplicada. A seguir, abordaremos os diferentes estágios que envolvem o algoritmo do relé de distância.

A Figura 30 ilustra o fluxograma do algoritmo implementado para o relé de distância. O fluxograma desenvolvido neste estudo foi uma extensão do trabalho proposto em Silva [57] 


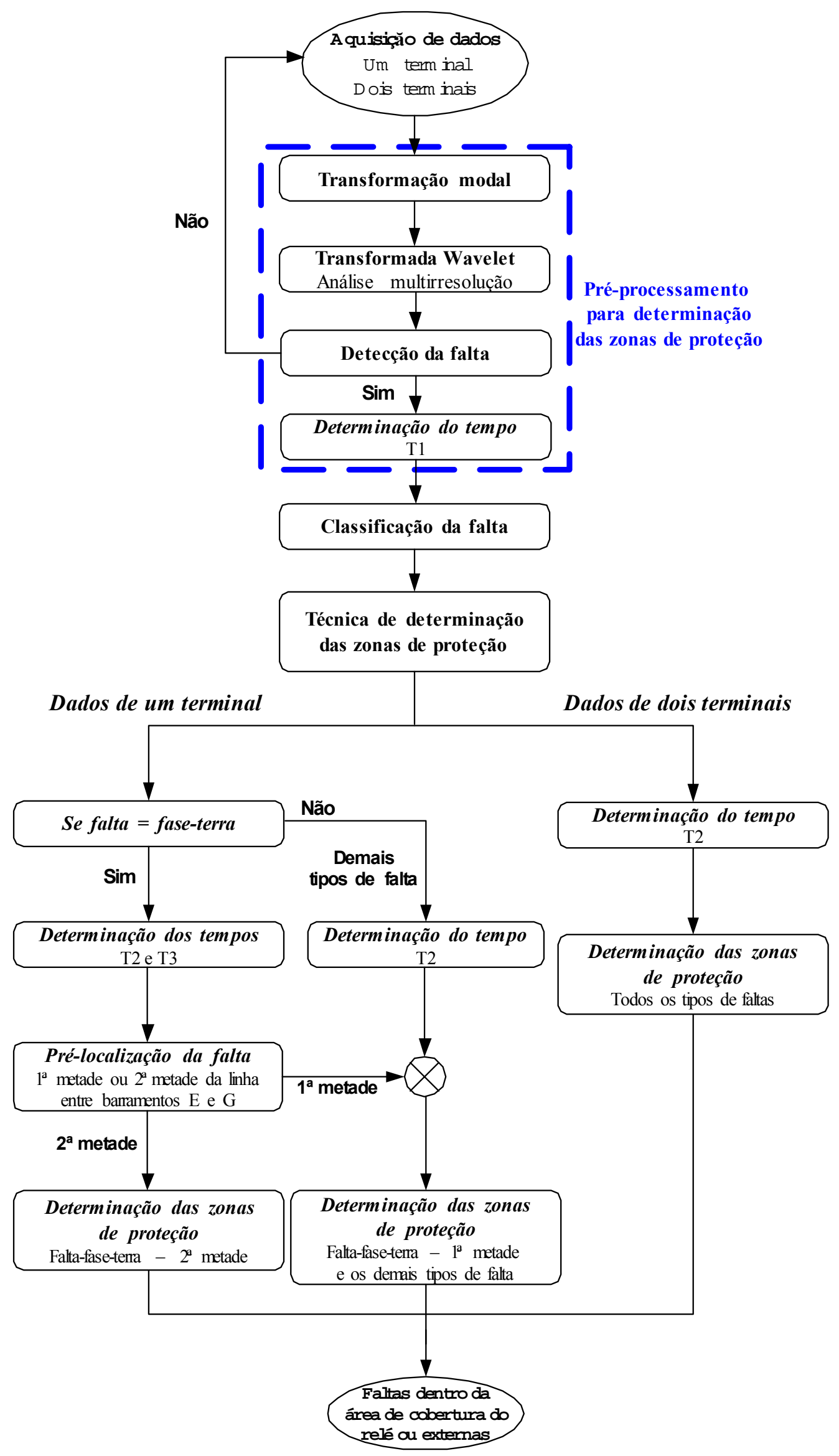

FIGURA 30 - Fluxograma do algoritmo do relé de distância 
O primeiro estágio do fluxograma da Figura 30 corresponde ao processo de obtenção dos dados digitalizados de tensão e corrente registrados em um terminal ou, se for o caso, em dois terminais através de registradores digitais de alta freqüência. Devese ressaltar que, no caso da utilização de dados provenientes de dois terminais, faz-se necessária a sincronização desses dados, assim como um canal de comunicação para transmissão dos dados do terminal remoto para o terminal local, onde será feita a etapa da determinação das zonas de proteção do relé.

As etapas que correspondem ao algoritmo do relé de distância como um todo, ilustrado na Figura 30, são as seguintes: aquisição dos dados, detecção e classificação da falta e determinação das zonas de proteção (técnica com dados provenientes de um terminal ou de dois terminais). Somam-se a essas etapas a aplicação da transformação modal, Transformada Wavelet, e a determinação dos tempos de reflexão. Quando da determinação das zonas de proteção com dados provenientes de um terminal, é inserida mais uma etapa ao algoritmo, denominada de pré-localização das zonas de proteção. Essas etapas serão descritas no que segue.

\subsubsection{Aquisição dos Dados}

Para a implementação desse algoritmo, a obtenção dos dados pode ser proveniente de registradores digitais de sinais de alta freqüência posicionados no terminal local ou em ambos os terminais, local e remoto. Todavia, para a segunda técnica, torna-se necessário que haja um meio de comunicação para a transferência dos dados entre os terminais, bem como um método para sincronização dos mesmos.

De acordo com Kim et al. e Zhao et al. [58 e 59], a utilização de um sinal de tempo de referência baseado em GPS (Global Positioning Satellite) oferece uma sincronização precisa dos dados a um custo acessível. Esse sistema consiste de 24 satélites, onde cada um transmite continuamente sua própria localização e um sinal de referência de tempo que fica disponível nos diversos pontos de uma rede elétrica, permitindo que os sinais sejam sincronizados, considerando qualquer esquema de comunicação de dados entre os terminais da linha. Em cada terminal, para cada amostra dos sinais, poderá ser armazenado o tempo real em que ela foi obtida, utilizando-se a referência de tempo obtida do GPS, de forma que um atraso na chegada dos dados do terminal remoto ao terminal local, poderá ser corrigido, verificando-se os instantes em que as amostras foram obtidas. Além disso, o GPS oferece uma sincronização de dados 
com um erro máximo de $1 \mu \mathrm{s}$, o que corresponde, aproximadamente, a 300 metros de imprecisão, considerando que a velocidade de propagação da luz é de $3 \times 10^{5} \mathrm{~km} / \mathrm{s}$.

Considerando a aquisição de dados provenientes de dois terminais e no sentido de proporcionar uma proteção de distância online, deve-se dispor de um meio de comunicação de dados entre os dois terminais que garanta velocidade e canais de comunicação contínuos. Um meio de transmissão de dados por meio da aplicação de fibra ótica no interior dos cabos-guarda vem sendo utilizado. Este foi proposto por Urusawa et al. [60], e é conhecido como OPGW (do inglês, Fiber Optic Overhead Ground Wire), oferecendo alta velocidade de transmissão e imunidade a interferências eletromagnéticas.

Reforça-se a idéia de que os dados obtidos não necessitam de ser filtrados, pois eles são analisados por métodos baseados em componentes de alta freqüência. De acordo com a literatura, a precisão do algoritmo é função da taxa de amostragem aplicada, sendo aplicadas, na maioria dos trabalhos analisados, taxas que variam de 100 $\mathrm{kHz}$ à dezenas de megahertz $(\mathrm{MHz})$. Neste trabalho, foi utilizada uma freqüência de amostragem de $120 \mathrm{kHz}$.

\subsubsection{Transformação Modal}

Em linhas de transmissão trifásicas, as fases estão mutuamente acopladas e, conseqüentemente, as perturbações de alta freqüência geradas durante uma falta podem também aparecer nas fases não faltosas.

Porém, pode-se fazer uso de componentes de sistemas para prover o desacoplamento eletromagnético das seções simétricas da linha de transmissão e, dessa forma, a linha de transmissão trifásica pode ser decomposta em três circuitos monofásicos, através dos quais pode-se estudar cada um desses circuitos de forma independente, como proposto em Siemens [61].

Considerando que, na modelagem do sistema, as linhas de transmissão sejam transpostas e simétricas, podem ser utilizadas as transformações modais de Clarke ou de Wedepohl. Nesse trabalho, utilizaram-se as componentes modais de Clarke para análise dos transitórios. Aplicando-se essa técnica, os valores de fase são transformados em três modos desacoplados: um modo-terra (modo zero), e dois modos aéreos (modo $\alpha$ e modo $\beta$ ), também conhecidos como modo aéreo 1 e modo aéreo 2, de acordo com Gross 
e Siemens [62 e 61]. O modo zero apresenta impedância característica e velocidade de propagação distinta em relação aos modos aéreos.

A matriz inversa da transformação de Clarke [63] é definida por:

$$
T=\frac{1}{3} \cdot\left[\begin{array}{ccc}
1 & 1 & 1 \\
2 & -1 & -1 \\
0 & \sqrt{3} & -\sqrt{3}
\end{array}\right]
$$

Por meio da matriz de transformação modal, as componentes 0 (zero), $\alpha$ (alfa) e $\beta$ (beta) de tensão e de corrente podem ser obtidas a partir das componentes de fase do sistema trifásico, respectivamente, como segue:

$$
\left[\begin{array}{l}
V_{0} \\
V_{\alpha} \\
V_{\beta}
\end{array}\right]=\frac{1}{3} \cdot\left[\begin{array}{ccc}
1 & 1 & 1 \\
2 & -1 & -1 \\
0 & \sqrt{3} & -\sqrt{3}
\end{array}\right] \cdot\left[\begin{array}{c}
V_{a} \\
V_{b} \\
V_{c}
\end{array}\right]
$$

E para as correntes temos:

$$
\left[\begin{array}{l}
I_{0} \\
I_{\alpha} \\
I_{\beta}
\end{array}\right]=\frac{1}{3} \cdot\left[\begin{array}{ccc}
1 & 1 & 1 \\
2 & -1 & -1 \\
0 & \sqrt{3} & -\sqrt{3}
\end{array}\right] \cdot\left[\begin{array}{c}
I_{a} \\
I_{b} \\
I_{c}
\end{array}\right]
$$

Ou de forma resumida:

$$
\left\lfloor V_{0 \alpha \beta}\right\rfloor=T \cdot\left[V_{a b c}\right] \quad \text { e } \quad\left\lfloor I_{0 \alpha \beta}\right\rfloor=T \cdot\left[I_{a b c}\right]
$$

em que $V_{0, \alpha, \beta} ; I_{0, \alpha, \beta}$ são os vetores modais de tensão e corrente, e $V_{a, b, c} ; I_{a, b, c}$ são os vetores de fase da tensão e corrente.

Com isso, cada modo, $0, \alpha$ e $\beta$, pode ser estudado separadamente como um simples circuito monofásico, sendo para cada um deles definida a velocidade de propagação do modo-terra $\left(v_{m 0}\right)$ e do modo aéreo $\left(v_{m l}\right)$, a qual é dada, respectivamente, por:

$$
\begin{aligned}
& v_{m 0}=\frac{1}{\sqrt{\left(L_{0} \cdot C_{0}\right)}} \\
& v_{m 1}=\frac{1}{\sqrt{\left(L_{1} \cdot C_{1}\right)}}
\end{aligned}
$$

em que $L_{0}, C_{0}, L_{1}$ e $C_{1}$ são as indutâncias e capacitâncias de seqüência zero e positiva das linhas de transmissão. 
Portanto, ao aplicar a teoria da transformação modal a um sistema trifásico, transposto e simétrico, o mesmo será decomposto em três sistemas monofásicos desacoplados, dos quais dois terão as mesmas impedâncias e velocidades de propagações de ondas, resultando em apenas dois circuitos para análise, os circuitos de modo-terra (modo zero) e de modo aéreo 1 (modo 1).

Uma vez feito o desacoplamento dos sinais de tensão, estes são empregados na fase de localização da situação faltosa e, conseqüentemente, na distinção entre as zonas de proteção a que essa situação pertence. Para tal, os sinais dos modos aéreo 1 (modo 1 ou M1) e, em casos especiais, o sinal do modo-terra (modo 0 ou M0) são empregados. Observa-se que os sinais do modo 1 estão presentes em todos os tipos de falta. Esses sinais serão aplicados para a determinação dos tempos de viagem e, conseqüentemente, das zonas de proteção.

O sinal do modo-terra é significativo somente para faltas com envolvimento do terra, ou seja, para faltas-fase-terra e fase-fase-terra. Entretanto, o modo-terra será utilizado em certas ocasiões para a técnica de determinação com dados registrados em um terminal, na ocorrência de faltas-fase-terra.

\subsubsection{Aplicação da Transformada Wavelet}

A ferramenta TW demonstra ser adequada para a caracterização das zonas de proteção sobre sistemas elétricos devido a sua capacidade de discriminar e identificar com precisão os instantes de descontinuidade sobre as formas de onda. Estes são representados através dos tempos de reflexão das ondas registradas nos terminais do sistema de transmissão em análise.

Para a técnica com dados provenientes de um ou de ambos os terminais, os sinais do modo aéreo 1 foram decompostos em um nível por meio da análise multirresolução wavelet, escolhendo como wavelet-mãe a symlet3 (sym3). Analogamente, esse procedimento é repetido para os sinais do modo-terra, para a técnica de determinação com dados registrados em um terminal, na ocorrência de faltasfase-terra.

Esses sinais modais decompostos representados pelos coeficientes wavelets (CWs) de detalhe 1 (D1), referentes ao modo 1 e ao modo-terra, foram avaliados pela lógica computacional implementada. Os sinais do detalhe 1, compreendidos entre uma faixa de freqüência de $60-120 \mathrm{kHz}$, contêm os instantes de reflexão das ondas viajantes 
do ponto de falta aos barramentos, necessários para a estimação da falta e, dessa maneira, permitindo também a indicação da zona de proteção. Sendo assim, para a determinação das zonas de proteção, será essencialmente empregado o tempo de reflexão das ondas, obtido através dos sinais de detalhe 1 do modo aéreo 1 .

\subsubsection{Detecção da Falta}

Nesta seção será apresentada a etapa de detecção da falta na linha de transmissão. Como já comentado, as faltas causam distorções nas formas de onda de tensão e corrente as quais caracterizam alterações nos valores de pico em magnitude e ou ângulo de fase com relação às condições encontradas antes da ocorrência da falta.

Após a etapa de aquisição de dados digitalizados de tensão, o algoritmo analisa o sinal de entrada, tomando uma janela de um milissegundo de dados (correspondente a 0,06 ciclo) com passo de meio milissegundo, como ilustrado na Figura 31. Tal janela de dados é transformada para o domínio modal, segundo a matriz de transformação de Clarke, utilizando-se apenas o modo aéreo 1. Em seguida, este é transformado para o domínio wavelet, considerando-se apenas a primeira escala de decomposição da AMR, utilizando-se como wavelet-mãe a symlet3 (sym3). Analogamente, esse procedimento é repetido para um sinal em regime permanente.

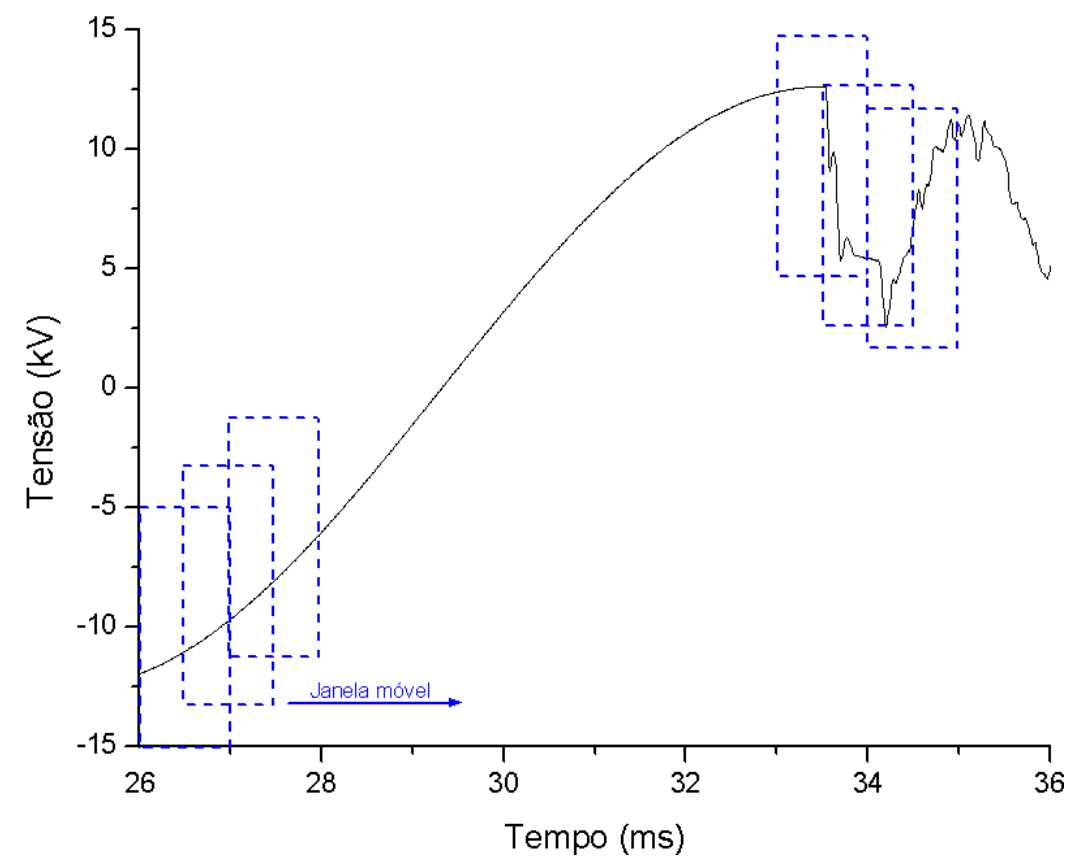

FIGURA 31 - Esquema de janelamento do sinal de entrada para detecção da falta 
Embora não exista um critério de seleção de uma wavelet-mãe para uma dada aplicação, escolheu-se a symlet3 como wavelet-mãe devido ao suporte compacto, além de conseguir representar melhor os sinais transitórios gerados pela falta, comprovada por meio de testes comparativos com as wavelets das famílias Symlet da segunda à oitava ordem e Daubechies da segunda à décima ordem, como proposto em Arruda et al. [64].

Nesta fase, os sinais dos coeficientes wavelets (CWs) de detalhe 1 (D1) (modo 1) do sinal de entrada são comparados com os coeficientes do detalhe 1 (modo 1) do sinal em regime permanente. Dessa maneira, diferenças entre essas formas de onda indicam a presença de falta, possibilitando a sua detecção.

As diferenças entre os sinais são mensuradas, avaliando-se a razão entre a média do detalhe 1 da janela de dados do sinal de entrada e do sinal de referência. Quando o sinal de entrada não apresenta nenhuma variação anormal para o sistema, a razão entre as médias assume valores próximos de um. Por outro lado, quando a janela do primeiro detalhe de decomposição apresenta variações com relação ao sinal em regime permanente, a razão entre as médias assume valores muito distintos de um. Dessa maneira, o valor empírico de 1,7 foi tomado como um parâmetro para um limiar característico da presença ou não de um distúrbio sobre o sistema em análise.

Após essa etapa, os sinais dos coeficientes wavelets (CWs) de detalhe 1 (D1) (modo 1) são elevados ao quadrado com o intuito de minimizar o ruído presente no sinal, como proposto em Santoso et al. [65].

A Figura 32 ilustra as formas de onda que são utilizadas pelo algoritmo para detecção através da AMR de um sinal.
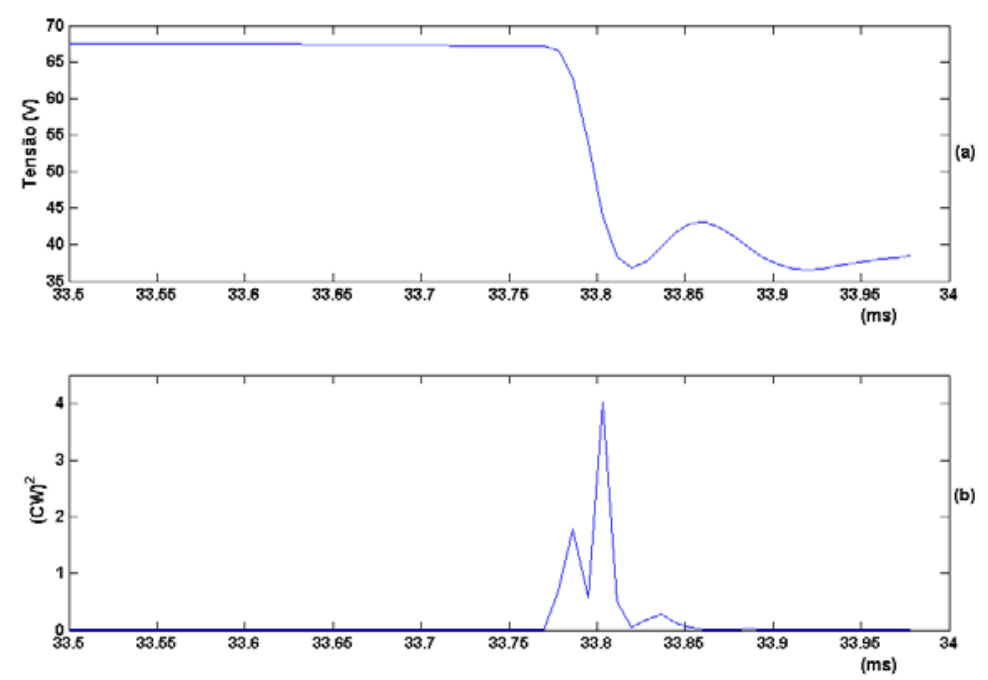
Parte de um sinal caracterizando uma falta-fase-terra é ilustrado na Figura 32a, e seu primeiro detalhe de decomposição é mostrado na Figura 32b. Pode-se observar, na Figura 32a, que no instante que precede a falta, o sinal de tensão encontra-se em regime permanente. Quando este se encontra em regime, o valor médio do primeiro detalhe de decomposição apresenta valores próximos de zero, como é ilustrado na Figura 32b. No instante em que ocorre a falta, o sinal decomposto indica a presença de picos que mostram o início do distúrbio. Esses picos, ilustrados na Figura 32b, alteram o valor médio do sinal em regime, permitindo a detecção do distúrbio.

Quando a razão entre as médias das janelas dos sinais for maior que 1,7, inicializa-se o estágio da determinação do primeiro instante de reflexão da onda no terminal local (T1). A determinação desse instante é representada por um pico no sinal de detalhe 1 do modo 1 .

A deteç̧ão desse instante é feita pela comparação do sinal do detalhe 1 com o limiar 1, sendo o sinal de detalhe 1 comparado, amostra por amostra, com esse limiar. Para o cálculo do limiar 1, utilizou-se a análise multirresolução wavelet, empregando-se o primeiro nível de decomposição do sinal de tensão em regime permanente medido na barra $E$. O limiar 1 é definido como sendo o maior valor desse sinal de detalhe 1. Para evitar algum erro devido à grandeza dos valores e à imprecisão dos sinais, o valor do limiar 1 foi acrescido de $3 \%$ do seu próprio valor. O valor desse acréscimo foi escolhido empiricamente. Detectada a variação do sinal, são consideradas mais oito amostras consecutivas, perfazendo um conjunto de nove amostras. O instante T1 estará relacionado ao maior valor desse conjunto. Na Figura 29, esse tempo corresponde a $t_{a}$. $\mathrm{O}$ número de amostras, a partir da detecção da primeira amostra, foi escolhido empiricamente. A detecção do instante de reflexão da onda no terminal remoto será apresentada na seção 5.3.8.

Para uma maior garantia na afirmação da existência de uma situação faltosa, incrementa-se à lógica implementada uma variável associada ao ocorrido. Cada vez que a razão entre as médias das janelas de dados em análise assumir um valor maior que 1,7, essa variável é incrementada de uma unidade. Esse procedimento é adotado para as janelas subseqüentes à primeira acusação. Quando a variável de confirmação atingir o valor de seis unidades, o processo é encerrado e caracterizada, dessa maneira, a real situação de falta. $\mathrm{O}$ valor acumulado dessa variável corresponde ao tempo de análise para a fase de detecção, o qual corresponde a $3 \mathrm{~ms}$ (ou 0,18 ciclos), independente do tipo de falta evidenciada. Esse tempo corresponde a seis janelas de dados de $1 \mathrm{~ms}$, com 
passo de 0,5 ms. Após esse tempo de $3 \mathrm{~ms}$, e confirmando-se a situação de falta, esse processo é encerrado, e se inicia a etapa de classificação da falta. Esse processo de confirmação é necessário para que o relé não atue, erroneamente, em situações diferentes das de faltas permanentes, como, por exemplo, na presença de uma falta transitória.

Por outro lado, quando essa razão entre as médias assumir um valor menor do que 1,7, a variável associada será reiniciada, retornado-se ao processo de análise das condições de operação do sistema.

Determinado o primeiro tempo de reflexão, caracterizado pela situação de falta sobre o sistema, passa-se ao próximo passo, que consiste na classificação da falta.

\subsubsection{Classificação da Falta}

Cabe salientar que a técnica de classificação da falta permite facilitar o deslocamento e trabalho de manutenção e restauração da linha, pela prévia identificação do tipo de falta e, conseqüentemente, das fases envolvidas.

Em se tratando da técnica da determinação das zonas de proteção que utiliza dados provenientes do terminal local, a identificação do tipo de falta ocorrido na linha de transmissão é um requisito básico, pois a metodologia aplicada é diferenciada segundo o tipo da falta considerada.

Em relação à técnica de classificação que dispõe de dados registrados em ambos os terminais da linha, foi observado nas simulações que, para certos tipos de faltas (entre duas fases sem conexão com a terra), essa técnica foi necessária a fim de que se determinasse corretamente o instante de reflexão no terminal remoto. Diante desse fato, convencionou-se a classificação do ocorrido para todas as situações analisadas.

Após a confirmação da caracterização de uma situação de falta, dispõe-se de uma janela de dados correspondendo a dez milissegundos, a qual contém os fasores de corrente para a etapa de classificação da falta. O método aplicado neste trabalho é fundamentado na comparação entre os fasores de corrente superpostos e de seqüência zero à forma de onda na freqüência fundamental $\left(I_{a}^{\prime \prime}, I_{b}^{\prime \prime}, I_{c}^{\prime \prime}\right.$ e $\left.I_{0}^{\prime \prime}\right)$ contidos na janela de dados em análise (10 ms pós-falta) e registrados em um terminal de referência, conforme trabalho apresentado por Coury [2]. A Tabela 5 ilustra a rotina de classificação da falta implementada neste trabalho. 


\begin{tabular}{|c|c|}
\hline SE & FALTA TIPO \\
\hline$I_{b}^{\prime \prime}<K I_{a}^{\prime \prime} \quad$ e $\quad I_{c}^{\prime \prime}<K I_{a}^{\prime \prime}$ & Falta A-terra \\
\hline$I_{a}^{\prime \prime}<K I_{b}^{\prime \prime} \quad$ e $\quad I_{c}^{\prime \prime}<K I_{b}^{\prime \prime}$ & Falta B-terra \\
\hline$I_{a}^{\prime \prime}<K I_{c}^{\prime \prime} \quad$ e $\quad I_{b}^{\prime \prime}<K I_{c}^{\prime \prime}$ & Falta C-terra \\
\hline$I_{c}^{\prime \prime}<K I_{a}^{\prime \prime} \quad e \quad I_{b}^{\prime \prime} \cong I_{a} \quad e$ & \\
\hline$I_{0}^{\prime \prime}>I_{\min }$ & Falta $\mathrm{AB}$-terra \\
\hline Caso contrário & Falta $A B$ \\
\hline$I_{a}^{\prime \prime}<K I_{b}^{\prime \prime} \quad e \quad I_{c}^{\prime \prime} \cong I_{b} \quad e$ & \\
\hline$I_{0}^{\prime \prime}>I_{\min }$ & Falta BC-terra \\
\hline Caso contrário & Falta BC \\
\hline$I_{b}^{\prime \prime}<K I_{a}^{\prime \prime} \quad e \quad I_{a}^{\prime \prime} \cong I_{c} \quad e$ & \\
\hline$I_{0}^{\prime \prime}>I_{\min }$ & Falta AC-terra \\
\hline Caso contrário & Falta AC \\
\hline$I_{a}^{\prime \prime} \cong I_{b}^{\prime \prime} \cong I_{c}^{\prime \prime}$ & Fase $\mathrm{ABC}$ \\
\hline
\end{tabular}

O parâmetro $K$, evidenciado na Tabela 5 , é a razão entre as correntes de fase sã e faltosa e depende da configuração do sistema, podendo ser determinado empiricamente. Para o sistema em questão, $K$ é igual a 0,52 .

Na prática, é necessário também aplicar um pequeno limiar $I_{\min }$ para as medidas, devido à existência de linhas não balanceadas, transdutores etc. Neste trabalho, é considerado um valor de $I_{\min }=0,01$, valor este também determinado empiricamente.

Os valores dos fasores de $I_{a}^{\prime \prime}, I_{b}^{\prime \prime}, I_{c}^{\prime \prime}$ e $I_{0}^{\prime \prime}$ são normalizados para a fase que possui o maior valor. Considera-se que os fasores de corrente inferiores a 0,3 são não faltosos, e os fasores de valor superior a 0,6 são faltosos. Quando a relação entre os fasores de corrente apresentar valores entre 0,3 a 0,6 , estes são considerados faltosos, entretanto, 
ainda não é possível distinguir quanto ao tipo de falta envolvida. A existência ou não da componente de seqüência zero, indicará então se a falta envolve ou não conexão com a terra.

Testes serão apresentados na seção 6.1.2 para demonstrarem que a rotina de classificação foi capaz de classificar corretamente todos os tipos de faltas consideradas neste trabalho.

\subsubsection{Procedimento para a Localização da Falta e Estimação da Zona de Proteção Alocada}

Como já mencionado, o algoritmo apresentado neste trabalho foi desenvolvido de tal maneira que o usuário possa escolher a técnica de determinação das zonas de proteção (com aquisição de dados provenientes de um ou dois terminais) que achar mais conveniente, ou que melhor se adapte ao seu sistema.

Uma vez realizada a aquisição de dados, a detecção e a classificação da situação de falta, apresenta-se no que segue, a estimação da localização da falta com a conseqüente indicação da zona de proteção a que a mesma pertence.

Inicialmente, serão descritos os estágios que constituem a técnica de determinação que se utiliza de dados provenientes de um terminal. Em seguida, será descrita a técnica que utiliza dados provenientes de dois terminais.

\subsubsection{Determinação dos Tempos de Reflexão no Terminal Local}

Como essa técnica faz uso dos sinais registrados apenas no terminal local da linha em análise, ela se torna uma técnica mais robusta e econômica quando comparada com a técnica que utiliza dados provenientes de dois terminais, já que esta última requer meios de comunicação ou mesmo sincronização dos dados.

Todavia, nessa técnica, a detecção ou determinação dos instantes de chegada das ondas no terminal local é mais complexa, pois envolve a detecção da primeira e segunda reflexão da forma de onda, como descrito no item 5.3.4.

Soma-se ainda a essa complexidade, o fato de que a determinação do segundo tempo (T2), referente à chegada da segunda onda no terminal local, é mais trabalhosa, pois, dependendo do tipo de falta sob análise, envolve ondas provenientes do ponto de 
falta ou do terminal remoto. Outro fator que dificulta essa detecção é a grande atenuação dessas ondas durante a sua viagem pelo sistema.

Como a informação relativa à determinação dos tempos de reflexão encontra-se disponível na etapa de detecção da falta, utilizou-se a mesma janela de dados de $3 \mathrm{~ms}$ previamente registrada, para a etapa da determinação das zonas de proteção. Com essa janela de dados, o tempo T2 é determinado pela comparação do sinal de detalhe 1 , do modo 1, com limiares auto-ajustáveis conforme cada tipo de falta em específico. A determinação desses limiares é realizada de maneira empírica. Visando a um maior esclarecimento sobre as etapas para a determinação de T2, é apresentado, na Figura 35, o fluxograma referente a essa rotina. O primeiro limiar, chamado de limiar 2, é definido pelo máximo entre as amostras 4 e 10 do sinal do detalhe 1, subseqüente à amostra relacionada a T1. Portanto, o limiar 2 é auto-ajustável conforme o sinal analisado.

Para faltas-fase-terra e fase-fase-terra, se um determinado conjunto de amostras iniciais não ultrapassarem o limiar 2, novos limiares são definidos para esses tipos de faltas. Esse procedimento busca eliminar o efeito da atenuação do sinal. Para faltas-faseterra é estabelecido um novo limiar (limiar 3), definido pela razão entre o limiar 2 e um coeficiente de falta (cf) determinado empiricamente e ilustrado na Tabela 6. O novo limiar 3 é então comparado com as amostras do sinal de detalhe 1, caso alguma amostra exceda o seu valor, T2 é determinado, analisando-se um conjunto de amostras prédefinido a partir dessa detecção. As Figuras 33 e 34 ilustram a determinação de T2 referente às situações de faltas-fase-terra, diferenciando-se pela necessidade ou não do limiar 3.

Em situações de faltas-fase-fase-terra, segue-se o mesmo procedimento ao de faltas-fase-terra, porém o novo limiar (limiar 4) é obtido pelo produto entre o limiar $2 \mathrm{e}$ um coeficiente de falta (cf). Com base no valor do limiar 4, o tempo T2 é determinado de modo análogo ao descrito para faltas-fase-terra. 


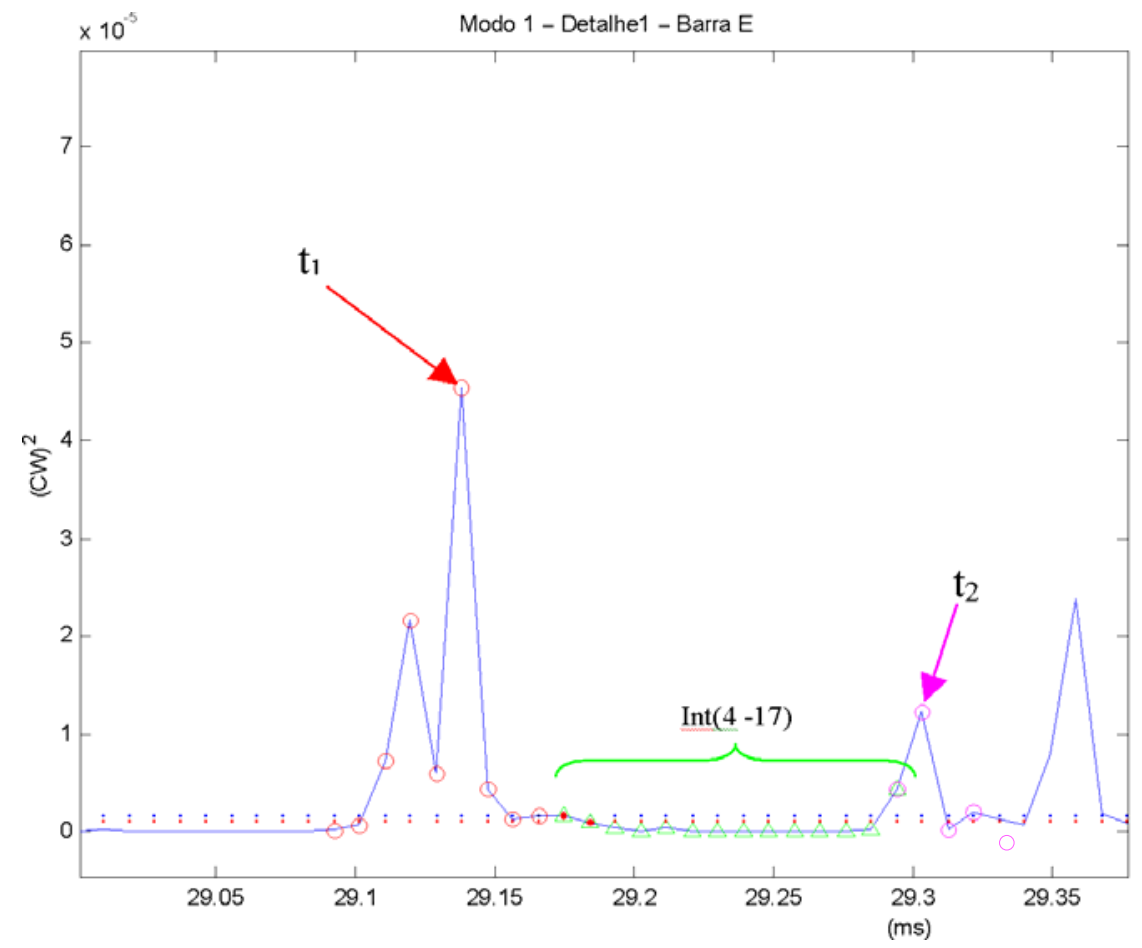

FIGURA 33 - Exemplo 1: deteç̧ão de T2 para uma falta-fase-terra, sem necessidade do limiar 3

TABELA 6-Coeficientes de falta (cf)

\begin{tabular}{cccc|ccc}
\hline & \multicolumn{3}{c|}{ Falta-fase-terra } & \multicolumn{3}{c}{ Falta-fase-fase-terra } \\
\hline & AT & BT & CT & ABT & ACT & BCT \\
\hline CF & 4,5 & 4,5 & 4,5 & 2,3 & 1,2 & 1,2 \\
\hline
\end{tabular}

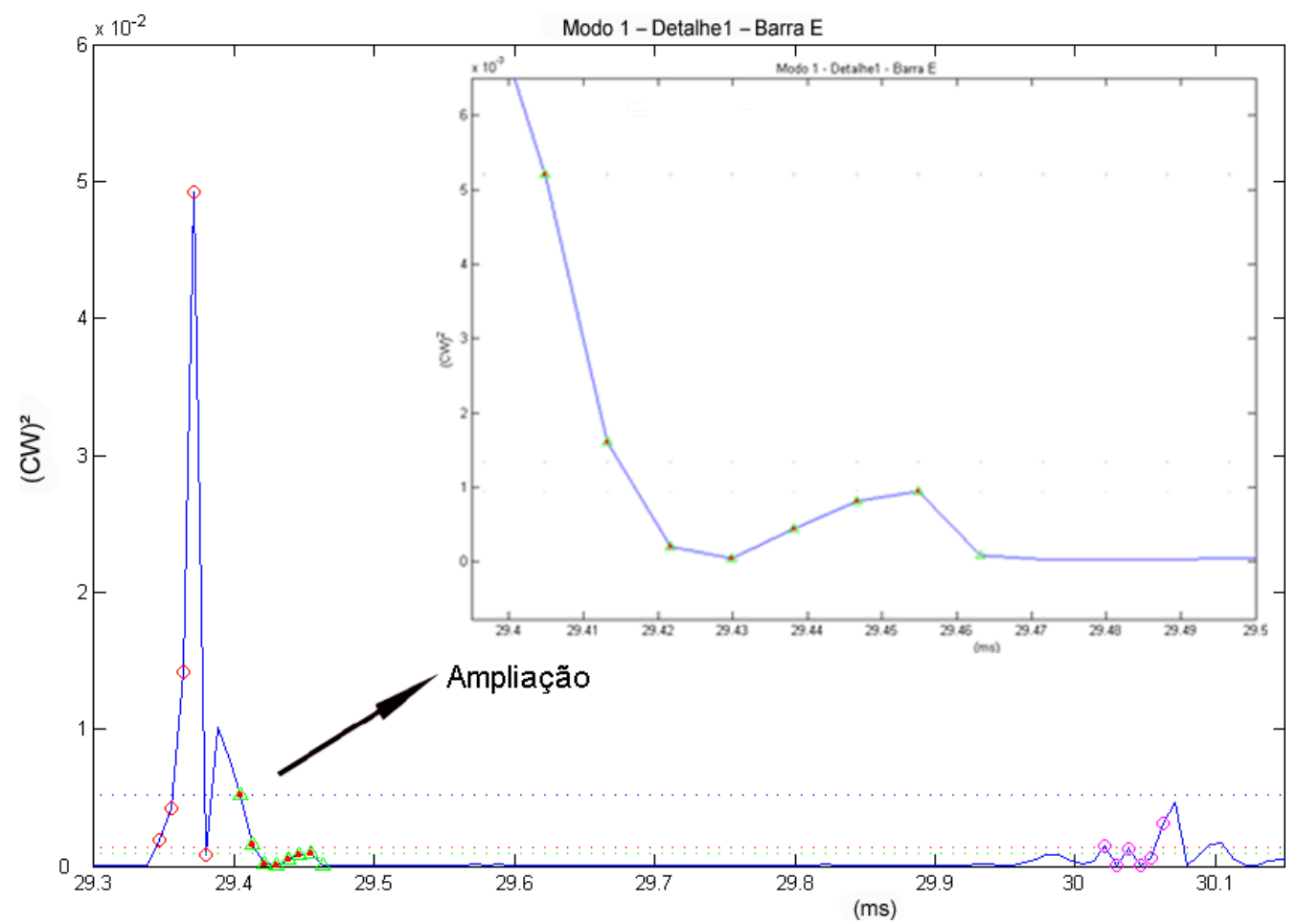

FIGURA 34 - Exemplo 2: detecção de T2 para uma falta-fase-terra, com necessidade do limiar 3 
Para faltas-fase-fase e trifásicas, o tempo T2 é determinado pela simples comparação do limiar 2 com as amostras do sinal de detalhe 1, subseqüentes à amostra que representa T1. Caso alguma amostra supere o limiar 2, T2 será determinado analisando-se um conjunto de amostras a partir dessa detecção.

Conforme o fluxograma ilustrado na Figura 30, para a técnica que utiliza dados de um terminal, observa-se a necessidade da determinação de um tempo T3. Entretanto, esse tempo somente é obtido na presença de faltas-fase-terra, sendo necessário definir primeiramente se a situação ocorreu na primeira ou na segunda metade da linha, o que conduz a equacionamentos diferentes na determinação exata da falta.

A determinação do tempo T3 é semelhante à determinação do tempo T1, visto no item 5.3.4, sendo que, nesse caso, o sinal é comparado a um limiar 5. Para se obter T3, ao invés de usar o sinal de detalhe 1 do modo 1 , utiliza-se o sinal de detalhe 1 do modo-terra (D1_terra). O limiar 5 é auto-ajustável e representa o valor médio do sinal de detalhe 1 do modo-terra analisado.

O sinal de detalhe 1 do modo-terra é comparado com o limiar 5 (D1_terra > limiar 5), caso haja alguma variação, esta é detectada e mais cinco amostras consecutivas são consideradas. O maior valor desse conjunto de seis amostras indicará o respectivo tempo $\mathrm{T} 3$.

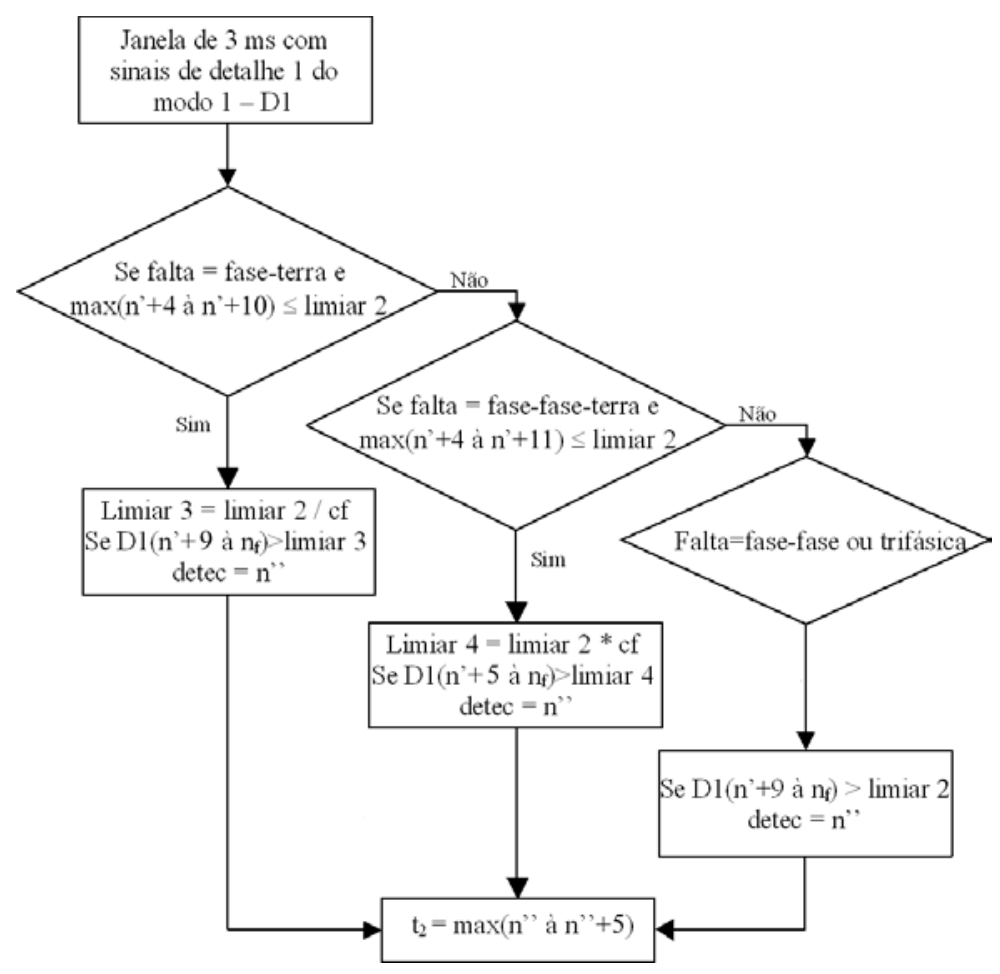

FIGURA 35 - Fluxograma referente às etapas para a determinação do tempo T2 


\subsubsection{Pré-Localização para Faltas-Fase-Terra}

Para o caso de faltas-fase-terra há a necessidade de uma pré-localização da mesma, isto é, associarmos a localização da situação à primeira ou segunda metade da linha. Utiliza-se a pré-localização da falta devido ao não conhecimento da procedência da segunda onda viajante no terminal local, que pode ser proveniente do ponto de falta, caso esta ocorra na primeira metade da linha, ou proveniente do terminal remoto, caso a falta ocorra na segunda metade da linha.

Essa metodologia pode apresentar padrões de faltas similares, isto é, pode-se obter intervalos de tempos iguais entre a primeira e a segunda onda. Isso ocasiona equacionamentos diferentes à determinação das zonas de proteção.

As Figuras 36a e 36b ilustram uma situação de falta-fase-terra na segunda e na primeira metade da linha, respectivamente. Em ambas as figuras, $t_{a}$ e $t_{b}$ correspondem aos tempos dos picos iniciais dos coeficientes wavelets de detalhe 1 do modo 1 para os sinais registrados nas barras $\mathrm{A}$ e $\mathrm{B}$, respectivamente. $\mathrm{O}$ cálculo do atraso entre os tempos de detecção da falta nos dois terminais é dado por:

$$
t_{d(a)}=t_{b}-t_{a}
$$

Nota-se que, se determinarmos o intervalo de tempo $\left(t_{d}=t_{2}-t_{1}\right)$ entre as duas primeiras ondas que chegam do ponto de falta alocado na segunda e na primeira metade da linha, respectivamente, teremos:

$$
\left.\begin{array}{l}
t_{d(a)}=2 t_{b}+t_{a}-t_{a}=2 t_{b} \\
t_{d(b)}=3 t_{a}-t_{a}=2 t_{a}
\end{array}\right\} \operatorname{mas} 2 t_{b}=2 t_{a} \text { ou } t_{b}=t_{a} \Leftrightarrow l-d
$$

em que:

$t_{d(a)}$ é o intervalo de tempo entre as duas primeiras ondas que chegam no terminal A, para uma falta-fase-terra na segunda metade da linha (Figura 36a);

$t_{d(b)}$ é o intervalo de tempo entre as duas primeiras ondas que chegam no terminal A, para uma falta-fase-terra na primeira metade da linha (Figura 36b). 


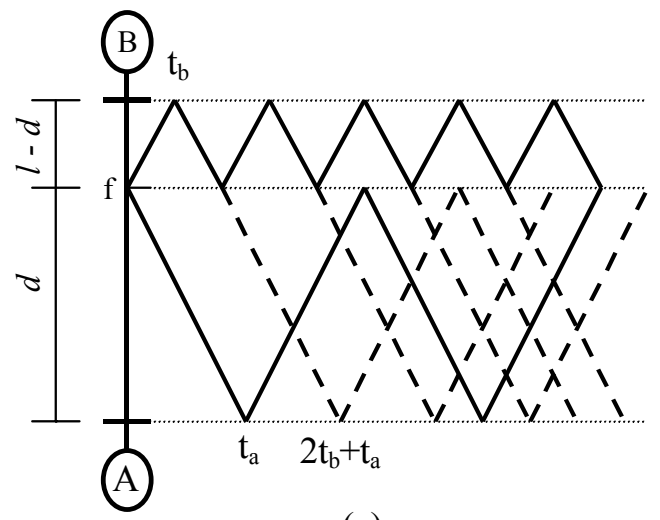

(a)

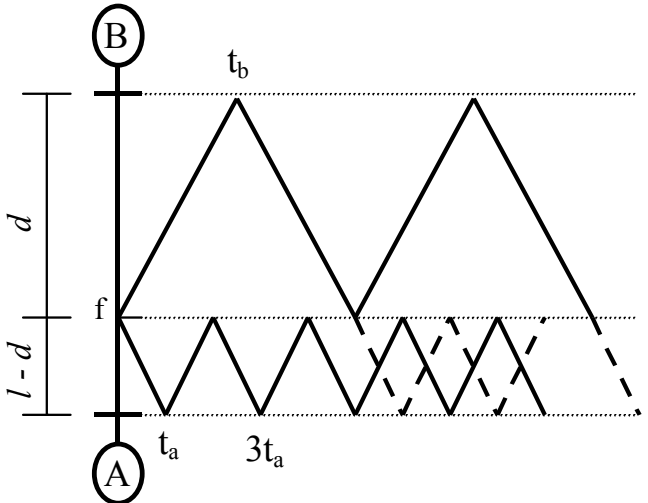

(b)

FIGURA 36 - (a) Falta-fase-terra na segunda metade da linha, (b) falta-fase-terra na primeira metade da linha

A pré-localização é realizada com base na diferença entre os tempos das reflexões iniciais revelados pela TW com relação ao modo-terra e modo aéreo 1 (Figura 37), com a diferença entre os tempos de propagação do modo-terra e aéreo 1 em relação ao meio da linha, como proposto por Magnago e Abur [66]. Em outras palavras, quanto maior a distância da falta, maior será a diferença entre os tempos de propagação das primeiras reflexões reveladas pela TW com relação a ambos os modos, uma vez que há diferença entre a velocidade de propagação do modo aéreo em relação ao modo-terra. Caso esse valor seja maior que a diferença dos tempos de reflexão para a metade da linha, a falta estará alocada na segunda metade, caso contrário, a falta estará alocada na primeira metade. A sub-rotina para a pré-localização de faltas-fase-terra pode ser formulada como segue:

$$
\begin{aligned}
& t_{m 0}=\frac{l}{2 \cdot v_{m 0}} ; \quad t_{m 1}=\frac{l}{2 \cdot v_{m 1}} \\
& t_{l / 2}=\left|t_{m 0}-t_{m 1}\right| \\
& t_{d m}=\left|t_{1}-t_{3}\right| \\
& t_{d m}>t_{l / 2} \quad \Leftrightarrow \quad 2^{\underline{a}} \text { metade }
\end{aligned}
$$

Caso contrário $\Leftrightarrow \quad 1^{\underline{a}}$ metade

em que $t_{m 0}$ e $t_{m 1}$ são os tempos em relação à velocidade dos modos-terra e aéreo 1 que a onda leva para ir do terminal local ao meio da linha, $t_{l}$ e $t_{3}$ são os tempos relacionados 
aos primeiros picos dos sinais de detalhe 1 do modo aéreo 1 (D1) e modo-terra (D1_terra), respectivamente.

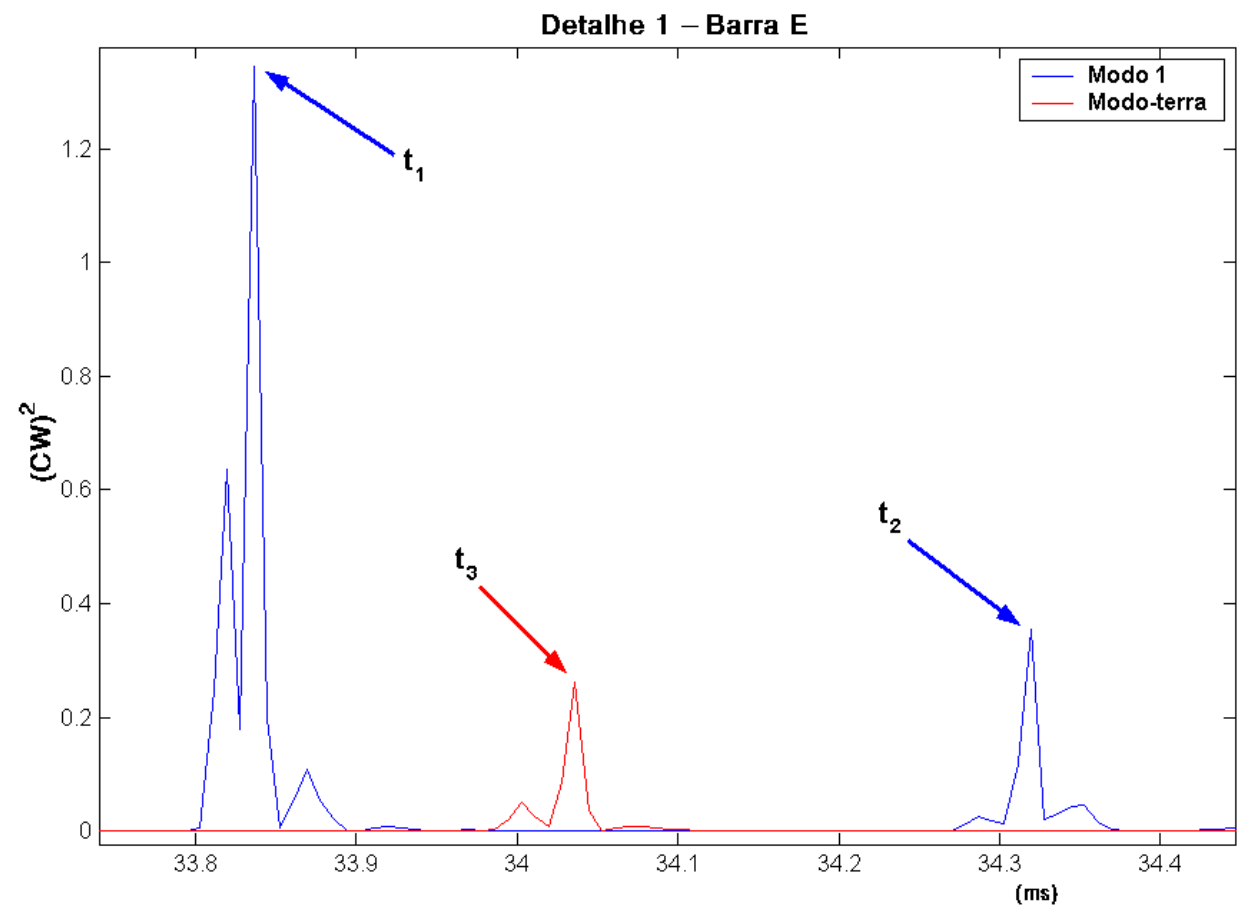

FIGURA 37 - Sinais de detalhe 1 dos modos aéreo 1 e terra para uma falta-fase-terra na segunda metade da linha

\subsubsection{Determinação das Zonas de Proteção para Faltas-Fase-Terra}

Analisou-se, na seção 5.2, as respectivas zonas de proteção consideradas para o sistema elétrico da Figura 20. Com base nessas informações, os tempos limites de viagem para as suas respectivas zonas de proteção com referência ao terminal local são os seguintes:

$$
t_{p z p}=\frac{123,6}{v_{m 1}} ; \quad t_{s z p}=\frac{185,4}{v_{m 1}} ; \quad t_{t z p}=\frac{240}{v_{m 1}}
$$

em que $t_{p z p}, t_{s z p}$ e $t_{t z p}$ correspondem aos tempos limites de viagem das ondas dos seus respectivos limites de zonas de proteção primária (+3\% sobre os $120 \mathrm{~km})$, secundária $(+3 \%$ sobre os $180 \mathrm{~km})$ e terciária $(240 \mathrm{~km})$, ao terminal de referência e $v_{m l}$ é a velocidade de propagação do modo aéreo $1 \mathrm{em}(\mathrm{km} / \mathrm{s})$. Observa-se que já estão inclusos nos tempos de viagens os índices de incerteza de $+3 \%$ sobre o alcance das respectivas zonas de proteção. 
Conforme foi explicitado anteriormente, em caso de faltas-fase-terra é necessário que seja feita uma pré-localização da falta conforme o item 5.3.7.1. Uma vez determinado em qual metade da linha ocorreu a falta, a localização da falta e, conseqüentemente, a determinação das zonas de proteção podem ser feitas como segue:

a) para faltas-fase-terra incidentes na primeira metade da linha, entre os barramentos $E$ e $G$, a determinação das zonas de proteção é realizada através da medição do tempo entre os dois primeiros picos consecutivos dos coeficientes wavelets do detalhe 1 , referente ao modo aéreo 1, realizando comparativos destes com os tempos de viagem dentro das respectivas zonas de proteção, como se segue:

$$
\begin{aligned}
& \frac{t_{d}}{2} \leq t_{p z p} \Leftrightarrow \text { Falta na zona primária } \\
& \frac{t_{d}}{2}>t_{p z p} e \frac{t_{d}}{2} \leq t_{s z p} \Leftrightarrow \text { Falta na zona secundária } \\
& \frac{t_{d}}{2}>t_{s z p} e \frac{t_{d}}{2} \leq t_{t z p} \Leftrightarrow \text { Falta na zona terciária }
\end{aligned}
$$

\section{Caso contrário $\Leftrightarrow$ Falta externa}

b) para faltas-fase-terra ocorridas na segunda metade da linha, temos que:

$$
\begin{aligned}
& t_{s e g}=\frac{2 . l}{v_{m 1}}-t_{d} \text { Logo, } \\
& \frac{t_{s e g}}{2} \leq t_{p z p} \Leftrightarrow \text { Falta na zona primária } \\
& \frac{t_{\text {seg }}}{2}>t_{p z p} e \frac{t_{s e g}}{2} \leq t_{s z p} \Leftrightarrow \text { Falta na zona secundária } \\
& \frac{t_{s e g}}{2}>t_{s z p} e \frac{t_{s e g}}{2} \leq t_{t z p} \Leftrightarrow \text { Falta na zona terciária }
\end{aligned}
$$

Caso contrário $\Leftrightarrow$ Falta externa

em que $t_{d}$ é a diferença entre os dois picos consecutivos dos coeficientes wavelets do detalhe 1 , referente ao modo aéreo $1, t_{\text {seg }}$ é o tempo de reflexão para a segunda metade 
da linha entre os barramentos $E$ e $G, l$ o comprimento da linha em questão em km, $v_{m l}$ a velocidade de propagação do modo $1 \mathrm{em} \mathrm{km} / \mathrm{s}$, e $t_{p z p}, t_{s z p}$ e $t_{t z p}$ são os tempos de viagem dentro das suas respectivas zonas de proteção.

Como informação adicional do algoritmo, realizou-se o produto entre a velocidade de propagação com o $t_{d}$, obtendo-se a distância estimada da falta. Desse modo:

a) para faltas-fase-terra incidentes na primeira metade da linha, entre os barramentos $E$ e $G$, a distância da falta pode ser expressa por:

$$
d=\frac{v_{m 1} \cdot t_{d}}{2}
$$

b) para faltas-fase-terra ocorridas na segunda metade da linha, entre os barramentos $E \mathrm{e}$ $G$, temos que:

$$
d=l-\frac{v_{m 1} \cdot t_{d}}{2}
$$

em que $d$ é a distância da falta em $(\mathrm{km})$.

\subsubsection{Determinação das Zonas de Proteção para Faltas-Fase-Fase-Terra, Fase- Fase e Trifásica}

No caso de faltas-fase-fase-terra, fase-fase e trifásicas, observa-se que estas não geram reflexões do terminal remoto, durante o transitório de falta. Assim, a determinação das zonas de proteção para esses tipos de faltas é realizada conforme a eq.(5.9). Como informação adicional ao algoritmo, realizou-se o cálculo da distância estimada da falta, por meio da eq.(5.11).

\subsubsection{Determinação das Zonas de Proteção com Dados Provenientes de Dois Terminais da Linha}

Antes de inicializar a etapa da determinação das zonas de proteção, será ilustrado o processo de detecção do instante de reflexão da onda no terminal remoto.

A detecção do primeiro instante de reflexão no terminal remoto será determinada de maneira análoga ao caso de um terminal (T1). Para a correta determinação do instante de reflexão no terminal remoto (T2), deve-se considerar a 
informação relativa sobre a classificação da falta. Uma vez realizada a detecção do instante T1 e a classificação da situação de falta, apresenta-se, no que segue, o processo de detecção do instante T2.

De maneira empírica, foi considerada como ideal a utilização de mais oito amostras consecutivas após detecção da primeira amostra, perfazendo um conjunto de nove amostras dos sinais do terminal remoto. Dessas oito amostras, o maior valor corresponderá ao instante T2. Na Figura 29, esse tempo corresponde a $t_{b}$.

A Figura 38 ilustra o processo de detecção dos tempos de reflexão, considerando uma situação de falta-fase-terra. Pode-se observar pela mesma Figura que o distúrbio é detectado e os picos escolhidos adequadamente pelo algoritmo.
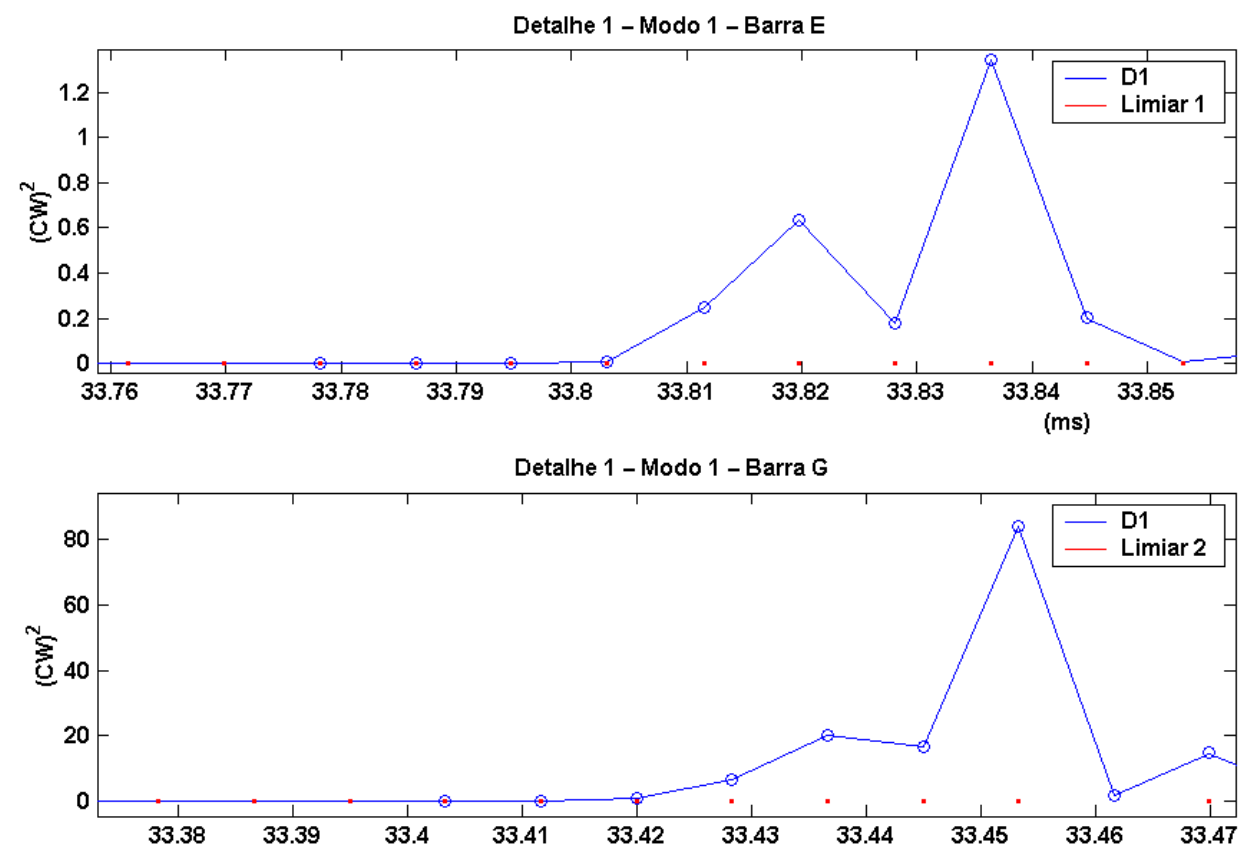

FIGURA 38 - Exemplo de detecção dos picos iniciais

No item 5.3.2, observa-se que $t_{a}$ e $t_{b}$ (Figura 29) correspondem ao tempo dos picos iniciais dos coeficientes wavelets de detalhe 1 do modo 1 , para os sinais registrados nas barras $\mathrm{A}$ e $\mathrm{B}$, respectivamente. Nota-se que, uma vez determinado o intervalo de tempo $\left(t_{d}=t_{b}-t_{a}\right)$ entre os dois sinais registrados em ambas as barras, e realizando comparativos deste com os tempos de viagem dentro das respectivas zonas de proteção, a localização da falta e, conseqüentemente, a determinação das zonas de proteção podem ser formuladas como se segue: 


$$
\begin{aligned}
& t_{2 \text { term }}=\frac{l}{v_{m 1}}-t_{d} \text { Logo, } \\
& \frac{t_{2 \text { term }}}{2} \leq t_{p z p} \Leftrightarrow \text { Falta na zona primária } \\
& \frac{t_{2 \text { term }}}{2}>t_{p z p} e \frac{t_{2 t e r m}}{2} \leq t_{s z p} \Leftrightarrow \text { Falta na zona secundária } \\
& \frac{t_{2 \text { term }}>t_{s z p} e \frac{t_{2 t e r m}}{2} \leq t_{t z p} \Leftrightarrow \text { Falta na zona terciária }}{\text { Caso contrário } \Leftrightarrow \text { Falta externa }}
\end{aligned}
$$

em que $t_{2 t e r m}$ é o tempo de reflexão para os sinais registrados nos barramentos $E$ e $G, l$ o comprimento da linha em questão em $\mathrm{km}, v_{m l}$ a velocidade de propagação do modo 1 em $\mathrm{km} / \mathrm{s}$, e $t_{p z p}, t_{s z p}$ e $t_{t z p}$ são os tempos de viagem dentro das suas respectivas zonas de proteção.

Como informação adicional ao algoritmo, realizou-se o cálculo da distância entre o ponto da falta e o terminal A dado pela seguinte equação:

$$
d=\frac{l-v_{m 1} \cdot t_{d}}{2}
$$

em que $l$ é o comprimento da linha de transmissão $(\mathrm{km}), v_{m l}$ é a velocidade de propagação do modo aéreo $1 \mathrm{em}(\mathrm{km} / \mathrm{s})$ e $d$ a distância da falta em relação ao barramento $A(\mathrm{~km})$.

Observa-se que essa técnica é de fácil aplicação e não envolve muitos cálculos. A única desvantagem encontrada é a necessidade de sincronização e transmissão dos dados, o que acaba elevando os custos de implentação. 


\section{TESTES E RESULTADOS OBTIDOS RELATIVOS AO ALGORITMO ESTUDADO}

O algoritmo para a detecção, classificação e localização das situações de falta que venham a ocorrer sobre determinado sistema de transmissão, com a conseqüente determinação das zonas de proteção, foi implementado através do software Matlab ${ }^{\circledR} \mathrm{e}$ testado utilizando-se de dados obtidos através de simulações do software ATP. Como descrito no Capítulo 4, foram considerados vários tipos de faltas em diferentes localizações, entre os barramentos $E$ e $G$, com diferentes ângulos de incidência e resistências de falta.

O sistema elétrico considerado (Figura 20) apresenta para o modo aéreo 1 (modo 1) uma velocidade de propagação de $2,9317 \times 10^{5} \mathrm{~km} / \mathrm{s}$ e para o modo-terra (modo 0 ) uma velocidade de propagação de $2,228 \times 10^{5} \mathrm{~km} / \mathrm{s}$, sendo o passo de amostragem usado de $8,33 \mu \mathrm{s}(120 \mathrm{kHz})$. Os sinais do modo 0 e modo 1 são decompostos em um nível, utilizando-se como wavelet-mãe a Symlet3 (Sym3). Os sinais dos coeficientes wavelets (CWs) de detalhe 1 do modo aéreo 1 (modo 1) são usados em ambas as técnicas de determinação das zonas de proteção. Além disso, os sinais dos CWs de detalhe 1 do modo-terra (modo 0) são aplicados apenas na técnica de determinação das zonas de proteção, para faltas-fase-terra, com dados provenientes de um terminal. Cabe mencionar que, para a determinação das zonas de proteção, foram empregadas somente as formas de ondas que dizem respeito às tensões trifásicas do sistema em análise.

Embora extensivos testes tenham sido realizados para se verificar e comprovar o desempenho do algoritmo do relé de distância proposto, somente uma parte deles com seus respectivos comentários serão apresentados no corpo deste documento. Resultados complementares serão apresentados no Apêndice A.

O cálculo do erro percentual (relativo) e erro médio total são obtidos através das equações (6.1) e (6.2), respectivamente. Deve-se salientar que, o erro percentual 
(relativo) apresentado é calculado em relação aos comprimentos limites respectivos das zonas primária $(120 \mathrm{~km})$, secundária $(180 \mathrm{~km})$ e terciária $(240 \mathrm{~km})$ :

$$
\begin{aligned}
& \varepsilon_{\text {rel }}(\%)=\left|\frac{d_{\text {estimado }}-d_{\text {real }}}{l_{\text {zona }}}\right| \cdot 100 \% \\
& \varepsilon_{\text {médio }}=\frac{\sum_{1}^{N} \varepsilon_{\text {rel }}(\%)}{N}
\end{aligned}
$$

em que $N$ é o número de situações consideradas, $d_{\text {estimado }}$ é a distância estimada pelo algoritmo, $d_{\text {real }}$ é a distância real da falta e $l_{z o n a}$ é o comprimento da linha para as respectivas zonas de proteção primária, secundária e terciária.

\subsection{Resultados Alcançados Utilizando-se Dados Provenientes de um Terminal da Linha}

Esta seção é dedicada à apresentação dos resultados obtidos pelo algoritmo proposto para a detecção, classificação e determinação das zonas de proteção, quando do emprego da técnica que utiliza dados de um terminal.

\subsubsection{Detecção da Falta}

Como ilustração da sub-rotina de detecção da falta, será mostrada a evolução de um sinal trifásico de tensão registrado na barra $E$, contendo uma falta-fase-terra aplicada a $180 \mathrm{~km}$ do barramento $E$, mostrada na Figura 39. A falta foi aplicada aproximadamente a 2 ciclos de simulação, com resistência de falta de $100 \Omega$ e ângulo de incidência de $90^{\circ}$. 


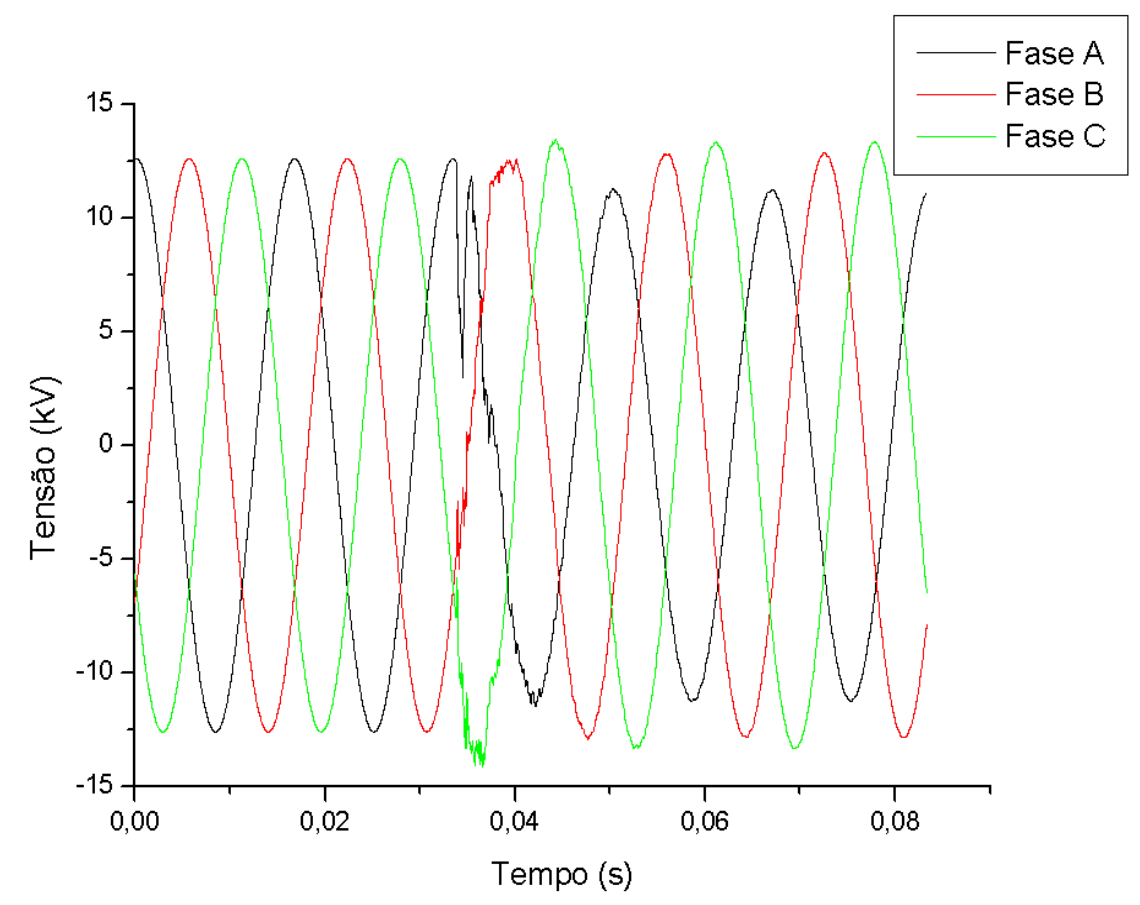

FIGURA 39 - Formas de onda da tensão para uma falta-fase-terra aplicada a $180 \mathrm{~km}$ da barra E

Uma comparação entre os coeficientes wavelets do detalhe 1 (modo 1) do sinal de entrada com os coeficientes do detalhe 1 (modo 1) do sinal de referência é o meio utilizado pelo método para a detecção do distúrbio, (seção 5.3.4). A comparação é realizada calculando-se a média de uma janela de dados que corresponde a um milissegundo do sinal de entrada e do sinal em regime permanente.

TABELA 7 - Detecção de falta-fase-terra

\begin{tabular}{c|c|c|c|c}
\hline $\begin{array}{c}\text { Número da janela } \\
\text { de deteç̧ão }\end{array}$ & $\begin{array}{c}\text { Média do sinal } \\
\text { de entrada }\end{array}$ & $\begin{array}{c}\text { Média do sinal } \\
\text { de referência }\end{array}$ & $\begin{array}{c}\text { Razão entre as } \\
\text { médias dos sinais }\end{array}$ & $\begin{array}{c}\text { Confirmação } \\
\text { da falta }\end{array}$ \\
\hline 1 & $1,960 \times 10^{-4}$ & $1,961 \times 10^{-4}$ & 0,9998 & 0 \\
\hline 2 & $3,711 \times 10^{-4}$ & $3,674 \times 10^{-4}$ & 1,0101 & 0 \\
\hline 3 & $6,493 \times 10^{-4}$ & $6,428 \times 10^{-4}$ & 1,0102 & 0 \\
\hline$\vdots$ & $\vdots$ & $\vdots$ & $\vdots$ & $\vdots$ \\
\hline 66 & $3,359 \times 10^{-4}$ & $3,358 \times 10^{-4}$ & 1,0001 & 1 \\
\hline 67 & $4,141 \times 10^{-2}$ & $2,575 \times 10^{-4}$ & 160,80 & 2 \\
\hline 68 & $6,705 \times 10^{-2}$ & $1,684 \times 10^{-4}$ & 398,28 & 3 \\
\hline 70 & $4,369 \times 10^{-2}$ & $4,395 \times 10^{-4}$ & 99,40 & 4 \\
\hline 71 & $2,813 \times 10^{-2}$ & $7,009 \times 10^{-4}$ & 40,13 & 5 \\
\hline 72 & $3,013 \times 10^{-2}$ & $8,890 \times 10^{-4}$ & 33,89 & 6 \\
\hline
\end{tabular}


Com base nas informações contidas no sinal sob análise, foram obtidos os dados apresentados na Tabela 7, onde a primeira coluna, referente ao número de janela utilizada para detecção, corresponde as janelas de dados apresentadas ao algoritmo para a detecção da falta. No cálculo da média do sinal de entrada e de referência, foram considerados os valores absolutos dos sinais.

Como esperado, a razão entre os sinais assumiu valores menores que 1,7 para os períodos que precedem a falta. No entanto, quando a janela de análise englobou parte da falta, variações ocorreram na média do sinal de entrada, indicando a presença da falta, uma vez que nessa situação superou-se o valor de 1,7, utilizado para diferenciação entre o regime permanente e o sinal com alguma anomalia.

Pela Tabela 7, observa-se que, após o primeiro instante de detecção de uma situação de falta (janela 67), inicializa-se uma variável que servirá para confirmar a real situação de falta. Como a razão entre as médias assume um valor maior que 1,7, essa variável é incrementada em uma unidade. Observa-se que com a janela 72, a variável de confirmação atinge o valor de seis unidades. O valor dessa variável de confirmação corresponde ao tempo de análise de $3 \mathrm{~ms}$ (ou 0,18 ciclos) da ocorrência da mesma (seção 5.3.4). Esse tempo corresponde a seis janelas de dados de $1 \mathrm{~ms}$, com passo de 0,5 ms. Após esse tempo de $3 \mathrm{~ms}$, e confirmando-se a situação de falta, a sub-rotina de detecção é encerrada.

A Figura 40 mostra as decomposições dos sinais de entrada e de referência no instante da detecção da falta em análise. Nesta figura, pode-se observar o instante em que a decomposição do sinal de entrada (em cor azul) apresentou variações que diferem do regime permanente do sinal (em cor preta).

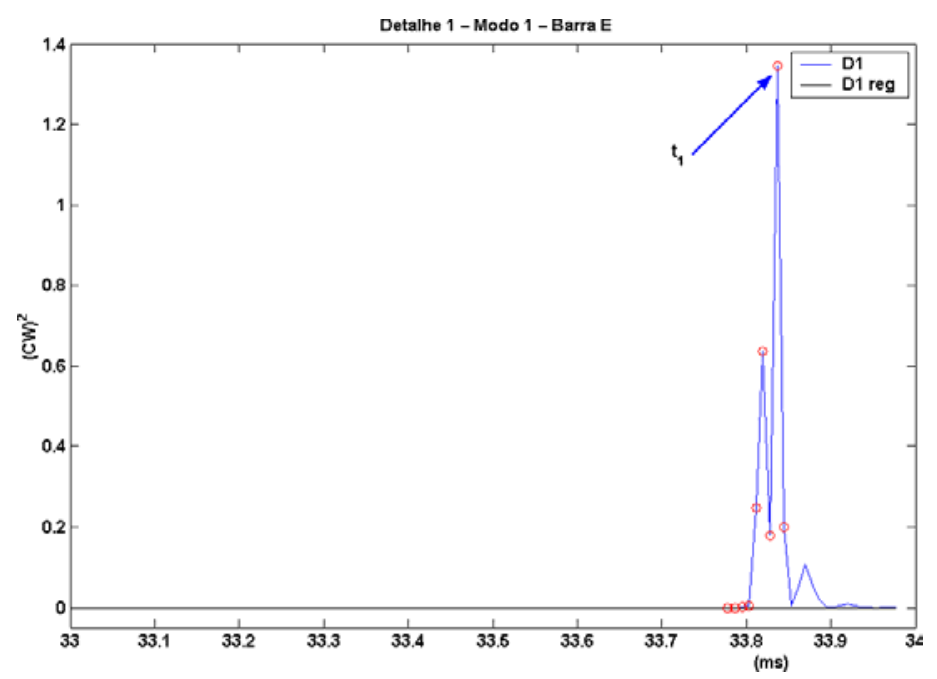


Após o instante de detecção, foram consideradas mais oito amostras consecutivas, após a análise da primeira amostra, perfazendo um conjunto de nove amostras. E dentro deste, o instante T1, ilustrado na Figura 40, está relacionado ao maior valor de pico desse conjunto. Para a falta-fase-terra em análise, o tempo de detecção retornado pelo algoritmo foi de 3 milissegundos.

O tempo de processamento para a sub-rotina de detecção, tanto para dados registrados em um como em ambos os terminais, corresponde unicamente ao tempo total necessário para a confirmação da situação de falta, ou seja, 3 milissegundos ou 0,18 ciclos do sinal em análise.

Por meio do procedimento ilustrado para faltas-fase-terra, o algoritmo detectou todos os 132 casos simulados. Além disso, deve ser salientado que, para todas as situações de faltas simuladas, tanto para dados registrados em um ou em dois terminais, obteve-se um índice de acerto de 100\%. Da correta definição de uma situação faltosa nessa fase, passa-se então à fase de classificação da falta.

\subsubsection{Classificação da Falta}

Após a confirmação da caracterização de uma situação de falta, descrita na seção anterior, dispõe-se de uma janela de dados correspondendo a dez milissegundos, ou seja, 0,6 ciclos, a qual contém os fasores de corrente para a etapa de classificação da falta. O tempo de processamento para essa sub-rotina corresponde ao tempo total da janela de dados empregada.

Alguns exemplos estão ilustrados na Figura 41 para a classificação de diferentes tipos de faltas aplicadas a uma distância de $190 \mathrm{~km}$ do barramento $E$, com ângulo de incidência de $0^{\circ}$, para a configuração da linha em circuito simples horizontal. O método empregado foi baseado na comparação entre fasores sobrepostos de fase e de seqüência zero da corrente $I_{a}^{\prime \prime}, I_{b}^{\prime \prime}, I_{c}^{\prime \prime}$ e $I_{0}^{\prime \prime}$.

A situação de falta-fase-terra (A-terra) foi corretamente classificada pelo algoritmo devido às seguintes características:

como o valor do fasor da corrente $I_{a}^{\prime \prime}$ é maior que 0,6 , ele é considerado faltoso;

a presença de componente zero $\left(I_{0}^{\prime \prime}>I_{\min }\right)$ indica que a falta envolve terra;

como os valores dos demais fasores de corrente $I_{b}^{\prime \prime}$ e $I_{c}^{\prime \prime}$ são menores que 0,3 , eles são considerados não faltosos. 

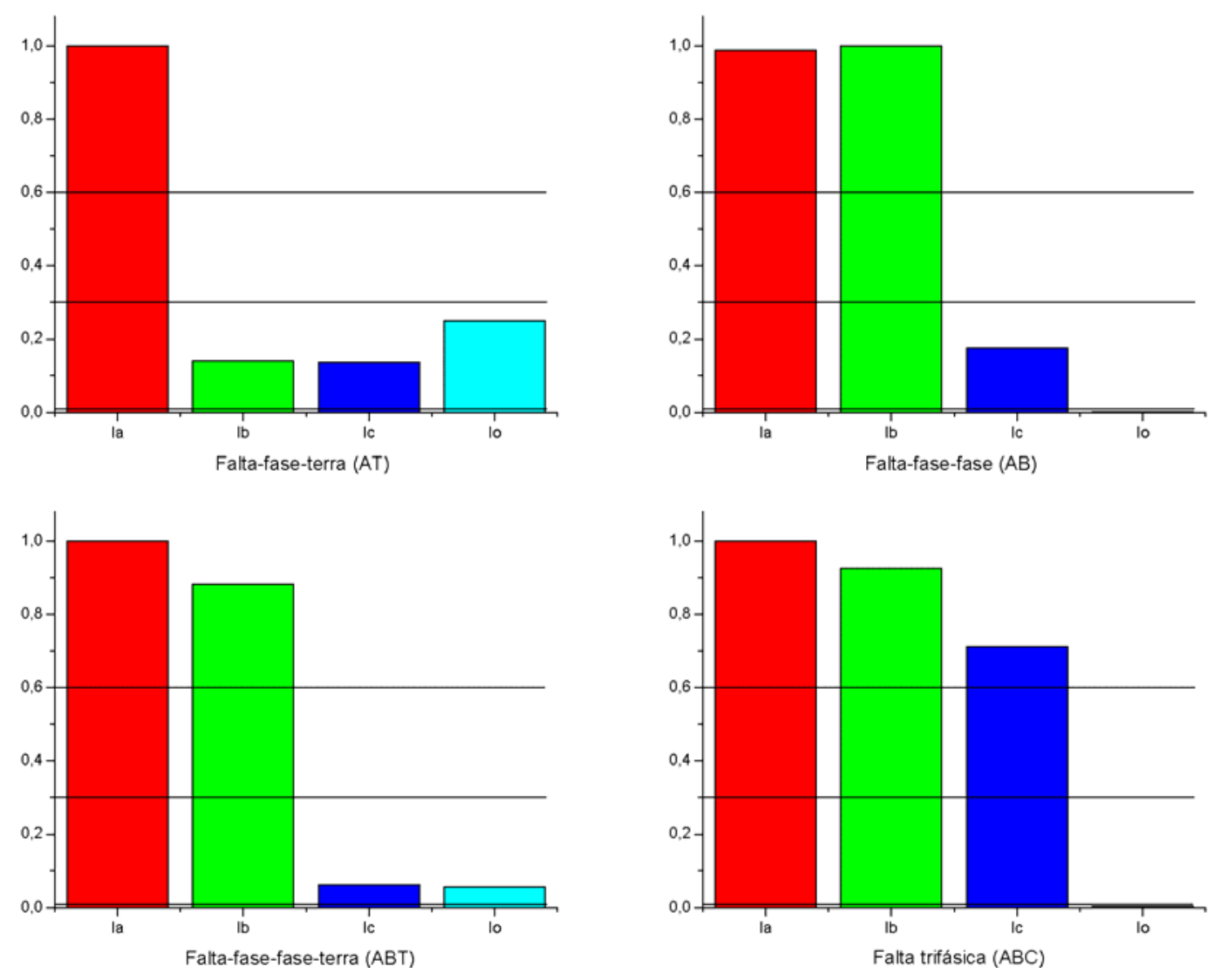

FIGURA 41 - Classificação dos diversos tipos de faltas

A situação de falta-fase-fase $(\mathrm{AB})$ foi corretamente classificada pelo algoritmo devido às seguintes características:

como os valores dos fasores das corrente $I_{a}^{\prime \prime}$ e $I_{b}^{\prime \prime}$ são maiores que 0,6 são considerados faltosos;

a ausência de componente zero $\left(I_{0}^{\prime \prime}<I_{\min }\right)$ indica que a falta não envolve terra; como o valor do fasor de corrente $I_{c}$ " é menor que 0,3 é considerado não faltoso. Os demais tipos de faltas seguem a mesma lógica anteriormente comentada.

Os testes demonstram que a sub-rotina de classificação foi capaz de classificar corretamente os dez tipos de faltas para todas as situações analisadas neste trabalho.

A próxima seção é dedicada à apresentação dos resultados obtidos pelo algoritmo de determinação das zonas de proteção para dados de um terminal. 


\subsubsection{Determinação das Zonas de Proteção}

Na técnica que utiliza dados provenientes do terminal local, após a detecção de uma situação de falta, procede-se à classificação da mesma conforme já apresentado (seção 5.3.5).

Sendo a situação caracterizada como uma falta-fase-fase-terra, fase-fase ou trifásica, o tempo de reflexão $t_{d}$ entre o ponto da falta e o terminal $E$ é obtido diretamente pela medida do intervalo de tempo entre os dois primeiros picos consecutivos dos sinais de detalhe 1 do modo 1 . Com essas informações, determina-se a zona de proteção dada pela eq.(5.9).

A Figura 42 mostra os sinais de detalhe 1 do modo 1 para uma falta-fase-fase, simulada a $170 \mathrm{~km}$ da barra $E$, com ângulo de incidência de $90^{\circ}$.

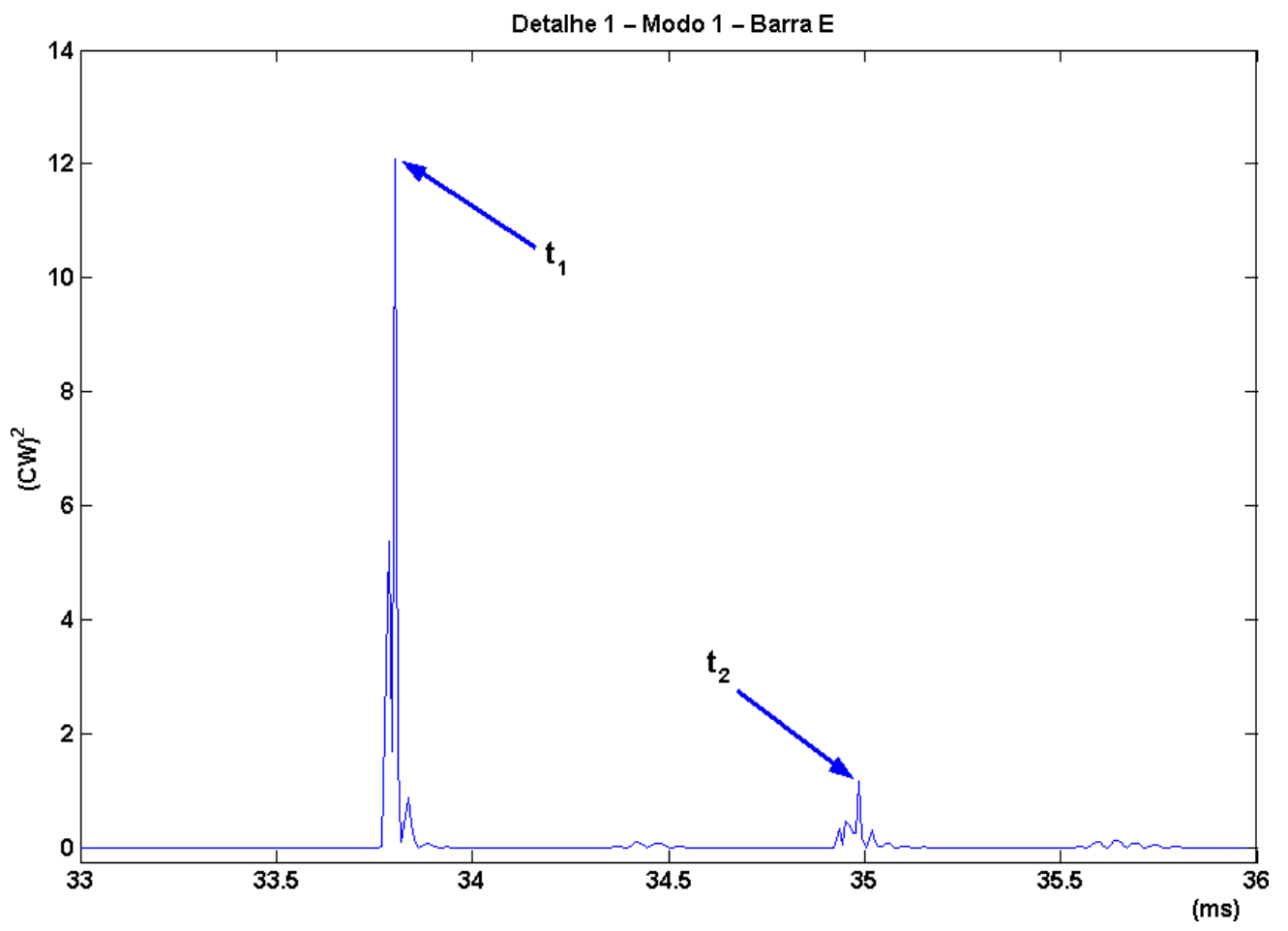

FIGURA 42 - Coeficientes wavelets para uma falta-fase-fase(AB) a $170 \mathrm{~km}$ da barra E, com ângulo de incidência de $90^{\circ}$

Nesse caso, temos que o intervalo do tempo $\left(t_{d}=t_{2}-t_{1}\right)$ entre os dois primeiros picos consecutivos dos CWs para a falta simulada na Figura 42 é igual a $1,183 \times 10^{-3} \mathrm{~s}$. Substituindo na eq.(5.9), temos que o algoritmo reconheceu que a falta está alocada na zona de proteção secundária: 


$$
\begin{gathered}
t_{p z p}=4,216 \times 10^{-4} s, \quad t_{s z p}=6,324 \times 10^{-4} s \text { e } t_{d}=1,183 \times 10^{-3} s \\
\frac{t_{d}}{2}=5,915 \times 10^{-4} s \\
\text { Logo, temos que: } \\
\left(5,915 \times 10^{-4} \mathrm{~s}>4,216 \times 10^{-4} \mathrm{~s}\right) \mathrm{e} \\
\left(5,915 \times 10^{-4} \mathrm{~s} \leq 6,324 \times 10^{-4} \mathrm{~s}\right) \Leftrightarrow \text { Falta na zona secundária }
\end{gathered}
$$

No equacionamento apresentado, observa-se a divisão de $t_{d}$ por 2 , uma vez que queremos o tempo de reflexão entre o terminal local e o ponto de falta.

Como informação adicional, realizou-se o cálculo da distância estimada da falta pela eq.(5.11), obtendo-se o valor de $\mathrm{d}=173,39 \mathrm{~km}$.

Nas Tabelas de 8 a 11, são apresentados os resultados obtidos pelo algoritmo de determinação das zonas de proteção referentes às situações de faltas que envolvem duas e três fases sem conexão com a terra. Os parâmetros que compõem essas tabelas são os seguintes:

a) distância real: representa o ponto exato da aplicação da situação de falta sobre o sistema, com relação ao barramento $E$;

b) ângulo de incidência da falta: indica o ângulo de inserção da mesma;

c) classificação do tipo de falta: expressa o envolvimento das fases presentes no distúrbio;

d) distância estimada: está relacionada com a localização da falta estimada pelo algoritmo;

e) erro relativo ou percentual: calculado conforme a eq.(6.1);

f) determinação da zona de proteção: em função da localização da falta, determinamse as zonas de proteção;

g) erro médio total: calculado conforme a eq.(6.2), para as situações de faltas. Esse valor encontra-se na parte inferior das tabelas.

Para faltas com conexão com a terra, adiciona-se às tabelas mais um item, denominado resistência de falta. 
Para ilustrar a boa precisão alcançada na localização das zonas de proteção pelo algoritmo, apresenta-se a Tabela 8, onde, por exemplo, se pode observar que a décima primeira linha representa uma situação de falta-fase-fase (AB), alocada a $130 \mathrm{~km}$ da barra $E$ com ângulo de incidência de $0^{\circ}$. A distância estimada pelo algoritmo foi de 129,43 km, distância esta que incidiu sobre a zona de proteção secundária. Essa distância representa um erro percentual de $0,32 \%$. O algoritmo alocou corretamente a zona de proteção.

Da análise dos resultados obtidos nas Tabelas de 8 a 11, observa-se a boa precisão do algoritmo, com exceção das últimas linhas dessas tabelas, as quais se referem a situações que estão fora da área de cobertura do relé, indicado pelo índice 0 . Com exceção dessas últimas linhas, o algoritmo determinou corretamente as zonas de proteção para as demais situações de faltas simuladas.

Os piores erros registrados foram de 3,89\% e 3,30\% para ângulos de incidência de $90^{\circ}$. Esses erros são devidos a imprecisões do algoritmo em detectar o segundo pico de reflexão, por estar muito atenuado. Mesmo apresentando pequenas imprecisões, eles não influenciaram na determinação das zonas de proteção.

Observa-se que os erros médios totais ficaram abaixo de 1,52\% para os resultados apresentados. Verifica-se também que o melhor índice obtido foi para a situação de falta-fase-fase (AB), com ângulo de incidência de falta de $0^{\circ}$, com um erro médio total de $1,27 \%$.

Verifica-se nas tabelas que o erro percentual ficou abaixo de $2,0 \%$ para a maioria dos casos analisados. Para os poucos casos que excederam esse valor, o erro percentual ficou abaixo de 4,0\%, sendo que o algoritmo também determinou corretamente as respectivas zonas de proteção. 
TABELA 8 -Faltas-fase-fase (AB), com ângulo de incidência de falta de $0^{0}$

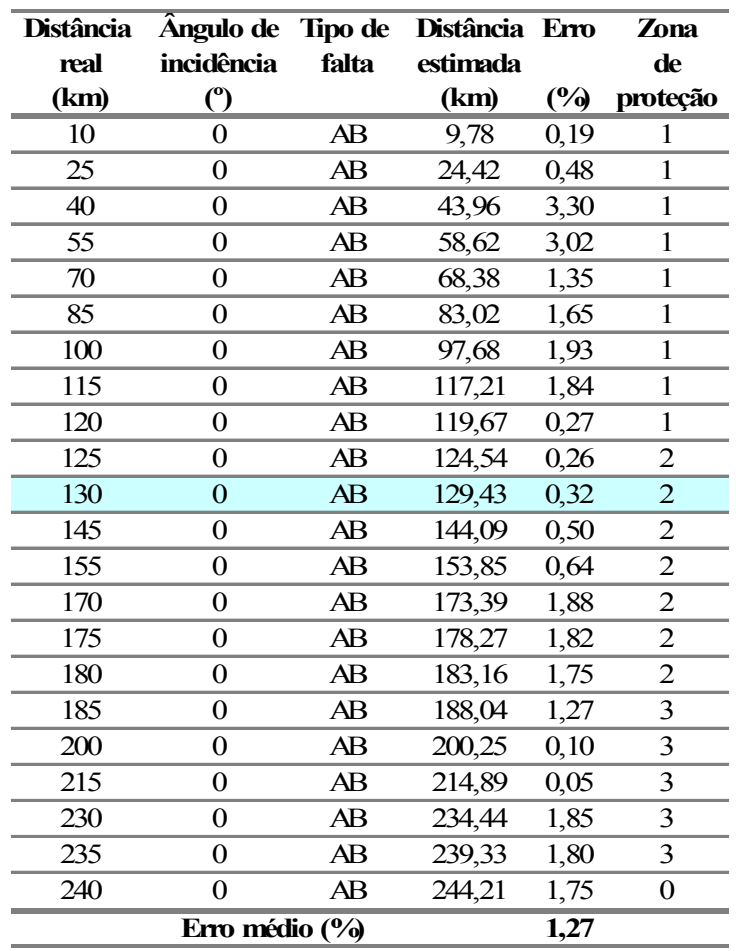

TABELA 10 - Faltas trifásicas $(A B C)$, com ângulo de incidência de falta de $0^{0}$

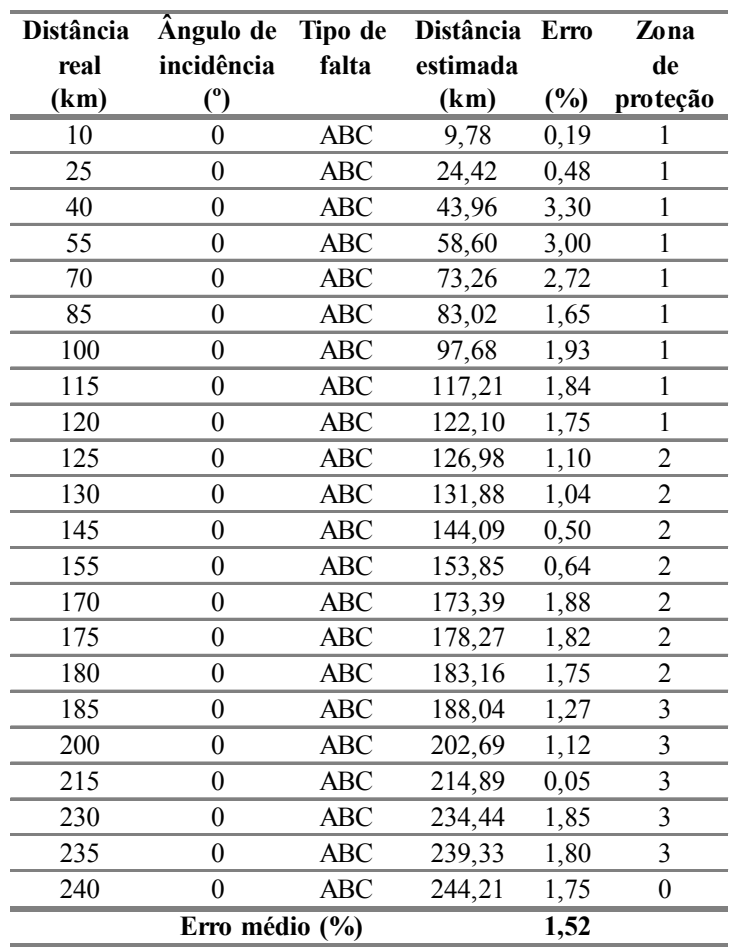

TABELA 9 - Faltas-fase-fase (AB), com ângulo de incidência de falta de $90^{\circ}$

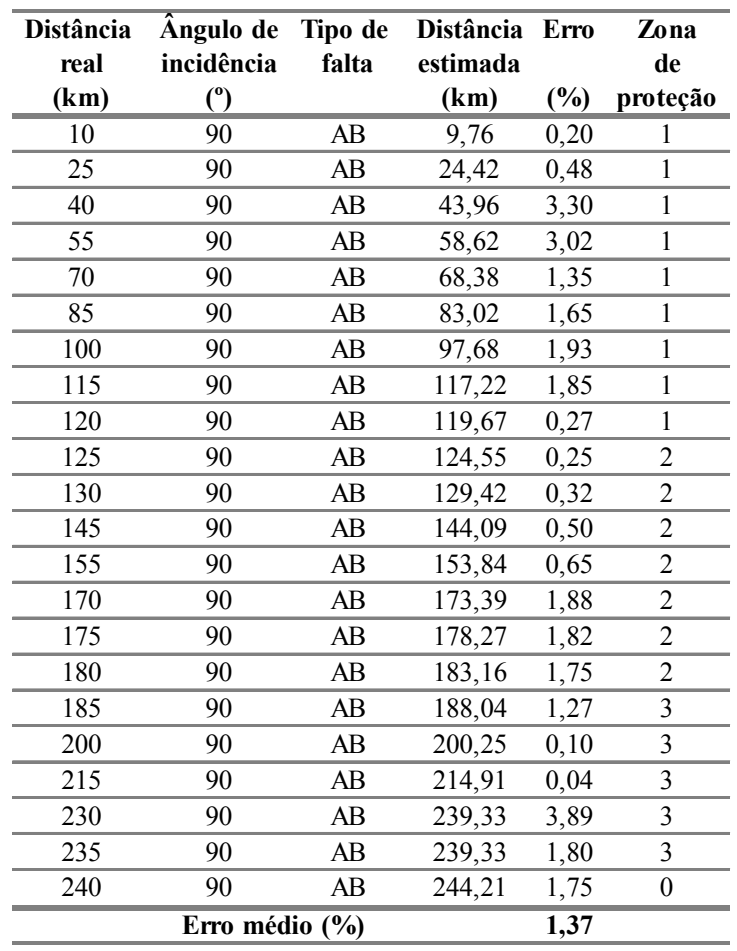

TABELA 11 - Faltas trifásicas $(A B C)$, com ângulo de incidência de falta de $90^{\circ}$

\begin{tabular}{|c|c|c|c|c|c|}
\hline $\begin{array}{c}\text { Distância } \\
\text { real } \\
(\mathbf{k m})\end{array}$ & $\begin{array}{c}\text { Ângulo de } \\
\text { incidência } \\
\left({ }^{\circ}\right)\end{array}$ & $\begin{array}{c}\text { Tipo de } \\
\text { falta }\end{array}$ & $\begin{array}{c}\text { Distância } \\
\text { estimada } \\
\quad(\mathbf{k m})\end{array}$ & $\begin{array}{l}\text { Erro } \\
(\%)\end{array}$ & $\begin{array}{c}\text { Zona } \\
\text { de } \\
\text { proteção }\end{array}$ \\
\hline 10 & 90 & $\mathrm{ABC}$ & 9,76 & 0,20 & 1 \\
\hline 25 & 90 & $\mathrm{ABC}$ & 24,42 & 0,48 & 1 \\
\hline 40 & 90 & $\mathrm{ABC}$ & 43,96 & 3,30 & 1 \\
\hline 55 & 90 & $\mathrm{ABC}$ & 58,62 & 3,02 & 1 \\
\hline 70 & 90 & $\mathrm{ABC}$ & 68,38 & 1,35 & 1 \\
\hline 85 & 90 & $\mathrm{ABC}$ & 83,02 & 1,65 & 1 \\
\hline 100 & 90 & $\mathrm{ABC}$ & 97,68 & 1,93 & 1 \\
\hline 115 & 90 & $\mathrm{ABC}$ & 117,22 & 1,85 & 1 \\
\hline 120 & 90 & $\mathrm{ABC}$ & 122,10 & 1,75 & 1 \\
\hline 125 & 90 & $\mathrm{ABC}$ & 124,55 & 0,25 & 2 \\
\hline 130 & 90 & $\mathrm{ABC}$ & 129,42 & 0,32 & 2 \\
\hline 145 & 90 & $\mathrm{ABC}$ & 144,09 & 0,50 & 2 \\
\hline 155 & 90 & $\mathrm{ABC}$ & 153,84 & 0,65 & 2 \\
\hline 170 & 90 & $\mathrm{ABC}$ & 173,39 & 1,88 & 2 \\
\hline 175 & 90 & $\mathrm{ABC}$ & 178,27 & 1,82 & 2 \\
\hline 180 & 90 & $\mathrm{ABC}$ & 183,16 & 1,75 & 2 \\
\hline 185 & 90 & $\mathrm{ABC}$ & 188,04 & 1,27 & 3 \\
\hline 200 & 90 & $\mathrm{ABC}$ & 200,25 & 0,10 & 3 \\
\hline 215 & 90 & $\mathrm{ABC}$ & 214,91 & 0,04 & 3 \\
\hline 230 & 90 & $\mathrm{ABC}$ & 239,33 & 3,89 & 3 \\
\hline 235 & 90 & $\mathrm{ABC}$ & 239,33 & 1,80 & 3 \\
\hline 240 & 90 & $\mathrm{ABC}$ & 244,21 & 1,75 & 0 \\
\hline \multicolumn{4}{|c|}{ Erro médio (\%) } & 1,43 & \\
\hline
\end{tabular}


No caso de faltas-fase-terra, como explicitado anteriormente, é necessário que haja uma pré-localização da falta, ou seja, determinar se a falta ocorreu na primeira ou na segunda metade da linha, entre os barramentos $E$ e $G$. O que ocorre é que, para essas situações de faltas, podem-se encontrar padrões similares de reflexão (mesmo tempo de reflexão) e, para se evitar localizações incorretas, dependendo da metade da linha em questão, equacionamentos distintos devem ser considerados. Tais situações são ilustradas considerando a ocorrência de duas faltas, uma a $60 \mathrm{~km}$ da barra $E$ (primeira metade) e a outra a $190 \mathrm{~km}$ da barra $E$ (segunda metade), lembrando que o comprimento dessa linha limitada pelos barramentos é de $250 \mathrm{~km}$.

Situação 1: falta-fase A-terra a $60 \mathrm{~km}$ da barra $E$.

Considerando-se a falta classificada e pré-localizada na primeira metade da linha, o tempo $t_{d}$ é extraído através dos dois primeiros picos consecutivos do sinal de detalhe 1 do modo 1, conforme Figura 43. Para esse exemplo, o intervalo do tempo $\left(t_{d}=\right.$ $t_{2}-t_{1}$ ) é igual a $4,33 \times 10^{-4} \mathrm{~s}$, o qual é substituído na eq.(5.9), temos que o algoritmo reconheceu que a falta está alocada na zona de proteção primária. Como informação adicional, realizou-se o cálculo da distância estimada da falta pela eq.(5.11), obtendo-se o valor de $\mathrm{d}=63,49 \mathrm{~km}$.
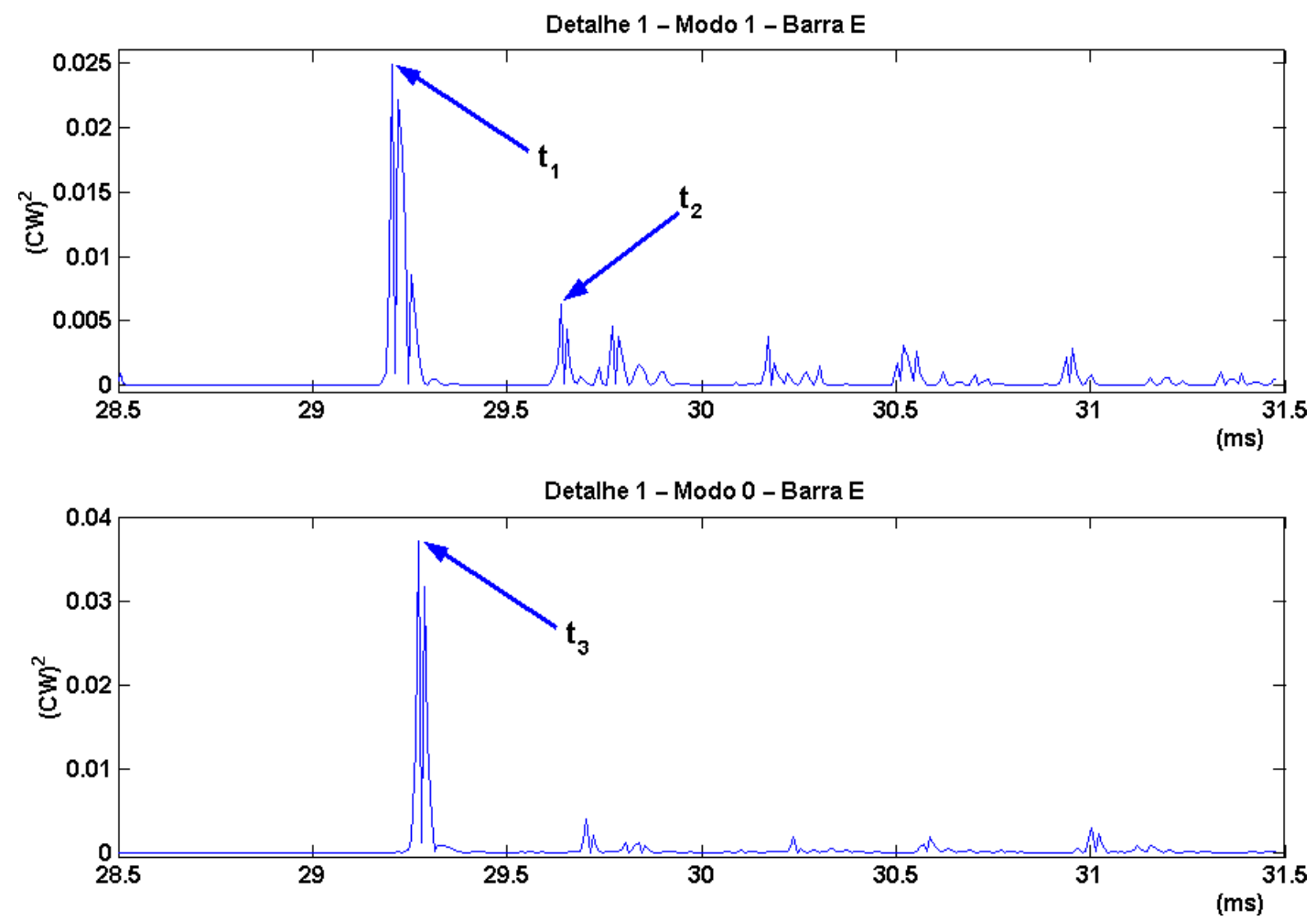

FIGURA 43 - Coeficientes wavelets para uma falta-fase A-terra a $60 \mathrm{~km}$ da barra E, com ângulo de incidência de $0^{\circ}$ e resistência de falta de $0,1 \Omega$ 
Situação 2: falta-fase A-terra à $190 \mathrm{~km}$ da barra $E$.

Análogo à situação 1 , encontramos $t_{d}=4,17 \times 10^{-4} \mathrm{~s}$ por meio dos dois primeiros picos consecutivos do sinal de detalhe 1 do modo 1, conforme Figura 44. Entretanto, para faltas-fase-terra na segunda metade da linha, a determinação da zona de proteção é dada pela eq.(5.10). Para esse exemplo, temos que a falta está alocada na zona de proteção terciária. Como informação adicional, realizou-se o cálculo da distância estimada da falta através da eq.(5.12), obtendo-se o valor de $\mathrm{d}=185,95 \mathrm{~km}$.

É importante observar que os valores de $t_{d}$ para as situações 1 e 2 são similares, o que ratifica a necessidade da pré-localização da falta para se estimar de maneira correta a determinação da zona de proteção.
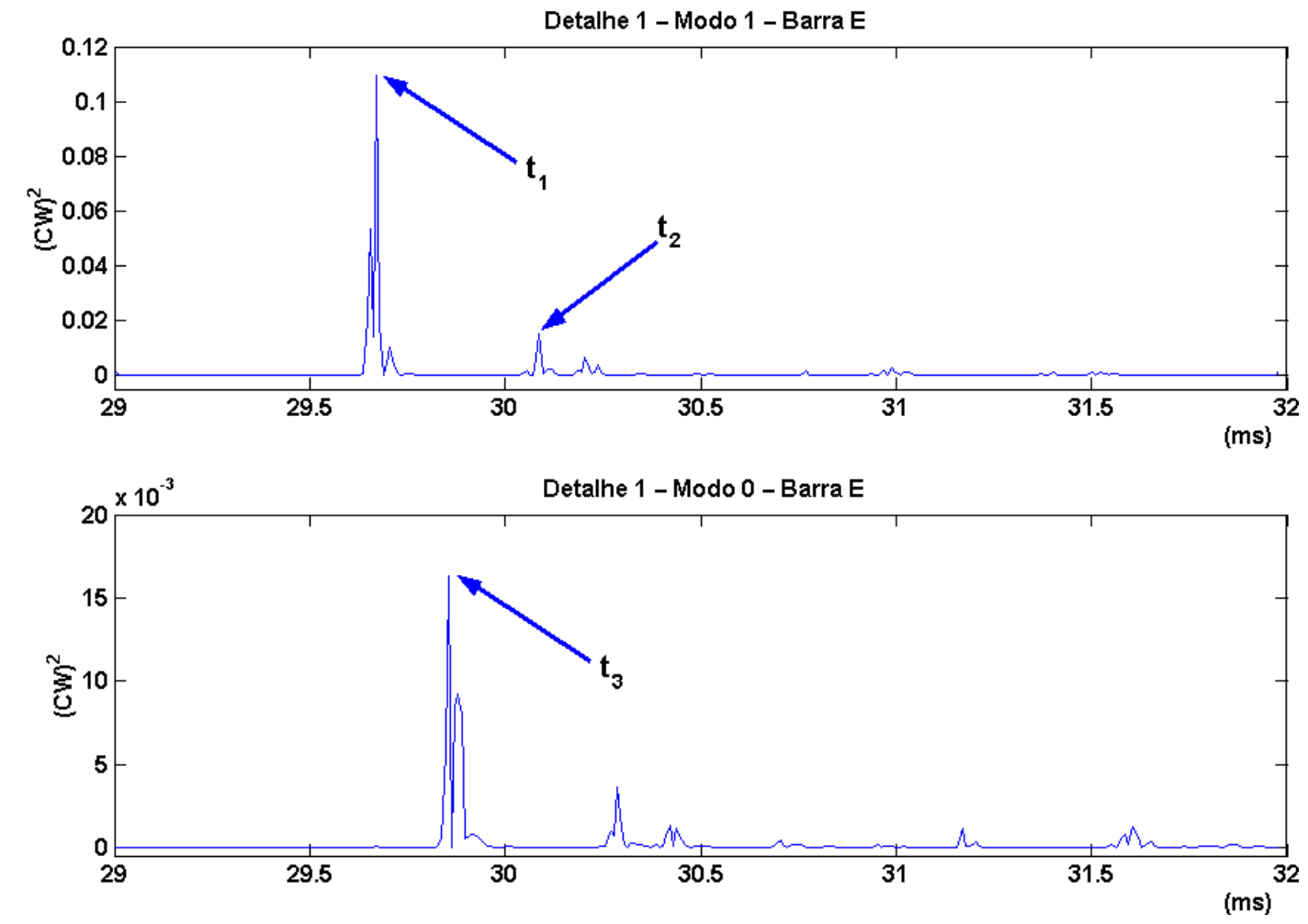

FIGURA 44 - Coeficientes wavelets para uma falta-fase A-terra a $190 \mathrm{~km}$ da barra E, com ângulo de incidência de $0^{\circ}$ e resistência de falta de $0,1 \Omega$

De um modo geral, pode-se concluir que a sub-rotina de determinação das zonas de proteção, trabalhando com dados provenientes de um terminal, apresentou bons resultados. Denota-se também pelos testes realizados que a distância da falta não influencia significantemente na precisão dessa técnica.

O tempo de processamento para a sub-rotina de determinação das zonas de proteção, tanto para dados de um como de ambos os terminais, conforme também será 
evidenciado posteriormente, corresponde unicamente ao tempo total da janela de dados empregada, ou seja, 3 milissegundos ou 0,18 ciclos do sinal em análise. empregada, ou seja, 3 milissegundos ou 0,18 ciclos do sinal em análise.

\subsubsection{Influência dos diferentes tipos de falta}

Com o objetivo de verificar a influência do tipo da falta no desempenho dessa técnica, foram realizados alguns testes. A Figura 45 ilustra algumas situações de faltasfase-terra $(\mathrm{AT})$, fase-fase-terra $(\mathrm{ABT})$, fase-fase $(\mathrm{AB})$ e trifásicas $(\mathrm{ABC})$, com ângulo de incidência de $90^{\circ}$ e resistência de falta de $0,1 \Omega$.

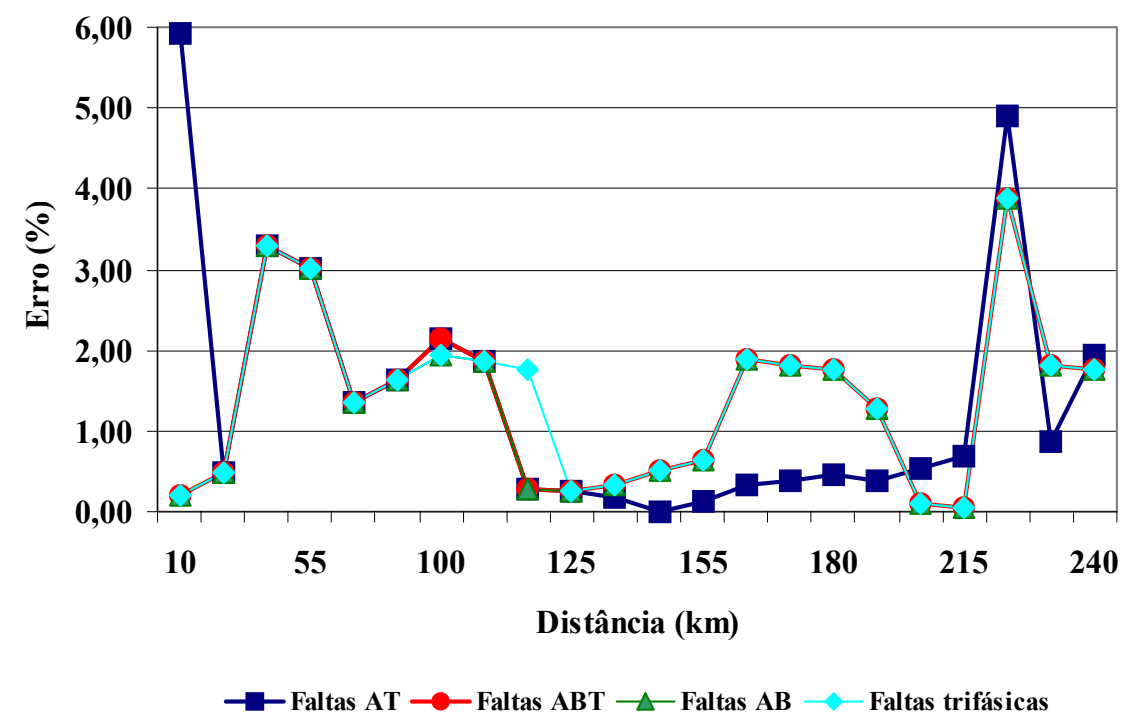

FIGURA 45 - Influência do tipo da falta na precisão do algoritmo

Observa-se na Figura 45 que grande parte dos erros percentuais foram inferiores a 2,0 \%. Para os poucos casos que excederam esse valor, o erro percentual ficou abaixo de 6,0\%. Nota-se também que, nesses casos apresentados, a falta-fase-terra apresentou uma menor precisão e que o algoritmo se comportou um pouco melhor para as demais situações de faltas.

Pelos testes realizados e resultados obtidos, observa-se que os erros introduzidos pelos diferentes tipos de faltas não afetam a validade e a confiabilidade da técnica de determinação das zonas de proteção utilizada. 


\subsubsection{Influência do ângulo de incidência da falta}

Testes foram realizados com o objetivo de verificar a influência do ângulo de incidência da falta no desempenho do algoritmo. Os valores de ângulo de incidência da falta utilizados foram de $0,45,70$ e $90^{\circ}$. A Figura 46 ilustra alguns casos de falta-fasefase $(\mathrm{AB})$ com diferentes ângulos de incidência de falta.

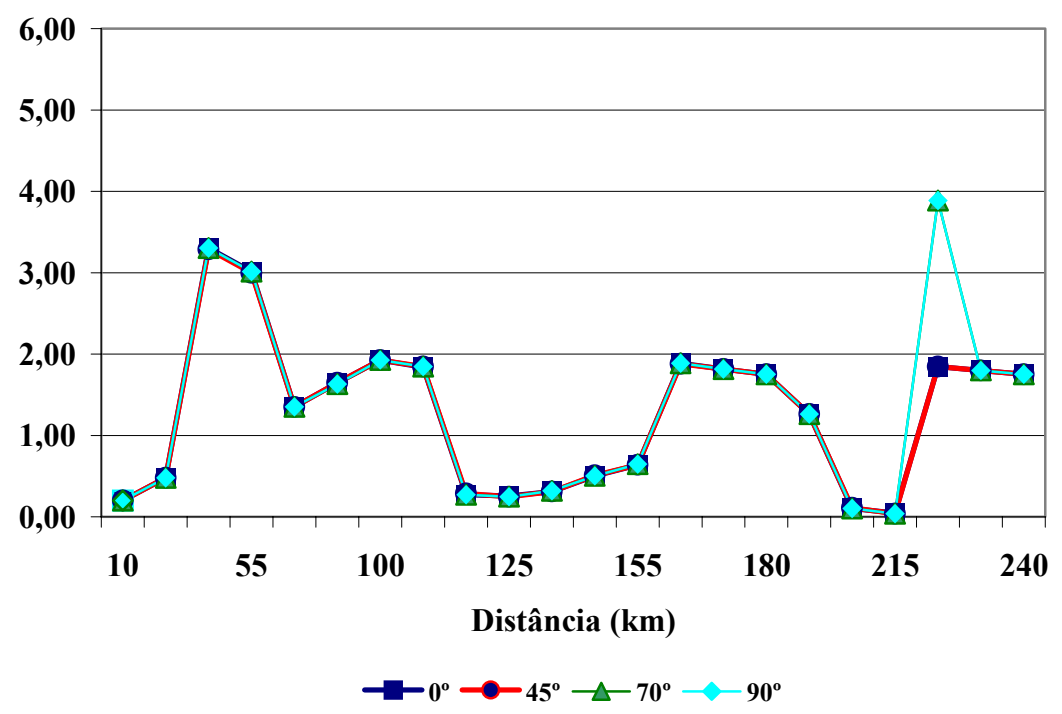

FIGURA 46 - Influência do ângulo de incidência da falta para faltas-fase-fase

Pela Figura 46 observa-se que a técnica de determinação com dados provenientes de um terminal não sofre influência significativa devido à variação do ângulo de incidência da falta, permanecendo a maioria dos resultados dentro de uma faixa de erro de 2,0\%. Nota-se também que, nesses casos apresentados, os ângulos de incidência de 70 e $90^{\circ}$ apresentaram uma menor precisão, contrária a uma melhor condição para ângulos de incidência de 0 e $45^{\circ}$. 


\subsubsection{Influência da Resistência de Falta}

Testes foram realizados utilizando valores de resistência de falta de 0,1, 50, 100, 200 e $400 \Omega$. A Figura 47 ilustra alguns casos de faltas-fase-fase-terra (ABT) com ângulo de incidência de $0^{\circ}$ e diferentes resistências de falta.

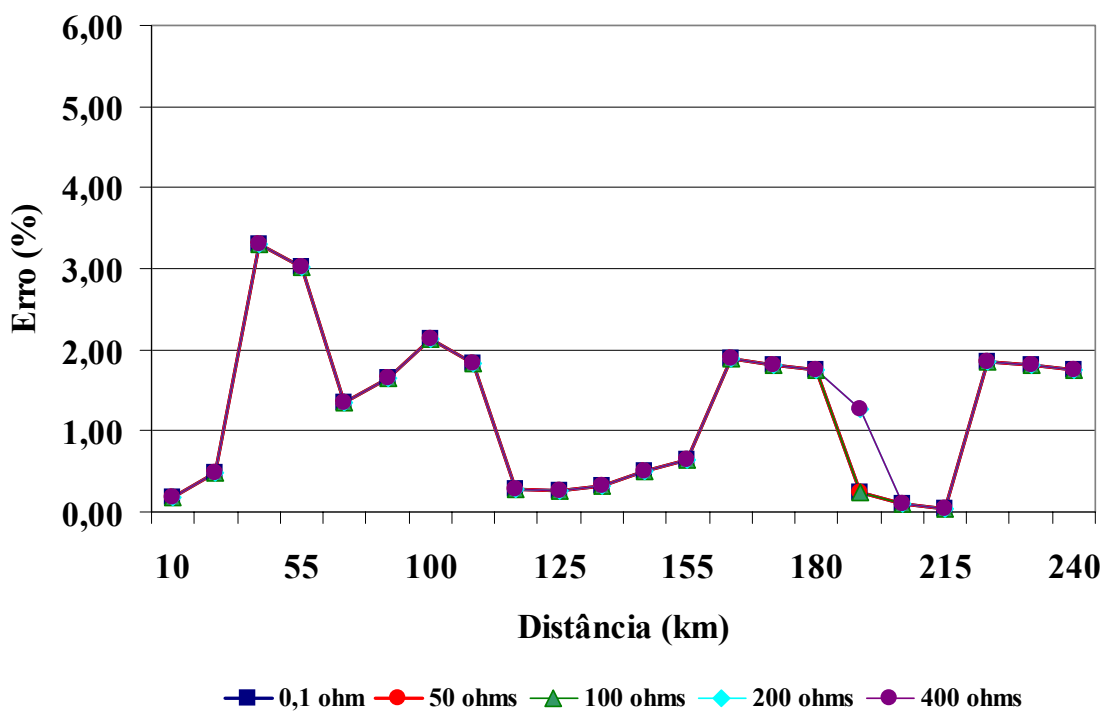

FIGURA 47 - Influência da resistência de falta para faltas-fase-fase-terra (ABT)

Observa-se que a técnica de determinação das zonas de proteção não sofre influência significativa devido à resistência de falta, permanecendo a maioria dos resultados dentro de uma faixa de erro de $2,0 \%$. Percebe-se que não se notou variação na precisão do algoritmo para as situações de faltas associadas com altas resistências de faltas tais como: 100, 200 e $400 \Omega$. 


\subsection{Resultados Alcançados Utilizando-se Dados Provenientes de Dois Terminais}

\subsubsection{Detecção da Falta}

Assumindo o registro dos sinais de tensão em ambos os barramentos $E$ e $G$ com a correta sincronização por GPS, uma falta-fase-terra é simulada a $100 \mathrm{~km}$ do barramento $E$, mostrada na Figura 26, com um ângulo de incidência de $90^{\circ}$ e resistência de falta de $100 \Omega$.

A Figura 48 ilustra a chegada das primeiras ondas de tensão em ambos os terminais da linha revelada pelos sinais de detalhe 1 , referentes ao modo aéreo 1 para a situação de falta simulada.
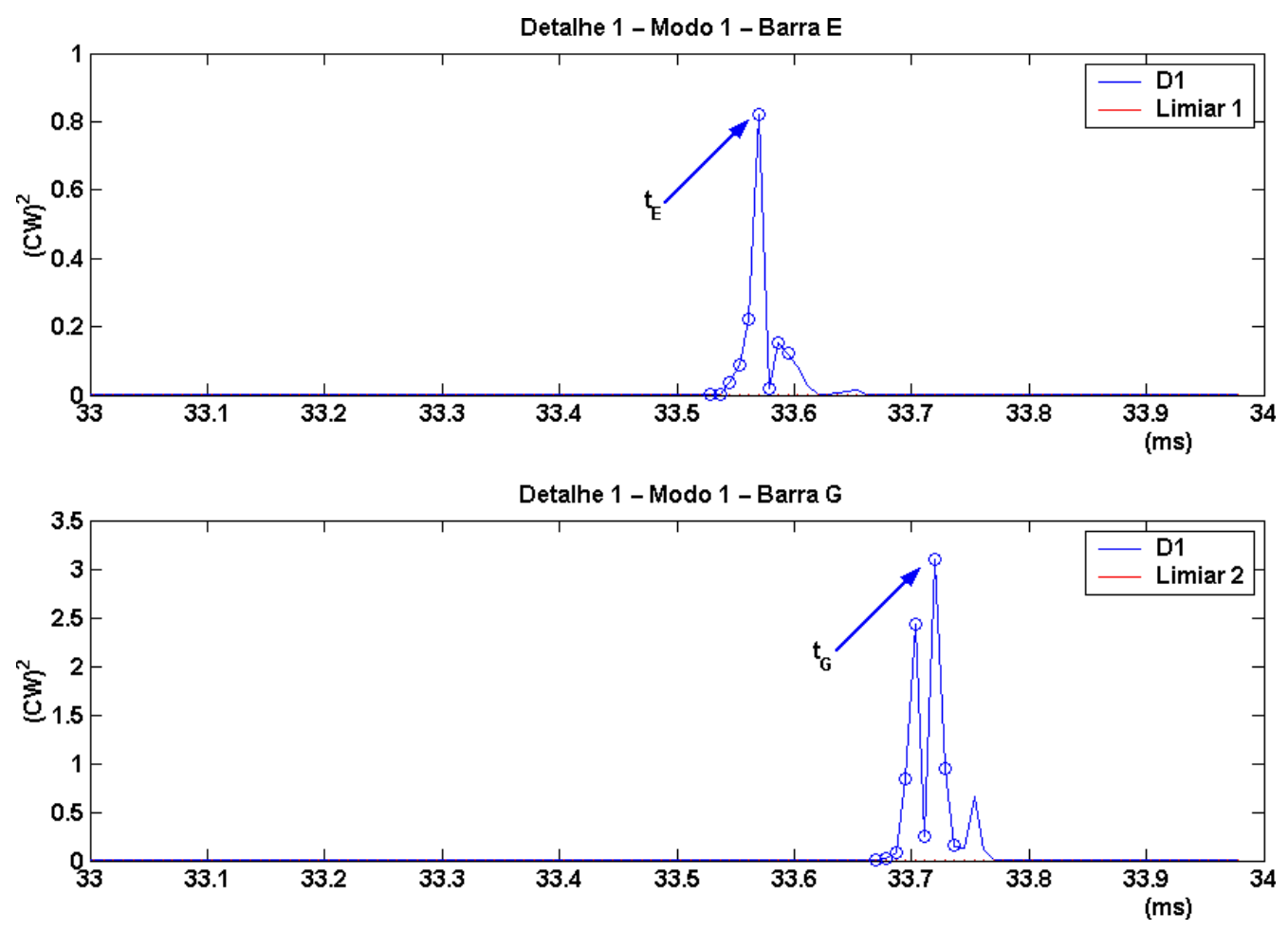

FIGURA 48 - Exemplo de detecção dos picos iniciais

Com base nas informações contidas nos sinais sob análise das barras $E$ e $G$, foram obtidos os dados apresentados na Tabela 12. No cálculo da média do sinal de entrada e de referência, foram considerados os valores absolutos dos sinais. 
TABELA 12 - Detecção de falta-fase-terra

\begin{tabular}{|c|c|c|c|c|c|c|c|c|}
\hline \multirow{3}{*}{$\begin{array}{c}\text { Núm. } \\
\text { da } \\
\text { janela }\end{array}$} & \multicolumn{4}{|c|}{ Barra E } & \multicolumn{4}{|c|}{ Barra G } \\
\hline & \multicolumn{2}{|c|}{ Média do sinal de } & \multirow{2}{*}{$\begin{array}{l}\text { Razão } \\
\text { Médias }\end{array}$} & \multirow{2}{*}{$\begin{array}{c}\text { Confirma } \\
\text { falta }\end{array}$} & \multicolumn{2}{|c|}{ Média do sinal de } & \multirow{2}{*}{$\begin{array}{l}\text { Razão } \\
\text { Médias }\end{array}$} & \multirow{2}{*}{$\begin{array}{c}\text { Confirma } \\
\text { falta }\end{array}$} \\
\hline & Entrada & Referência & & & Entrada & Referência & & \\
\hline 1 & $1,960 \times 10^{-4}$ & $1,961 \times 10^{-4}$ & 0,9829 & 0 & $2,247 \times 10^{-4}$ & $2,209 \times 10^{-4}$ & 1,0173 & 0 \\
\hline 2 & $3,675 \times 10^{-4}$ & $3,674 \times 10^{-4}$ & 1,0005 & 0 & $1,941 \times 10^{-4}$ & $1,966 \times 10^{-4}$ & 0,9874 & 0 \\
\hline 3 & $6,537 \times 10^{-4}$ & $6,428 \times 10^{-4}$ & 1,0170 & 0 & $4,210 \times 10^{-4}$ & $4,210 \times 10^{-4}$ & 1,0010 & 0 \\
\hline$\vdots$ & $\vdots$ & $\vdots$ & $\vdots$ & $\vdots$ & $\vdots$ & $\vdots$ & $\vdots$ & $\vdots$ \\
\hline 66 & $3,386 \times 10^{-4}$ & $3,358 \times 10^{-4}$ & 1,0084 & 0 & $4,061 \times 10^{-4}$ & $4,016 \times 10^{-4}$ & 1,0113 & 0 \\
\hline 67 & $3,353 \times 10^{-2}$ & $2,575 \times 10^{-4}$ & 130,21 & 1 & $6,934 \times 10^{-2}$ & $2,736 \times 10^{-4}$ & 253,39 & 1 \\
\hline 68 & $5,688 \times 10^{-2}$ & $1,684 \times 10^{-4}$ & 337,86 & 2 & $1,394 \times 10^{-2}$ & $2,004 \times 10^{-4}$ & 695,87 & 2 \\
\hline 69 & $5,429 \times 10^{-2}$ & $4,395 \times 10^{-4}$ & 124,96 & 3 & $1,093 \times 10^{-2}$ & $2,578 \times 10^{-4}$ & 423,92 & 3 \\
\hline 70 & $5,439 \times 10^{-2}$ & $7,009 \times 10^{-4}$ & 77,589 & 4 & $9,305 \times 10^{-2}$ & $5,222 \times 10^{-4}$ & 178,19 & 4 \\
\hline 71 & $4,373 \times 10^{-2}$ & $8,890 \times 10^{-4}$ & 49,184 & 5 & $8,585 \times 10^{-2}$ & $7,748 \times 10^{-4}$ & 110,81 & 5 \\
\hline 72 & $3,306 \times 10^{-2}$ & $1,050 \times 10^{-3}$ & 31,495 & 6 & $6,014 \times 10^{-2}$ & $9,201 \times 10^{-3}$ & 65,364 & 6 \\
\hline
\end{tabular}

Como esperado, as razões entre os sinais assumiram valores menores que 1,7 para os períodos que precedem a falta. No entanto, quando as janelas de análise englobaram parte da falta (janela 67), variações ocorreram nas médias dos sinais de entrada, tanto da barra $E$ quanto da barra $G$, indicando a presença da falta, uma vez que se superou o valor de 1,7 , utilizado para diferenciação entre regime permanente e sinal com alguma anomalia.

Através da Tabela 12, observa-se também que, obtendo-se os instantes de detecção das faltas em ambas as barras (janela 67), foram inicializadas as variáveis de confirmação da real situação de falta. Como as razões entre as médias assumiram valores maiores que 1,7 , as variáveis associadas foram incrementadas de uma unidade. Observa-se que, com a análise da janela de número 72 apresentada ao algoritmo, as variáveis de confirmação atingem valores iguais a seis unidades em ambas as barras, vindo a confirmar uma real situação de falta. Os valores dessas variáveis correspondem ao tempo total de $3 \mathrm{~ms}$, (seção 5.3.4). Esse tempo total, correspondente a seis janelas de dados de $1 \mathrm{~ms}$, com passo de $0,5 \mathrm{~ms}$, é necessário para a confirmação da situação de falta em ambas as barras. Com base nessas informações, a sub-rotina de detecção é encerrada.

Após o instante de detecção em ambas as barras, foram consideradas mais oito amostras consecutivas, após a análise da primeira amostra, perfazendo um conjunto de nove amostras. Para a Figura 48, o primeiro maior pico dos CWs na barra $E$ ocorreu em $t_{E}=33,570 \mathrm{~ms}$ e, na barra $G$ em $t_{G}=33,720 \mathrm{~ms}$. Logo, $t_{d}=0,1499 \mathrm{~ms}$. Substituindo $t_{d}$ na eq.(5.14), temos que a distância estimada é igual a 103,03 km. 
Através do procedimento ilustrado para faltas-fase-terra, o algoritmo detectou todos os 132 casos simulados, possibilitando as análises posteriores no que dizem respeito à classificação e a determinação das zonas de proteção.

\subsubsection{Determinação das Zonas de Proteção}

Em busca de uma melhor visualização e análise dos resultados obtidos por essa técnica, os resultados serão apresentados por meio de gráficos, os quais seguem os mesmos padrões dos resultados apresentados anteriormente.

As Tabelas de 13 a 16 apresentam os resultados obtidos pelo algoritmo de determinação das zonas de proteção referentes às situações de faltas que envolvem duas e três fases sem conexão com a terra.

Da análise dos resultados obtidos e apresentados nas Tabelas de 13 a 16, observa-se uma ótima precisão na localização das zonas de proteção do algoritmo para as situações de faltas sem envolvimento da terra. Além disso, observa-se um desempenho superior dessa técnica com relação à técnica de determinação com dados de um terminal. Com exceção das últimas linhas dessas tabelas, as quais se referem às situações de faltas alocadas fora da área de cobertura do relé, indicado pelo índice 0,0 algoritmo alocou corretamente as zonas de proteção para as demais situações de faltas simuladas.

Constata-se que os erros médios totais ficaram abaixo de 1,26\% para os resultados apresentados. Verifica-se também que o melhor índice obtido foi para a situação de falta-fase-fase (AB), com ângulo de incidência de falta de $0^{\circ}$, com um erro médio total de $1,08 \%$.

Verifica-se nas tabelas que a grande maioria dos erros foram inferiores a 3,0 \%. Para os poucos casos que excederam esse valor, o erro percentual ficou abaixo de 5,0\%. Mesmo apresentando esses índices, os mesmos não influenciaram na determinação das zonas de proteção.

De um modo geral, pode-se concluir que a sub-rotina de determinação das zonas de proteção, trabalhando com dados provenientes de dois terminais, apresentou resultados superiores quando comparados com a sub-rotina para dados de um terminal. 
TABELA 13 - Faltas-fase-fase (AB), com ângulo de incidência de falta de $0^{\circ}$

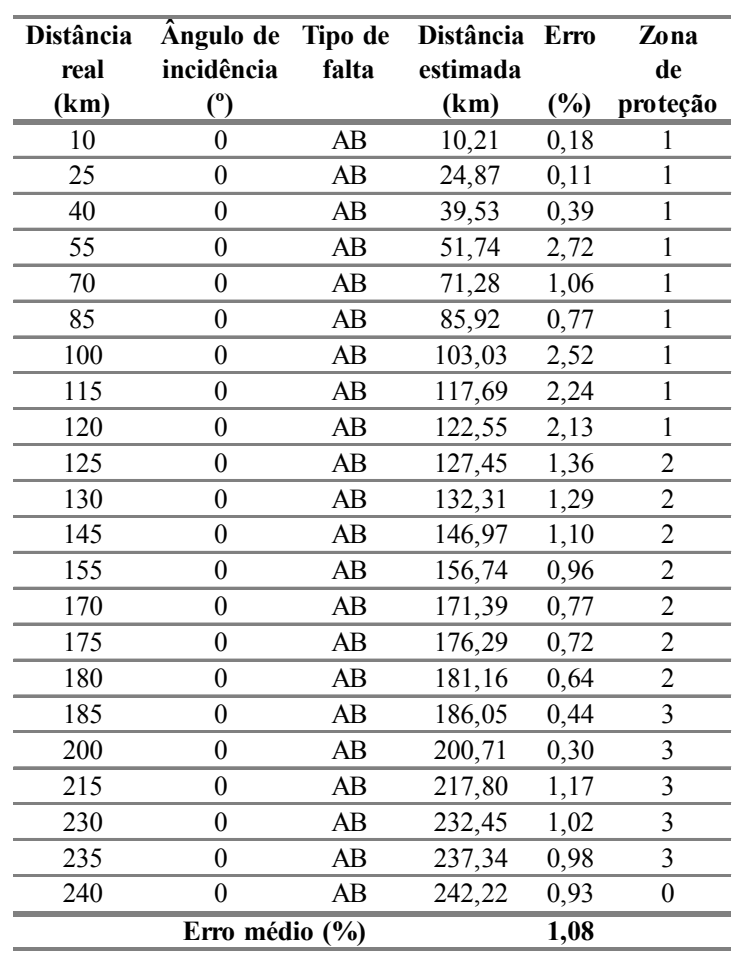

TABELA 15 - Faltas trifásicas (ABC), com ângulo de incidência de falta de $0^{\circ}$

\begin{tabular}{|c|c|c|c|c|c|}
\hline $\begin{array}{c}\text { Distância } \\
\text { real } \\
(\mathbf{k m})\end{array}$ & $\begin{array}{l}\text { Ângulo de } \\
\text { incidência } \\
\quad\left(^{\circ}\right)\end{array}$ & $\begin{array}{l}\text { Tipo de } \\
\text { falta }\end{array}$ & $\begin{array}{c}\text { Distância } \\
\text { estimada } \\
(\mathbf{k m})\end{array}$ & $\begin{array}{l}\text { Erro } \\
(\%)\end{array}$ & $\begin{array}{c}\text { Zona } \\
\text { de } \\
\text { proteção }\end{array}$ \\
\hline 10 & 0 & $\mathrm{ABC}$ & 10,21 & 0,18 & 1 \\
\hline 25 & 0 & $\mathrm{ABC}$ & 24,87 & 0,11 & 1 \\
\hline 40 & 0 & $\mathrm{ABC}$ & 39,53 & 0,39 & 1 \\
\hline 55 & 0 & $\mathrm{ABC}$ & 54,19 & 0,68 & 1 \\
\hline 70 & 0 & $\mathrm{ABC}$ & 66,40 & 3,00 & 1 \\
\hline 85 & 0 & $\mathrm{ABC}$ & 90,82 & 4,85 & 1 \\
\hline 100 & 0 & $\mathrm{ABC}$ & 103,03 & 2,52 & 1 \\
\hline 115 & 0 & $\mathrm{ABC}$ & 117,69 & 2,24 & 1 \\
\hline 120 & 0 & $\mathrm{ABC}$ & 122,55 & 2,13 & 1 \\
\hline 125 & 0 & $\mathrm{ABC}$ & 127,45 & 1,36 & 2 \\
\hline 130 & 0 & $\mathrm{ABC}$ & 132,31 & 1,29 & 2 \\
\hline 145 & 0 & $\mathrm{ABC}$ & 146,97 & 1,10 & 2 \\
\hline 155 & 0 & $\mathrm{ABC}$ & 156,74 & 0,96 & 2 \\
\hline 170 & 0 & $\mathrm{ABC}$ & 171,39 & 0,77 & 2 \\
\hline 175 & 0 & $\mathrm{ABC}$ & 176,29 & 0,72 & 2 \\
\hline 180 & 0 & $\mathrm{ABC}$ & 181,16 & 0,64 & 2 \\
\hline 185 & 0 & $\mathrm{ABC}$ & 186,05 & 0,44 & 3 \\
\hline 200 & 0 & $\mathrm{ABC}$ & 200,71 & 0,30 & 3 \\
\hline 215 & 0 & $\mathrm{ABC}$ & 217,80 & 1,17 & 3 \\
\hline 230 & 0 & $\mathrm{ABC}$ & 232,45 & 1,02 & 3 \\
\hline 235 & 0 & $\mathrm{ABC}$ & 237,34 & 0,98 & 3 \\
\hline 240 & 0 & $\mathrm{ABC}$ & 242,22 & 0,93 & 0 \\
\hline
\end{tabular}

TABELA 14 - Faltas-fase-fase (AB), com ângulo de incidência de falta de $90^{\circ}$

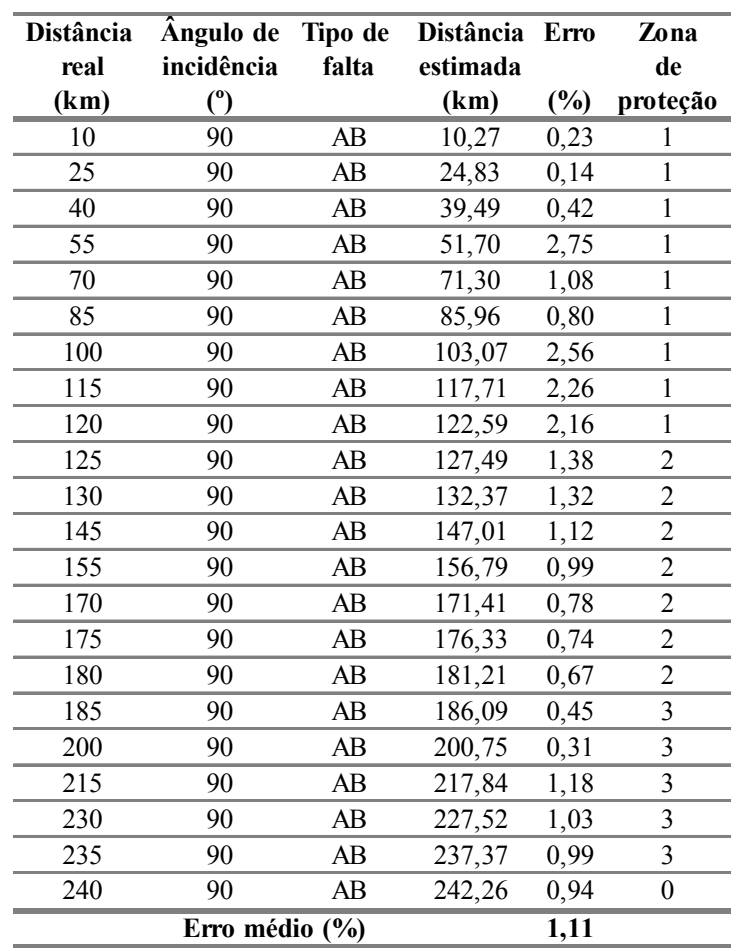

TABELA 16 - Faltas trifásicas (ABC), com ângulo de incidência de falta de $90^{\circ}$

\begin{tabular}{|c|c|c|c|c|c|}
\hline $\begin{array}{c}\text { Distância } \\
\text { real } \\
(\mathrm{km})\end{array}$ & $\begin{array}{l}\text { Ângulo de } \\
\text { incidência } \\
\quad\left(^{\circ}\right)\end{array}$ & $\begin{array}{l}\text { Tipo de } \\
\text { falta }\end{array}$ & $\begin{array}{c}\text { Distância } \\
\text { estimada } \\
(\mathbf{k m})\end{array}$ & $\begin{array}{l}\text { Erro } \\
(\%)\end{array}$ & $\begin{array}{c}\text { Zona } \\
\text { de } \\
\text { proteção }\end{array}$ \\
\hline 10 & 90 & $\mathrm{ABC}$ & 10,26 & 0,22 & 1 \\
\hline 25 & 90 & $\mathrm{ABC}$ & 24,85 & 0,12 & 1 \\
\hline 40 & 90 & $\mathrm{ABC}$ & 39,51 & 0,41 & 1 \\
\hline 55 & 90 & $\mathrm{ABC}$ & 51,72 & 2,73 & 1 \\
\hline 70 & 90 & $\mathrm{ABC}$ & 71,28 & 1,07 & 1 \\
\hline 85 & 90 & $\mathrm{ABC}$ & 85,94 & 0,78 & 1 \\
\hline 100 & 90 & $\mathrm{ABC}$ & 103,05 & 2,54 & 1 \\
\hline 115 & 90 & $\mathrm{ABC}$ & 117,69 & 2,24 & 1 \\
\hline 120 & 90 & $\mathrm{ABC}$ & 122,57 & 2,14 & 1 \\
\hline 125 & 90 & $\mathrm{ABC}$ & 127,47 & 1,37 & 2 \\
\hline 130 & 90 & $\mathrm{ABC}$ & 132,35 & 1,31 & 2 \\
\hline 145 & 90 & $\mathrm{ABC}$ & 146,99 & 1,11 & 2 \\
\hline 155 & 90 & $\mathrm{ABC}$ & 156,77 & 0,98 & 2 \\
\hline 170 & 90 & $\mathrm{ABC}$ & 171,41 & 0,78 & 2 \\
\hline 175 & 90 & $\mathrm{ABC}$ & 176,31 & 0,73 & 2 \\
\hline 180 & 90 & $\mathrm{ABC}$ & 181,19 & 0,66 & 2 \\
\hline 185 & 90 & $\mathrm{ABC}$ & 186,07 & 0,45 & 3 \\
\hline 200 & 90 & $\mathrm{ABC}$ & 200,73 & 0,30 & 3 \\
\hline 215 & 90 & $\mathrm{ABC}$ & 217,82 & 1,18 & 3 \\
\hline 230 & 90 & $\mathrm{ABC}$ & 227,54 & 1,03 & 3 \\
\hline 235 & 90 & $\mathrm{ABC}$ & 237,35 & 0,98 & 3 \\
\hline 240 & 90 & $\mathrm{ABC}$ & 242,24 & 0,93 & 0 \\
\hline \multicolumn{4}{|c|}{ Erro médio (\%) } & 1,09 & \\
\hline
\end{tabular}




\subsubsection{Influência dos Diferentes Tipos de Falta}

Com o objetivo de verificar a influência do tipo da falta no desempenho dessa técnica, foram realizados alguns testes. A Figura 49 ilustra algumas situações de faltasfase-terra $(\mathrm{AT})$, fase-fase-terra $(\mathrm{ABT})$, fase-fase $(\mathrm{AB})$ e trifásicas $(\mathrm{ABC})$, com ângulo de incidência de $90^{\circ}$ e resistência de falta de $0,1 \Omega$.

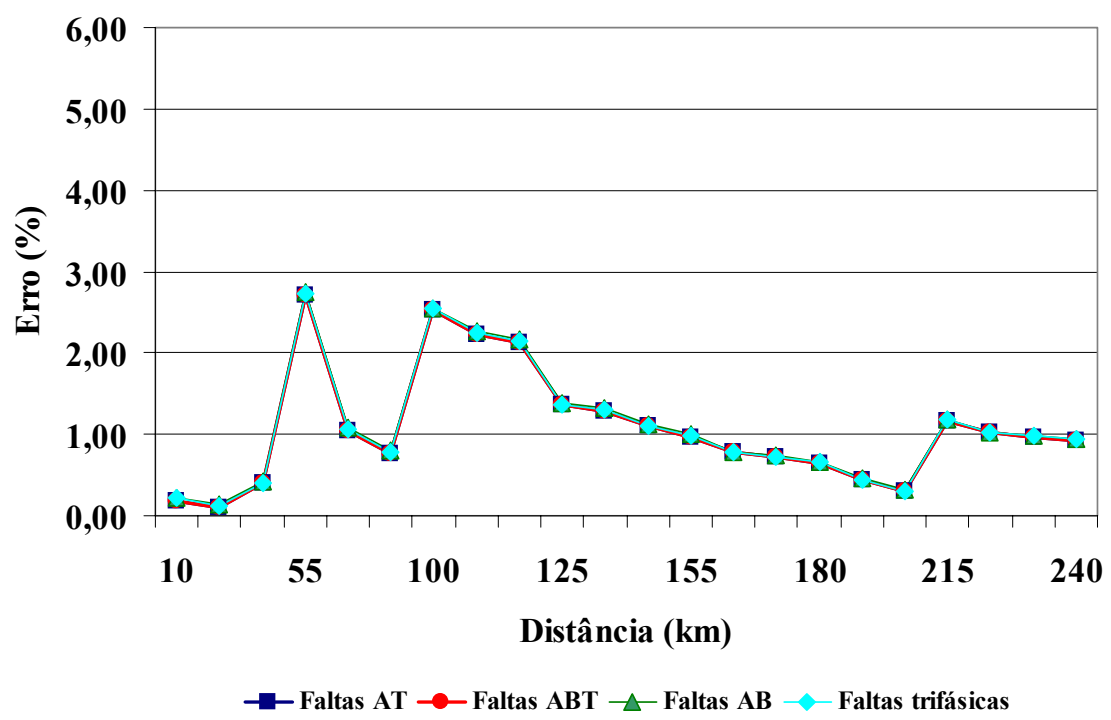

FIGURA 49 - Influência do tipo da falta na precisão do algoritmo

Observa-se na Figura 49 que os erros percentuais foram inferiores a 3,0 \% para os casos analisados. Pelos testes realizados e resultados obtidos, observa-se que os erros introduzidos pelos diferentes tipos de faltas não afetam significativamente a validade e a confiabilidade da técnica de determinação de zonas de proteção utilizada.

Resultados evidenciando o bom desempenho do algoritmo implementado em relação às situações de faltas $\mathrm{BT}, \mathrm{CT}, \mathrm{BCT}, \mathrm{ACT}, \mathrm{BC}$ e $\mathrm{AC}$ são apresentados no Apêndice A. 


\subsubsection{Influência do Ângulo de Incidência da Falta}

Testes foram realizados com o intuito de verificar a variação do ângulo de incidência da falta na precisão do algoritmo. Os valores de ângulo de incidência da falta utilizados foram de $0,45,70$ e $90^{\circ}$. A Figura 50 ilustra alguns casos de faltas-fase-fase (AB) com diferentes ângulos de incidência de falta.

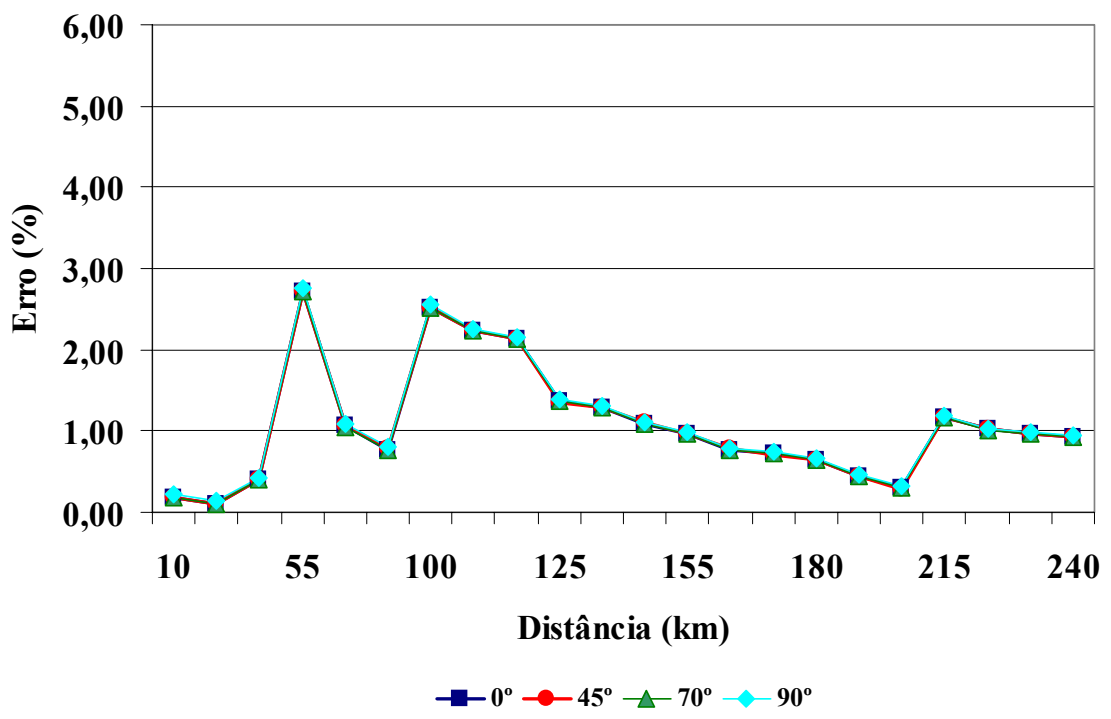

FIGURA 50 - Influência do ângulo de incidência da falta para faltas-fase-fase

Como a maioria dos resultados apresentados na Figura 50 permanece dentro de uma faixa de erro de 3,0\%, aponta-se que a técnica que dispõe de dados provenientes de dois terminais não sofre influência significativa devido à variação do ângulo de incidência da falta. 


\subsubsection{Influência da Resistência de Falta}

Como no caso de dados de um terminal, fizeram-se testes variando a resistência de falta para dados de dois terminais. A Figura 51 ilustra alguns casos de faltas-fasefase-terra $(\mathrm{ABT})$ com ângulo de incidência de $0^{\circ}$ e diferentes resistências de falta.

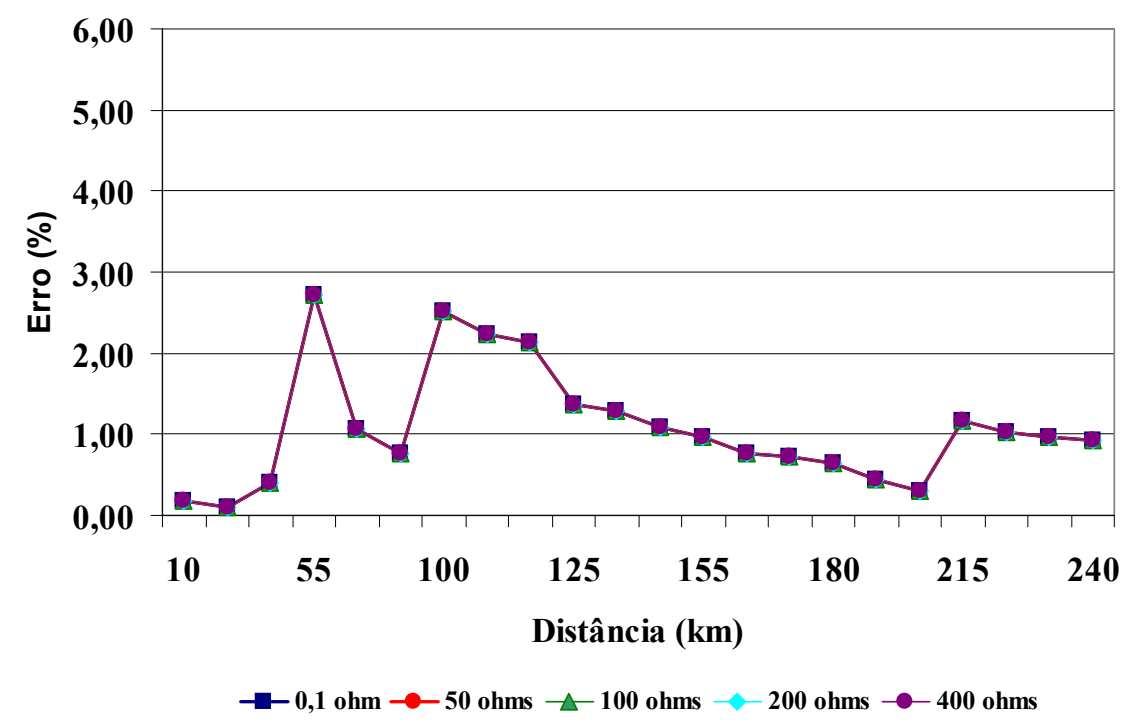

FIGURA 51 - Influência da resistência de falta para faltas-fase-fase-terra (ABT)

De maneira análoga aos testes efetuados para um terminal, constatou-se que essa técnica não sofreu grande influência significativa da resistência de falta, mesmo para resistências muito altas (200 e $400 \Omega$ ), permanecendo a maioria dos resultados abaixo de uma faixa de erro de $3,0 \%$. 


\subsubsection{Influência da Perda de Sincronismo dos Dados}

Outro importante estudo realizado neste trabalho, diz respeito à sincronização dos dados registrados em ambos os terminais, ou melhor dizendo, o efeito de um possível mau sincronismo dos dados na precisão do algoritmo.

Como já descrito anteriormente, a técnica de sincronismo sugerida foi a utilização do GPS, por apresentar alto grau de segurança e precisão, o que justificaria o custo a ser empreendido para a instalação e a manutenção de tal dispositivo.

Além disso, o GPS oferece uma sincronização de dados com um erro máximo de $1 \mu \mathrm{s}$, o que corresponde a aproximadamente 300 metros de imprecisão, considerando que a velocidade de propagação da luz é de $3 \times 10^{5} \mathrm{~km} / \mathrm{s}$.

A fim de comprovarmos o efeito da influência de um mau sincronismo, o algoritmo foi testado, considerando uma perda de sincronismo igual a uma amostra $(8,33 \mu \mathrm{s})$ em relação aos dados registrados no terminal remoto. Os resultados observados estão apresentados nas Tabelas 19 e 20 do Apêndice A, as quais mostram que o algoritmo apresentou um erro de $\pm 1,22 \mathrm{~km}$ para a maioria dos casos analisados. Observa-se que o erro encontrado é aproximadamente a metade do erro introduzido pelo tempo de atraso total, confirmando o exposto acima. Isso se deve à formulação característica dessa técnica dada pela eq.(5.14), que determina que a influência causada por um mau sincronismo dos dados seja diretamente proporcional à metade do tempo do erro total de sincronismo.

Devido à observação quanto ao efeito causado pela perda de sincronismo, o algoritmo foi testado considerando-se uma perda de sincronismo igual a duas amostras. Os resultados observados estão apresentados nas Tabelas 21 e 22 do Apêndice A.

A Figura 52 ilustra alguns casos de faltas-fase-terra (AT) em que foi considerada uma perda de sincronismo correspondente a uma amostra. Outros resultados referentes à situação de falta-fase-fase (AB) são expostos no Apêndice $A$. 


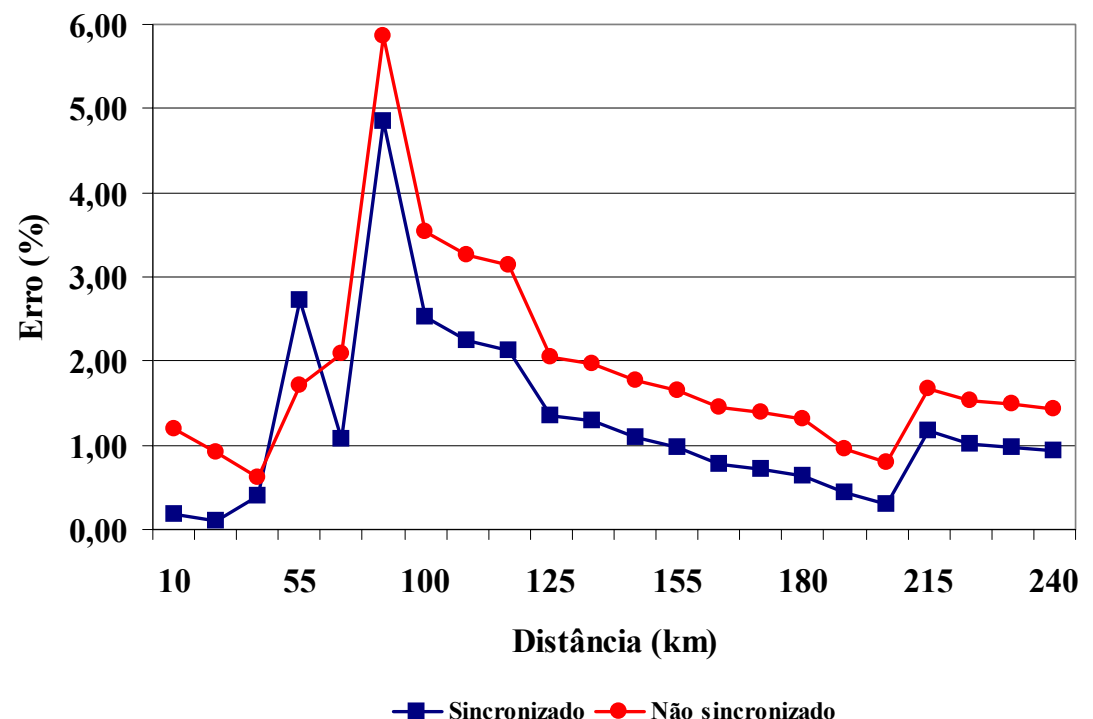

FIGURA 52 - Influência da perda de sincronismo (1 amostra), considerando situações de faltas-faseterra (AT), com ângulo de incidência de $0^{\circ}$ e resistência de falta de $0,1 \Omega$

Após a análise dos testes e resultados obtidos com a aplicação do algoritmo, serão apresentadas, no próximo capítulo, as conclusões do trabalho em discussão. 


\section{CONCLUSÕES}

O trabalho apresentado teve como objetivo a implementação de um algoritmo para proteção digital de distância fundamentado na teoria de ondas viajantes e na utilização da Transformada Wavelet.

Através de simulações, dispondo-se do software ATP, gerou-se um banco de dados consistindo de 1936 casos, sendo 968 para dados registrados em um terminal, e 968 situações para dados registrados em ambos os terminais da linha de transmissão sob análise. Deve se salientar que esse algoritmo de relé de distância não usa o cálculo da impedância aparente como base de decisão, mas sim, de componentes de alta freqüência geradas pela situação de falta.

Com respeito à sub-rotina de detecção da falta, para todas as situações de faltas simuladas (faltas-fase-terra, fase-fase-terra, fase-fase e trifásicas), tanto para dados registrados em um como em dois terminais, obteve-se um índice de acerto de 100\%, dispondo-se de um tempo de análise de três milissegundos. Tais situações levaram em consideração variações na distância de aplicação da falta, resistência e ângulo de incidência da falta. O mesmo índice de acerto foi constatado para a sub-rotina de classificação para um tempo de análise correspondente a dez milissegundos. Essa subrotina analisou e classificou corretamente os dez tipos de faltas que possam vir a ocorrer no sistema elétrico avaliado, tanto para dados registrados em um como em dois terminais.

Com relação à sub-rotina de determinação das zonas de proteção, ela foi subdividida em duas técnicas, uma delas possibilita a determinação das zonas de proteção, usando dados registrados em apenas um terminal da linha, e a outra técnica realiza a determinação da zona de proteção do relé utilizando dados obtidos em dois terminais da linha.

A técnica que utiliza dados provenientes de um terminal mostrou um elevado grau de desempenho acompanhado de uma precisão bastante satisfatória na maioria dos 
testes avaliados. É importante lembrar que essa técnica necessita da implementação obrigatória da sub-rotina de pré-localização da falta, sendo necessária somente para as situações de faltas classificadas pelo envolvimento de uma das fases com a terra.

Analisando todos os resultados obtidos, utilizando-se da técnica com dados de um terminal, podemos comprovar o bom desempenho do algoritmo, obtendo-se boa precisão na maioria dos testes. Para ilustrar a eficiência apresentada pela técnica, podese tomar como referência a Tabela 17 .

TABELA 17 - Resultados alcançados pela técnica de um terminal aplicada a um circuito simples

\begin{tabular}{cc}
\hline Falta & $\begin{array}{c}\text { Erro médio } \\
(\mathbf{\%})\end{array}$ \\
\hline Fase-terra & 1,33 \\
\hline Fase-fase-terra & 1,90 \\
\hline Fase-fase & 1,32 \\
\hline Trifásicas & 1,48 \\
\hline
\end{tabular}

A Tabela 17 ilustra os erros médios gerais apresentados pela sub-rotina de determinação das zonas de proteção (dados registrados em um terminal), definidas com as seguintes proporções: com $80 \%$ (zona de proteção primária), $120 \%$ (zona de proteção secundária) e 160\% (zona de proteção terciária) do comprimento da linha de transmissão protegida. As situações de faltas consideradas foram: faltas-fase-terra (AT, $\mathrm{BT}, \mathrm{CT}$ ), fase-fase-terra (ABT, $\mathrm{ACT}$ e $\mathrm{BCT})$, fase-fase (AB, $\mathrm{AC}$ e $\mathrm{BC}$ ) e trifásicas $(\mathrm{ABC})$, considerando-se variações nas resistências e ângulos de incidência da falta. Índices de incertezas de $\pm 3 \%$ sobre o alcance das zonas de proteção anteriormente definidas foram considerados.

Pela análise da Tabela 17 observa-se uma precisão altamente satisfatória na maioria dos testes, visto que os erros médios totais ficaram abaixo de 1,9\% para todos os resultados observados. Esse índice está relacionado com as imprecisões constatadas pelo algoritmo em se determinar corretamente a chegada da segunda onda na barra local. A dificuldade em se determinar a chegada da segunda onda deve-se à atenuação da mesma no decorrer do seu percurso pela linha ou devido a ruídos presentes no sinal. Verifica-se também que o melhor índice obtido foi para as situações de faltas-fase-fase ( $\mathrm{AB}, \mathrm{BC}$ e $\mathrm{AC})$, obtendo-se um erro médio total de 1,32\%. 
A Tabela 18 ilustra os resultados dos testes avaliados com relação a dados registrados em dois terminais.

TABELA 18 - Resultados alcançados pela técnica de dois terminais aplicada a um circuito simples

\begin{tabular}{cc}
\hline Falta & $\begin{array}{c}\text { Erro médio } \\
(\mathbf{\%})\end{array}$ \\
\hline Fase-terra & 1,11 \\
\hline Fase-fase-terra & 1,10 \\
\hline Fase-fase & 1,11 \\
\hline Trifásicas & 1,18 \\
\hline
\end{tabular}

Da análise da Tabela 18 observa-se um desempenho superior quando comparado com a técnica de determinação das zonas de proteção com dados registrados de um terminal, visto que o erro médio geral foi menor do que $1,2 \%$.

Como característica específica, essa técnica não necessita da implementação da sub-rotina de pré-localização da falta. Porém, necessita de um meio de sincronização dos dados, assim como de um canal de comunicação entre os terminais para transmissão desses dados. Outra vantagem constatada nessa técnica está ligada à simplicidade do algoritmo e à confiabilidade da técnica.

Por uma análise geral dos resultados, constata-se que o algoritmo de relé digital de distância implementado não é significantemente influenciado pelos seguintes parâmetros: distância da falta, tipo da falta, resistência e ângulo de incidência da falta.

Em ambas as técnicas, observou-se que o algoritmo é capaz de perceber e indicar faltas fora da sua área de proteção, detectando-as como faltas externas.

Outra vantagem caracterizada pelo algoritmo diz respeito ao tempo de atuação do sistema de proteção de apenas 13 ms, após a ocorrência da situação de falta. Os três primeiros milissegundos seriam destinados às tarefas de detecção e de determinação das zonas de proteção dos relés associados. A partir da detecção de uma anomalia sobre o sistema, a tarefa de classificação do tipo de falta ocorrida dispõem dos $10 \mathrm{~ms}$ restantes do tempo total acima apresentado.

Como limitação ao emprego deste método tem-se a necessidade do emprego de uma taxa amostral elevada (120 kHz). Entretanto, com o enorme avanço proporcionado em grande parte pela tecnologia digital, essa limitação já está sendo superada.

Pelos resultados alcançados, pode-se observar uma precisão altamente satisfatória na localização das zonas de proteção, conseqüentemente, observa-se uma diminuição da área de incerteza do algoritmo, conferindo maior seletividade ao mesmo. 
Finalmente, pelos resultados apresentados, pode-se dizer que a aplicação desse algoritmo se mostra bastante propícia para uso em um relé digital de distância.

\subsection{Continuidade da Pesquisa}

Tendo em vista o aperfeiçoamento do algoritmo apresentado, principalmente no tocante à técnica que utiliza dados de um terminal, propõe-se a submissão do mesmo a novos testes, tais como verificar a influência da taxa de amostragem e da imprecisão dos parâmetros da linha no desempenho do algoritmo, a utilização de outras famílias de wavelets-mãe na metodologia de detecção dos picos corretos de reflexão, entre outros.

Além disso, sugere-se o aperfeiçoamento da etapa de detecção e classificação da falta através da aplicação da Transformada Wavelet. Através destas idéias, pode-se diminuir o tempo de processamento do algoritmo, conferindo maior velocidade ao mesmo.

Outra proposta é a aplicação da metodologia vista neste trabalho em um sistema de linhas de transmissão com três terminais, por serem economicamente viáveis e de difícil proteção, dispondo-se das técnicas convencionais existentes. 


\section{REFERÊNCIAS BIBLIOGRÁFICAS}

[1] CAMINHA, A. C. (1978). Introdução à proteção dos sistemas elétricos. São Paulo: Edgard Blücher.

[2] COURY, D. V. (1987). Um estimador ótimo aplicado à proteção dos sistemas elétricos de potência. Dissertação (Mestrado) - Escola de Engenharia de São Carlos, Universidade de São Paulo.

[3] STEVENSON JR., W. D. (1986). Elementos de análise de sistemas de potencia. Rio de Janeiro: McGraw-Hill do Brasil.

[4] HOROWITZ, S.; PHADKE, A. G. (1996). Power system relaying. England: Research Studies Press Ltd.

[5] SACHEDEV, M. S.; BARIBEAU, M. A. (1979). A new algorithm for digital impedance relays. IEEE Transactions on Power Apparatus and Systems, v.PAS98, n.6, pp. 2232-2240, nov./dec.

[6] PHADKE, A. G.; THORP, J. S. (1988). Computer relaying for power systems. England: Research Studies Press Ltd.

[7] BO, Z. Q.; REDFERN, M. A.; WELLER, G. C. (2000). Positional protection of transmission line using fault generated high frequency transient signals. IEEE Transactions on Power Delivery, v.15, n.3, pp. 888-894, jul.

[8] SOLANKI, M.; SONG, Y. H. (2003). Transient protection of ehv transmission line using discrete wavelet analysis. IEEE Power Engineering Society Winter Meeting, v.3, pp. 1868-1873, jul.

[9] ZHANG, D. J.; WU, Q. H.; BO, Z. Q.; CAUNCE, B. (2003). Transients positional protection of transmission lines using complex wavelets analysis. IEEE Transactions on Power Delivery, v.18, n.3, pp. 705-710, jul. 
[10] GHERALDE, A. L. J. (1996). Aplicação de relés adaptativos na proteção digital a ditância. Dissertação (Mestrado) - Escola de Engenharia de São Carlos, Universidade de São Paulo.

[11] PHADKE, A. G.; HLIBKA, T.; IBRAHIM, M. (1976). A digital computer system for ehv substations: analysis and field tests. IEEE Transactions on Power Apparatus and Systems, v.PAS-95, n.1, pp. 291-301, jan./feb.

[12] PHADKE, A. G.; HLIBKA, T.; IBRAHIM, M. (1977). Fundamental basis for distance relaying with symmetrical components. IEEE Transactions on Power Apparatus and Systems, v.PAS-96, n.2, pp. 635-646, mar./abr.

[13] EICHHORN, K. FR.; LADNIAK, L.; LOBOS, T. (1993). Algorithms for digital distance protection with improved transient behaviour. IEEE/NTUA Athens Power Tech Conference, Greece, v.1, pp. 290-294, sept. 5-8.

[14] ALTUVE F., H. J.; DIAZ V., I.; VAZQUEZ M., E. (1996). Fourier and walsh digital filtering algorithms for distance protection. IEEE Transactions on Power Delivery, v.11, n.1, pp. 457-462, feb.

[15] YU, S. L.; GU, J. G. (2001). Removal of decaying dc in current and voltage signals using a modified fourier filter algorithm. IEEE Transactions on Power Delivery, v.16, n.3, pp. 372-379, jul.

[16] MICHELETTI, R.; PIERI, R. (2002). Walsh digital filters applied to distance protection. In: Instrumentation and Measurement Technology Conference, Proceedings of the 19th IEEE, v. 1, pp. 487-490.

[17] SILVA, C. M. L.; KUGA, H. K.; LOPES, R. V. F. (2004). Estimação conjunta de atitude e órbita de satélites artificiais estabilizados por rotação utilizando observações do magnetômetro e sensor solar. In: Terceiro Congresso Temático de Dinâmica e Controle, Ilha Solteira. Anais do Terceiro Congresso Temático de Dinâmica e Controle. Ilha Solteira: UNESP 2004. v. 1, pp. 1819-1823.

[18] GIRGIS, A. A. (1982). A new kalman filtering based digital distance relay. IEEE Transactions on Power Apparatus and Systems, v.PAS-101, n.9, pp. 34713480 , sept. 
[19] SOLIMAN, S. A.; EL-HAWARY, M. E. (1996). Application of kalman filtering for online estimation of symmetrical components for power system protection. Electric Power Systems Research, v.38, n.2, pp. 113-123, aug.

[20] SACHDEV, M. S.; NAGPAL, M. (1991). A recursive least error squares algorithm for power system relaying and measurements applications. IEEE Transactions on Power Delivery, v.6, n.3, pp. 1008-1015, jul.

[21] MCINNES, A. D., MORRISON, I. F. (1971). Real time calculation of resistance and reactance for transmission line protection by digital computer. IEE Transaction, Institution of. Engineers. Austrália, EE7, n.1, pp. 16-23, jan.

[22] SANDERSON, J. V. H.; WRIGHT, A. (1974). Protective scheme for seriescompensated transmission lines. Proceedings of IEE, v.121, n.11, pp. 13771384, nov.

[23] RANJBAR, A. M.; CORY, B. J. (1975). An improved method for the digital protection of high voltage transmission lines. IEEE Transactions on Power Apparatus and Systems, v.PAS-94, n.2, pp. 544-550, mar./apr.

[24] BREINGAN, W. D.; CHEN, M. M.; GALLEN, T. F. (1979). The laboratory investigation of a digital system for the protection of transmission lines. IEEE Transactions on Power Apparatus and Systems, v.PAS-98, n.2, pp. 350-368, mar./apr.

[25] SMOLINSKI, W. J. (1979). An algorithm for digital impedance calculation using a simgle PI section transmission line model. IEEE Transactions on Power Apparatus and Systems, v.PAS-98, n.5, pp. 1546-1551, sept./oct.

[26] JEYASURYA, B.; SMOLINSKI, W. J. (1983). Identification of a best algorithm for digital distance protection of transmission lines. IEEE Transactions on Power Apparatus and Systems, v.PAS-102, n.10, pp. 33583369 , oct.

[27] OHURA, Y.; MATSUDA, T.; SUZUKI, M.; YAMAMURA, M.; KUROSAWA, Y.; YOKOYAMA, T. (1989). Digital distance relay with improved characteristics against distorted transient waveforms. IEEE Transactions on Power Delivery, v.4, n.4, pp. 2025-2031, oct. 
[28] ROSOLOWSKI, E.; IZYKOWSKI, J.; KASZTENNY, B.; SAHA, M. M. (1997). A new distance relaying algorithm based on complex differential equation for symmetrical components. Electric Power Systems Research, v.40, n.3, pp. 175-180, mar.

[29] AKKE, M.; THORP, J. S. (1998). Some improvements in three-phase differential equation algorithm for fast transmission line protection. IEEE Transactions on Power Delivery, v.13, n.1, pp. 66-72, jan.

[30] CHO, K. R.; KANG, Y. C.; KIM, S. S.; PARK, J. K.; KANG, S. H.; KIM, K. H. (1999). An ANN based approach to improve the speed of a differential equation based distance relaying algorithm. IEEE Transactions on Power Delivery, v.14, n.2, pp. 349-357, apr.

[31] MACÊDO, R. A.; COURY, D. V. (2003). Um esquema completo para proteção rápida de linhas de transmissão com o uso de equações diferenciais. Revista Controle \& Automação, v.14, n.2, pp. 176-186, maio/junho.

[32] BEWLEY, L. V. (1963). Traveling waves on transmission systems. New York: John Wiley \& Sons.

[33] VITINS, M. (1978). A correlation method for transmission line protection. IEEE Transactions on Power Apparatus and Systems, v.PAS-97, n.5, pp. 16071615, sept./oct.

[34] CROSSlEY, P. A.; MCLAREN, P. G. (1983). Distance protection based on travelling waves. IEEE Transactions on Power Apparatus and Systems, v.PAS102, n.9, pp. 2971-2983, sept.

[35] SHEHAB-ELDIN, E. H.; MCLAREN, P. G. (1988). Traveling wave distance protection - Problem areas and solutions. IEEE Transactions on Power Delivery, v.3, n.3, pp. 894-902, jul.

[36] Christopoulos, C.; THOMAS, D. W. P.; WRIGHT, A. (1988). Scheme, based on travelling waves, for the protection of major transmission lines. Proceedings of IEE, v.135, n.C, pp. 63-73, jan.

[37] Christopoulos, C.; THOMAS, D. W. P.; WRIGHT, A. (1989). Signal processing and discriminating techniques incorporated in a protective scheme based on travelling waves. Proceedings of IEE, v.136, n.C, pp. 279-288, sept. 
[38] LiAnG, J.; ElanBovAn, S.; DeVotTA, J. B. X. (1998). A wavelet multiresolution analysis approach to fault detection and classification in transmission lines. Electric Power Systems Research, v.20, n.5, pp. 327-332, jun.

[39] XINZHOU, D.; YAOZHONG, G.; BINGYN, X. (2000). Fault position relay based on current travelling waves and wavelets. Proceedings of IEEE PES Winter Meeting, Singapore, pp. 1997-2004.

[40] LiAnG, J.; ElAnBOVAN, S.; DEVOTTA, J. B. X. (2000). Application of wavelet transform in traveling wave protection. Electric Power Systems Research, v.22, n.5, pp. 537-542, apr.

[41] SHANG, L.; HEROLD, G. JAEGER, L. (2001). A new approach to high-speed protection for transmission line based on transient signal analysis using wavelets. Developments in Power System Protection, Conference Publication, v.479, pp. 173-176.

[42] YOUSSEF, O. A. S. (2003). A modified wavelet-based fault classification technique. Electric Power Systems Research, v.64, n.2, pp. 165-172, feb.

[43] VITINS, M. (1981). A fundamental concept for high speed relaying. IEEE Transactions on Power Apparatus and Systems, v.PAS-100, n.1, pp. 163-173, jan.

[44] RAJENDRA, S.; MCLAREN, P. G. (1985). Traveling wave techniques applied to the protection of teed circuits: Principle of traveling wave techniques. IEEE Transactions on Power Apparatus and Systems, v.PAS-104, n.12, pp. 35443550, dec.

[45] MANSOUR, M. M.; SWIFT, G. W. (1986). A multimicroprocessor based travelling wave relay - theory and realization. IEEE Transactions on Power Delivery, v.PWRD-101, n.1, pp. 272-279, jan.

[46] THOMAS, D. W. P.; de LIMA, F. R. F.; CHRISTOPOULOS, C. (1993). $A$ travelling-wave relay for the protection of ehv transmission-lines with teed feeds. In: Fifth International Conference on Developments in Power System Protection, pp. 232-235. 
[47] NAIDU, S. R. (1985). Transitórios eletromagnéticos em sistemas de potência. Editora Grafset - Co-edição Eletrobrás/Universidade Federal do Paraíba.

[48] GREENWOOD, A. (1991). Electrical transients in power systems. New York: John Wiley \& Sons, Inc.

[49] MARTI, J. R. (1982). Accurate modeling of frequency dependent transmission lines in eletromagnetic transient simulations. IEEE Transactions on Power Apparatus and Systems, v.PAS-101, n.1, pp. 147-155, jan.

[50] ALTERNATIVE TRANSIENTS PROGRAM - Rule Book. (1987). Leuven EMTP Center (LEC).

[51] MISITI, M., MISITI, Y., OPPENHEIM, G. and POGGI, J.-M. (2002). Wavelet toolbox: user's guide. Natick, MA: The MathWorks, 934 p.

[52] KIM, C. H.; AGGARWAL, R. (2000). Wavelet transforms in power systems: Part 1 General introduction to the wavelet transforms. Power Engineering Journal, v.14, n.2, pp. 81-87, apr.

[53] GRAPS, A. (1995). An introduction to wavelets. IEEE Computational Science and Engineering, v.2, pp. 50-61, summer.

[54] DAUBECHIES, I. (1992). Ten lectures on wavelets. Philadelphia, Pa.: Society for Industrial and Applied Mathematics, $357 \mathrm{p}$.

[55] KIM, C. H.; AGGARWAL, R. (2001). Wavelet transforms in power systems: Part 2 Examples of application to actual power system transients. Power Engineering Journal, pp. 193-202, aug.

[56] OLESKOVICZ, M. (2001). Aplicação de redes neurais artificiais na proteção de distância. Tese (Doutorado) - Escola de Engenharia de São Carlos, Universidade de São Paulo.

[57] SILVA, M. (2003). Localização de faltas em linhas de transmissão. Dissertação (Mestrado) - Escola de Engenharia de São Carlos, Universidade de São Paulo.

[58] KIM, G. T.; KIM, H. S.; CHOI, J. Y.. (2001). Wavelet transform based power transmission line fault location using GPS for accurate time synchronization. IEEE/IECON: The $27^{\text {th }}$ Annual Conference of the IEEE Industrial Electronics Society, pp. 495-499. 
[59] ZHAO, W.; SONG, Y. H.; CHEN, W. R. (2001). Improved GPS traveling wave fault locator for power cables by using wavelet analysis. Electric Power Systems Research, v.23, pp. 403-411.

[60] URUSAWA, K.; KANEMARU, K.; TOYOTA, S.; SUGIYAMA, K. (1989). New fault location system for power transmission lines using composite fiberoptic overhead ground wire $(O P G W)$. IEEE Transactions on Power Delivery, v.4, n.4, pp.2005-2011, oct.

[61] SIEMENS, AG. (1981). Eletrical engineering handbook. Whitefriars Press Ltd.

[62] GROSS, C. A. (1979). Power systems analysis. New York: John Wiley \& Sons.

[63] CLARKE, E. (1943). Circuit analysis of AC power systems. New York: John Wiley \& Sons.

[64] ARRUDA, E. F.; DELMONT, O. F.; COURY, D. V.; CARNEIRO, A. A. F. M. (2002). Um estudo das famílias wavelets aplicadas à qualidade da energia elétrica. In: XIV Congresso Brasileiro de Automática, Natal/RN (CD), pp. 1749-1754, set.

[65] SANTOSO, S.; POWERS, E. J.; GRADY, W. M.; HOFMANN, P. (1996). Power quality assessment via wavelet transform analysis. IEEE Transactions on Power Delivery, v.11, n.2, pp. 924-930, apr.

[66] ABUR, A.; MAGNAGO, F. H. (2000). Use of time delays between modal components in wavelet based fault location. ELSEVIER Electrical Power and Energy Systems, v.22, pp. 397-403. 


\section{APÊNDICE A - Resultados dos testes sobre o circuito simples de transmissão}

O objetivo deste apêndice é ilustrar outros resultados referentes a simulações sobre o sistema simples de transmissão, a fim de confirmar a aplicabilidade, confiabilidade e precisão do algoritmo de determinação das zonas de proteção proposto.

\section{A1. Técnica que utiliza dados de um terminal}

Nas Figuras de 53 a 59 são mostrados os resultados obtidos pelo algoritmo, referentes a diversas situações de faltas onde foram variados os seguintes parâmetros: distância, tipo, ângulo de incidência e resistência de falta.

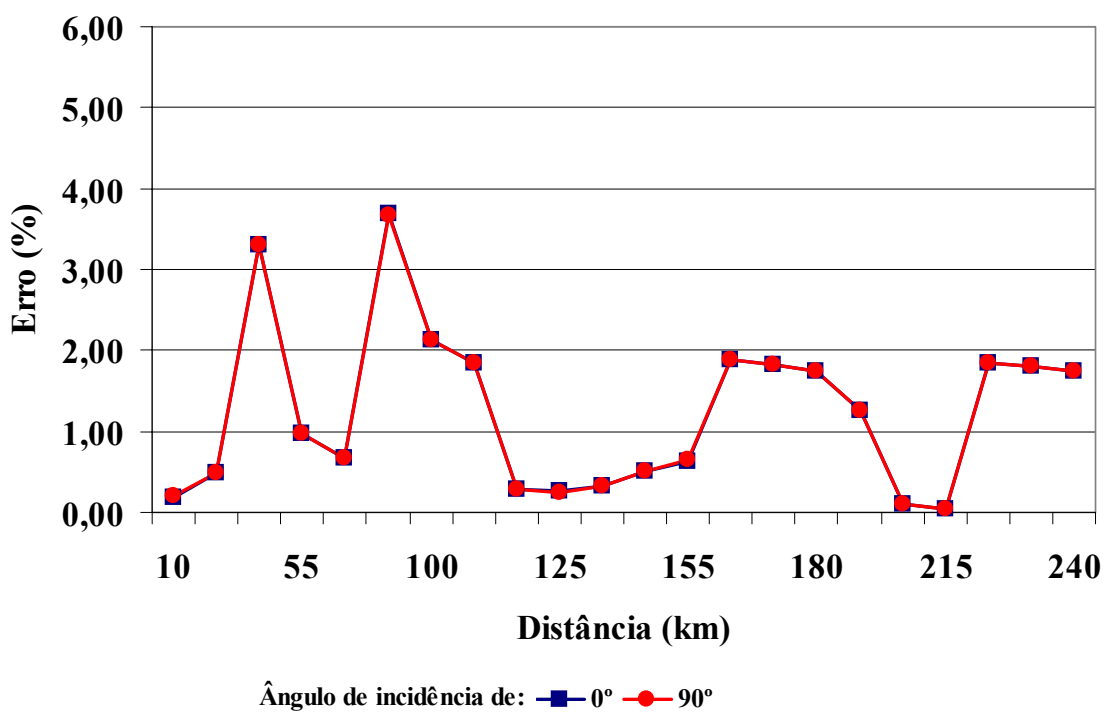

FIGURA 53 - Influência da distância para faltas-fase-fase (BC) 


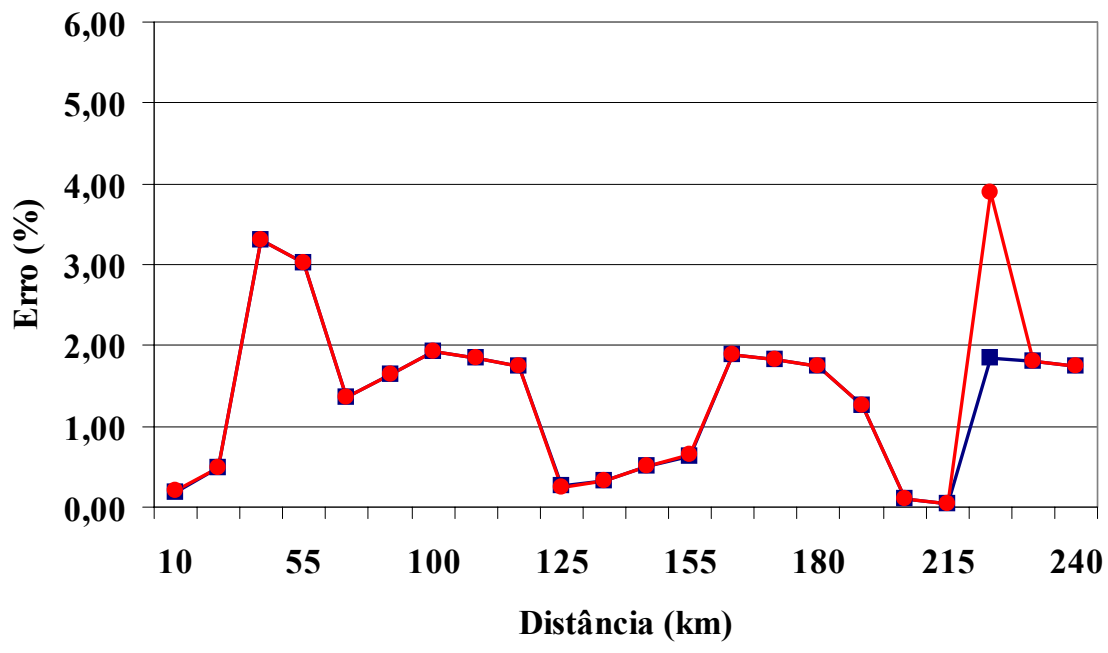

Ângulo de incidência de: $\neg-0^{\circ} \multimap 90^{\circ}$

FIGURA 54 - Influência da distância para faltas-fase-fase (AC)

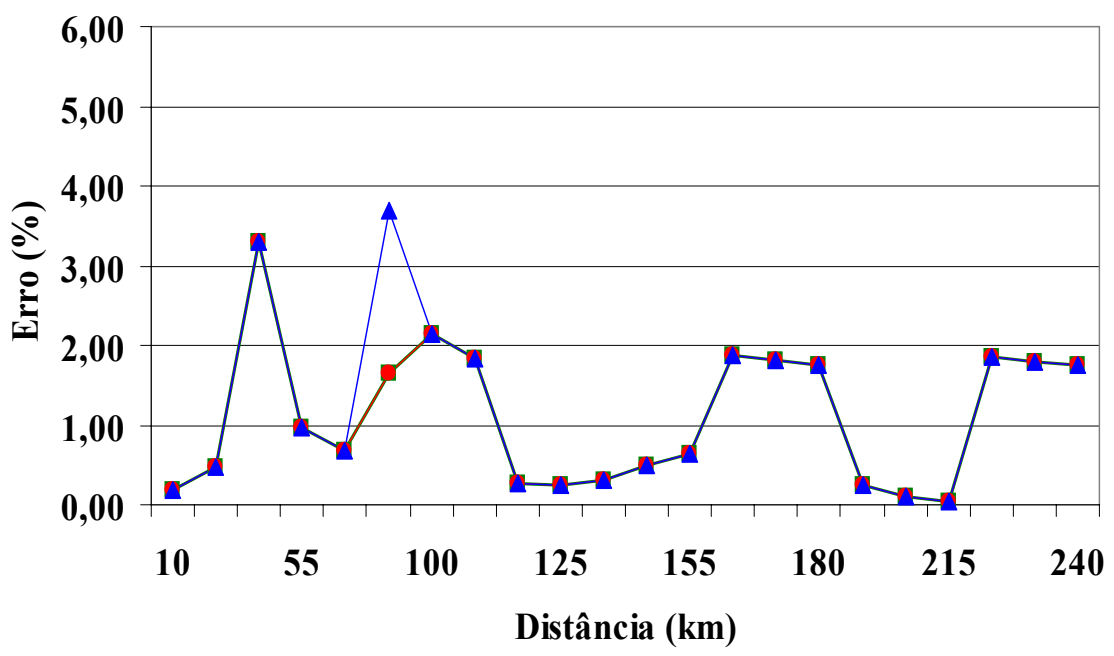

$\dashv 0$ ohm $\longrightarrow 50$ ohms $\triangle-100$ ohms

FIGURA 55 - Influência da distância para faltas-fase-fase-terra (BCT), com ângulo de incidência de $0^{\circ}$ 
A Figura 56 ilustra a influência da variação da distância em situações de faltasfase-fase-terra (BCT) denotando o desempenho do algoritmo na determinação das zonas de proteção.

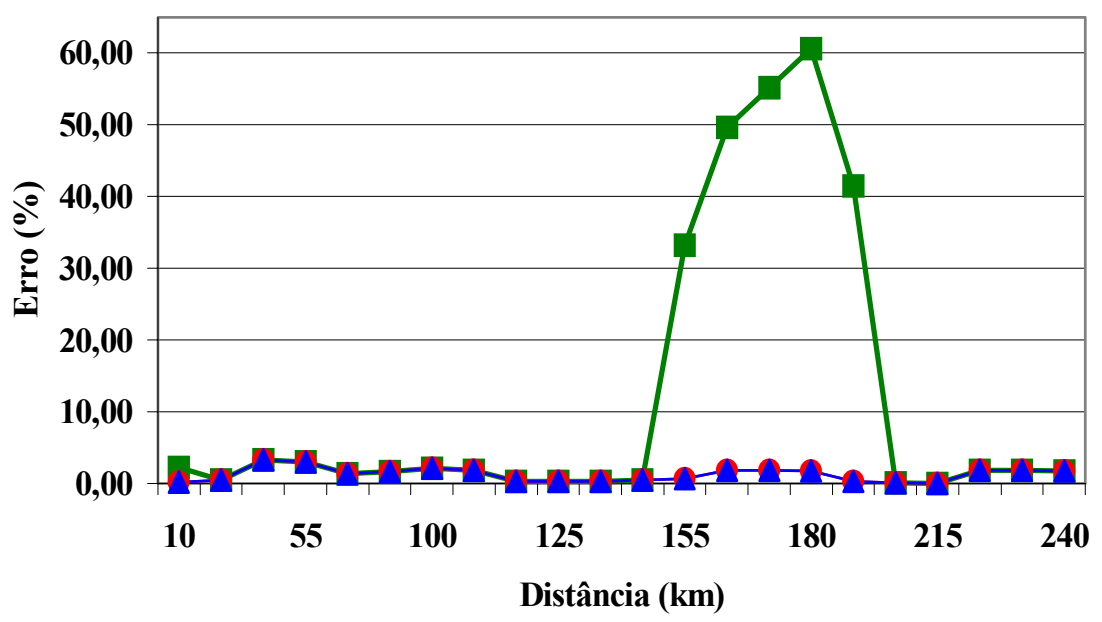

$-0 \mathrm{ohm}-50 \mathrm{ohms} \rightarrow-100 \mathrm{ohms}$

FIGURA 56 - Influência da distância para faltas-fase-fase-terra (BCT), com ângulo de incidência de $90^{\circ}$

Na Figura 56, observam-se cinco casos errôneos para ângulo de incidência de $90^{\circ}$ e resistência de falta de $0,1 \Omega$. Esses altos percentuais de erros são devidos à imprecisão do algoritmo na detecção do segundo pico de reflexão por ser muito atenuado.

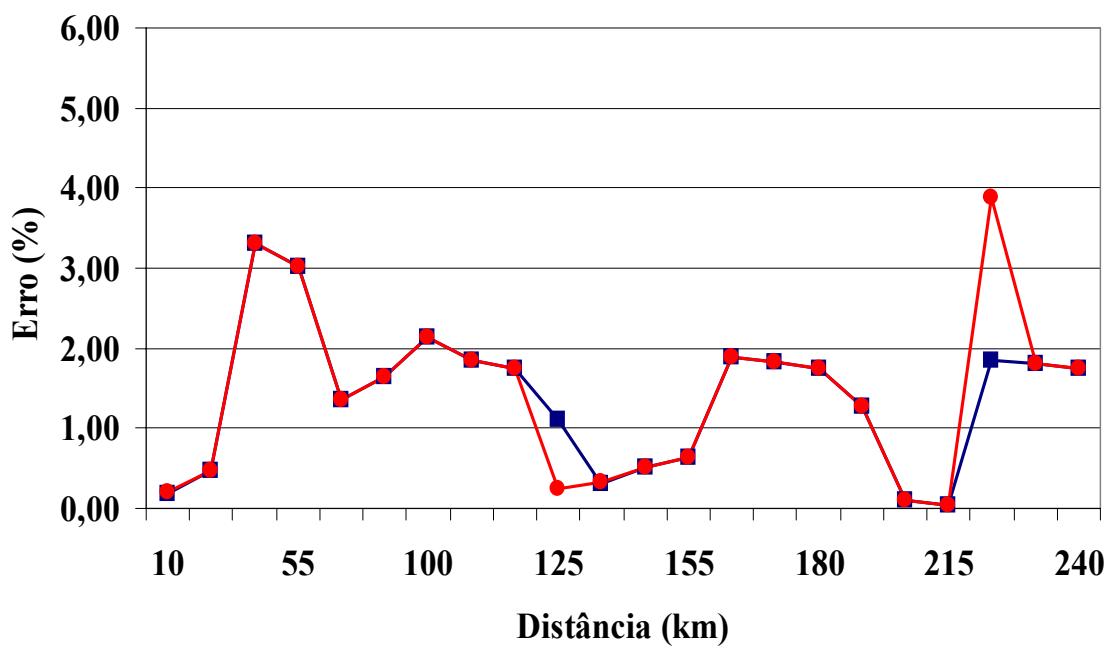

Ângulo de incidência de: $\rightarrow-0^{\circ}-\overbrace{}^{\circ}$ 


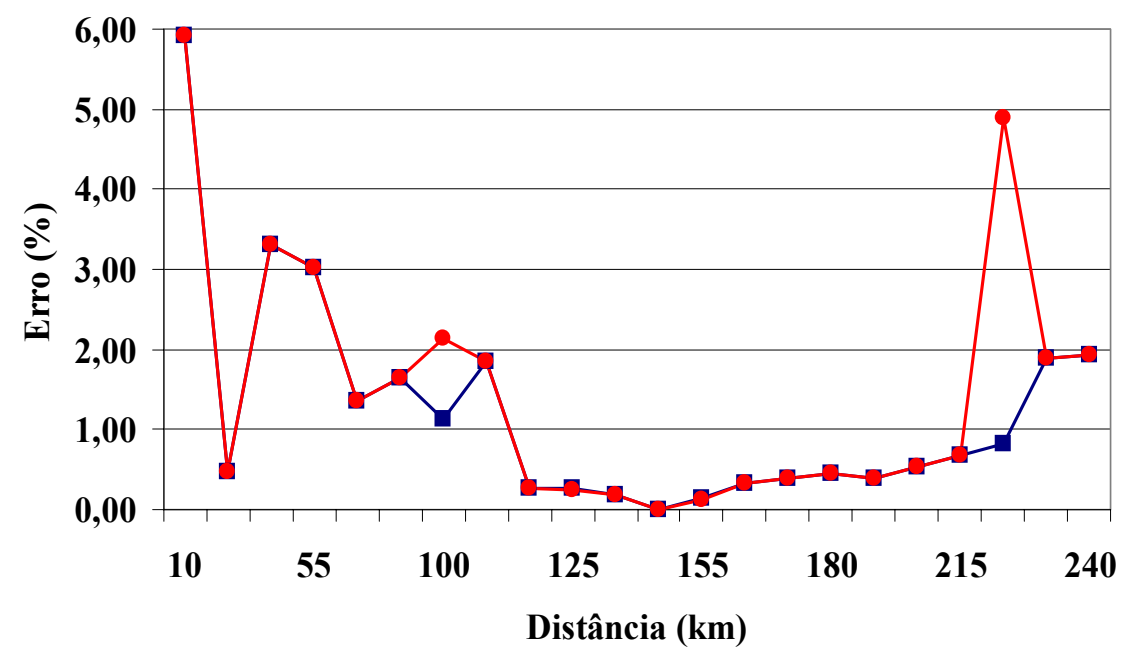

Ângulo de incidência de: $\because-0^{\circ} \longrightarrow 90^{\circ}$

FIGURA 58 - Influência da distância para faltas-fase-terra (BT), com resistência de falta de 0,1 $\Omega$

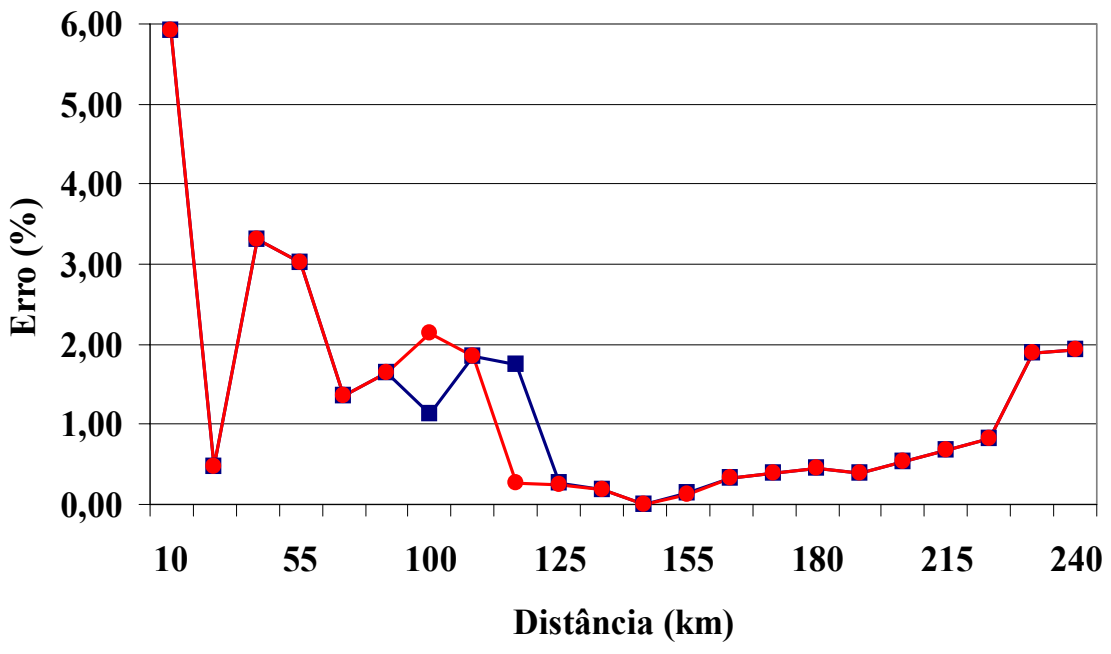

Ângulo de incidência de: $\neg-0^{\circ} \rightarrow 90^{\circ}$

FIGURA 59 - Influência da distância para faltas-fase-terra (CT), com resistência de falta de $100 \Omega$ 


\section{A2. Técnica que utiliza dados de dois terminais}

Nas Figuras de 60 a 65, são mostrados os resultados obtidos pelo algoritmo referentes a diversas situações de faltas onde foram variados os seguintes parâmetros: distância, tipo, ângulo de incidência e resistência de falta.

Nas Tabelas de 19 a 26, são demonstrados testes aplicados com o intuito de se verificar a influência de dados não sincronizados na precisão da técnica de determinação das zonas de proteção abordada.

A Figura 60 ilustra a influência da variação da distância de falta-fase-fase (BC) no desempenho do algoritmo.

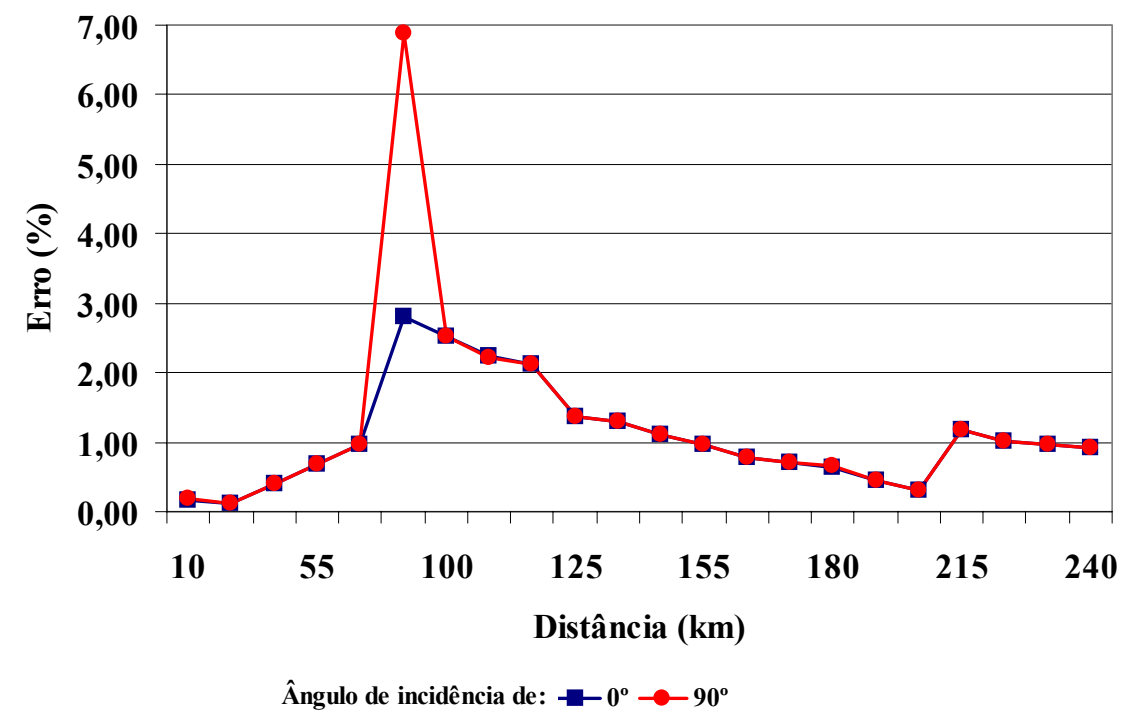

FIGURA 60 - Influência da distância para faltas-fase-fase (BC)

Na Figura 60, observa-se uma situação com erro percentual de 6,85\% para uma falta $\mathrm{BC}$ aplicada a $85 \mathrm{~km}$ do barramento $E$, com ângulo de incidência de $90^{\circ}$. Contudo, ainda assim o algoritmo determinou corretamente a zona de proteção. 


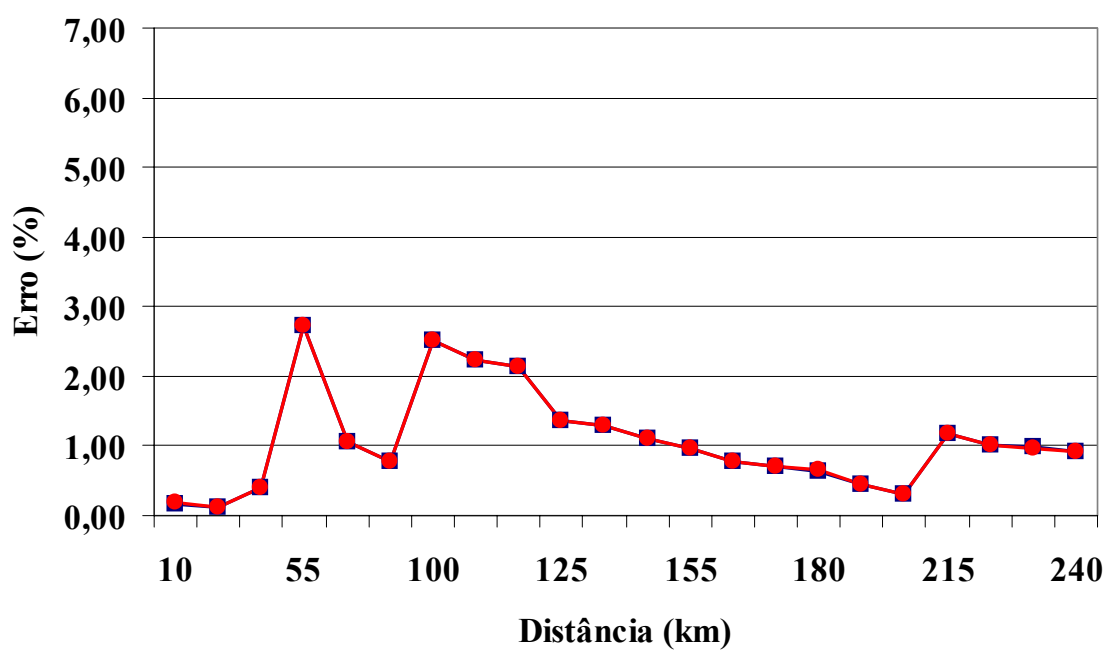

Ângulo de incidência de: $\rightarrow-0^{\circ} \rightarrow 90^{\circ}$

FIGURA 61 - Influência da distância para faltas-fase-fase (AC)

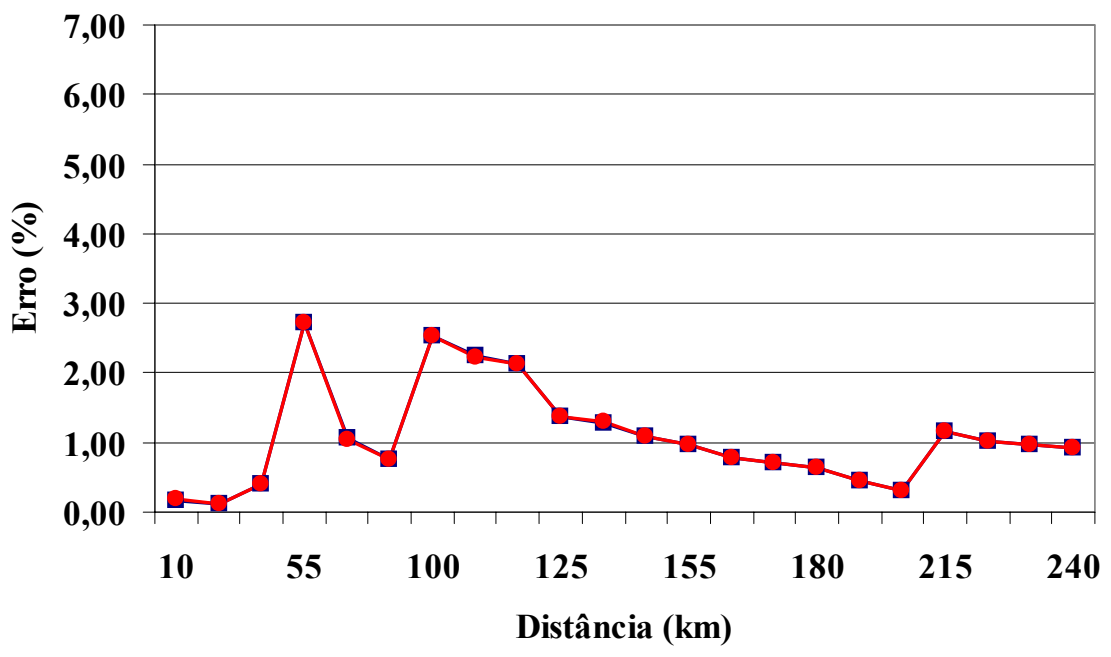

Ângulo de incidência de : $\rightarrow-0^{\circ} \rightarrow-90^{\circ}$ 


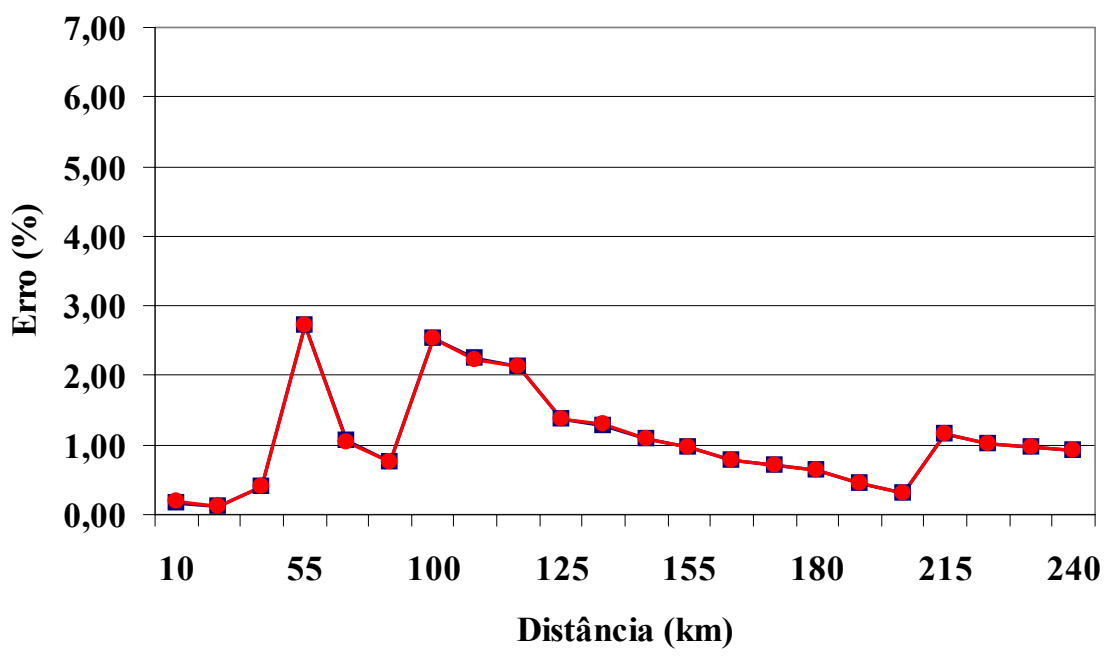

Ângulo de incidência de: $\neg-0^{\circ} \longrightarrow 9^{\circ}$

FIGURA 63 - Influência da distância para faltas-fase-terra (CT), com resistência de falta de $50 \Omega$

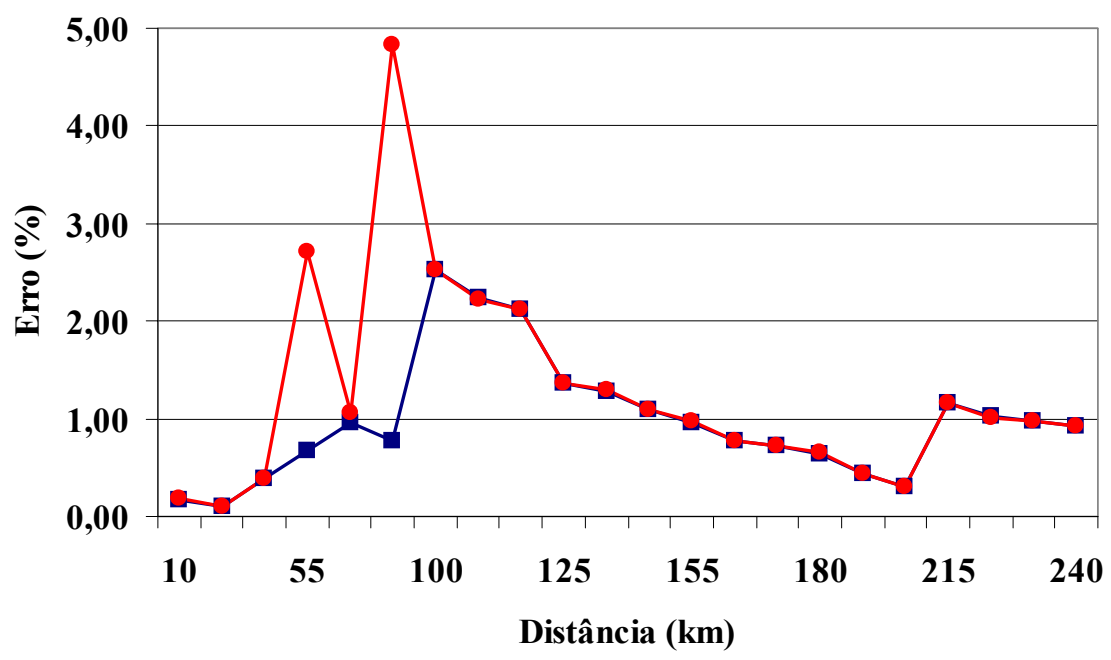

Ângulo de incidência de: $\_-0^{\circ}-90^{\circ}$

FIGURA 64 - Influência da distância para faltas-fase-fase-terra (BCT), com resistência de falta de $100 \Omega$ 


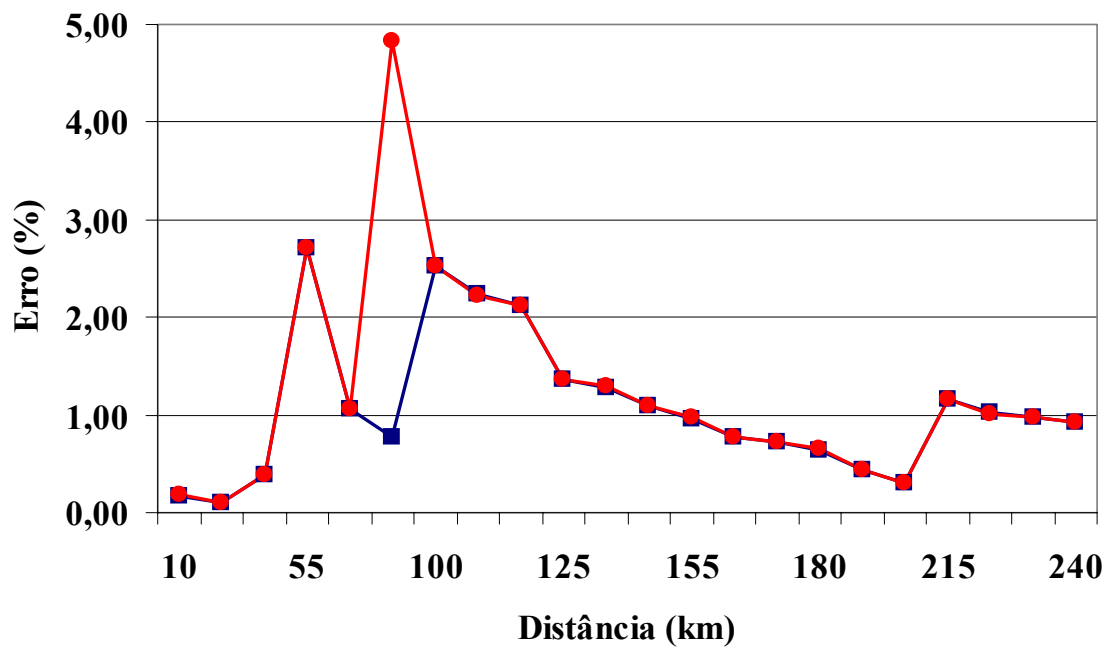

Ângulo de incidência de: $\rightarrow-0^{\circ} \rightarrow-90^{\circ}$

FIGURA 65 - Influência da distância para faltas-fase-fase-terra (ACT), com resistência de falta de 0,1 $\Omega$ 
TABELA 19 - Perda de sincronismo (1 amostra) para faltas AT, com ângulo de incidência de falta de $0^{0}$.

\begin{tabular}{|c|c|c|c|c|c|c|c|c|c|}
\hline $\begin{array}{c}\text { Distância } \\
\text { real } \\
\text { (km) }\end{array}$ & $\begin{array}{c}\text { Resist. } \\
\text { falta } \\
(\Omega)\end{array}$ & $\begin{array}{c}\text { Ângulo de } \\
\text { incidência } \\
\text { (o) }\end{array}$ & $\begin{array}{c}\text { Tipo de } \\
\text { falta }\end{array}$ & $\begin{array}{c}\text { Dist. } \\
\text { sincron } \\
(\mathbf{k m})\end{array}$ & $\begin{array}{c}\text { Dist. } \\
\text { ñ sincron } \\
(\mathbf{k m})\end{array}$ & $\begin{array}{c}\text { Emo } \\
\text { sincr }-\tilde{\mathbf{n}} \text { sincr } \\
(+-\mathbf{k m})\end{array}$ & $\begin{array}{c}\text { Emo } \\
\text { sincron } \\
(\%)\end{array}$ & $\begin{array}{c}\text { Emo } \\
\tilde{\text { n sincron }} \\
(\%)\end{array}$ & $\begin{array}{c}\text { Zona } \\
\text { de } \\
\text { proteção }\end{array}$ \\
\hline 10 & 0,1 & 0 & AT & 10,21 & 11,43 & 1,22 & 0,18 & 1,19 & 1 \\
\hline 10 & 50 & 0 & AT & 10,21 & 11,43 & 1,22 & 0,18 & 1,19 & 1 \\
\hline 10 & 100 & 0 & AT & 10,21 & 11,43 & 1,22 & 0,18 & 1,19 & 1 \\
\hline 25 & 0,1 & 0 & AT & 24,87 & 26,09 & 1,22 & 0,11 & 0,91 & 1 \\
\hline 25 & 50 & 0 & AT & 24,87 & 26,09 & 1,22 & 0,11 & 0,91 & 1 \\
\hline 25 & 100 & 0 & AT & 24,87 & 26,09 & 1,22 & 0,11 & 0,91 & 1 \\
\hline 40 & 0,1 & 0 & AT & 39,53 & 40,75 & 1,22 & 0,39 & 0,62 & 1 \\
\hline 40 & 50 & 0 & AT & 39,53 & 40,75 & 1,22 & 0,39 & 0,62 & 1 \\
\hline 40 & 100 & 0 & AT & 39,53 & 40,75 & 1,22 & 0,39 & 0,62 & 1 \\
\hline 55 & 0,1 & 0 & AT & 51,74 & 52,96 & 1,22 & 2,72 & 1,70 & 1 \\
\hline 55 & 50 & 0 & AT & 51,74 & 52,96 & 1,22 & 2,72 & 1,70 & 1 \\
\hline 55 & 100 & 0 & AT & 51,74 & 52,96 & 1,22 & 2,72 & 1,70 & 1 \\
\hline 70 & 0,1 & 0 & AT & 71,28 & 72,50 & 1,22 & 1,06 & 2,08 & 1 \\
\hline 70 & 50 & 0 & AT & 71,28 & 72,50 & 1,22 & 1,06 & 2,08 & 1 \\
\hline 70 & 100 & 0 & AT & 71,28 & 72,50 & 1,22 & 1,06 & 2,08 & 1 \\
\hline 85 & 0,1 & 0 & AT & 90,82 & 92,04 & 1,22 & 4,85 & 5,86 & 1 \\
\hline 85 & 50 & 0 & AT & 90,82 & 92,04 & 1,22 & 4,85 & 5,86 & 1 \\
\hline 85 & 100 & 0 & AT & 90,82 & 92,04 & 1,22 & 4,85 & 5,86 & 1 \\
\hline 100 & 0,1 & 0 & AT & 103,03 & 104,25 & 1,22 & 2,52 & 3,54 & 1 \\
\hline 100 & 50 & 0 & AT & 103,03 & 104,25 & 1,22 & 2,52 & 3,54 & 1 \\
\hline 100 & 100 & 0 & AT & 103,03 & 104,25 & 1,22 & 2,52 & 3,54 & 1 \\
\hline 115 & 0,1 & 0 & AT & 117,69 & 118,91 & 1,22 & 2,24 & 3,26 & 1 \\
\hline 115 & 50 & 0 & AT & 117,69 & 118,91 & 1,22 & 2,24 & 3,26 & 1 \\
\hline 115 & 100 & 0 & AT & 117,69 & 118,91 & 1,22 & 2,24 & 3,26 & 1 \\
\hline 120 & 0,1 & 0 & AT & 122,55 & 123,77 & 1,22 & 2,13 & 3,14 & 2 \\
\hline 120 & 50 & 0 & AT & 122,55 & 123,77 & 1,22 & 2,13 & 3,14 & 2 \\
\hline 120 & 100 & 0 & AT & 122,55 & 123,77 & 1,22 & 2,13 & 3,14 & 2 \\
\hline 125 & 0,1 & 0 & AT & 127,45 & 128,67 & 1,22 & 1,36 & 2,04 & 2 \\
\hline 125 & 50 & 0 & AT & 127,45 & 128,67 & 1,22 & 1,36 & 2,04 & 2 \\
\hline 125 & 100 & 0 & AT & 127,45 & 128,67 & 1,22 & 1,36 & 2,04 & 2 \\
\hline 130 & 0,1 & 0 & AT & 132,31 & 133,54 & 1,22 & 1,29 & 1,96 & 2 \\
\hline 130 & 50 & 0 & AT & 132,31 & 133,54 & 1,22 & 1,29 & 1,96 & 2 \\
\hline 130 & 100 & 0 & AT & 132,31 & 133,54 & 1,22 & 1,29 & 1,96 & 2 \\
\hline 145 & 0,1 & 0 & AT & 146,97 & 148,19 & 1,22 & 1,10 & 1,77 & 2 \\
\hline 145 & 50 & 0 & AT & 146,97 & 148,19 & 1,22 & 1,10 & 1,77 & 2 \\
\hline 145 & 100 & 0 & AT & 146,97 & 148,19 & 1,22 & 1,10 & 1,77 & 2 \\
\hline 155 & 0,1 & 0 & AT & 156,74 & 157,96 & 1,22 & 0,96 & 1,64 & 2 \\
\hline 155 & 50 & 0 & AT & 156,74 & 157,96 & 1,22 & 0,96 & 1,64 & 2 \\
\hline 155 & 100 & 0 & AT & 156,74 & 157,96 & 1,22 & 0,96 & 1,64 & 2 \\
\hline 170 & 0,1 & 0 & AT & 171,39 & 172,61 & 1,22 & 0,77 & 1,45 & 2 \\
\hline 170 & 50 & 0 & AT & 171,39 & 172,61 & 1,22 & 0,77 & 1,45 & 2 \\
\hline 170 & 100 & 0 & AT & 171,39 & 172,61 & 1,22 & 0,77 & 1,45 & 2 \\
\hline 175 & 0,1 & 0 & AT & 176,29 & 177,51 & 1,22 & 0,72 & 1,39 & 2 \\
\hline 175 & 50 & 0 & AT & 176,29 & 177,51 & 1,22 & 0,72 & 1,39 & 2 \\
\hline 175 & 100 & 0 & AT & 176,29 & 177,51 & 1,22 & 0,72 & 1,39 & 2 \\
\hline 180 & 0,1 & 0 & AT & 181,16 & 182,38 & 1,22 & 0,64 & 1,32 & 2 \\
\hline 180 & 50 & 0 & AT & 181,16 & 182,38 & 1,22 & 0,64 & 1,32 & 2 \\
\hline 180 & 100 & 0 & AT & 181,16 & 182,38 & 1,22 & 0,64 & 1,32 & 2 \\
\hline 185 & 0,1 & 0 & AT & 186,05 & 187,27 & 1,22 & 0,44 & 0,95 & 3 \\
\hline 185 & 50 & 0 & AT & 186,05 & 187,27 & 1,22 & 0,44 & 0,95 & 3 \\
\hline 185 & 100 & 0 & AT & 186,05 & 187,27 & 1,22 & 0,44 & 0,95 & 3 \\
\hline 200 & 0,1 & 0 & AT & 200,71 & 201,93 & 1,22 & 0,30 & 0,80 & 3 \\
\hline 200 & 50 & 0 & AT & 200,71 & 201,93 & 1,22 & 0,30 & 0,80 & 3 \\
\hline 200 & 100 & 0 & AT & 200,71 & 201,93 & 1,22 & 0,30 & 0,80 & 3 \\
\hline 215 & 0,1 & 0 & AT & 217,80 & 219,02 & 1,22 & 1,17 & 1,68 & 3 \\
\hline 215 & 50 & 0 & AT & 217,80 & 219,02 & 1,22 & 1,17 & 1,68 & 3 \\
\hline 215 & 100 & 0 & AT & 217,80 & 219,02 & 1,22 & 1,17 & 1,68 & 3 \\
\hline 230 & 0,1 & 0 & AT & 232,45 & 233,67 & 1,22 & 1,02 & 1,53 & 3 \\
\hline 230 & 50 & 0 & AT & 232,45 & 233,67 & 1,22 & 1,02 & 1,53 & 3 \\
\hline 230 & 100 & 0 & AT & 232,45 & 233,67 & 1,22 & 1,02 & 1,53 & 3 \\
\hline 235 & 0,1 & 0 & AT & 237,34 & 238,56 & 1,22 & 0,98 & 1,48 & 3 \\
\hline 235 & 50 & 0 & AT & 237,34 & 238,56 & 1,22 & 0,98 & 1,48 & 3 \\
\hline 235 & 100 & 0 & AT & 237,34 & 238,56 & 1,22 & 0,98 & 1,48 & 3 \\
\hline 240 & 0,1 & 0 & AT & 242,22 & 243,44 & 1,22 & 0,93 & 1,43 & 0 \\
\hline 240 & 50 & 0 & AT & 242,22 & 243,44 & 1,22 & 0,93 & 1,43 & 0 \\
\hline 240 & 100 & 0 & AT & 242,22 & 243,44 & 1,22 & 0,93 & 1,43 & 0 \\
\hline \multicolumn{7}{|c|}{ Erro médio (\%) } & 1,27 & 1,90 & \\
\hline
\end{tabular}


TABELA 20 - Perda de sincronismo (1 amostra) para faltas AT, com ângulo de incidência de falta de $90^{\circ}$

\begin{tabular}{|c|c|c|c|c|c|c|c|c|c|}
\hline $\begin{array}{c}\text { Distância } \\
\text { real } \\
(\mathbf{k m})\end{array}$ & $\begin{array}{c}\text { Resist. } \\
\text { falta } \\
(\Omega)\end{array}$ & $\begin{array}{c}\text { Ângulo de } \\
\text { incidência } \\
\left({ }^{\circ}\right)\end{array}$ & $\begin{array}{c}\text { Tipo de } \\
\text { falta }\end{array}$ & $\begin{array}{c}\text { Dist. } \\
\text { sincron } \\
\text { (km) }\end{array}$ & $\begin{array}{c}\text { Dist. } \\
\text { ñ sincron } \\
\text { (km) }\end{array}$ & $\begin{array}{c}\text { Emo } \\
\text { sincr }-\tilde{\mathbf{n}} \text { sincr } \\
(+/-\mathbf{k m})\end{array}$ & $\begin{array}{c}\text { Emo } \\
\text { sincron } \\
(\%)\end{array}$ & $\begin{array}{c}\text { Emo } \\
\tilde{\text { n sincron }} \\
(\%)\end{array}$ & $\begin{array}{c}\text { Zona } \\
\text { de } \\
\text { proteção }\end{array}$ \\
\hline 10 & 0,1 & 90 & AT & 10,23 & 11,45 & 1,22 & 0,19 & 1,21 & 1 \\
\hline 10 & 50 & 90 & AT & 10,23 & 11,45 & 1,22 & 0,19 & 1,21 & 1 \\
\hline 10 & 100 & 90 & AT & 10,23 & 11,45 & 1,22 & 0,19 & 1,21 & 1 \\
\hline 25 & 0,1 & 90 & AT & 24,87 & 26,09 & 1,22 & 0,11 & 0,91 & 1 \\
\hline 25 & 50 & 90 & AT & 24,87 & 26,09 & 1,22 & 0,11 & 0,91 & 1 \\
\hline 25 & 100 & 90 & AT & 24,87 & 26,09 & 1,22 & 0,11 & 0,91 & 1 \\
\hline 40 & 0,1 & 90 & AT & 39,53 & 40,75 & 1,22 & 0,39 & 0,62 & 1 \\
\hline 40 & 50 & 90 & AT & 39,53 & 40,75 & 1,22 & 0,39 & 0,62 & 1 \\
\hline 40 & 100 & 90 & AT & 39,53 & 40,75 & 1,22 & 0,39 & 0,62 & 1 \\
\hline 55 & 0,1 & 90 & AT & 51,74 & 52,96 & 1,22 & 2,72 & 1,70 & 1 \\
\hline 55 & 50 & 90 & AT & 51,74 & 52,96 & 1,22 & 2,72 & 1,70 & 1 \\
\hline 55 & 100 & 90 & AT & 51,74 & 52,96 & 1,22 & 2,72 & 1,70 & 1 \\
\hline 70 & 0,1 & 90 & AT & 71,26 & 72,48 & 1,22 & 1,05 & 2,07 & 1 \\
\hline 70 & 50 & 90 & AT & 71,26 & 72,48 & 1,22 & 1,05 & 2,07 & 1 \\
\hline 70 & 100 & 90 & AT & 71,26 & 72,48 & 1,22 & 1,05 & 2,07 & 1 \\
\hline 85 & 0,1 & 90 & AT & 85,92 & 87,14 & 1,22 & 0,77 & 1,79 & 1 \\
\hline 85 & 50 & 90 & AT & 85,92 & 87,14 & 1,22 & 0,77 & 1,79 & 1 \\
\hline 85 & 100 & 90 & AT & 85,92 & 87,14 & 1,22 & 0,77 & 1,79 & 1 \\
\hline 100 & 0,1 & 90 & AT & 103,03 & 104,25 & 1,22 & 2,52 & 3,54 & 1 \\
\hline 100 & 50 & 90 & AT & 103,03 & 104,25 & 1,22 & 2,52 & 3,54 & 1 \\
\hline 100 & 100 & 90 & AT & 103,03 & 104,25 & 1,22 & 2,52 & 3,54 & 1 \\
\hline 115 & 0,1 & 90 & AT & 117,67 & 118,89 & 1,22 & 2,23 & 3,24 & 1 \\
\hline 115 & 50 & 90 & AT & 117,67 & 118,89 & 1,22 & 2,23 & 3,24 & 1 \\
\hline 115 & 100 & 90 & AT & 117,67 & 118,89 & 1,22 & 2,23 & 3,24 & 1 \\
\hline 120 & 0,1 & 90 & AT & 122,55 & 123,77 & 1,22 & 2,13 & 3,14 & 2 \\
\hline 120 & 50 & 90 & AT & 122,55 & 123,77 & 1,22 & 2,13 & 3,14 & 2 \\
\hline 120 & 100 & 90 & AT & 122,55 & 123,77 & 1,22 & 2,13 & 3,14 & 2 \\
\hline 125 & 0,1 & 90 & AT & 127,45 & 128,67 & 1,22 & 1,36 & 2,04 & 2 \\
\hline 125 & 50 & 90 & AT & 127,45 & 128,67 & 1,22 & 1,36 & 2,04 & 2 \\
\hline 125 & 100 & 90 & AT & 127,45 & 128,67 & 1,22 & 1,36 & 2,04 & 2 \\
\hline 130 & 0,1 & 90 & AT & 132,33 & 133,55 & 1,22 & 1,29 & 1,97 & 2 \\
\hline 130 & 50 & 90 & AT & 132,33 & 133,55 & 1,22 & 1,29 & 1,97 & 2 \\
\hline 130 & 100 & 90 & AT & 132,33 & 133,55 & 1,22 & 1,29 & 1,97 & 2 \\
\hline 145 & 0,1 & 90 & AT & 146,97 & 148,19 & 1,22 & 1,10 & 1,77 & 2 \\
\hline 145 & 50 & 90 & AT & 146,97 & 148,19 & 1,22 & 1,10 & 1,77 & 2 \\
\hline 145 & 100 & 90 & AT & 146,97 & 148,19 & 1,22 & 1,10 & 1,77 & 2 \\
\hline 155 & 0,1 & 90 & AT & 156,75 & 157,97 & 1,22 & 0,97 & 1,65 & 2 \\
\hline 155 & 50 & 90 & AT & 156,75 & 157,97 & 1,22 & 0,97 & 1,65 & 2 \\
\hline 155 & 100 & 90 & AT & 156,75 & 157,97 & 1,22 & 0,97 & 1,65 & 2 \\
\hline 170 & 0,1 & 90 & AT & 171,39 & 172,61 & 1,22 & 0,77 & 1,45 & 2 \\
\hline 170 & 50 & 90 & AT & 171,39 & 172,61 & 1,22 & 0,77 & 1,45 & 2 \\
\hline 170 & 100 & 90 & AT & 171,39 & 172,61 & 1,22 & 0,77 & 1,45 & 2 \\
\hline 175 & 0,1 & 90 & AT & 176,29 & 177,51 & 1,22 & 0,72 & 1,39 & 2 \\
\hline 175 & 50 & 90 & AT & 176,29 & 177,51 & 1,22 & 0,72 & 1,39 & 2 \\
\hline 175 & 100 & 90 & AT & 176,29 & 177,51 & 1,22 & 0,72 & 1,39 & 2 \\
\hline 180 & 0,1 & 90 & AT & 181,17 & 182,39 & 1,22 & 0,65 & 1,33 & 2 \\
\hline 180 & 50 & 90 & AT & 181,17 & 182,39 & 1,22 & 0,65 & 1,33 & 2 \\
\hline 180 & 100 & 90 & AT & 181,17 & 182,39 & 1,22 & 0,65 & 1,33 & 2 \\
\hline 185 & 0,1 & 90 & AT & 186,05 & 187,27 & 1,22 & 0,44 & 0,95 & 3 \\
\hline 185 & 50 & 90 & AT & 186,05 & 187,27 & 1,22 & 0,44 & 0,95 & 3 \\
\hline 185 & 100 & 90 & AT & 186,05 & 187,27 & 1,22 & 0,44 & 0,95 & 3 \\
\hline 200 & 0,1 & 90 & AT & 200,71 & 201,93 & 1,22 & 0,30 & 0,80 & 3 \\
\hline 200 & 50 & 90 & AT & 200,71 & 201,93 & 1,22 & 0,30 & 0,80 & 3 \\
\hline 200 & 100 & 90 & AT & 200,71 & 201,93 & 1,22 & 0,30 & 0,80 & 3 \\
\hline 215 & 0,1 & 90 & AT & 217,80 & 219,02 & 1,22 & 1,17 & 1,68 & 3 \\
\hline 215 & 50 & 90 & AT & 217,80 & 219,02 & 1,22 & 1,17 & 1,68 & 3 \\
\hline 215 & 100 & 90 & AT & 217,80 & 219,02 & 1,22 & 1,17 & 1,68 & 3 \\
\hline 230 & 0,1 & 90 & AT & 227,56 & 228,79 & 1,22 & 1,01 & 0,51 & 3 \\
\hline 230 & 50 & 90 & AT & 227,56 & 228,79 & 1,22 & 1,01 & 0,51 & 3 \\
\hline 230 & 100 & 90 & AT & 227,56 & 228,79 & 1,22 & 1,01 & 0,51 & 3 \\
\hline 235 & 0,1 & 90 & AT & 237,33 & 238,55 & 1,22 & 0,97 & 1,48 & 3 \\
\hline 235 & 50 & 90 & AT & 237,33 & 238,55 & 1,22 & 0,97 & 1,48 & 3 \\
\hline 235 & 100 & 90 & AT & 237,33 & 238,55 & 1,22 & 0,97 & 1,48 & 3 \\
\hline 240 & 0,1 & 90 & AT & 242,22 & 243,44 & 1,22 & 0,93 & 1,43 & 0 \\
\hline 240 & 50 & 90 & AT & 242,22 & 243,44 & 1,22 & 0,93 & 1,43 & 0 \\
\hline 240 & 100 & 90 & AT & 242,22 & 243,44 & 1,22 & 0,93 & 1,43 & 0 \\
\hline \multicolumn{7}{|c|}{ Erro médio (\%) } & 1,08 & 1,67 & \\
\hline
\end{tabular}


TABELA 21 - Perda de sincronismo (2 amostras) para faltas AT, com ângulo de incidência de falta de $0^{0}$

\begin{tabular}{|c|c|c|c|c|c|c|c|c|c|}
\hline $\begin{array}{c}\text { Distância } \\
\text { real } \\
\text { (km) }\end{array}$ & $\begin{array}{c}\text { Resist. } \\
\text { falta } \\
(\Omega)\end{array}$ & $\begin{array}{c}\text { Ângulo de } \\
\text { incidência } \\
\left({ }^{\circ}\right)\end{array}$ & $\begin{array}{c}\text { Tipo de } \\
\text { falta }\end{array}$ & $\begin{array}{c}\text { Dist. } \\
\text { sincron } \\
(\mathbf{k m})\end{array}$ & $\begin{array}{c}\text { Dist. } \\
\tilde{\mathbf{n}} \text { sincron } \\
(\mathbf{k m})\end{array}$ & $\begin{array}{c}\text { Emo } \\
\text { sincr }-\tilde{\mathbf{n}} \text { sincr } \\
(+-\mathbf{k m})\end{array}$ & $\begin{array}{c}\text { Emo } \\
\text { sincron } \\
(\%)\end{array}$ & $\begin{array}{c}\text { Emro } \\
\tilde{\text { ñ sincron }} \\
(\%)\end{array}$ & $\begin{array}{c}\text { Zona } \\
\text { de } \\
\text { proteção }\end{array}$ \\
\hline 10 & 0,1 & 0 & AT & 10,21 & 12,65 & 2,44 & 0,18 & 2,21 & 1 \\
\hline 10 & 50 & 0 & AT & 10,21 & 12,65 & 2,44 & 0,18 & 2,21 & 1 \\
\hline 10 & 100 & 0 & AT & 10,21 & 12,65 & 2,44 & 0,18 & 2,21 & 1 \\
\hline 25 & 0,1 & 0 & AT & 24,87 & 27,31 & 2,44 & 0,11 & 1,93 & 1 \\
\hline 25 & 50 & 0 & AT & 24,87 & 27,31 & 2,44 & 0,11 & 1,93 & 1 \\
\hline 25 & 100 & 0 & AT & 24,87 & 27,31 & 2,44 & 0,11 & 1,93 & 1 \\
\hline 40 & 0,1 & 0 & AT & 39,53 & 41,97 & 2,44 & 0,39 & 1,64 & 1 \\
\hline 40 & 50 & 0 & AT & 39,53 & 41,97 & 2,44 & 0,39 & 1,64 & 1 \\
\hline 40 & 100 & 0 & AT & 39,53 & 41,97 & 2,44 & 0,39 & 1,64 & 1 \\
\hline 55 & 0,1 & 0 & AT & 51,74 & 54,18 & 2,44 & 2,72 & 0,68 & 1 \\
\hline 55 & 50 & 0 & AT & 51,74 & 54,18 & 2,44 & 2,72 & 0,68 & 1 \\
\hline 55 & 100 & 0 & AT & 51,74 & 54,18 & 2,44 & 2,72 & 0,68 & 1 \\
\hline 70 & 0,1 & 0 & AT & 71,28 & 73,72 & 2,44 & 1,06 & 3,10 & 1 \\
\hline 70 & 50 & 0 & AT & 71,28 & 73,72 & 2,44 & 1,06 & 3,10 & 1 \\
\hline 70 & 100 & 0 & AT & 71,28 & 73,72 & 2,44 & 1,06 & 3,10 & 1 \\
\hline 85 & 0,1 & 0 & AT & 90,82 & 93,26 & 2,44 & 4,85 & 6,88 & 1 \\
\hline 85 & 50 & 0 & AT & 90,82 & 93,26 & 2,44 & 4,85 & 6,88 & 1 \\
\hline 85 & 100 & 0 & AT & 90,82 & 93,26 & 2,44 & 4,85 & 6,88 & 1 \\
\hline 100 & 0,1 & 0 & AT & 103,03 & 105,47 & 2,44 & 2,52 & 4,56 & 1 \\
\hline 100 & 50 & 0 & AT & 103,03 & 105,47 & 2,44 & 2,52 & 4,56 & 1 \\
\hline 100 & 100 & 0 & AT & 103,03 & 105,47 & 2,44 & 2,52 & 4,56 & 1 \\
\hline 115 & 0,1 & 0 & AT & 117,69 & 120,13 & 2,44 & 2,24 & 4,27 & 1 \\
\hline 115 & 50 & 0 & AT & 117,69 & 120,13 & 2,44 & 2,24 & 4,27 & 1 \\
\hline 115 & 100 & 0 & AT & 117,69 & 120,13 & 2,44 & 2,24 & 4,27 & 1 \\
\hline 120 & 0,1 & 0 & AT & 122,55 & 124,99 & 2,44 & 2,13 & 4,16 & 2 \\
\hline 120 & 50 & 0 & AT & 122,55 & 124,99 & 2,44 & 2,13 & 4,16 & 2 \\
\hline 120 & 100 & 0 & AT & 122,55 & 124,99 & 2,44 & 2,13 & 4,16 & 2 \\
\hline 125 & 0,1 & 0 & AT & 127,45 & 129,89 & 2,44 & 1,36 & 2,72 & 2 \\
\hline 125 & 50 & 0 & AT & 127,45 & 129,89 & 2,44 & 1,36 & 2,72 & 2 \\
\hline 125 & 100 & 0 & AT & 127,45 & 129,89 & 2,44 & 1,36 & 2,72 & 2 \\
\hline 130 & 0,1 & 0 & AT & 132,31 & 134,76 & 2,44 & 1,29 & 2,64 & 2 \\
\hline 130 & 50 & 0 & AT & 132,31 & 134,76 & 2,44 & 1,29 & 2,64 & 2 \\
\hline 130 & 100 & 0 & AT & 132,31 & 134,76 & 2,44 & 1,29 & 2,64 & 2 \\
\hline 145 & 0,1 & 0 & AT & 146,97 & 149,41 & 2,44 & 1,10 & 2,45 & 2 \\
\hline 145 & 50 & 0 & AT & 146,97 & 149,41 & 2,44 & 1,10 & 2,45 & 2 \\
\hline 145 & 100 & 0 & AT & 146,97 & 149,41 & 2,44 & 1,10 & 2,45 & 2 \\
\hline 155 & 0,1 & 0 & AT & 156,74 & 159,18 & 2,44 & 0,96 & 2,32 & 2 \\
\hline 155 & 50 & 0 & AT & 156,74 & 159,18 & 2,44 & 0,96 & 2,32 & 2 \\
\hline 155 & 100 & 0 & AT & 156,74 & 159,18 & 2,44 & 0,96 & 2,32 & 2 \\
\hline 170 & 0,1 & 0 & AT & 171,39 & 173,84 & 2,44 & 0,77 & 2,13 & 2 \\
\hline 170 & 50 & 0 & AT & 171,39 & 173,84 & 2,44 & 0,77 & 2,13 & 2 \\
\hline 170 & 100 & 0 & AT & 171,39 & 173,84 & 2,44 & 0,77 & 2,13 & 2 \\
\hline 175 & 0,1 & 0 & AT & 176,29 & 178,73 & 2,44 & 0,72 & 2,07 & 2 \\
\hline 175 & 50 & 0 & AT & 176,29 & 178,73 & 2,44 & 0,72 & 2,07 & 2 \\
\hline 175 & 100 & 0 & AT & 176,29 & 178,73 & 2,44 & 0,72 & 2,07 & 2 \\
\hline 180 & 0,1 & 0 & AT & 181,16 & 183,60 & 2,44 & 0,64 & 2,00 & 2 \\
\hline 180 & 50 & 0 & AT & 181,16 & 183,60 & 2,44 & 0,64 & 2,00 & 2 \\
\hline 180 & 100 & 0 & AT & 181,16 & 183,60 & 2,44 & 0,64 & 2,00 & 2 \\
\hline 185 & 0,1 & 0 & AT & 186,05 & 188,49 & 2,44 & 0,44 & 1,46 & 2 \\
\hline 185 & 50 & 0 & AT & 186,05 & 188,49 & 2,44 & 0,44 & 1,46 & 2 \\
\hline 185 & 100 & 0 & AT & 186,05 & 188,49 & 2,44 & 0,44 & 1,46 & 2 \\
\hline 200 & 0,1 & 0 & AT & 200,71 & 203,15 & 2,44 & 0,30 & 1,31 & 3 \\
\hline 200 & 50 & 0 & AT & 200,71 & 203,15 & 2,44 & 0,30 & 1,31 & 3 \\
\hline 200 & 100 & 0 & AT & 200,71 & 203,15 & 2,44 & 0,30 & 1,31 & 3 \\
\hline 215 & 0,1 & 0 & AT & 217,80 & 220,24 & 2,44 & 1,17 & 2,18 & 3 \\
\hline 215 & 50 & 0 & AT & 217,80 & 220,24 & 2,44 & 1,17 & 2,18 & 3 \\
\hline 215 & 100 & 0 & AT & 217,80 & 220,24 & 2,44 & 1,17 & 2,18 & 3 \\
\hline 230 & 0,1 & 0 & AT & 232,45 & 234,89 & 2,44 & 1,02 & 2,04 & 3 \\
\hline 230 & 50 & 0 & AT & 232,45 & 234,89 & 2,44 & 1,02 & 2,04 & 3 \\
\hline 230 & 100 & 0 & AT & 232,45 & 234,89 & 2,44 & 1,02 & 2,04 & 3 \\
\hline 235 & 0,1 & 0 & AT & 237,34 & 239,78 & 2,44 & 0,98 & 1,99 & 3 \\
\hline 235 & 50 & 0 & AT & 237,34 & 239,78 & 2,44 & 0,98 & 1,99 & 3 \\
\hline 235 & 100 & 0 & AT & 237,34 & 239,78 & 2,44 & 0,98 & 1,99 & 3 \\
\hline 240 & 0,1 & 0 & AT & 242,22 & 244,66 & 2,44 & 0,93 & 1,94 & 0 \\
\hline 240 & 50 & 0 & AT & 242,22 & 244,66 & 2,44 & 0,93 & 1,94 & 0 \\
\hline 240 & 100 & 0 & AT & 242,22 & 244,66 & 2,44 & 0,93 & 1,94 & 0 \\
\hline \multicolumn{7}{|c|}{ Erro médio (\%) } & 1,27 & 2,58 & \\
\hline
\end{tabular}


TABELA 22 - Perda de sincronismo (2 amostras) para faltas AT, com ângulo de incidência de falta de $90^{\circ}$

\begin{tabular}{|c|c|c|c|c|c|c|c|c|c|}
\hline $\begin{array}{c}\text { Distância } \\
\text { real } \\
(\mathbf{k m})\end{array}$ & $\begin{array}{c}\text { Resist. } \\
\text { falta } \\
(\Omega)\end{array}$ & $\begin{array}{c}\text { Ângulo de } \\
\text { incidência } \\
\left({ }^{\circ}\right)\end{array}$ & $\begin{array}{c}\text { Tipo de } \\
\text { falta }\end{array}$ & $\begin{array}{c}\text { Dist. } \\
\text { sincron } \\
(\mathbf{k m})\end{array}$ & $\begin{array}{c}\text { Dist. } \\
\tilde{\mathbf{n}} \text { sincron } \\
\text { (km) }\end{array}$ & $\begin{array}{c}\text { Ermo } \\
\text { sincr }-\tilde{\mathbf{n}} \text { sincr } \\
(H-\mathbf{k m})\end{array}$ & $\begin{array}{c}\text { Emo } \\
\text { sincron } \\
(\%)\end{array}$ & $\begin{array}{c}\text { Emo } \\
\tilde{\mathbf{n}} \text { sincron } \\
(\%)\end{array}$ & $\begin{array}{c}\text { Zona } \\
\text { de } \\
\text { proteção }\end{array}$ \\
\hline 10 & 0,1 & 90 & AT & 10,23 & 12,67 & 2,44 & 0,19 & 2,22 & 1 \\
\hline 10 & 50 & 90 & AT & 10,23 & 12,67 & 2,44 & 0,19 & 2,22 & 1 \\
\hline 10 & 100 & 90 & AT & 10,23 & 12,67 & 2,44 & 0,19 & 2,22 & 1 \\
\hline 25 & 0,1 & 90 & AT & 24,87 & 27,31 & 2,44 & 0,11 & 1,93 & 1 \\
\hline 25 & 50 & 90 & AT & 24,87 & 27,31 & 2,44 & 0,11 & 1,93 & 1 \\
\hline 25 & 100 & 90 & AT & 24,87 & 27,31 & 2,44 & 0,11 & 1,93 & 1 \\
\hline 40 & 0,1 & 90 & AT & 39,53 & 41,97 & 2,44 & 0,39 & 1,64 & 1 \\
\hline 40 & 50 & 90 & AT & 39,53 & 41,97 & 2,44 & 0,39 & 1,64 & 1 \\
\hline 40 & 100 & 90 & AT & 39,53 & 41,97 & 2,44 & 0,39 & 1,64 & 1 \\
\hline 55 & 0,1 & 90 & AT & 51,74 & 54,18 & 2,44 & 2,72 & 0,68 & 1 \\
\hline 55 & 50 & 90 & AT & 51,74 & 54,18 & 2,44 & 2,72 & 0,68 & 1 \\
\hline 55 & 100 & 90 & AT & 51,74 & 54,18 & 2,44 & 2,72 & 0,68 & 1 \\
\hline 70 & 0,1 & 90 & AT & 71,26 & 73,70 & 2,44 & 1,05 & 3,09 & 1 \\
\hline 70 & 50 & 90 & AT & 71,26 & 73,70 & 2,44 & 1,05 & 3,09 & 1 \\
\hline 70 & 100 & 90 & AT & 71,26 & 73,70 & 2,44 & 1,05 & 3,09 & 1 \\
\hline 85 & 0,1 & 90 & AT & 85,92 & 88,36 & 2,44 & 0,77 & 2,80 & 1 \\
\hline 85 & 50 & 90 & AT & 85,92 & 88,36 & 2,44 & 0,77 & 2,80 & 1 \\
\hline 85 & 100 & 90 & AT & 85,92 & 88,36 & 2,44 & 0,77 & 2,80 & 1 \\
\hline 100 & 0,1 & 90 & AT & 103,03 & 105,47 & 2,44 & 2,52 & 4,56 & 1 \\
\hline 100 & 50 & 90 & AT & 103,03 & 105,47 & 2,44 & 2,52 & 4,56 & 1 \\
\hline 100 & 100 & 90 & AT & 103,03 & 105,47 & 2,44 & 2,52 & 4,56 & 1 \\
\hline 115 & 0,1 & 90 & AT & 117,67 & 120,11 & 2,44 & 2,23 & 4,26 & 1 \\
\hline 115 & 50 & 90 & AT & 117,67 & 120,11 & 2,44 & 2,23 & 4,26 & 1 \\
\hline 115 & 100 & 90 & AT & 117,67 & 120,11 & 2,44 & 2,23 & 4,26 & 1 \\
\hline 120 & 0,1 & 90 & AT & 122,55 & 124,99 & 2,44 & 2,13 & 4,16 & 2 \\
\hline 120 & 50 & 90 & AT & 122,55 & 124,99 & 2,44 & 2,13 & 4,16 & 2 \\
\hline 120 & 100 & 90 & AT & 122,55 & 124,99 & 2,44 & 2,13 & 4,16 & 2 \\
\hline 125 & 0,1 & 90 & AT & 127,45 & 129,89 & 2,44 & 1,36 & 2,72 & 2 \\
\hline 125 & 50 & 90 & AT & 127,45 & 129,89 & 2,44 & 1,36 & 2,72 & 2 \\
\hline 125 & 100 & 90 & AT & 127,45 & 129,89 & 2,44 & 1,36 & 2,72 & 2 \\
\hline 130 & 0,1 & 90 & AT & 132,33 & 134,77 & 2,44 & 1,29 & 2,65 & 2 \\
\hline 130 & 50 & 90 & AT & 132,33 & 134,77 & 2,44 & 1,29 & 2,65 & 2 \\
\hline 130 & 100 & 90 & AT & 132,33 & 134,77 & 2,44 & 1,29 & 2,65 & 2 \\
\hline 145 & 0,1 & 90 & AT & 146,97 & 149,41 & 2,44 & 1,10 & 2,45 & 2 \\
\hline 145 & 50 & 90 & AT & 146,97 & 149,41 & 2,44 & 1,10 & 2,45 & 2 \\
\hline 145 & 100 & 90 & AT & 146,97 & 149,41 & 2,44 & 1,10 & 2,45 & 2 \\
\hline 155 & 0,1 & 90 & AT & 156,75 & 159,19 & 2,44 & 0,97 & 2,33 & 2 \\
\hline 155 & 50 & 90 & AT & 156,75 & 159,19 & 2,44 & 0,97 & 2,33 & 2 \\
\hline 155 & 100 & 90 & AT & 156,75 & 159,19 & 2,44 & 0,97 & 2,33 & 2 \\
\hline 170 & 0,1 & 90 & AT & 171,39 & 173,84 & 2,44 & 0,77 & 2,13 & 2 \\
\hline 170 & 50 & 90 & AT & 171,39 & 173,84 & 2,44 & 0,77 & 2,13 & 2 \\
\hline 170 & 100 & 90 & AT & 171,39 & 173,84 & 2,44 & 0,77 & 2,13 & 2 \\
\hline 175 & 0,1 & 90 & AT & 176,29 & 178,73 & 2,44 & 0,72 & 2,07 & 2 \\
\hline 175 & 50 & 90 & AT & 176,29 & 178,73 & 2,44 & 0,72 & 2,07 & 2 \\
\hline 175 & 100 & 90 & AT & 176,29 & 178,73 & 2,44 & 0,72 & 2,07 & 2 \\
\hline 180 & 0,1 & 90 & AT & 181,17 & 183,61 & 2,44 & 0,65 & 2,01 & 2 \\
\hline 180 & 50 & 90 & AT & 181,17 & 183,61 & 2,44 & 0,65 & 2,01 & 2 \\
\hline 180 & 100 & 90 & AT & 181,17 & 183,61 & 2,44 & 0,65 & 2,01 & 2 \\
\hline 185 & 0,1 & 90 & AT & 186,05 & 188,49 & 2,44 & 0,44 & 1,46 & 2 \\
\hline 185 & 50 & 90 & AT & 186,05 & 188,49 & 2,44 & 0,44 & 1,46 & 2 \\
\hline 185 & 100 & 90 & AT & 186,05 & 188,49 & 2,44 & 0,44 & 1,46 & 2 \\
\hline 200 & 0,1 & 90 & AT & 200,71 & 203,15 & 2,44 & 0,30 & 1,31 & 3 \\
\hline 200 & 50 & 90 & AT & 200,71 & 203,15 & 2,44 & 0,30 & 1,31 & 3 \\
\hline 200 & 100 & 90 & AT & 200,71 & 203,15 & 2,44 & 0,30 & 1,31 & 3 \\
\hline 215 & 0,1 & 90 & AT & 217,80 & 220,24 & 2,44 & 1,17 & 2,18 & 3 \\
\hline 215 & 50 & 90 & AT & 217,80 & 220,24 & 2,44 & 1,17 & 2,18 & 3 \\
\hline 215 & 100 & 90 & AT & 217,80 & 220,24 & 2,44 & 1,17 & 2,18 & 3 \\
\hline 230 & 0,1 & 90 & AT & 227,56 & 230,01 & 2,44 & 1,01 & 0,00 & 3 \\
\hline 230 & 50 & 90 & AT & 227,56 & 230,01 & 2,44 & 1,01 & 0,00 & 3 \\
\hline 230 & 100 & 90 & AT & 227,56 & 230,01 & 2,44 & 1,01 & 0,00 & 3 \\
\hline 235 & 0,1 & 90 & AT & 237,33 & 239,77 & 2,44 & 0,97 & 1,99 & 3 \\
\hline 235 & 50 & 90 & AT & 237,33 & 239,77 & 2,44 & 0,97 & 1,99 & 3 \\
\hline 235 & 100 & 90 & AT & 237,33 & 239,77 & 2,44 & 0,97 & 1,99 & 3 \\
\hline 240 & 0,1 & 90 & AT & 242,22 & 244,66 & 2,44 & 0,93 & 1,94 & 0 \\
\hline 240 & 50 & 90 & AT & 242,22 & 244,66 & 2,44 & 0,93 & 1,94 & 0 \\
\hline 240 & 100 & 90 & AT & 242,22 & 244,66 & 2,44 & 0,93 & 1,94 & 0 \\
\hline \multicolumn{7}{|c|}{ Erro médio (\%) } & 1,08 & 2,30 & \\
\hline
\end{tabular}


TABELA 23 - Perda de sincronismo (1amostra) para faltas AB, com ângulo de incidência de falta de $0^{0}$

\begin{tabular}{|c|c|c|c|c|c|c|c|c|}
\hline $\begin{array}{c}\text { Distância } \\
\text { real } \\
\text { (km) }\end{array}$ & $\begin{array}{c}\text { Ângulo de } \\
\text { incidência } \\
\left({ }^{\circ}\right)\end{array}$ & $\begin{array}{l}\text { Tipo de } \\
\text { falta }\end{array}$ & $\begin{array}{l}\text { Dist. } \\
\text { sincron } \\
(\mathbf{k m})\end{array}$ & $\begin{array}{c}\text { Dist. } \\
\text { ñ sincron } \\
\text { (km) }\end{array}$ & $\begin{array}{c}\text { Emo } \\
\text { sincr - ñ sincr } \\
(+/-\mathbf{k m})\end{array}$ & $\begin{array}{c}\text { Emo } \\
\text { sincron } \\
(\%)\end{array}$ & $\begin{array}{c}\text { Erro } \\
\text { ñ sincron } \\
\text { (\%) }\end{array}$ & $\begin{array}{c}\text { Zona } \\
\text { de } \\
\text { proteção }\end{array}$ \\
\hline 10 & 0 & $\mathrm{AB}$ & 10,21 & 11,43 & 1,22 & 0,18 & 1,19 & 1 \\
\hline 25 & 0 & $\mathrm{AB}$ & 24,87 & 26,09 & 1,22 & 0,11 & 0,91 & 1 \\
\hline 40 & 0 & $\mathrm{AB}$ & 39,53 & 40,75 & 1,22 & 0,39 & 0,62 & 1 \\
\hline 55 & 0 & $\mathrm{AB}$ & 51,74 & 52,96 & 1,22 & 2,72 & 1,70 & 1 \\
\hline 70 & 0 & $\mathrm{AB}$ & 71,28 & 72,50 & 1,22 & 1,06 & 2,08 & 1 \\
\hline 85 & 0 & $\mathrm{AB}$ & 85,92 & 87,14 & 1,22 & 0,77 & 1,79 & 1 \\
\hline 100 & 0 & $\mathrm{AB}$ & 103,03 & 104,25 & 1,22 & 2,52 & 3,54 & 1 \\
\hline 115 & 0 & $\mathrm{AB}$ & 117,69 & 118,91 & 1,22 & 2,24 & 3,26 & 1 \\
\hline 120 & 0 & $\mathrm{AB}$ & 122,55 & 123,77 & 1,22 & 2,13 & 3,14 & 2 \\
\hline 125 & 0 & $\mathrm{AB}$ & 127,45 & 128,67 & 1,22 & 1,36 & 2,04 & 2 \\
\hline 130 & 0 & $\mathrm{AB}$ & 132,31 & 133,54 & 1,22 & 1,29 & 1,96 & 2 \\
\hline 145 & 0 & $\mathrm{AB}$ & 146,97 & 148,19 & 1,22 & 1,10 & 1,77 & 2 \\
\hline 155 & 0 & $\mathrm{AB}$ & 156,74 & 157,96 & 1,22 & 0,96 & 1,64 & 2 \\
\hline 170 & 0 & $\mathrm{AB}$ & 171,39 & 172,61 & 1,22 & 0,77 & 1,45 & 2 \\
\hline 175 & 0 & $\mathrm{AB}$ & 176,29 & 177,51 & 1,22 & 0,72 & 1,39 & 2 \\
\hline 180 & 0 & $\mathrm{AB}$ & 181,16 & 182,38 & 1,22 & 0,64 & 1,32 & 2 \\
\hline 185 & 0 & $\mathrm{AB}$ & 186,05 & 187,27 & 1,22 & 0,44 & 0,95 & 3 \\
\hline 200 & 0 & $\mathrm{AB}$ & 200,71 & 201,93 & 1,22 & 0,30 & 0,80 & 3 \\
\hline 215 & 0 & $\mathrm{AB}$ & 217,80 & 219,02 & 1,22 & 1,17 & 1,68 & 3 \\
\hline 230 & 0 & $\mathrm{AB}$ & 232,45 & 233,67 & 1,22 & 1,02 & 1,53 & 3 \\
\hline 235 & 0 & $\mathrm{AB}$ & 237,34 & 238,56 & 1,22 & 0,98 & 1,48 & 3 \\
\hline 240 & 0 & $\mathrm{AB}$ & 242,22 & 243,44 & 1,22 & 0,93 & 1,43 & 0 \\
\hline \multicolumn{6}{|c|}{ Erro médio (\%) } & 1,08 & 1,71 & \\
\hline
\end{tabular}

TABELA 24 - Perda de sincronismo (lamostra) para faltas AB, com ângulo de incidência de falta de $90^{\circ}$

\begin{tabular}{|c|c|c|c|c|c|c|c|c|}
\hline $\begin{array}{c}\text { Distância } \\
\text { real } \\
(\mathbf{k m})\end{array}$ & $\begin{array}{c}\text { Ângulo de } \\
\text { incidência } \\
\left({ }^{\circ}\right)\end{array}$ & $\begin{array}{l}\text { Tipo de } \\
\text { falta }\end{array}$ & $\begin{array}{l}\text { Dist. } \\
\text { sincron } \\
(\mathbf{k m})\end{array}$ & $\begin{array}{c}\text { Dist. } \\
\text { ñ sincron } \\
\text { (km) }\end{array}$ & $\begin{array}{c}\text { Emo } \\
\text { sincr }-\tilde{\mathbf{n}} \text { sincr } \\
(+-\mathbf{k m})\end{array}$ & $\begin{array}{l}\text { Emo } \\
\text { sincron } \\
(\%)\end{array}$ & $\begin{array}{c}\text { Emo } \\
\tilde{\text { ñ sincron }} \\
(\%)\end{array}$ & $\begin{array}{c}\text { Zona } \\
\text { de } \\
\text { proteção }\end{array}$ \\
\hline 10 & 90 & $\mathrm{AB}$ & 10,23 & 11,45 & 1,22 & 0,19 & 1,21 & 1 \\
\hline 25 & 90 & $\mathrm{AB}$ & 24,87 & 26,09 & 1,22 & 0,11 & 0,91 & 1 \\
\hline 40 & 90 & $\mathrm{AB}$ & 39,53 & 40,75 & 1,22 & 0,39 & 0,62 & 1 \\
\hline 55 & 90 & $\mathrm{AB}$ & 51,74 & 52,96 & 1,22 & 2,72 & 1,70 & 1 \\
\hline 70 & 90 & $\mathrm{AB}$ & 71,26 & 72,48 & 1,22 & 1,05 & 2,07 & 1 \\
\hline 85 & 90 & $\mathrm{AB}$ & 85,92 & 87,14 & 1,22 & 0,77 & 1,79 & 1 \\
\hline 100 & 90 & $\mathrm{AB}$ & 103,03 & 104,25 & 1,22 & 2,52 & 3,54 & 1 \\
\hline 115 & 90 & $\mathrm{AB}$ & 117,67 & 118,89 & 1,22 & 2,23 & 3,24 & 1 \\
\hline 120 & 90 & $\mathrm{AB}$ & 122,55 & 123,77 & 1,22 & 2,13 & 3,14 & 2 \\
\hline 125 & 90 & $\mathrm{AB}$ & 127,45 & 128,67 & 1,22 & 1,36 & 2,04 & 2 \\
\hline 130 & 90 & $\mathrm{AB}$ & 132,33 & 133,55 & 1,22 & 1,29 & 1,97 & 2 \\
\hline 145 & 90 & $\mathrm{AB}$ & 146,97 & 148,19 & 1,22 & 1,10 & 1,77 & 2 \\
\hline 155 & 90 & $\mathrm{AB}$ & 156,75 & 157,97 & 1,22 & 0,97 & 1,65 & 2 \\
\hline 170 & 90 & $\mathrm{AB}$ & 171,39 & 172,61 & 1,22 & 0,77 & 1,45 & 2 \\
\hline 175 & 90 & $\mathrm{AB}$ & 176,29 & 177,51 & 1,22 & 0,72 & 1,39 & 2 \\
\hline 180 & 90 & $\mathrm{AB}$ & 181,17 & 182,39 & 1,22 & 0,65 & 1,33 & 2 \\
\hline 185 & 90 & $\mathrm{AB}$ & 186,05 & 187,27 & 1,22 & 0,44 & 0,95 & 3 \\
\hline 200 & 90 & $\mathrm{AB}$ & 200,71 & 201,93 & 1,22 & 0,30 & 0,80 & 3 \\
\hline 215 & 90 & $\mathrm{AB}$ & 217,80 & 219,02 & 1,22 & 1,17 & 1,68 & 3 \\
\hline 230 & 90 & $\mathrm{AB}$ & 227,56 & 228,79 & 1,22 & 1,01 & 0,51 & 3 \\
\hline 235 & 90 & $\mathrm{AB}$ & 237,33 & 238,55 & 1,22 & 0,97 & 1,48 & 3 \\
\hline 240 & 90 & $\mathrm{AB}$ & 242,22 & 243,44 & 1,22 & 0,93 & 1,43 & 0 \\
\hline \multicolumn{6}{|c|}{ Eno médio (\%) } & 1,08 & 1,67 & \\
\hline
\end{tabular}


TABELA 25 - Perda de sincronismo (2 amostras) para faltas AB, com ângulo de incidência de falta de $0^{0}$

\begin{tabular}{|c|c|c|c|c|c|c|c|c|}
\hline $\begin{array}{c}\text { Distância } \\
\text { real } \\
\text { (km) }\end{array}$ & $\begin{array}{c}\text { Ângulo de } \\
\text { incidência } \\
\left({ }^{\circ}\right)\end{array}$ & $\begin{array}{l}\text { Tipo de } \\
\text { falta }\end{array}$ & $\begin{array}{l}\text { Dist. } \\
\text { sincron } \\
(\mathbf{k m})\end{array}$ & $\begin{array}{c}\text { Dist. } \\
\text { ñ sincron } \\
\text { (km) }\end{array}$ & $\begin{array}{c}\text { Emo } \\
\text { sincr - ñ sincr } \\
(+/-\mathbf{k m})\end{array}$ & $\begin{array}{c}\text { Emo } \\
\text { sincron } \\
(\%)\end{array}$ & $\begin{array}{c}\text { Erro } \\
\text { ñ sincron } \\
\text { (\%) }\end{array}$ & $\begin{array}{c}\text { Zona } \\
\text { de } \\
\text { proteção }\end{array}$ \\
\hline 10 & 0 & $\mathrm{AB}$ & 10,21 & 12,65 & 2,44 & 0,18 & 2,21 & 1 \\
\hline 25 & 0 & $\mathrm{AB}$ & 24,87 & 27,31 & 2,44 & 0,11 & 1,93 & 1 \\
\hline 40 & 0 & $\mathrm{AB}$ & 39,53 & 41,97 & 2,44 & 0,39 & 1,64 & 1 \\
\hline 55 & 0 & $\mathrm{AB}$ & 51,74 & 54,18 & 2,44 & 2,72 & 0,68 & 1 \\
\hline 70 & 0 & $\mathrm{AB}$ & 71,28 & 73,72 & 2,44 & 1,06 & 3,10 & 1 \\
\hline 85 & 0 & $\mathrm{AB}$ & 85,92 & 88,36 & 2,44 & 0,77 & 2,80 & 1 \\
\hline 100 & 0 & $\mathrm{AB}$ & 103,03 & 105,47 & 2,44 & 2,52 & 4,56 & 1 \\
\hline 115 & 0 & $\mathrm{AB}$ & 117,69 & 120,13 & 2,44 & 2,24 & 4,27 & 1 \\
\hline 120 & 0 & $\mathrm{AB}$ & 122,55 & 124,99 & 2,44 & 2,13 & 4,16 & 2 \\
\hline 125 & 0 & $\mathrm{AB}$ & 127,45 & 129,89 & 2,44 & 1,36 & 2,72 & 2 \\
\hline 130 & 0 & $\mathrm{AB}$ & 132,31 & 134,76 & 2,44 & 1,29 & 2,64 & 2 \\
\hline 145 & 0 & $\mathrm{AB}$ & 146,97 & 149,41 & 2,44 & 1,10 & 2,45 & 2 \\
\hline 155 & 0 & $\mathrm{AB}$ & 156,74 & 159,18 & 2,44 & 0,96 & 2,32 & 2 \\
\hline 170 & 0 & $\mathrm{AB}$ & 171,39 & 173,84 & 2,44 & 0,77 & 2,13 & 2 \\
\hline 175 & 0 & $\mathrm{AB}$ & 176,29 & 178,73 & 2,44 & 0,72 & 2,07 & 2 \\
\hline 180 & 0 & $\mathrm{AB}$ & 181,16 & 183,60 & 2,44 & 0,64 & 2,00 & 2 \\
\hline 185 & 0 & $\mathrm{AB}$ & 186,05 & 188,49 & 2,44 & 0,44 & 1,46 & 3 \\
\hline 200 & 0 & $\mathrm{AB}$ & 200,71 & 203,15 & 2,44 & 0,30 & 1,31 & 3 \\
\hline 215 & 0 & $\mathrm{AB}$ & 217,80 & 220,24 & 2,44 & 1,17 & 2,18 & 3 \\
\hline 230 & 0 & $\mathrm{AB}$ & 232,45 & 234,89 & 2,44 & 1,02 & 2,04 & 3 \\
\hline 235 & 0 & $\mathrm{AB}$ & 237,34 & 239,78 & 2,44 & 0,98 & 1,99 & 3 \\
\hline 240 & 0 & $\mathrm{AB}$ & 242,22 & 244,66 & 2,44 & 0,93 & 1,94 & 0 \\
\hline \multicolumn{6}{|c|}{ Erro médio (\%) } & 1,08 & 2,39 & \\
\hline
\end{tabular}

TABELA 26 - Perda de sincronismo (2 amostras) para faltas AB, com ângulo de incidência de falta de $90^{\circ}$

\begin{tabular}{|c|c|c|c|c|c|c|c|c|}
\hline $\begin{array}{c}\text { Distância } \\
\text { real } \\
(\mathbf{k m})\end{array}$ & $\begin{array}{c}\text { Ângulo de } \\
\text { incidência } \\
\left({ }^{\circ}\right)\end{array}$ & $\begin{array}{c}\text { Tipo de } \\
\text { falta }\end{array}$ & $\begin{array}{l}\text { Dist. } \\
\text { sincron } \\
(\mathbf{k m})\end{array}$ & $\begin{array}{c}\text { Dist. } \\
\text { ñ sincron } \\
(\mathbf{k m})\end{array}$ & $\begin{array}{c}\text { Erro } \\
\text { sincr- }-\tilde{\mathbf{n}} \text { sincr } \\
(+/-\mathbf{k m})\end{array}$ & $\begin{array}{l}\text { Emo } \\
\text { sincron } \\
(\%)\end{array}$ & $\begin{array}{c}\text { Eno } \\
\tilde{\text { ñ sincron }} \\
(\%)\end{array}$ & $\begin{array}{c}\text { Zona } \\
\text { de } \\
\text { proteção }\end{array}$ \\
\hline 10 & 90 & $\mathrm{AB}$ & 10,23 & 12,67 & 2,44 & 0,19 & 2,22 & 1 \\
\hline 25 & 90 & $\mathrm{AB}$ & 24,87 & 27,31 & 2,44 & 0,11 & 1,93 & 1 \\
\hline 40 & 90 & $\mathrm{AB}$ & 39,53 & 41,97 & 2,44 & 0,39 & 1,64 & 1 \\
\hline 55 & 90 & $\mathrm{AB}$ & 51,74 & 54,18 & 2,44 & 2,72 & 0,68 & 1 \\
\hline 70 & 90 & $\mathrm{AB}$ & 71,26 & 73,70 & 2,44 & 1,05 & 3,09 & 1 \\
\hline 85 & 90 & $\mathrm{AB}$ & 85,92 & 88,36 & 2,44 & 0,77 & 2,80 & 1 \\
\hline 100 & 90 & $\mathrm{AB}$ & 103,03 & 105,47 & 2,44 & 2,52 & 4,56 & 1 \\
\hline 115 & 90 & $\mathrm{AB}$ & 117,67 & 120,11 & 2,44 & 2,23 & 4,26 & 1 \\
\hline 120 & 90 & $\mathrm{AB}$ & 122,55 & 124,99 & 2,44 & 2,13 & 4,16 & 2 \\
\hline 125 & 90 & $\mathrm{AB}$ & 127,45 & 129,89 & 2,44 & 1,36 & 2,72 & 2 \\
\hline 130 & 90 & $\mathrm{AB}$ & 132,33 & 134,77 & 2,44 & 1,29 & 2,65 & 2 \\
\hline 145 & 90 & $\mathrm{AB}$ & 146,97 & 149,41 & 2,44 & 1,10 & 2,45 & 2 \\
\hline 155 & 90 & $\mathrm{AB}$ & 156,75 & 159,19 & 2,44 & 0,97 & 2,33 & 2 \\
\hline 170 & 90 & $\mathrm{AB}$ & 171,39 & 173,84 & 2,44 & 0,77 & 2,13 & 2 \\
\hline 175 & 90 & $\mathrm{AB}$ & 176,29 & 178,73 & 2,44 & 0,72 & 2,07 & 2 \\
\hline 180 & 90 & $\mathrm{AB}$ & 181,17 & 183,61 & 2,44 & 0,65 & 2,01 & 2 \\
\hline 185 & 90 & $\mathrm{AB}$ & 186,05 & 188,49 & 2,44 & 0,44 & 1,46 & 3 \\
\hline 200 & 90 & $\mathrm{AB}$ & 200,71 & 203,15 & 2,44 & 0,30 & 1,31 & 3 \\
\hline 215 & 90 & $\mathrm{AB}$ & 217,80 & 220,24 & 2,44 & 1,17 & 2,18 & 3 \\
\hline 230 & 90 & $\mathrm{AB}$ & 227,56 & 230,01 & 2,44 & 1,01 & 0,00 & 3 \\
\hline 235 & 90 & $\mathrm{AB}$ & 237,33 & 239,77 & 2,44 & 0,97 & 1,99 & 3 \\
\hline 240 & 90 & $\mathrm{AB}$ & 242,22 & 244,66 & 2,44 & 0,93 & 1,94 & 0 \\
\hline \multicolumn{6}{|c|}{ Enro médio (\%) } & 1,08 & 2,30 & \\
\hline
\end{tabular}

